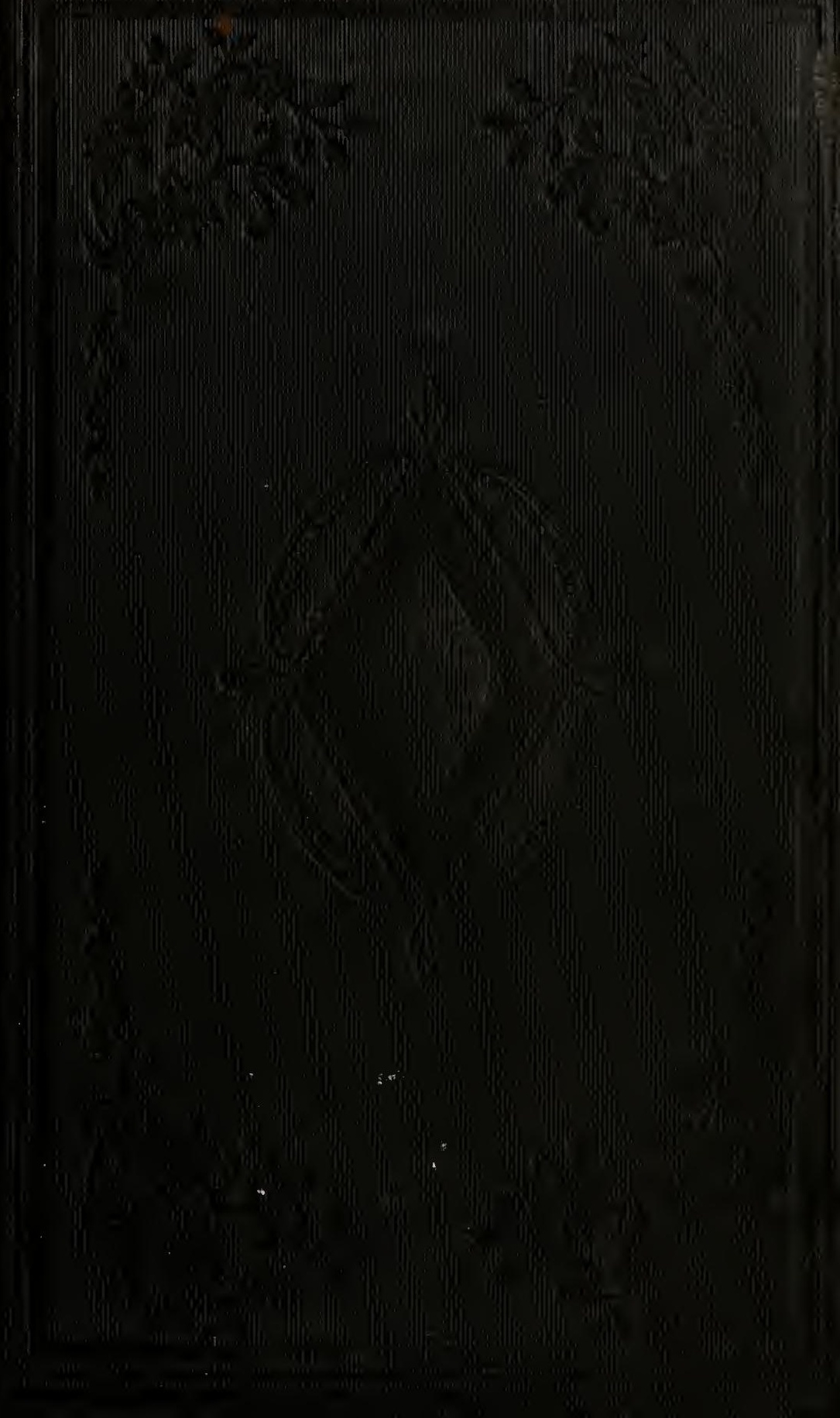


Dons thea I. Widmeter

Eleama R. Webster

EX LIBRIS

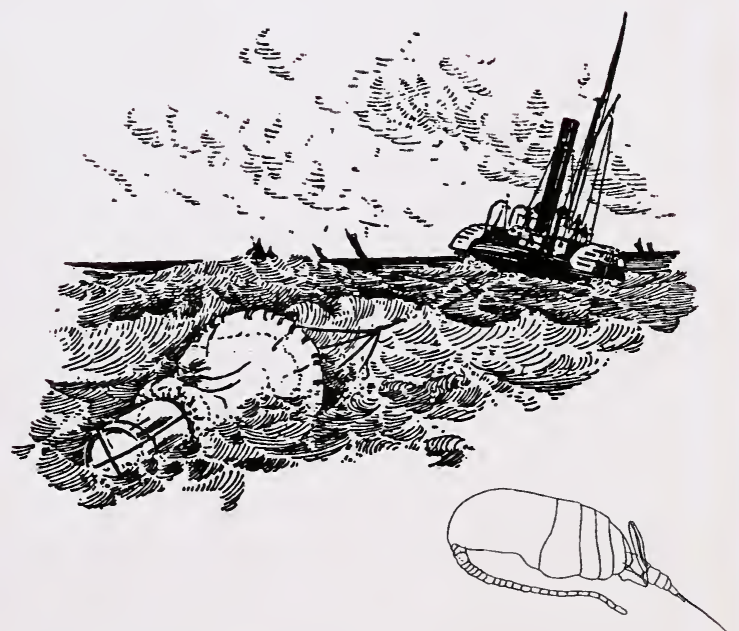

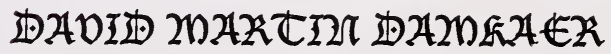

"Come and take choice of all my library, And so beguile thy sorrow."-Shakespeare 



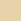






\section{PRINCIPIES OF ZOÖLOGY,}

Touching the Structure, Development, Distribution and Natural Arrangement of the Races of Animals, living and extinct; with numerous Illustrations. For the use of Schools and Colleges. Part 1.-Comparative Physiology.

\section{By Louis Agassiz and Augustus A. Gould.}

\section{EXTRACTS FRON THE PREFACE.}

"The design of this work is to furnish an epitome of the leading principles of the science of Zoology, as deduced from the present state of knowledge, so illustrated as to be intelligible to the beginning student. No similar treatise now exists in this country, and, indeed, some of the topics have not been touched upon in the language, unless in a strictly technical form, and in scattered articles."

"Being designed for American students, the illustrations have been drawn, as far as possible, from American objects. . . . Popular names have been employed as far as possible, and to the scientific names, an English termination has generally been given. The first part is devoted to Comparative Physiology, as the basis of Classification; the second, to Systematic Zoology, in which the principles of Classification will be applied, and the principal groups of animals briefly characterized."

\section{NOTICES OF THE PRESS.}

"This work has been expected with great interest. It is not simply a system by which we are taught the classification of Animals, but it is really what it professes to be, the 'Principles of Zoology,' carrying us on step by step, from the simplest truths to the comprehension of that infinite plan which the Author of Nature has established. . . . This book places us in possession of information half a century in advance of all our elementary works on this subject. . . No work of the same dimensions has ever appeared in the English language, containing so much new and valuable information on the subject of which it treats." - Prof. James Hall, in the Albany Journal.

"A work emanating from so high a source as the 'Principles of Zoology,' hardly requires commendation to give it currency. The public have become acquainted with the eminent abilities of Prof. Agassiz through his lectures, and are aware of his vast learning, wide reach of mind, and popular mode of illustrating scientific subjects. In the preparation of this work, he has had an able coadjutor in Dr. A. A. Gould, a frequent contributor to the Transactions of the Boston Society of Natural History, and at present engaged upon the department of Concliology, for the publication of the late exploring expedition. The volume is prepared for the student in zoological science; it is simplc and elementary in its style, full in its illustrations, comprehensive in its range, yet well condensed, and broughtiuto the narrow compass requisite for the purpose intended."-Silliman's Journal, June, 1848.

"The work is admirably adapted to the use of schools and colleges, and ought to be made a study in all our higher seminaries, both male and female."-New York Observer.

"To the testimony which is furnished by their distinguished scholarship, we may add, however, that the classifications of the work are so admirably arranged, and its descriptions given with so much simplicity and clearness of language, that the book cannot fail of its practical aim - to facilitate the progress of the bcginuing student. It is a work for schools." - 
"The announcement of this work some time ago, as being in a course of preparation, excited a high degree of intercst among teachers, students, and the friends of science. The names of its authors gave ample assurance that it was no compilation drawn from other works, no mere reconstruction of existing materials. The work will undoubtedly meet the expectations that have been formed of it, and already it has been adopted as a text-book in several colleges. It breaks new ground; as is said in the preface, 'some of its topics have not been touched upon in the language, unless in a strictly technical form, and in scattered articles.' The volume exhibits throughout great labor and care in preparing it for the public eye, and for the use of students. As it has no rival, we suppose its adoption will be almost universal in literary institutions, and it will do much to awaken in the minds of multitudes an enthusiastic love of natural history." - Christian Reflector of Watchman.

"This work is designed as a text book for schools and colleges, and as an exposition of the interesting science of which it treats, it has many obvious advantages over any other treatise extant. It is the joint production of two gentlemen, whose researches in natural history have enlarged the domain of human knewledge, and one of whom stands confessedly at the head of the science of the age. It hence contains the latest and most approved classifications, with explanations and illustrations borrowed from the forms of animated nature, both living and extinct, and made accurate and pcrfect by the fullest acquaintance with the present condition of zoological science. As a text book it is admirably conceived.

"The presence of Prof Agassiz in the United States, has given a new impulse to every branch of natural history, and we are happy to find him thus associated with Dr. Gould, one of our leading American naturalists, in explaining his favorite science to the youth of our schools and colleges.' Providence Journal.

"No such work had previously appeared in our country. The production is worthy of the great names under whose care it has been prepared. Prof. Agassiz has a world-wide reputation, and Dr. Gould is regarded by the scientific men of Europe as the most eminent naturalist of our country. Schools and Academies will find it opens up a new and attractive study for the young, and in no country is there a finer field opened up to the naturalist than in our own."-Christian Alliance, Boston.

"A new and highly valuable publication, intended for a school book, but which will be found equally interesting and important for all to study. . . . Such a work as this has long been a great desidcratum, and we rejoice that a want so strongly felt, has now, at length, been so well and so completely supplied."-Boston Atlas.

"This is entirely a new field in American elcmentary literature, no similar treatise existing in this country. At first sight, the work appeared to us too abstruse for begimners, and for the use of those whom the author aims to benefit - the scholars in our common schools. A more careful examination convinces us that any teacher or scholar, who is in earnest to understand the subject, will find the application necessary at the commencement comparatively trifling, while the subsequent benefit will bc immense. This is the first volume of the work, and is devoted to Comparative Plysiology, on which branch it is exceedingly complete. It is freely illustrated with the nccessary wood cuts. The names of the authors will be a higher guarantee for scicntific accuracy than any judgment we might pronouncc." New York Commercial Advertiser.

"It is designed chiefly for the use of schools and colleges, and as an epitome of the subject on which it treats, contains more in a small space, than any hook of the kind that has yet fallen under our notice."-Saturday Gleaner, Philadelphia. 



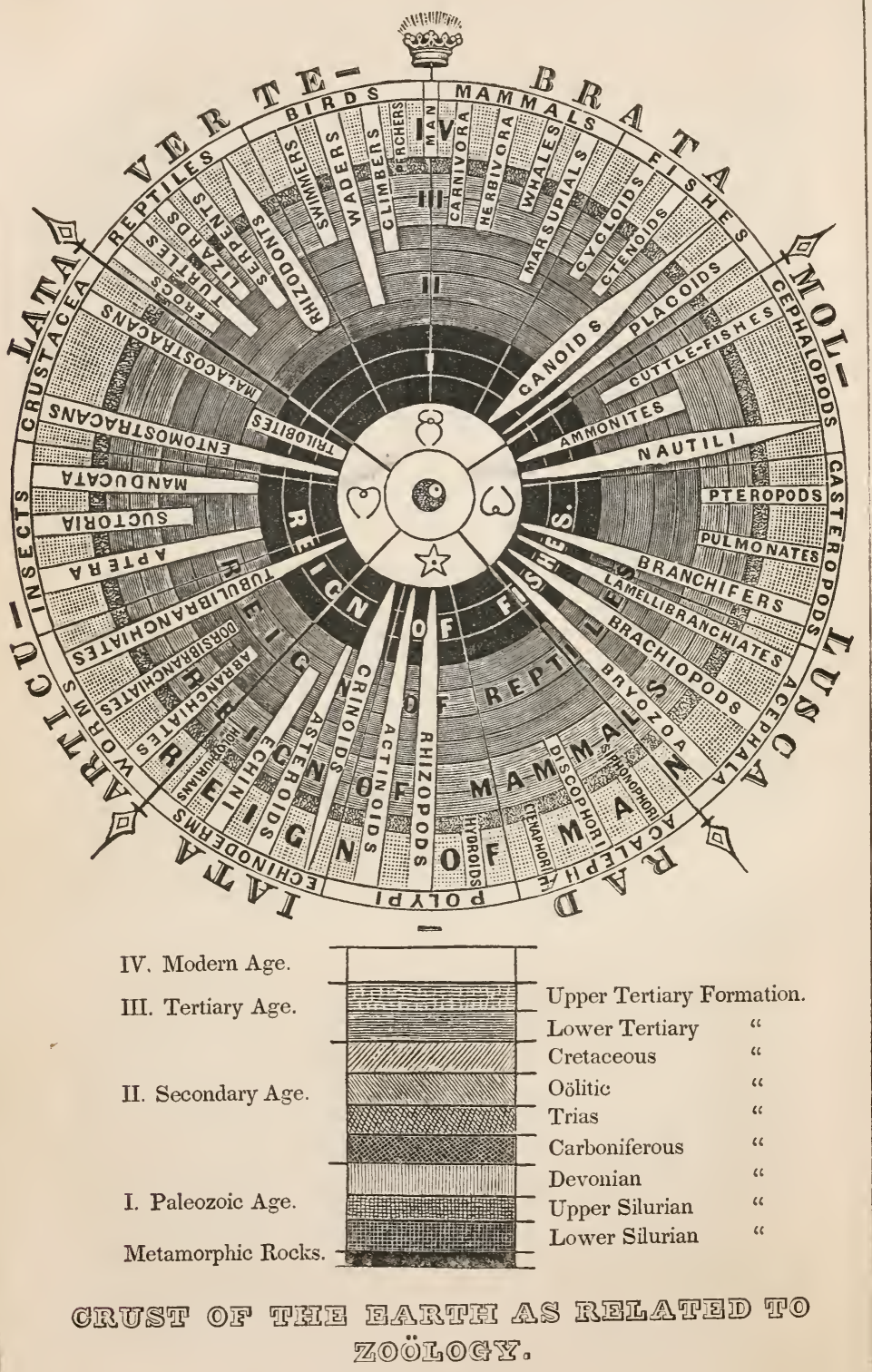




\section{PRINCIPLES OF ZOÖLOGY:}

TOUCHING

THE Structure, DEVElopMient, Distribution, AND NATURAL ARRANGEMENT

OF THE

RACES OF ANIMALS, LIVING AND EXTINCT;

WITH NUMEROUS ILLUSTRATIONS.

FOR THE USE OF SCHOOLS AND COLLEGES.

PART I.

COMPARATIVE PHYSIOLOGY.

BI

LOUIS A A ASIZ, AND

AUGUSTUS A. GOULD.

B O S T O N :

GOULD, KENDALL AND LINCOLN.

59 , WASHITTON STREET.

1848 . 
Entered according to Act of Congress, in the year 1848,

$$
\text { By Gould, Kendali, and Lincoln, }
$$

in the Clerk's Office of the District Court of the District of Massachusetts.

B O S T O N :

PRINTED BY FREEMAN AND BOLLES, DEVONSHIRE STREE'T. 


\section{P R E F A C E.}

THe design of this work is to furnish an epitome of the leading principles of the science of Zoölogy, as deduced from the present state of knowledge, so illustrated as to be intelligible to the beginning student. No similar treatise now exists in this country, and indeed some of the topics have not been touched upon in the language, unless in a strictly technical form, and in scattered articles. On this account, some of the chapters, like those on Embryology, and Metamorphosis, may at first seem too abstruse for scholars in our common schools. This may be the case, until teachers shall have made themselves somewhat familiar with subjects comparatively new to them. But so essential have these subjects now become to a correct interpretation of philosophical zoölogy, that the study of them will hereafter be indispensable. They furnish a key to many phenomena which have been heretofore locked in mystery.

Being designed for American students, the illustrations have been drawn, as far as possible, from American objects; some of them are intended merely as ideal outlines, which convey a more definite idea than if accu- 
rately drawn from nature; others have been left imperfect, except as to the parts especially in question; a large proportion of them however, are accurate and original. Popular names have been employed as far as possible, and to the scientific names an English termination has generally been given. Definitions of those least likely to be understood, may be found in the Index.

The principles of Zoölogy developed by Professor Agassiz in his published works have been generally adopted in this, and the results of many new researches have been added.

The authors gratefully acknowledge the aid they have received in preparing the illustrations and working out the details from Mr. E. Desor, for many years an associate of Professor Agassiz, from Count Pourtalés and E. C. Cabot, Esq., and also from Prof. Asa Gray, by valuable suggestions in the revision of the letter-press.

The first part is devoted to Comparative Physiology as the basis of Classification; the second to Systematic Zoölogy, in which the principles of Classification will be applied, and the principal groups of animals will be briefly characterized.

Should our aim be attained, this work will produce more enlarged ideas of man's relations to Nature, and more exalted conceptions of the plan of Creation and its Great Author.

Boston, June 1, 1848. 


\section{TABLE OF C ONTENT.}

INTRODUCTION

\section{CHAPTER FIRST.}

The Sphere and fundanental Principles of Zoölogy • 1

CHAPTER SECOND.

General Properties of Organized Bodies . . . . 11

SECTION I.

Organized and Unorganized Bodies . . . . . . 11

SECTION II.

Elementary Structure of Organized Bodies • . . • . 13

SECTION III.

Differences between Animals and Plants . . . . . 17

CHAPTER THIRD.

Functions and Organs of Anlmal Life • • • . 20

SECTION I.

Of the Nervous System and General Sensation 
Of the Special Senses . . . . . . . . . . 24

1. Of Sight . . . . . . . . . . . 24

2. Of Hearing . . . . . . . . . . 31

3. Of Smell . . . . . . . . . . . . 36

4. Of Taste . . . . . . . . . . 38

5. Of Touch . . . . . . . . . . . . 39

6. Of the Voice . . . . . . . . . 40

CHAPTER FOURTH.

OF INTELLIGENCE AND INSTLNCT • . • . . . . 43

\section{CHAPTER FIFTH.}

Of Motion

SECTION I.

Apparatus of Motion

\section{SECTION II.}

Of Locomotion . . . . . . . . . . . 55

1. Plan of the Organs of Locomotion . . . . . 58

2. Of Standing, and the Modes of Progression . • . . 64

Walking . . . . . . . . . . 66

Running . . . . . . . . . . 67

Leaping . . . . . . . . . 67

Climbing . . . . . . . . . . 68

Flying . . . . . . . . . . . 68

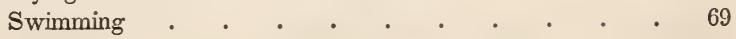

\section{CHAPTER SIXTH.}

OF Nutrition

SECTION I.

Of Digestion

Digestive Tube

Chymification

Chylification

Mastication 
TABLE OF CONTENTS.

Page

CHAPTER SEVENTH.

Of the Blood and Circulation . . . . . .

CHAPTER EIGHTH.

Of Respiration

CHAPTER NINTH.

OF THE SECRETIONS

\section{CHAPTER TENTH.}

EMbryology

SECTION I.

Of the Egg . . . . . . . . . . . 102

Form of the Egg . . . . . . . . 103

Formation of the Egg . . . . . . . . 104

Ovulation . . . . . . . . . . . 105

Laying . . . . . . . . . . . . 105

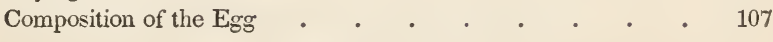

SECTION II.

Development of the Young witlin the Egg . . . . . . 109

SECTION III.

Zoölogical Importance of Embryology • • • • • 122

CHAPTER ELEVENTH.

Peculiar Modes of Reproduction . . . . . . 125

SECTION I.

Gemmiparous and Fissiparous Generation . . . . 125

SECTION II.

Alternate and Equivocal Reproduction . . . . . 127 
SECTION III.

\section{CHAPTER TWELFTH.}

Metamorphoses of Ayturats

\section{CHAPTER THIRTEENTH.}

Geographical Distribution of Aximals

SECTION I.

General Laws of Distribution

SECTION II.

Distribution of the Faunas

I. Arctic Fauna

II. Temperate Faunas

III. Tropical Faunas

SECTION III.

Conclusions

\section{CHAPTER FOURTEENTH.}

Geological Succession of Aninals; or their Distribution in Time 182 SECTION I.

Structure of the Earth's Crust

SECTION II.

Ages of Nature

Paleozoic Age

Secondary Age

Tertiary Age 195

Modern Age 201

Conclusions 


\section{EXPLANATION OF THE FIGURES.}

Frontispiece. - The diagram opposite the title page is intended to present, at one view, the distribution of the principal types of animals, and the order of their successive appearance in the layers of the earth's crust. The four Ages of Nature, mentioned at page 190, are represented by four zones, of different shades, each of which is subdivided by circles, indicating the number of formations of which they are composed. The whole disc is divided by radiating lines into four segments, to include the four great departments of the Animal Kingdom; the Vertebrates, with Man at their head, are placed in the upper compartment, the Articulates at the left, the Mollusks at the right, and the Radiates below, as being the lowest in rank. Each of these compartments is again subdivided to include the different classes belonging to it, which are named at the outer circle. At the centre is placed a figure to represent the primitive egg, with its germinative vesicle and germinative dot (278), indicative of the universal origin of all animals, and the epoch of life when all are apparently alike $(275,276)$. Surrounding this, at the point from which each department radiates, are placed the symbols of the sereral departments, as explained on page 124 . The zones are traversed by rays which represent the principal types of animals, and their origin and termination indicates the age at which they first appeared or disappeared, all those which reach the circumference being still in existence. The width of the ray indicates the greater or less prevalence of the type at different geological ages. Thus, in the class of Crustaceans, the Trilobites appear to commence in the earliest strata, and to disappear with the carboniferous formation. The Ammonites also appeared in the Silurian formation, and did not become extinct before the deposition of the Cretaceous rocks. The Belemnites appear in the lower Oölitic beds; many forms commence in the Tertiary; a great number of types make their appearance only in the Modern 
age; while only a few have continued from the Silurian, through every period to the present. Thus, the Crinoids were very numerous in the Primary Age, and are but slightly developed in the Tertiary and Modern Age. It is seen, at a glance, that the Animal Kingdom is much more diversified in the later, than in the earlier Ages.

Below the circle is a section, intended to show more distinctly the relative position of the ten principal formations of stratified rocks (461), composing the four great geological ages; the numerals corresponding to those on the ray leading to Man, in the circular figure. See also figure 154.

The Chart of Zoölogical Regions, page 163, is intended to show the limits of the several Faunas of the American Continent, corresponding to the climatal regions. And as the higher regions of the mountains correspond in temperature to the climate of higher latitudes, it will be seen that the northern temperate fauna extends, along the mountains of Mexico and Central America, much farther towards the Equator, than it does on the lower levels. In the same manner, the southern warm fauna extends northward, along the Andes.

FIG.

1. Simple cell, magnified, as seen in the house-leek.

2. Cells when altered by pressure upon each other; from the pith of elder.

3. Nucleated cells $(a)$, magnified; $b$, nucleolated cells.

4. Cartilaginous tissue from a horse, magnified 120 diameters.

5. Osseous tissue from a horse, magnified 450 diameters.

6. Nervous fibres, showing the loops as they terminate in the skin of a frog.

7. Gray substance of the brain, magnified.

8. Head of an embryo fish, to show its cellular structure throughout.

9. Diagram, to show the nervous system of the Vertebrates, as found in a monkey.

10. Diagram of the nervous system of the Articulates, as seen in a lobster.

11. Diagram of the nervous system of the Mollusks, as found in Natica heros.

12. Diagram of the nervous system of the Radiates, as found in Scutella (Echinarachnius parma).

13. Section of the eye. $a$, optic nerve; $b$, sclerotic coat ; $c$, choroid coat; $d$, retina ; $e$, crystalline lens ; $f$, cornea ; $g$, iris ; $h$, vitreous body ; $i$, chamber, divided by the iris.

14. Diagram, showing the effect of the eye on rays of light.

15. Position of the eye of the snail.

16. Eyes (ocelli) of a spider.

17. Eye-spots of a star-fish (Echinaster sanguinolentus).

18. Compound eyes, showing the arrangement of the façettes, and their connection with the optic nerve, as seen in a crab's eye.

19. Diagram of the human ear, to show the different chambers, canals, and bones. 
FIG.

20. Tympanum and small bones of the ear, twice the natural size; $c$, tympanum; $m$, malleus ; $n$, incus ; $o$, orbiculare $s$, stapes.

21. Section of the brain of a crow, showing the origin of the nerves of the special senses.

22. Diagram of the larynx, in man.

23. Larynx of the merganser (Mergus merganser).

24. Nests of Ploceus Philippinus, male and female.

25. Distribution of nerves to the muscular fibres.

26. Test, or crust-like covering of an Echinoderm (Cidaris).

27. Muscular ribbons of the willow-moth (Cossus ligniperda).

28. Vertcbra of a cod-fish.

29. Disposition of the muscles of the trout (Salmo trutta).

30. Disposition of the muscles of an owl (Strix brachyotis).

31. Jelly-fishes (Stomobrachium cruciatum, Hippocrene Bougainvillii).

32. Leech, showing the terminal cups.

33. Portion of a Nereis, showing the gills as organs of motion.

34-43. Modifications of the fore-arm.

34. Monkey. 35. Deer. 36. Tiger. 37. Whale. 38. Bat.

39. Pigeon. 40. Turtle. 41. Sloth. 42. Mole. 43. Whale.

44. Leg of a beetle.

45. Leg of a lizard.

46. Slieleton of a tiger.

47. Cuttle-fish (Loligo illecebrosa).

48. Sea-anemone (Actinia marginata); $a$, mouth; $b$, stomach; $c$, general cavity of the body.

49. Planaria, showing the mouth, stomach, and its branches.

50. Jaws, stomach, and intestine of a sea-urchin (Echinus lividus).

51. Plan of the digestive organs of an Insect.

52. Plan of the digestive organs of a land-slug (Tebennophorus Caroliniensis).

53. Globules of chyle.

54. Portion of intestine, showing the lacteals of man, and their entrance into a vein.

55. Jaws of an Echinoderm (Echinarachnius parma).

56. Jaws of a sea-urchin (Eclinus granulatus).

57. Beak of a cuttle-fish.

58. Portion of the tongue of a Mollusk (Natica heros), magnified.

59. Jaws of an Annelide (Nereis).

60. Trophi (organs for taking food) of a beetle.

61. " of a bee.

62,63 " of a squash-bug.

64. " of a butterfly.

65. " of a Rotifer (Brachionus).

66. Jaws of ditto, magnified. 
FIG.

67. Skull of a tiger, showing the muscles for mastication.

68. Head of a snapping-turtle (Emysaurus serpentina).

69. Head of a Whale, showing the whalebone.

70. Head of an ant-eater.

71. Head of an alligator.

72. Head of a skate-fish (Myliobatis), showing the palate bone.

73. Head of a monkey, showing the three different kinds of teeth.

74. Teeth of an insectivorous animal, the mole.

75. Teeth of a carnivorous animal, the tiger.

76. Teeth of a rodent.

77. A polyp ( Tubularia indivisa) ; $m$, mouth; $o$, ovaries; $p$, tentacles.

78. Blood globules in man, magnified.

79. " " $"$ in birds, "

80. " " " " " "

81. " " in fishes, "

82. Portion of a vein opened, to show the valves.

83. Network of capillary vessels.

84. Dorsal vessel of an insect, with its valves.

85. Cavities of the heart of mammals and birds.

86 . " " " " " a reptile.

87. " " " of a fish.

88. Heart and blood vessels of a gasteropod mollusk (Natica).

89. Tracheæ, or air tubes of an insect; $s$, stigmata; $t$, trachea.

90. Relative position of the heart and lungs in man.

91. Respiratory organs of a naked mollusk (Polycera illuminata).

92. Respiratory organs (gills) of a fish.

93. Vesicles and canals of the salivary glands.

94. Section of the skin, magnified, to show the sweat glands; $a$, the leather; $b$, blood-layer; $c$, epidermis ; $g$, gland imbedded in the fat-layer $(f)$.

95. Egg of a skate-fish (Myliobatis).

96. Egg of hydra.

97. Egg of snow-flea (Podurella).

98. Section of an ovarian egg; $d$, germinative dot; $g$, germinative vesicle; $s$, shell-membrane; $v$, vitelline membrane.

99. Egg cases of Pyrula.

100. Monoculus bearing its eggs, $a a$.

101. Section of a bird's egg; $a$, albumen ; $c$, chalaza ; $e$, embryo; $s$, shell ; $y$, yolk.

102. Cell-layer of the germ.

103. Separation of the cell-layer into three layers ; $s$, serous or nervous layer; $m$, mucous or vegetative layer; $v$, vascular or blood-layer.

104. Embryo of a crab, showing its incipient rings.

105. Embryo of a vertebrate, showing the dorsal furrow. 
FlG.

106-8. Sections of the embryo, showing the formation of the dorsal canal.

109. Section, showing the position of the embryo of a vertcbrate, in relation to the yolk.

110. Scction, showing the same in an articulate (Podurella).

111-22. Sections, showing the successive stages of derelopment of the embryo of the white-fish, magnified.

123. Young white-fish just eseaped from the egg, with the yolk not yet fully taken in.

124, 125. Sections of the embryo of a bird, showing the formation of the allantois; $e$, embryo; $x x$, membrane rising to form the ammios; $a$, allantois; $y$, yolk.

126. The same more fully developed. The allantois $(a)$ is further developed, and bent upwards. The upper part of the yolk $(d d)$ is ncarly separated from the yolk sphere, and is to become the intestine. The heart $(h)$ is already distinct, and connected by threads with the blood-layer of the body.

127. Section of the egg of a mammal; $v$, the thick vitelline membrane, or chorion; $y$, yolk; $s$, germinative dot; $g$, germinative resicle.

12S. The same, showing the empty space $(k)$ between the vitelline sphere and chorion.

129. Shows the first indicationis of the germ already divided in two layers, the serous layer $(s)$, and the mucous layer $(m)$.

130. The mucous layer $(m)$ expands over nearly half of the yolk, and becomes covercd with many little fringes.

131. The cmbryo $(e)$ is seen surrounded by the amnios $(b)$, and covered by a large allantois $(a) ; p e$, fringes of the chorion ; $p m$, fringes of the matrix.

132. Hydra, showing its reproduction by buds.

133. Vorticella, showing its reproduction by division.

131. Polyps, showing the same.

135. A chain of Salpæ.

136. An individual salpa; $m$, the mouth; $a$, embryos.

137. Cercaria, or carly form of the Distoma.

135. Distoma, with its two suckers.

139. Nurse of the Cercaria.

140. The same, magnified, showing the included young.

141. Grand nurses of the Cercaria, enclosing the young nurses.

142. Stages of development of a jelly-fish (Medusa); $a$, the embryo in its first stage, much magnified; $\ell$, summit, showing the mouth; $c, f$, $g$, tcntacles shooting forth; $e$, embryo adhering, and forming a pedicle; $h, i$, separation into segments; $d$, a scgment beeome free; $k$, form of the adult.

143. Portion of a plant-like polyp (Campanularia); $a$, the cup which bears tentacles; $b$, the female cup, containing eggs; $c$, the cups in which the young are nursed, and from which they issue. 
FIG.

144. Young of the same, with its ciliated margin, magnified.

145. Eye of the perch, containing parasitic worms (Distoma).

146. One of the worms magnified.

147. Transformations of the canker-worm (Geometra vernalis); $a$, the canker-worm ; $b$, its chrysalis ; $c$, female moth; $d$, male moth.

148. Metamorphoses of the duck-barnacle (Anatifa); $a$, eggs, magnified; $b$, the animal as it escapes from the egg; $c$, the stem and eye appearing, and the shell enclosing them; $d$, animal removed from the shell, and further magnified; $e, f$, the mature barnacle, affixed.

149. Metamorphoses of a star-fish (Echinaster sanguinolentus), showing the changes of the yolk $(e)$; the formation of the pedicle $(\mu)$; and the gradual change into the pentagonal and rayed form.

150. Comatula, a West India species, in its early stage, attached to a stem.

151. The same detached, and swimming free.

152. Longitudinal section of the sturgeon, to show its cartilaginous vertebral column.

153. Amphioxus, natural size, showing its imperfect organization.

154. Section of the earth's crust, to show the relative positions of the rocks composing it; $E$, plutonic or massive rocks; $M$, metamorphic rocks; $T$, trap rocks ; $L$, lava. 1. Lower Silurian formation; 2. Upper Silurian; 3. Devonian; 4. Carboniferous ; 5. Trias, or Saliferous ; 6. Oōlitic ; 7. Cretaceous ; 8. Lower Tertiary or Eocene; 9. Upper Tertiary, or Miocene, and Pleiocene; 10. Drift.

155. Fossils of the Paleozoic age; $a$, Lingula prima; $b$, Leptæna alternata; $c$, Euomphalus hemisphericus ; $d$, Trocholites ammonius ; $e$, Avicula decussata ; $f$ : Bucania expansa ; $g$, Orthoceras fusiforme ; $i$, Cyathocrinus ornatissimus, Hall ; $j$, Cariocrinus ornatus, Say ; $k$, Melocrinus amphora, Goldf.; $l$, Columnaria alveolata; $m$, Cyathophyllum quadrigeminum, Goldf. ; $n, o$, Caninia flexuosa ; $p$, Chætetes lycoperdon.

156. Articulata of the Paleozoic age ; $a$, Harpes ; $b$, Arges ; $c$, Brontes ; $d$, Platynotus; $e$, Eurypterus remipes.

157. Fishes of the Paleozoic age; $a$, Pterichthys ; $b$, Coccosteus ; $c$, Dipterus ; $d$, palatal bone of a shark; $e$, spine of a shark.

158. Representations of the tracks of supposed birds and reptiles in the sandstone rocks.

159. Supposed outlines of Ichthyosaurus (a), and Plesiosaurus (b).

160. Supposed outline of Pterodactyle.

161. Shells of the Secondary age : $a$, Terebratula ; $b$, Goniomya ; $c$, Trigonia; $d$, Ammonite.

162. Supposed outline of the cuttle-fish (a), from which the Belemnite was derived.

163. Radiata from the Secondary age : $a$, Lobophyllia flabellum; $b$, Litho- 
$F_{1 G}$.

dendron pseudostylina ; $c$, Pentacrinus briareus; $d$, Pterocoma pinnata ; $e$, Cidaris ; $f$, Dysaster; $g$, Nucleolites.

164. Shells of the Cretaceous formation; $a$, Ammonites; $\ell$, Crioceras ; $c$, Scaphites; $d$, Ancyloceras ; $e$, Hamites ; $f$, Baculites ; $g$, Turrilites.

165. Shells of the Cretaceous formation : $a$, Magas ; $b$, Inoceramus ; $c$, Hippurites ; $d$, Spondylus ; $e$, Pleurotomaria.

166. Radiata from the Cretaceous formation: $a$, Diploctenium cordatum; $b$, Marsupites ; $d$, Galerites ; $c$, Salenia ; $e$, Micraster cor-anguinum.

167. Nummulite.

168. Supposed outline of Paleotherium.

169. Supposed outline of Anoplotherium.

170. Skeleton of the Mastodon, in the Cabinet of Dr. J. C. Warren. 



\section{INTRODUCTION.}

Every art and science has a language of technical terms peculiar to itself. With those terms every student must make himself familiarly acquainted at the outset; and first of all, he will desire to know the names of the objects about which he is to be engaged.

The names of objects in Natural History are double, that is to say, they are composed of two terms. Thus, we speak of the white-bear, the black-bear, the hen-hawk, the sparrowhawk; or, in strictly scientific terms, we have Felis leo, the lion, Felis tigris, the tiger, Felis catus, the cat, Canis lupus, the wolf, Canis vulpes, the fox, Canis familiaris, the dog, \&c. They are always in the Latin form, and consequently the adjective name is placed last. The first is called the generic name; the second is called the trivial, or specific name.

These two terms are inseparably associated with every object of which we treat. It is very important, therefore, to have a clear idea of what is meant by the terms genus and species; 
and although the most common of all others, they are not the easiest to be clearly understood. The Genus is founded upon some of the minor peculiarities of anatomical structure, such as the number, disposition, or proportions of the teeth, claws, fins, \&c., and usually includes several kinds. Thus, the lion, tiger, leopard, cat, \&c., agree in the structure of their fect, claws, and teeth, and they belong to the genus Felis; while the dog, fox, jackal, wolf, \&c., have another and a different peculiarity of the feet, claws, and teeth, and are arranged in the genus Canis.

The Species is founded upon less important distinctions, such as color, size, proportions, sculpture, \&c. Thus we have different kinds, or species, of duck, different species of squirrel, different species of monkey, \&c., varying from each other in some trivial circumstance, while those of each group agree in all their general structure. The specific name is the lowest term to which we descend, if we except certain peculiarities, generally induced by some modification of native habits, such as are seen in domestic animals. These are called varieties, and seldom endure beyond the causes which occasion them.

Several genera which have certain traits in common are combined to form a family. Thus, the alewives, herrings, shad, \&c., form a family called Clupeidæ; the crows, blackbirds, jays, \&c., form the family Corvidæ. Families are combined to form orders, and orders form classes, and finally, classes are combined to form the four primary divisions of the Animal Kingdom, namely, the departments.

For each of these groups, whether larger or smaller, we involuntarily picture in our minds an image, made up of the traits which characterize the group. This ideal image is called a TYPE, a term which there will be frequent occasion to employ, in our general remarks on the Animal Kingdom. This image may correspond to some one member of the 
group; but it is rare that any one species embodies all our ideas of the class, family, or genus to which it belongs. Thus, we have a general idea of a bird; but this idea does not correspond to any particular bird, or any particular character of a bird. It is not precisely an ostrich, an owl, a hen, or a sparrow; it is not because it has wings, or feathers, or two legs ; or because it has the power of flight, or builds nests. Any, or all of these characters would not fully represent our idea of a bird; and yet every one has a distinct ideal notion of a bird, a fish, a quadruped, \&c. It is common however, to speak of the animal which embodies most fully the characters of a group, as the type of that group. Thus, we might perhaps regard an eagle as the type of a bird, the duck as the type of a swimming-bird, and the mallard as the type of a duck.

As we must necessarily make frequent allusions to animals, with reference to their systematic arrangement, it seems requisite to give a sketch of their classification in as popular terms as may be, before entering fully upon that subject, and with particular reference to the diagram fronting the title-page.

The Animal Kingdom consists of four great divisions which we call Departients, namely,

I. The department of Vertebrates.

II. The department of Articulates.

III. The department of Mollusks.

IV. The department of Radiates.

I. The department of Vertebrates includes all animals which have an internal skeleton, with a back-bone for its axis. It is divided into four classes.

1. Mammals (animals which nurse their young).

2. Birds.

3. Reptiles.

4. Fishes. 
The class of Mammals is subdivided into three orders.

a. Beasts of prey (Carnivora).

b. Those which feed on vegetables (Herbivora).

c. Animals of the whale kind (Cetaceans).

The class of Binds is divided into four orders, namely,

a. Birds of prey (Incessores).

b. Climbers (Scansores).

c. Waders (Grallatores).

d. Swimmers (Natatores).

The class of Reptiles is divided into five orders.

a. Large reptiles with hollow teeth, most of which are now extinct (Rhizodonts).

b. Lizards (Lacertans).

c. Snakes (Ophidians).

d. Turtles (Chelonians).

e. Frogs (Batrachians).

The class of Fishes is divided into four orders:

a. Those with enamelled scales, like the gar-pike (Ganoids), fig. 157.

b. Those with the skin like shagreen, as the sharks and skates (Placoids).

c. Those which have the edge of the scales toothed, and usually with some bony rays to the fins, as the perch (Ctenoids).

$d$. Those whose scales are entire, and whose fin rays are soft, like the salmon (Cycloids).

II. Department of Articulates. Animals whose body is composed of rings or joints. It embraces three classes.

1. Insects.

2. Crustaceans, like the crab, lobster, \&c.

3. Worms. 
The class of Insecrs includes three orders.

a. Those which have jaws for dividing their food (Manducaia) fig. 60.

b. Those with a trunk for sucking fluids, like the butterfly, (Suctoria) fig. 62-64.

c. Those destitute of wings, like spiders, fleas (Aptera).

The class Crustaceans may be divided as follows :

a. Those furnished with a shield like the crab and lobster (Malacostraca).

b. Such as are not thus protected (Entomostraca).

c. An extinct race, intermediate between these two (Trilobites) fig. 156.

The class of Worms comprises three orders :

a. Those which have thread-like gills about the head (Tubulibranchiates).

b. Those whose gills are placed along the sides (Dorsibranchiates).

$c$. Those which have no exterior gills, like the earthworm (Abranchiates).

III. The department of Mollusks is divided into three classes, namely :

1. Those which have arms about the mouth, like the cuttle-fish (Cephalopods) fig. $4 \%$.

2. Those which creep on a flattened disc or foot, like snails (Gasteropods) fig. 88, 89.

3. Those which have no distinct head, and are enclosed in a bivalve shell, like the clams (Acephals).

The Cephalopods may be divided into

a. The cuttle-fishes, properly so called (Teuthideans), fig. $4 \%$.

b. Those having a shell, divided by sinuous partitions into numerous chambers (Ammonites), fig. 164. 
c. Those having a chambered shell with simple partitions (Nautilus).

The Gasteropods contain three orders:

a. The land snails which breathe air (Pulmonates).

$b$. The aquatic snails which breathe water (Branchifers), fig. 88.

$c$. Those which have wing-like appendages about the head, for swimming (Pteropods).

The class of AcEphals contains three orders:

a. Those having shells of two valves (bivalves), like the clam (Lamellibranchiates).

$b$. Those having two unequal valves, and furnished with peculiar arms (Brachiopods).

c. Mollusks living in chains or clusters, like the Salpa, or upon plant-like stems, like Flustra (Bryozoa), fig. 135.

IV. The department of Radiates is divided into three classes :

1. Sea-urchins, bearing spines upon the surface (Echinoderms), figs. 12, 26, 31 .

2. Jelly-fishes (Acalephs), fig. 31.

3. Polyps, fixed like plants, and with a series of flexible arms around the mouth, figs. 48, 77, 143.

The Echinoderms are divided into four orders :

a. Sea-slugs, like biche-le-mar (Holothurians).

b. Sea-urchins (Echini) fig. 26.

c. Free star-fishes (Asterida), fig. 17.

d. Star-fishes mostly attached by a stem (Crinoids), fig. 150, 151.

The Acalephs include the following orders :

a. The Medusæ, or common jelly fishes (Discophori), figs. 31, 142. 
b. Those provided with aerial vesicles (Siphonophori).

$c$. Those furnished with vibrating hairs, by which they move (Ctenophori).

The class of PoLys includes three orders.

a. Fresh-water polyps, and similar marine forms ( $H y$ droïds), fig. 132.

b. Marine polyps, like the sea-anemone and coralpolyp (Actinoids), figs. 48, 143.

c. A still lower form, allied to the mollusks by their shell (Rhizopods).

In addition to these, there are numberless kinds of microscopic animalcules, commonly called infusory animals (Infusoria), from their being found specially abundant in water infused with vegetable matter. Indeed, a great many that were formerly supposed to be animals are now found to be vegetables. Others are ascertained to be crabs, mollusks, worms, \&c. in their earliest stages of development. In general, however, they are exceedingly minute, and exhibit the simplest forms of animal life, and are now grouped together, under the title of Protozoa. But, as they are still very imperfectly understood, notwithstanding the beautiful researches already published on this subject, and as most of them, are likely to be finally distributed among vegetables and the legitimate classes in the Animal Kingdom, we have not assigned any special place for them. 



\section{PHYSIOLOGICAL ZOÖLOGY.}

\section{CHAPTER FIRST}

THE SPHERE AND FUNDAMENTAL PRINCIPLES OF ZOÖLOGY.

1. ZoöLogy is that department of Natural History which relates to Animals.

2. The enumeration and naming of the animals which are found on the globe, the description of their forms, and the investigation of their habits and modes of life are the principal, but by no means the only objects of this science. Animals are worthy of our regard not only when considered as to the variety and elegance of their forms, or their adaptation to the supply of our wants; but the Animal Kingdom, as a whole, has also a still higher signification. It is the exhibition of the divine thought, as it is carried out in one department of that grand whole which we call $\mathrm{Na}$ ture ; and considered as such, it teaches us the most important lessons.

3. Man, in virtue of his twofold constitution, the spiritual and the material, is qualified to comprehend Nature. 
Having been made in the spiritual image of God, he is competent to rise to the conception of His plan and purpose in the works of Creation. Having also a material body, like that of animals, he is also prepared to understand the mechanism of organs, and to appreciate the necessities of matter, as well as the influence which it exerts over the intellectual element, throughout the whole domain of Nature.

4. The spirit and preparation we bring to the study of Nature, is not a matter of indifference. When we would study with profit a work of literature, we first endeavor to make ourselves acquainted with the genius of the author; and in order to know what end he had in view, we must have regard to his previous labors, and to the circumstances under which the work was executed. Without this, although we may perhaps enjoy the perfection of the whole, and ad. mire the beauty of its details, yet the spirit which pervades it will escape us, and many passages may even remain unintelligible.

5. So, in the study of Nature, we may be astonished at the infinite variety of her products, and may even study some portion of her works with enthusiasm, and nevertheless remain strangers to the spirit of the whole, ignorant of the plan on which it is based; and may fail to acquire a proper conception of the varied affinities which combine beings together, so as to make of them that vast picture, in which each animal, each plant, each group, each class, has its place, and from which nothing could be removed without destroying the proper meaning of the whole.

6. Besides the beings which inhabit the earth at the present time, this picture also embraces the extinct races which are now known to us by their fossil remains only. And these are of the greatest importance, since they furnish us with the means of ascertaining the changes and modifications which the Animal Kingdom has undergone in the suc- 
cessive creations, since the first appearance of living beings.

7. It is but a short time since it was not difficult for a man to possess himself of the whole domain of positive knowledge in Zoölogy. A century ago, the number of known animals did not exceed 8000 ; that is to say, from the whole Animal Kingdom, fewer species were then known, than are now contained in many private collections of certain families of insects merely. At the present day, the number of living species which have been satisfactorily made out and described, is more than 50,000* The fossils already described exceed 6000 species; and if we

* The number of vertebrate animals may be estimated at 20,000 . About 1500 species of mammals are pretty precisely known, and the number may probably be carried to about 2000 .

The number of Birds well known is 4 or 5000 species, and the probahle number is 6000 .

The Reptiles number about the same as the Mammals, 1500 described species, and they will probably reach the number of 2000 .

The Fishes are more numerous; there are from 5 to 6000 species in the museums of Europe, and the number may probably amount to 8 or 10,000 .

The number of Mollusks already in collections, probably reaches 8 or 10,000. There are collections of marine shells, bivalve and univalve, which amount to 5 or 6000 ; and collections of land and fluviatile shells, which count as many as 2000 . The total number of mollusks would therefore probably exceed 15,000 species.

Among the articulated animals it is difficult to estimate the number of species. There are collections of coleopterous insects which number 20 to 25,000 species ; and it is quite probable, that by uniting the principal collections of insects, 60 or 80,000 species might now be counted; for the whole department of articulata, comprising the crustacea, the cirrhipeda, the insects, the red-blooded worms, the intestinal worms, and the infusoria, as far as they belong to this department, the number would already amount to 100,000 ; and we might safely compute the probable number of species actually existing, at double that sum.

Add to these about 10,000 for radiata, echini, star-fishes, medusæ, and polypi, and we have about 250,000 species of living animals ; and supposing the number of fossil species only to equal them, we have, at a very moderate computation, half a million of species. 
consider that wherever any one stratum of the earth has been well explored, the number of species discovered has not fallen below that of the living species which now inhabit any particular locality of equal extent, and then bear in mind that there is a great number of geological strata, we may anticipate the day when the ascertained fossil species will far exceed the living species.*

8. These numbers, far from discouraging, should, on the contrary, encourage those who study Natural History. Each new species is, in some respects, a radiating point which throws additional light on all around it; so that as the picture is enlarged, it at the same time becomes more intelligible to those who are competent to seize its prominent traits.

9. To give a detailed account of each and all of these animals, and to show their relations to each other, is the task of the Naturalist. The number and extent of the volumes already published upon the various departments of Natural History show, that only a mere outline of a domain so vast could be fully sketched in an elementary work, and that none but those who make it their special study can be expected to survey its individual parts.

10. Every well-educated person, however, is expected to have a general acquaintance with the great natural phenomena constantly displayed before his eyes. There is a general knowledge of man and the subordinate animals, embracing their structure, races, habits, distribution, mutual relations, \&c., which is calculated not only to conduce es-

* In a separate work, entitled "Nomenclator Zoölogicus," by L. Agassiz, the principles of nomenclature are discussed, and a list of the names of genera and families proposed by authors is given. To this work those are referred who may desire to become more familiar with nomenclature, and to know in detail the genera and families in each class of the Animal Kingdom. 
sentially to our happiness, but which it would be quite inexcusable to neglect. This general view of Zoölogy, it is the purpose of this work to afford.

11. A sketch of this nature should render prominent the more general features of animal life, and delineate the arrangement of the species according to their most natural relations and their rank in the scale of being; and thus give a panorama, as it were, of the entire Animal Kingdom. To accomplish this, we are at once involved in the question, what is it that gives an animal precedence in rank?

12. In one sense, all animals are equally perfect. Each species has its definite sphere of action, whether more or less extended, - its own peculiar office in the economy of nature; and it is perfectly adapted to fulfil all the purposes of its creation, beyond the possibility of improvement. In this sense, every animal is perfect. But there is a wide difference among them, in respect to their organization. In some it is very simple, and very limited in its operation; in others, extremely complicated, and capable of exercising a great variety of functions.

13. In this physiological point of view, an animal may be said to be more perfect in proportion as its relations with the external world are more varied; in other words, the more numerous its functions are. Thus, an animal, like a quadruped, or a bird, which has the five senses fully developed, and which has, moreover, the faculty of readily transporting itself from place to place, is more perfect than a snail, whose senses are very obtuse, and whose motion is very sluggish.

14. In like manner, each of the organs, when separately considered, is found to have every degree of complication, and, consequently, every degree of nicety in the performance of its function. Thus, the eye-spots of the star-fish and jelly-fish, probably are endowed with merely the fac- 
ulty of perceiving light, without the power of distinguishing objects. The keen eye of the bird, on the contrary, discerns minute objects at a great distance, and when compared with the eye of a fly, is found to be not only more complicated, but constructed on an entirely different plan. It is the same with every other organ.

15. We understand the faculties of animals, and appreciate their value, just in proportion as we become acquainted with the instruments which execute them. The study of the functions or uses of organs therefore requires an examination of their structure; they must never be disjoined, and must precede the systematic distribution of animals into classes, families, genera, and species.

16. In this general view of organization, we must ever bear in mind the necessity of carefully distinguishing between affinities and analogies, a fundamental principle recognized even by Aristotle, the founder of scientific Zoölogy. Analogy or homology is the relation between organs or parts of the body which are constructed on the same plan, however much they vary in form, but which serve for very different uses. Analogy, on the contrary, indicates the similarity of purposes or functions performed by organs of different structure.

17. Thus, there is an analogy between the wing of a bird and that of a butterfly, since both of them serve for flight. But there is no affinity between them, since, as we shall hereafter see, they differ totally in their anatomical relations. On the other hand, there is an affinity between the bird's wing and the hand of a monkey, since, although they serve for different purposes, the one for climbing, and the other for flight, yet they are constructed on the same plan. Accordingly, the bird is more nearly allied to the monkey than to the butterfly, though it has the faculty of flight in common with the latter. Affinities, and not analogies, therefore, must guide us in the arrangement of animals. 
18. Our investigations should not be limited to adult animals, but the changes which they undergo during the whole course of their development must also be considered. Otherwise, we shall be liable to exaggerate the importance of certain peculiarities of structure which have a predominant character in the full-grown animal, but which are shaded off, and vanish, as we revert to the earlier periods of life.

19. Thus, for example, by regarding only adult individuals, we might be induced to divide all animals into two groups, according to their mode of respiration; uniting, on the one hand, all those which breathe by gills, and, on the other, those which breathe by lungs. But this distinction loses its importance, when we consider that various animals, for example, frogs, which respire by lungs in the adult state, have only gills when young. It is thence evident that the respiratory organs cannot be taken as a satisfactory basis of our fundamental classification. They are, as we shall see, subordinate to a more important organism, namely, the nervous system.

20. Again, we have a means of appreciating the relative grade of animals by the comparative study of their development. It is evident that the caterpillar, in becoming a butterfly, passes from a lower to a higher state. Clearly, therefore, animals resembling the caterpillar, the worms, for instance, must occupy a lower rank than those approaching the butterfly, like most insects. There is no animal which does not undergo a series of changes similar to those of the caterpillar or the chicken; only, in many of them, the most imporiant ones occur before birth, during what is called the embryonic period.

21. The life of the chicken has not just commenced when it issues from the egg; for if we break the egg some days previous to the time of hatching, we find in it a living ani- 
mal, which, although imperfect, is nevertheless a chicken ; it has been developed from a hen's egg, and we know that, should it continue to live, it would infallibly display all the characteristics of the parent bird. Now, if there existed in Nature an adult bird as imperfectly organized as the chicken on the day, or the day before it was hatched, we should assign to it an inferior rank.

22. In studying the embryonic states of the mollusks or worms, we observe in them points of resemblance to many animals of a lower grade, and to which they at length become entirely dissimilar. For example, the myriads of minute aquatic animals embraced under the name of Infusoria, in their organization generally, very simple, remind us of the embryonic forms of other animals. We shall have occasion to show that the Infusoria are not to be considered as a distinct class of animals, but that among them are found members of all the lower classes of animals, mollusks, crustaceans, polyps, and many of them are even found to belong to the Vegetable Kingdom.

23. Not less striking are the relations that exist between animals and the regions they inhabit. Every animal has its home. Animals of the cold regions are not the same as those of temperate climates; and these latter, in their turn, differ from those of tropical regions. Certainly, no one will maintain it to be the effect of accident that the monkeys, the most perfect of all brute animals, are found only in hot countries; or that it is by chance that the white-bear and reindeer inhabit only cold regions.

24. Nor is it by chance that the largest of all animals, of every class, the whales, the aquatic birds, the sea-turtles, dwell in the water rather than on the land. And while the water affords freedom of motion to the largest, so is it also the home of the smallest of living things, affording to them a freedom from obstacles to their motion, which they could not enjoy elsewhere. 
25. Nor are our researches to be limited to the animals now living. There are buried in the crust of the earth the remains of a great number of animals belonging to species which do not exist at the present day. Many of these remains present forms so extraordinary that it is almost impossible to trace their connection with any animals now living. In general, they bear a striking analogy to the embryonic forms of existing species. For example, the curious fossils known under the name of Trilobites (Fig. 156), have a shape so singular that it might well be doubted to what group of articulated animals they belong. But if we compare them with the embryo crab, we find so remarkable a resemblance that we hesitate not to refer them to the crustaceans. We shall also see that some of the Fishes of ancient epochs present shapes entirely peculiar to themselves (Fig. 157), but resembling in a striking manner, the embryonic forms of our common fishes. A determination of the successive appearance of animals in the order of time is therefore of much importance in assisting to determine the relative rank of animals.

26. Besides the distinctions to be derived from the varied structure of organs, there are others less subject to rigid analysis, but no less decisive, to be drawn from the immaterial principle, with which every animal is endowed. It is this which determines the constancy of species from generation to generation, and which is the source of all the varied exhibitions of instinct and intelligence which we see displayed, from the simple impulse to receive the food which is brought within their reach, as observed in the polyps, through the higher manifestations, in the cunning fox, the sagacious elephant, the faithful $d o g$, and the exalted intellect of man, which is capable of indefinite expansion.

27. Such are some of the general aspects in which we are to contemplate the animal creation. Two points of 
view should never be lost sight of, or disconnected, namely, the animal in respect to its own organism, and the animal in its relations to creation as a whole. By adopting too exclusively either of these points of view, we are in danger of falling either into gross materialism, or into vague and profitless pantheism. He who beholds in Nature nothing besides organs and their functions, may persuade himself that the animal is merely a combination of chemical and mechanical actions and reactions, and thus becomes a materialist.

28. On the contrary, he who considers only the manifestations of intelligence and of creative will, without taking into account the means by which they are executed, and the physical laws by virtue of which all beings preserve their characteristics, will be very likely to confound the Creator with the creature.

29. It is only as it contemplates, at the same time, matter and mind, that Natural History arises to its true character and dignity, and leads to its worthiest end, by indicating to us, in Creation, the execution of a plan fully matured in the beginning, and invariably pursued; the work of a God infinitely wise, regulating Nature according to immutable laws, which He has himself imposed on her. 


\title{
CHAPTER SECOND.
}

GENERAL PROPERTIES OF ORGANIZED BODIES.

\author{
SECTION I. \\ ORGANIZED AND UNORGANIZED BODIES.
}

30. Natural History, in its broadest sense, embraces the study of all the bodies which compose the crust of the earth, or which are dispersed over its surface.

31. These bodies may be divided into two great groups; inorganic bodies (minerals and rocks), and living or organized bodies (vegetables and animals). These two groups have nothing in common, save the universal properties of matter, such as weight, color, \&c. They differ at the same time, as to their form, their structure, their composition, and their mode of existence.

32. The distinctive characteristic of inorganic bodies, is rest ; the distinctive trait of organized bodies, is independent motion, LIFE. The rock or the crystal, once formed, never changes ; their constituent parts or molecules invariably preserve the position which they have once taken in respect to each other. Organized bodies, on the contrary, are continually in action. The sap circulates in the tree, the blood flows through the animal, and in both there is, 
besides, the incessant movement of growth, decomposition, and renovation.

33. Their mode of formation is also entirely different. They are, in the first place, derived from sources unlike themselves; and if a mineral is enlarged, it is simply by the outward addition of particles constituted like itself. Organized bodies are not formed in this manner. They always, and necessarily, are derived from beings similar to themselves; and once formed, they increase always from within outward, by the interposition of new particles, which go to complete the individual.

34. Finally, organized bodies are limited in their duration. Animals and plants are constantly losing some of their parts by decomposition during life, which at length cease to be supplied, and they die, after having lived for a longer or shorter period. Inorganic bodies, on the contrary, contain within themselves no principle of destruction; and unless subjected to some foreign influence, a crystal or a rock would never change. The limestone and granite of our mountains remain just as they were formed in ancient geological epochs; while numberless generations of plants and animals have lived and perished upon their surface.

\section{SECTION II.}

ELEMENTARY STRUCTURE OF ORGANIZED BODIES.

35. The exercise of the functions of life, which is the essential characteristic of organized bodies (32), requires a degree of flexibility of the organs. This is secured by means of a certain quantity of watery fluid, which pene- 
trates all parts of the body, and forms one of its principal constituents.

36. All living bodies, without exception, are made up of tissues so constructed as to be permeable to liquids. There is no part of the body, no organ, however hard and compact it may appear, which has not this peculiar property. It exists in the bones of animals, as well as in their flesh and fat; in the most solid wood, as well as in the bark and flowers of plants. It is to this general structure that the term organism is now applied. Hence the collective name of organized beings, ${ }^{*}$ which includes both the animal and the vegetable kingdoms.

37. The vegetable tissues and most of the organic struc-

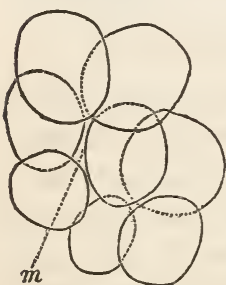

Fig. 1. tures, when examined by the microscope, in their early states of growth, are found to be composed of hollow vesicles or cells. The natural form of the cells is that of a sphere or of an ellipsoid, as may be easily seen in many plants; for example, in the tissue of the house-leek (Fig. 1). The intervals which sometimes separate them from each other, are called intercellular passages or spaces $(m)$. When the cellules are very numerous, and crowd each other, their outlines become angular, and the intercel-

* Formerly, animals and plants were said to be organized because they are furnished with definite parts, called organs, which execute particular functions. Thus, animals have a stomach, a heart, lungs, \&c. ; plants have leaves, petals, stamens, pistils, roots, \&c., all of which are indispensable to the maintenance of life, and the perpetuation of the species. Since the discovery of the identity of the structure of animal and vegetable tissues, a common denomination for this uniformity of texture, has been justly preferred; and the existence of tissues is now regarded as the basis of organization. 
lular spaces disappear, as seen in figure 2, which represents

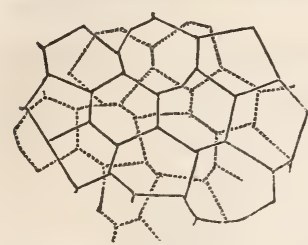

Fig 2. the pith of the elder. They then have the form of a honey-comb; whence they have derived their name of cellules.

38. All the organic tissues, whether animal or vegetable, originate from the cell. The cell is to the organized body what the primary form of the crystal is to the secondary, in minerals. As a general fact, it may be stated that animal cells, are smaller than vegetable $a \quad b$ cells, and contain a central dot or vesicle, called nucleus. Hence those cells are called nucleated cells (Fig. 3,a). Sometimes the nucleus itself contains a still smaller dot, called nucleolus $(b)$.

39. The elementary structure of vegetables is easily observed in every part of a plant, and its cellular character has been long known. But with the animal tissues there is far greater difficulty. Their variations are so great, and their transformations so diverse, that after the embryonic period it is often difficult, even by the closest examination, to detect their original structure.

40. Several kinds of tissues have been designated in the animal structure; but their differences are not always well marked, and they pass into each other by insensible shades. Their modifications are still a matter of investigation, and we refer only to the most important distinctions.

41. The areolar tissue. It is the most generally diffused. The cells are usually large, but irregular, with their walls often imperfect. In man, as well as in the higher animals, it is interposed, in layers of various thickness, between the organs of the body, and contains more or less fat. Most of the membranes are mere modifications of it.

42. The cartilaginous tissue is composed of nucleated 
cells, the intercellular spaces being filled with a more compact substance called the hyaline matter. Figure 4 represents a slip of cartilage from a horse, under a magnifying power of one hundred and twenty diameters.

43. The osseous or bony tissue differs from the cartilaginous tissue, in having the meshes filled with salts of lime, instead of hyaline sub-

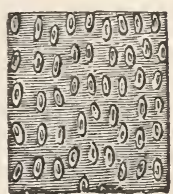

Fig. 4. stance, whence its compact and solid appearance. It con-

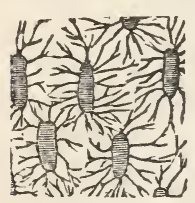

Fig. 5. tains, besides, minute, rounded, or star-like points, improperly called bone-corpuscles, which are found to be cavities or canals, and are sometimes fancifully branched, as is seen in figure 5 , representing the section of a horse bone, magnified four hundred and fifty times.

44. The muscular tissue, which forms the flesh of animals, is composed of bundles of parallel fibres, which, in the muscles under the control of the will, are commonly crossed by very fine lines or wrinkles, and possess the peculiar property of contracting or shortening themselves, under the influence of the nerves. Every one is sufficiently familiar with this tissue, in the form of lean meat.

45. The nervous tissue is of different kinds. In the

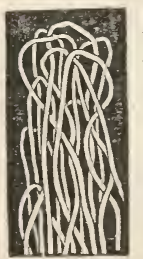
nerves proper, it is composed of very delicate fibres, which return back at their extremities, and form loops, as shown in figure 7 , representing nervous threads, as they

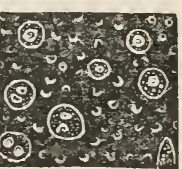

Fig. 7. terminate in the skin of a frog. The same fibrous Fig. 6. structure is found in the white portion of the brain. But the gray substance is composed of very minute granulations, with larger cells, collected in clusters, as seen in figure 8 .

46. The tissues above enumerated differ from each other 
more widely, in proportion as they are examined in animals of a higher rank. As we descend in the scale of being, the differences become gradually effaced. The soft body of a snail is much more uniform in its composition, than the body of a bird, or a quadruped. Indeed, multitudes of animals are known, made up of nothing but cells in contact with each other. Such is the case with most of the Infusoria, which nevertheless live and move most freely, by means of little hair-like organs at their surface, that are themselves merely modified cells.

47. A no less remarkable uniformity of structure is to be observed in the higher animals, in the earlier periods of their existence, before the body has arrived at its definite form. The head of the adult salmon, for instance, contains all the tissues we have mentioned, namely, bone,

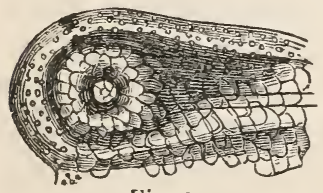

Fig. 8 . cartilage, muscle, nerve, brain, vessels, and membranes. But let us examine it during the embryonic state, that is, while it is yet in the egg, and we find that the whole head is made up of cells which differ merely in their dimensions; those at the top of the head being very small, those surrounding the eye a little larger, and those beneath being still larger. It is only at a later period, after still further development, that these cellules become transformed, some of them into bone, others into blood, others into flesh, \&c.

48. Again, the growth of the body, the introduction of various tissues, the change of form and structure, proceed in such a manner as to give rise to several cavities, variously combined among themselves, and each containing, at the end of these transformations, peculiar organs, or peculiar systems of organs. 


\section{SECTION III.}

\section{DIFFERENCES BETWEEN ANIMALS AND PLANTS.}

49. At first thought, nothing would seem more widely different than animals and plants. What is there in common, for instance, between an oak or an elm, and the bird which seeks shelter under their foliage?

50. The differences are usually so obvious, that this question would be superfluous had we to apply it to only the higher forms of the two kingdoms. But this contrast diminishes, in proportion as their construction is simplified; and as we descend to the lower forms, the distinctions are so few and so feebly characterized, that it becomes at length difficult to pronounce whether the object we have before us is an animal or a plant. Thus the sponges have so great a resemblance to some of the polypi, that they have generally been classed among animals, although in reality they belong to the vegetable kingdom.

51. Animals and plants differ in the relative predominance of the elements, oxygen, carbon, hydrogen and nitrogen, of which they are composed. In vegetables, only a trace of nitrogen is found, and that merely in the seeds, and some other products of the plant; while it enters largely into the composition of the animal tissues.

52. Another peculiarity of the Animal Kingdom is, the presence of large, distinctly limited cavities, destined for the lodgment of certain organs; such is the skull and the chest in the higher animals, the cavity of the gills in fishes, and of the abdomen or general cavity of the body, for the reception of the digestive organs, which exists in all animals, without exception. 
53. The well-defined and compact forms of the organs lodged in these cavities, is also another peculiarity of animals. In plants, the organs designed for special purposes are not embodied into one mass, but are distributed over various parts of the individual. Thus, the leaves, which answer to the lungs, instead of being condensed into one organ, are scattered in countless numbers over the branches. Nor is there any one organ corresponding to the brain, the heart, the liver, or the stomach.

54. Moreover, the presence of a proper digestive cavity, involves marked differences between the two kingdoms, in respect to alimentation or the use of food. In plants, the fluids absorbed by the roots are carried, through the trunk and all the branches, to the whole plant, before they arrive at the leaves, where they are to be digested. In animals, on the contrary, the food is at once received into the digestive cavity, where it is elaborated ; and it is only after it has been thus dissolved and prepared, that it is introduced into the other parts of the body.

55. Plants commence their development from a single point, the seed, and, in like manner, all animals are developed from the egg. But the animal germ is the result of successive transformations of the yolk, while nothing similar takes place in the plant. The subsequent development of individuals is also different in the two kingdoms. No limit is placed to the increase of plants; trees put out new branches and new roots as long as they live. Animals, on the contrary, have all a limited size and figure ; and these once attained, the subsequent changes are accomplished without any increase of volume or essential alteration of form; while the appearance of vegetables is frequently modified, in a notable manner, by the development of new branches.

56. In the effects they produce upon the air, by respira- 
tion, there is an important difference. Animals consume the oxygen, and give out carbonic acid gas which is destructive to animal life; while plants, by respiration, which they, in most instances, perform by means of the leaves, reverse the process, and thus furnish oxygen, which is so essential to animals. If an animal be confined in a small portion of air, or water containing air, this soon becomes so vitiated by respiration as to be unfit to sustain life; but if living plants are confined with the animal at the same time, the air is maintained pure, and no difficulty is experienced. The practical effect of this compensation, in the economy of Nature, is obviously most important; vegetation restoring to the atmosphere what is consumed by animal respiration, combustion, \&c., and vice versa.

57. But there are two things which, more than all others, distinguish the animal from the plant, namely, the power of moving itself or its parts at will, and the power of perceiving other objects or their influences; in other words, voluntary motion and sensation.

58. All animals are susceptible of undergoing pleasure and pain. Plants have also a certain sensibility. 'They wither and fade under a burning sun, or when deprived of moisture; and they die when subjected to too great a degree of cold, or to the action of poisons. But they have no consciousness of these influences, and suffer no pain; while animals under similar circumstances suffer. Hence they have been called animate beings, in opposition to plants, which are inanimate beings. 


\section{CHAPTER THIRD.}

FUNCTIONS AND ORGANS OF ANIMAL L.IFE.

\section{SECTION I.}

OF THE NERVOUS SYSTEIT AND GENERAL SENSATION.

59. Life, in animals, is manifested by two sorts of functions, viz. : First, the peculiar functions of animal life, or those of relation, which include the functions of sensation and voluntary motion; those which enable us to approach, and perceive our fellow beings and the objects about us, and to bring us into relation with them: Second, the functions of vegetative life, which are nutrition and reproduction;* those indeed, which are essential to the maintenance and perpetuation of life.

60. The two distinguishing characteristics of animals, namely, motion and sensation (57), depend upon a special apparatus, which is wanting in plants, and which is called the nervous system. The nervous system, therefore, is the

* This distinction is the more important, inasmuch as the organs of animal life, and those of vegetative life, spring from very distinct layers of the embryonic membrane. The first are developed from the upper layer, and the second from the lower layer of the germ of the animal. See Chapter on Embryology, p. 112. 
part characteristic of the animal body. It is the grand centre from which all the commands of the will issue, and to which all sensations tend.

61. Greatly as the form, the arrangement, and the vol-

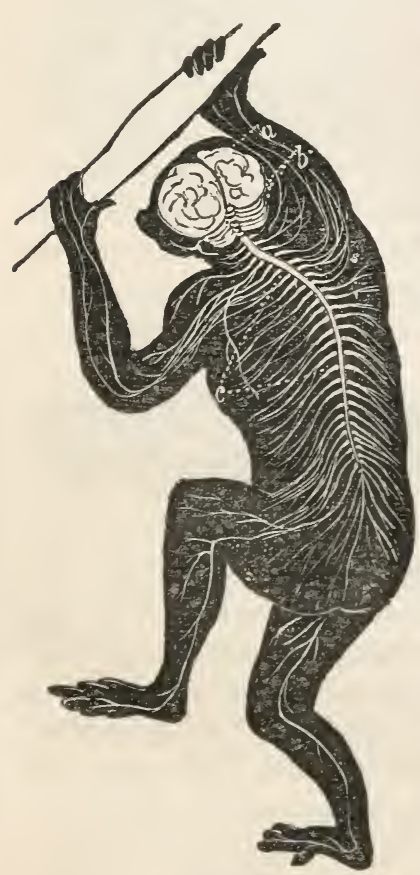

Fig. 9. ume of the nervous system vary in different animals, they may all be reduced to four principal types, which correspond moreover, to the four great departments of the Animal Kingdom. In the vertebrate animals, namely, the fishes, reptiles, birds, and mammals, the nervous system is composed of two principal masses, the spinal marrow (Fig. 9, c), which runs along the back, and the brain, contained within the skull.* The volume of the brain is proportionally larger, as the animal occupies a more elevated rank in the scale of being. Man, who stands at the head of Creation, is in this respect also, the most highly endowed being.

62. The brain and spinal marrow give origin to the nerves, which are distributed, in the form of branching threads, through every part of the body. The branches

* The brain is composed of several distinct parts which vary greatly, in their relative proportions, in different animals, as will appear hereafter. They are : 1. The medulla oblongata; 2. Cerebellum; 3. Optic lohes; 4. Cerebral hemispheres; 5 . Olfactory lobes. See figures 9 and 21. 
which arise from the brain are twelve pairs, called the cerebral nerves, and are chiefly destined for the organs of sense located in the head. Those which arise from the spinal marrow are also in pairs, one pair for each vertebra or joint of the back. The number of pairs varies, therefore, in different classes and families, according to the number of vertebræ. Each nerve is double, in fact, being composed of two threads, which spring from the spinal marrow by separate roots, and accompany each other throughout their whole course. One of these transmits the commands of the will, which produce motion; the other receives and conveys impressions to the brain, and produces sensations.

63. In the Articulated animals, comprising the crabs, barnacles, worms, spiders, insects, and other animals formed of rings, the nervous system consists of a se-

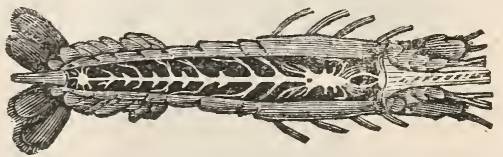

Fig. 10. ries of small centres or swellings, called ganglions (Fig. 10), placed beneath the alimentary canal, on the floor of the general cavity of the body, and connected by threads ; and of a more considerable mass placed above the œsophagus or throat, connected with the lower ganglions by threads which form a collar around the alimentary canal. 'The number of ganglions generally corresponds to the number of rings.

64. In the Mollusks (Fig. 11), the nervous system con-

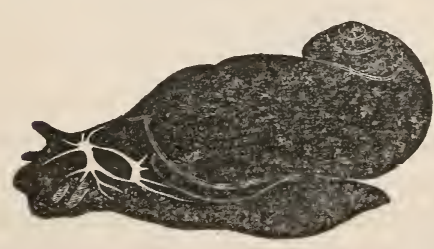

Fig. 11 . sists of a single ganglionic circle, the principal swellings of which are placed symmetrically above and below the œsophagus, and from whence the filaments, which supply the organs in different directions, take their origin. 
65. In the Radiata (Fig. 12), the nervous system is re-

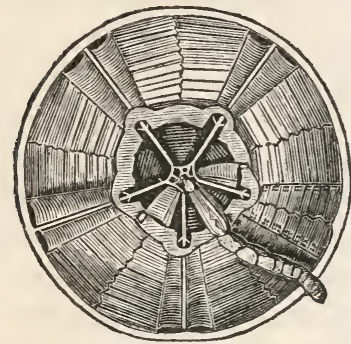

Fig. 12. duced to a single ring, encircling the mouth. It differs essentially from that of the Mollusks, by being disposed in a horizontal position, and by its star-like form.

66. The nerves branch off and diffuse sensibility to every portion of the body, and thereby men and the higher animals are enabled to gain a knowledge of the general properties of the objects which surround them; every point of the body being made capable of determining whether an object is hot or cold, dry or moist, hard or soft. There are some parts, however, the ends of the fingers, for example, in which this sensibility is especially acute, and these also receive a larger supply of nerves.

67. On the contrary, those parts which are destitute of sensibility, such as the feathers of birds, the wool of animals, or the hair of man, are likewise destitute of nerves. But the conclusive proof that sensibility resides in the nerves is, that when the nerve which supplies any member of the body is severed, that member at once becomes insensible.

68. There are animals in which the faculty of perception is limited to this general sensation; but their number is small, and in general, they occupy the lowest place in the series. Most animals, in addition to the general sensibility, are endowed with peculiar organs for certain kinds of perceptions, which are called the senses. These are five in number, namely : sight, hearing, smell, taste, and touch. 


\section{SECTION II. \\ OF THE SPECIAL SENSES.}

1. Of Sight.

69. Sight is the sense by which light is perceived, and by means of which, the form, dimensions, position, color and brilliancy of surrounding objects, are discerned. Some of these properties may be also ascertained, though in a less perfect manner, by the sense of touch. We may obtain an idea of the size and shape of an object, by handling it; but the properties that have a relation to light, such as color and brilliancy, and also the form and size of bories that are beyond our reach, are exclusively recognized by sight.

70. The EYE is the organ of vision. The number, structure, and position of the eyes in the body, is considerably varied in the different classes. But whatever may be their position, these organs are always in connection with particular nerves, called the optic nerves (Fig. 13, a). In the vertebrates, these constitute the second pair of the cerebral nerves, and arise directly from the middle mass of the brain (Fig. 21, b), which, in the embryo, is the most considerable of all.

71. Throughout the whole series of vertebrate animals, the eyes are only two in number, and occupy bony cavities of the skull, called the orbits. The organ is a globe or hollow sphere, formed by three membranes enclosed one within the other, and filled with transparent matter. Figure 13 represents a vertical section through

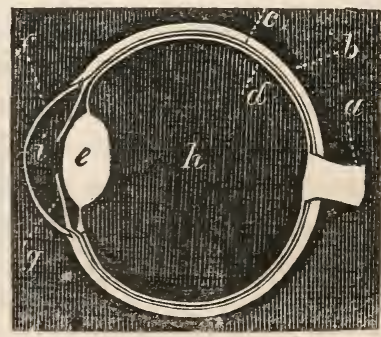

Fig. 13. the eye, and will give an idea of the relative position of these different parts. 
72. The outer coat is called the sclerotic $(b)$; it is a thick, firm, white membrane, having its anterior portion transparent. This transparent segment, which seems set in the opaque portion, like a watch-glass in its rim, is called the cornea $(f)$.

73. The inside of the sclerotic, is lined by a thin, dark colored membrane, the choroid $(c)$. It becomes detached from the sclerotic, when it reaches the edge of the cornea, and forms a curtain behind it. This curtain gives to the eye its peculiar color, and is called the $i r i s(g)$. The iris readily contracts and dilates, so as to enlarge or diminish an opening at its centre, the pupil, according as more or less light is desired. Sometimes the pupil is circular, as in man, the dog, the monkey; sometimes in the form of a vertical ellipse, as in the cat; or, it is elongated sidewise as in the sheep.

74. The third membrane is the retina $(d)$. It is formed by the optic nerve, which enters the back part of the eye, by an opening through both the sclerotic and choroid coats, and expands upon the interior into a whitish and most delicate membrane. It is upon the retina that the images of objects are received, and produce impressions, which are conveyed by the nerve to the brain.

75. The fluids which occupy the cavity of the eye, are of different densities. Behind, and directly opposite to the pupil, is placed a spheroidal body, called the crystalline lens $(e)$. It is tolerably firm, perfectly transparent, and composed of layers of unequal density, the interior being always more compact than the exterior. Its form varies in different classes of animals. In general, it is more convex in aquatic than in land animals; whilst with the cornea, it is directly the contrary, being flat in the former, and convex in the latter.

76. By means of the iris; the cavity in front of the crys- 
talline is divided into two compartments, called the anterior and posterior chambers (i). The fluid which fills these chambers is a clear watery liquid, called the aqueous humor. The portion of the globe behind the lens, which is much the largest, is filled by a gelatinous liquid, perfectly transparent, like that of the chambers, but somewhat more dense. This is called the vitreous humor $(h)$.

77. The object of this apparatus is to receive the rays of light, which diverge from all points of bodies placed before it, and to bring them to a point again upon the retina. It is a well-known fact, that when a ray of light passes obliquely from one medium to another of different density, it will be refracted or turned out of its course more or less, according to the difference of this density, and the obliquity at which the ray strikes the surface. This may be illustrated by the following figure. (Fig. 14).

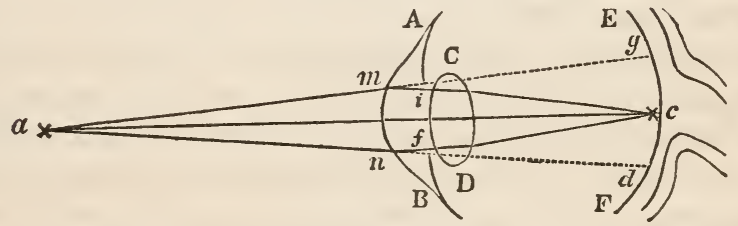

Fig. 14.

The ray $a c$, which strikes the cornea A B perpendicularly, continues without deviation, until it reaches the bottom of the eye at $c$. But the rays $a m$ and $a n$, which strike the eye obliquely, change their direction, and instead of proceeding onward to $m g$ and $n d$, take the direction $m i$ and $n f$. A still further refraction, though less considerable, is occasioned by passing through the crystalline lens $\mathrm{C} \mathrm{D}$, and the vitreous humor, so that the two rays $m i$ and $n f$, will at last meet in a point. This point is called the focus (c), and in distinct vision, is always precisely at the retina, $\mathrm{E} \mathrm{F}$.

78. From this arrangement, the image found upon the 
retina, will be inverted. We may satisfy ourselves of this by direct observation. The eye of the white rabbit being destitute of the black pigment of the choroid, is quite transparent. Take the eye, soon after the death of the animal, and arrange it in one end of a tube, so that the cornea will look outwards; then if we look through from the other end of the tube, we may see objects to which it is directed exactly pictured upon the retina, but in a reversed position.

79. The mechanical structure of the eye, may be perfectly imitated by art. Indeed, the camera obscura is an instrument constructed on the very same plan. By it, external objects are pictured upon a screen, placed at the bottom of the instrument, behind a magnifying lens. The screen represents the retina; the dark walls of the instrument represent the choroid; and the cornea, the crystalline and the vitreous humor combined, are represented by the magnifying lens. But there is this important difference, that the eye has the power of changing its form, and of adapting it so as to discern with equal precision, very remote, as well as very near objects.

80. By means of muscles which are attached to the ball, the eyes may be rolled in every direction, so as to view objects on all sides, without moving the head. The eyes are usually protected by lids, which are two in the mammals, and generally furnished with a range of hairs at their edges, called eye-lashes. The birds have a third lid, which is vertical, and is also found in most of the reptiles and a few mammals. In fishes, the lids are wanting, or immovable.

81. The eye constructed as above described, is called a simple eye, and belongs more especially to the vertebrate animals. In man, it arrives at its highest perfection. In him, the eye also performs a more exalted office than mere vision. It is a mirror in which the inner man is reflected. His passions, his joys, and his sorrows, his inmost self, are 
reflected, with the utmost fidelity, in the expression of his eye, and it has been rightly called " the window of the soul."

82. Many of the invertebrate animals, have the eyes constructed upon the same plan as that of the vertebrate animals, but with this essential difference, that the optic nerve which forms the retina, is not derived from a nervous centre, analogous to the brain, but arises from one of the ganglions. Thus, the eyes of the cuttle-fish contain all the parts essential to the eye of the superior animals, and what is no less important, they are only two in number, placed upon the sides of the head.

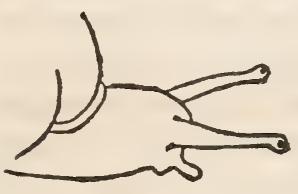

Fig. 15.

83. The snail, and kindred animals have, in like manner, only two eyes, mounted on the tip of a long stalk, (the tentacle), or situated at its base, or on a short pedestal by its side. Their structure is less perfect than the eyes of the cuttle-fish, but still there is a crystalline, and more or less distinct traces of the vitreous body. Some bivalve mollusks, the scollops for example, have likewise a crystalline, but instead of two, they are furnished with numerous eyes, which are arranged like a border around the lower margin of the animal.

84. In spiders, the eyes are likewise simple, and usually eight in number. These little organs, usually called ocelli, instead of being placed on the sides of the body or of the head, occupy the anterior

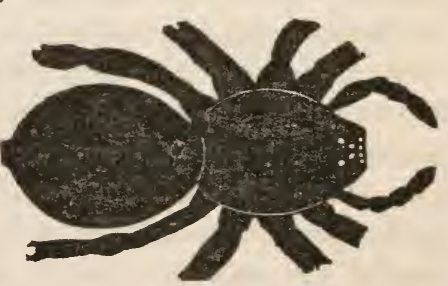

Fig. 16. part of the back. All the essential parts of a simple eye, the cornea, the crystalline, the vitreous body, are found in 
them, and even the choroid, which presents itself in the form of a black ring around the crystalline. Many insects, in their caterpillar state, also have simple eyes.

85. Rudiments of eyes have been observed in very many of the worms. They generally appear as small black spots on the head; such as are seen on the head of the Leech, the Planaria and the Nereis. In these latter animals there are four spots. According to Müller, they are small bodies, rounded behind, and flattened in front, composed of a black, cup-shaped membrane, containing a small white, opaque body, which seems to be a continuation of the optic nerve. It cannot be doubted, therefore, that these are eyes; but as they lack the optical apparatus which produces images, we must suppose that they can only receive a general impression of light, without the power of discerning objects.

86. Eye-spots very similar to those of the Nereis, are found at the extremity of the rays of some of the star-fishes, in the sea-urchins, at the margin of many Medusæ, and in some Polypi. M. Ehrenberg has shown that they also exist in a large number of the Infusoria.

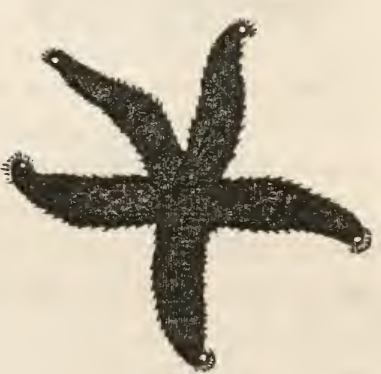

Fig. 17 .

87. In all the animals already mentioned, the eyes, whatever their number, are apart from each other. But there is still another type of simple eyes, known as aggregate eyes. In some of the millipedes, the pill-bugs, for instance, the eyes are collected into groups, like those of spiders; each eye inclosing a crystalline and a vitreous body, surrounded by a retina and choroid. Such eyes consequently form a 
natural transition to the compound eyes of insects, to which we now give our attention.

88. Compound eyes have the same general form as simple eyes; they are placed either on the sides of the head, as in insects, or supported on pedestals, as in the crabs. But if we examine an eye of this kind by a magnifying lens, we find its surface to be composed of an infinite number of angular, usually six-sided faces. If these façettes are removed, we find beneath, a corresponding number of cones $(c)$, side by side, five or six times as long as they are broad, and arranged like rays around the optic nerve, from which each one receives a little filament, so as to present, according to Müller, the following disposition.

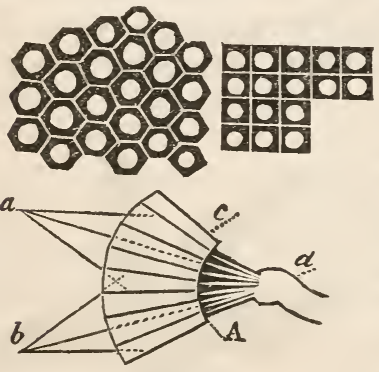

Fig. 18. (Fig. 18). The cones are perfectly transparent, but separated from each other by walls of pigment, in such a manner, that only those rays which are parallel to the axes, can reach the retina $A$; all those which enter obliquely, are lost; so that of all the rays which proceed from the points $a$ and $b$, only the central ones in each pencil will arrive at the optic nerve $(d)$; the others will strike against the walls of the cones. To compensate for the disadvantage of such an arrangement, and for the want of motion, the number of façettes is greatly multiplied, so that no less than 25,000 have been counted in a single eye. The image on the retina, in this case, may be compared to a mosaic, composed of a great number of small images, each of them representing a portion of the figure. The entire picture is, of course, more perfect, 
in proportion as the pieces are smaller and more numerous.

89. Compound eyes, being destitute of the optical apparatus necessary to collect the rays of light, cannot adapt themselves to the distance of objects ; they see, but cannot look. The perfection of their sight depends on the number of façettes or cones, and the manner in which they are placed. Their field of vision is wide, when the eye is prominent; it is very limited, on the contrary, when the eye is flat. Thus the dragon-flies, on account of the great prominency of their eyes, see equally well in all directions, before, behind, or laterally, whilst the water-bugs, which have the eyes nearly on a level with the head, can see to only a very short distance before them.

90. Those animals which are destitute of eyes are either of a very inferior rank, such as most of the polypi, or else they comprise animals which live under unusual circumstances, such as the intestinal worms. Even among the vertebrates, there are some which lack the faculty of sight, as the Myxine glutinosa, which has merely a rudimentary eye concealed under the skin, and destitute of a crystalline. Others, which live in darkness, have not even rudimentary eyes, as for example, the fishes which live in the Mammoth Cave, (Amblyopsis spelous), and which appear to want even the orbital cavity. The craw-fishes, (Astacus pellucidus), of this same cave, are also blind; having merely the pedicle for the eyes, without any traces of façettes.

\section{Hearing.}

91. To hear, is to perceive sounds. The faculty of perceiving sounds is seated in a peculiar apparatus, the $\mathrm{E}_{A R}$, which is constructed with a view to collect and augment the sonorous vibrations of the atmosphere, and convey them to 
the acoustic or auditory nerve, which arises from the poste. rior part of the brain. (Fig. 21, c).

92. The ears never exceed two in number, and are placed, in all the vertebrates, at the hinder part of the head. In a large proportion of animals, as the dog, horse, rabbit, and most of the mammals, they are generally quite conspicuous externally, and as they are at the same time quite movable, they become one of the prominent features of physiognomy.

93. These external appendages, however, do not constitute the organ of hearing, properly speaking. The true seat of hearing is deeper, quite in the interior of the head. It is usually a very complicated apparatus, especially in the superior animals. In mammals it is composed of three parts, the external ear, the middle ear, and the internal ear, and its structure is as follows: (Fig. 19).

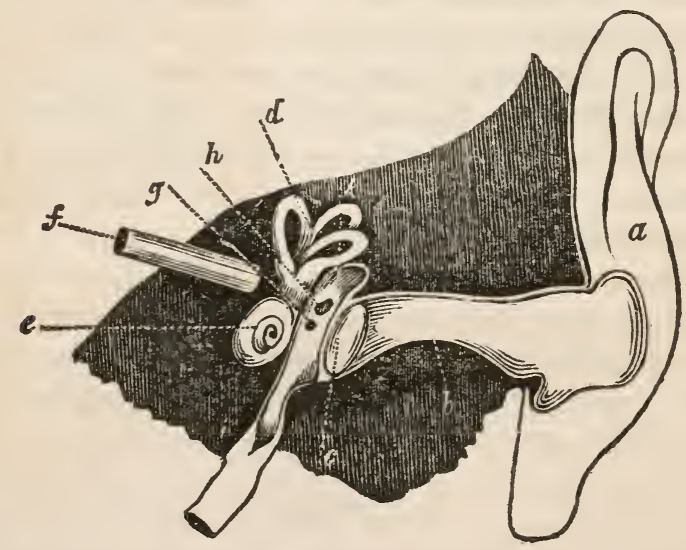

Fig. 19.

94. The external ear, which is ordinarily regarded as the ear, consists of the conch, $(a)$, and the canal which leads from it, the external auditory passage, $(b)$. The first is a 
gristly expansion, in the form of a horn or a funnel, the object of which is to collect the waves of sound; for this reason, animals prick up their ears when they listen; and for the same reason, persons who are hard of hearing, employ an artificial trumpet, by which they may collect the vibrations from a much more extended surface. The external ear is peculiar to mammals; and is wanting even in a few aquatic species of these, such as the seals and the Ornithorynchus. The ear of man is remarkable for being nearly immovable.

95. The middle ear has received the name of the tympanic cavity $(k)$. It is separated from the auditory passage by a membranous partition, the tympanum or drum $(c)$; though it still communicates with the open air by means of a narrow canal, called the Eustachian tube, $(i)$ which opens at the back part of the mouth. In the interior of the chamber, are four little bones of singular forms, which anatomists have distinguished by the names of malleus (Fig. 20, c), incus $(n)$, stapes $(s)$, and os orbiculare $(o)$; which are articulated together, as here represented, so as to form a continuous chain.

96. The internal ear, which is

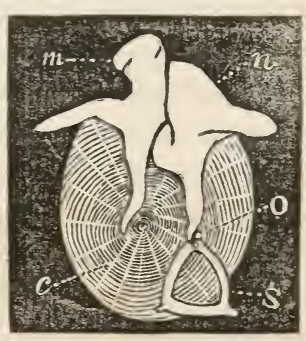

Fig. 20. also denominated the labyrinth, is an irregular cavity formed in the most solid part of the temporal bone, beyond the chamber of the middle ear, from which it is separated by a bony partition, which is perforated by two small holes, called, from their form, the round and the oval apertures, the foramen rotundum, (Fig. 19, g), and the foramen ovale $(h)$. The first is closed by a membrane, similar to that of the tympanum, while the latter is closed by the stapes, one of the little bones in the chamber. 
97. Three parts are to be distinguished in the labyrinth, namely, the vestibule, which is the part at the entrance of the cavity; the semicircular canals $(d)$, which occupy its upper part, in the form of three arched tubes; and the cochlea, which is a narrow canal placed beneath, at the lower part of the vestibule, having exactly the form of a snail-shell $(e)$. The entire labyrinth is filled with a watery fluid, in which membranous sacs or pouches float. Within these sacs, the auditory nerve $(f)$ terminates. These pouches, therefore, are the actual seat of hearing, and the most essential parts of the ear. The auditory nerve is admitted to them by a long passage, the internal auditory canal.

98. By this mechanism, the vibrations of the air are first collected by the external ear, whence they are conveyed along the auditory passage, at the bottom of which is the tym. panum. The tympanum, by its delicate vibrations, augments the sound, and transmits it to the internal ear, partly by means of the little bones in the chamber, which are disposed in such a manner that the stapes exactly fits the oval aperture, (foramen ovale); and partly by means of the air which strikes the membrane covering the round aperture $(g)$, and produces vibrations there, analogous to those of the tympanum. After all these modifications, the sonorous vibrations at last arrive at the labyrinth and the auditory nerve, which transmits the impression to the brain.

99. But the mechanism of hearing is not so complicated in all classes of animals, and is found to be more and more simplified, as we descend the series. In birds, the middle and interior ears are constructed on the same plans as in the mammals; but the outer ear no longer exists, and the auditory passage, opening on a level with the surface of the head behind the eyes, is surrounded only by a circle of peculiarly formed feathers. The bones of the middle ear are also loss numerous, there being generally but one. 
100. In reptiles, the whole exterior ear disappears; the auditory passage is always wanting, and the tympanum becomes external. In some toads, even the middle ear also is completely wanting. The fluid of the vestibule is charged with salts of lime, which frequently give it a milky appearance, and which, when examined by the microscope, are found to be composed of an infinite number of crystals.

101. In fishes, the middle and external ear are both wanting; and the organ of hearing is reduced to a membranous vestibule, situated in the cavity of the skull, and surmounted by semicircular canals, from one to three in number. The liquid of the vestibule contains chalky concretions of irregular forms, which are called Otolites, and whose use is doubtless to render the vibration of sounds more sensible.

102. In crabs, the organ of hearing is found on the lower face of the head, at the base of the large antennæ. It is a bony chamber closed by a membrane, in the interior of which is suspended a membranous sac filled with water. On this sac, the auditory nerve is expanded. In the cuttlefish, the vestibule is a simple excavation of the cartilage of the head, containing a little membranous sac, in which the auditory nerve terminates.

103. Finally, some insects, the grasshopper for instance, have a sort of ear, no longer situated in the head, as with other animals, but in the legs; and from this fact, we may be allowed to suppose, that if no organ of hearing has yet been found in most insects, it is because it has been sought for in the head only.

104. It appears from these examples, that the part of the organ of hearing which is uniformly present in all animals furnished with ears, is precisely that in which the auditory nerve ends, that is to say, this is the essential part of the organ. The other parts of the apparatus, the tympanum, 
auditory passage, and even the semicircular canals, have for their object merely to cause the perception of sound with more precision and accuracy. Hence we may conclude that hearing is dull in animals where the organ is reduced to its most simple form; and that animals which have merely a simple membranous sac, without tympanum and auditory passage, as the fishes, or without semi-circular canals, as the crabs, perceive sounds but in a very imperfect manner.

\section{Of Smell.}

105. SMeli is the faculty of perceiving odors. Like

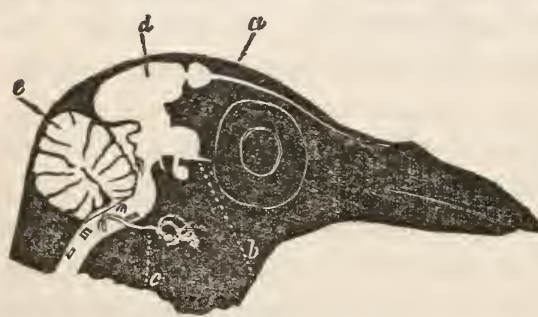

Fig. 21. Head of a Crow. sight and hearing, smell depends upon special nerves, the olfactory $(a)$, which form the first pair of cerebral nerves, and which, in the embryo, are direct prolongations of the $a$, olfactory nerve; $b$, optic nerve; $c$, auditory brain. nerve; $d$, cerebrum; $e$, cerebellum.

106. The organ of smell, is the Nose. Throughout the series of vertebrates, it makes a part of the face, and in man, by reason of its prominent form, it becomes one of the dominant traits of his countenance; in other mammals, the nose loses this prominency by degrees, and the nostrils no longer open downwards, but forwards. In birds, the position of the nostrils is a little different; they open farther back and higher, at the origin of the beak.

107. The nostrils are usually two in number. They are similar openings, separated by a partition upon the middle line of the body. In man and the mammals, the outer walls of the nose are composed of cartilage; but internally, the 
nostrils communicate with bony cavities situated in the bones of the face and forehead. These cavities are lined by a thick membrane, the pituitary membrane, on which are expanded the nerves of smell, namely, the olfactory nerve, and some filaments of the nerve which goes to the face.

108. The process of smelling is as follows. Odors are particles of extreme delicacy which escape from very many bodies, and are diffused through the air. These particles are recognized by the nerves of smell only, which transmit the impressions made by them to the brain. Smell differs, consequently, from sight and hearing, in being produced by a material body, and not by a simple undulatory movement. To facilitate the perception of odors, the nostrils are placed in the course of the respiratory passages, so that all the odors which are diffused in the air inspired pass over the pituitary membrane.

109. The perfection of smell depends on the extent to which the membrane is developed. Man is not so well endowed in this respect as many animals, which have the internal surface of the nostrils extremely complicated, as it is especially among the beasts of prey.

110. The sense of smell in Reptiles is less delicate than in the mammals; the pituitary membrane also is less developed. Fishes are probably still less favored in this respect. As they perceive odors through the medium of water, we should anticipate that the structure of their apparatus would be different from that of animals which breathe air. 'Their nostrils are mere superficial pouches, lined with a membrane gathered into folds which generally radiate from a centre, but are sometimes arranged in parallel ridges on each side of a central band. The perfection of smell depending on the amount of surface exposed, it follows that those fishes which have these 
folds most multiplied are also those in which this sense is most acute.

111. No special apparatus for smell has yet been found in Invertebrates. And yet there can be no doubt that insects, crabs, and some mollusks perceive odors, since they are attracted from a long distance by objects which diffuse them. Some of them may be deceived by odors similar to those of their prey; which clearly shows that they are led by this sense.

\section{Of Taste.}

112. TAste is the sense by which the flavor of bodies is perceived. It guides animals in the choice of their food, and warns them to abstain from what is noxious. There is also an intimate connection between the taste and the smell, so that both these senses are called into requisition in the selection of food. To perceive the flavor of a body, it must come into immediate contact with the nerves of taste, and hence these nerves are distributed at the entrance to the digestive tube, on the surface of the tongue and the palate.

113. The nerves of taste are not so strictly special as those of sight and hearing. They do not proceed from one single trunk, and, in the embryo, do not correspond to a particular part of the brain. The tongue in particular, receives nerves from several trunks; and taste is perfect in proportion as the nerves which go to the tongue are more minutely distributed. The extremities of the nerves generally terminate in little asperities of the surface, called papilla. Sometimes these papillæ are very harsh, as in the cat and the ox; and again they are very delicate, as in the human tongue, in that of the dog, horse, \&c.

114. Birds have the tongue cartilaginous, sometimes beset with little stiff points; sometimes fibrous and fringed 
at the edges. In the parrots, it is thick and fleshy; or it is even barbed at its point as in the woodpeckers. In some reptiles, the crocodile, for example, the tongue is adherent; in others, on the contrary, it is capable of extensive motion, and serves as an organ of touch, as in the serpents, or it may be thrust out to take prey, like that of the chameleon. In fishes it is usually cartilaginous as in birds, generally adherent, and its surface is frequently covered with teeth. Some of the inferior animals select their food with no little discernment. Thus, flies always select the sugary portions of bodies. Some of the mollusks, as the snails for example, are particularly dainty in the choice of their food.

115. It is to be presumed that in animals which have a cartilaginous tongue the taste must be very obtuse, especially in those which, like most fishes and many granivorous birds, swallow their prey without mastication. In fishes, especially, the taste is very imperfect, as is proved by their readily swallowing artificial bait. It is probable that they are guided in the choice of their prey by sight, rather than by taste or smell.

116. In general, the taste is but imperfectly developed except in the mammals, and they are the only animals which enjoy the flavor of their food. With man, the cultivation of this sense becomes a matter of study; and it is capable of being brought to a high degree of delicacy.

\section{Of Touch.}

117. The sense of толсH is merely a peculiar manifestation of the general sensibility, seated in the skin, and dependent upon the nerves of sensation which expand over the surface of the body. By the aid of this general sensibility, we learn whether a body is hot or cold, wet or dry. We may also, by simple contact, gain an idea, to a certain 
extent, of the form and consistence of a body, as for example, whether it be sharp or blunt, soft or hard.

118. This faculty resides more especially in the hand, which is not only endowed with a more delicate tact, but owing to the disposition of the fingers and the opposition of the thumb to the other fingers, is capable of so moulding itself around objects, as to multiply the points of contact. Hence touch is an attribute of man rather than of other animals; for among these latter, scarcely any, except the monkeys, have the faculty of touch in their hands, or as it is technically termed, of palpation.

119. In some animals, this faculty is exercised by other organs. Thus the trunk of the elephant is a most perfect organ of touch; and probably the mastodon, whose numerous relics are found scattered in the superficial layers of the earth's crust, was furnished with a similar organ. Serpents make use of their tongue for touch; insects employ their palpi, and snails their tentacles for the same purpose.

\section{The Voice.}

120. Animals have not only the power of perceiving, but many of them have also the faculty of producing sounds of every variety, from the roaring of the lion to the song of the bird as it salutes the rising sun. It is moreover to be remarked that those which are endowed with a voice, are precisely those in whom the organ of hearing is most developed.

121. Animals employ their voice, either for communication with each other, or to express their sensations, their enjoyments, their sufferings. Nevertheless, this faculty is enjoyed by but a small minority of animals; with but very few exceptions, only the mammals, the birds, and a few reptiles are endowed with it. All others are dumb. 
Worms and insects have no true voice; for we must not mistake for it, the buzzing of the bee, which is merely a noise created by the vibration of the wings; nor the shrill sound of the cricket, which is caused by the friction of his legs against the wing; nor the shriek of the locust, produced by the resonance of his cymbals, when put in vibration by the opening and closing of the wings.

122. Consequently, were the mammals, the birds and the frogs, to be struck out of existence, the whole Animal Kingdom would be dumb. It is difficult for us, living in the midst of the thousand various sounds which strike our ear from all sides, to conceive of such a state. Yet, such a state did prevail for thousands of ages, on the surface of our globe, when the watery world alone was inhabited, and before man, the birds, and the mammals were called into being.

123. In man and the mammals, the voice is formed in an organ called the larynx, situated at the upper part of the windpipe, below the bone of the tongue $(a)$. The human larynx, the part called Adam's apple, is composed of several cartilaginous pieces, called the thyroid cartilage $(b)$, the cricoid cartilage $(c)$, and the small arytenoid cartilages. Within these, are found two large folds of elastic substance, known by the name of the rocal cords $(m)$. Two other

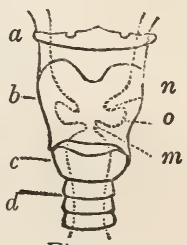

Fig. 22 . analogous folds, the superior ligaments of the glottis $(n)$, are situated a little above the preceding. The glottis $(o)$, is the space between these four folds. The arrangement of the vocal cords, and of the interior of the glottis in man, is indicated by dotted lines in Fig. 22.

124. The mechanism of the voice is as follows: the air, on its way to the lungs, passes the vocal cords. So long as these are in repose, no sound is produced; but the moment they are put upon the stretch, they oppose an obstacle to the current of air, and it cannot pass without causing them to 
vibrate. These vibrations produce the roice; and as the vocal cords are susceptible of different degrees of tension, these tensions determine different sounds; giving an acute tone when the tension is great, but a grave and dull one when the tension is feeble.

125. Some mammals have, in addition, large cavities which communicate with the glottis, and into which the air reverberates, as it passes the larynx. This arrangement is especially remarkable in the howling monkeys, which are distinguished above all other animals, for their deafening howls.

126. In birds, the proper larynx is very simple, destitute of vocal cords, and incapable of producing sounds; but at the lower end of the windpipe there is a second or inferior larynx, which is very complicated in structure. It is a kind of bony drum (a), having with-

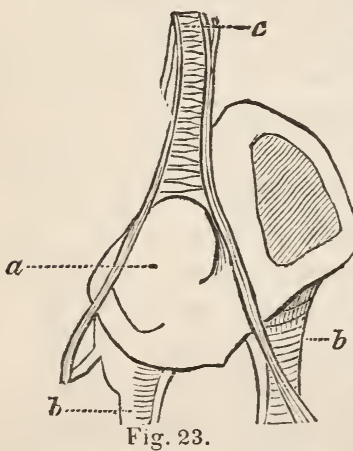

in it two glottides, formed at the top of the two branches $(b b)$ of the windpipe $(c)$, each provided with two vocal cords. The different pieces of this apparatus are moved by peculiar muscles, the number of which varies in different families. In birds which have a very monotonous cry, such as the gulls, the herons, the cuckoos, and the mergansers (Fig. 23), there is but one or two pairs; parrots have three; and the birds of song have five.

127. Man alone, of all the animal creation, has the power of giving, to the tones he utters, a variety of definite sounds; in other words, he alone has the gift of speech. 


\section{CHAPTER FOURTH.}

\section{OF INTELLIGENCE AND INSTINCT.}

128. BEsides the material substance of which the body is constructed, there is also an immaterial principle, which, though it eludes detection, is none the less real, and to which we are constantly obliged to recur in considering the phenomena of life. It originates with the body, and is developed with it, while yet it is totally apart from it. The study of this inscrutable principle belongs to one of the highest branches of Philosophy; and we shall here merely allude to some of its phenomena which elucidate the development and rank of animals.

129. The constancy of species is a phenomenon depending on the immaterial nature. Animals, and plants also, produce their kind, generation after generation. We shall hereafter show that all animals may be traced back, in the embryo, to a mere point upon the yolk of the egg, bearing no resemblance whatever to the future animal. But even here, an immaterial principle, which no external influence can prevent or modify, is present, and determines its future form; so that the egg of the hen can produce nothing but a chicken, and the egg of the cod-fish produces only the cod. It may therefore be said with truth, that the chicken and the cod existed in the egg before their formation.

130. Perception is a faculty springing from this princi- 
ple. The organs of sense are the instruments for perceiving sensations, but they are not the faculty itself, and indeed without it they would be useless. We all know that the eye and ear may be open to the sights and sounds about us, but if the mind happens to be preoccupied, we perceive them not. We may even be searching for something which actually lies within the compass of our vision; the light enters the eye as usual, and the image is formed on the retina; but, to use a common expression, we look without seeing, unless the mind that perceives is directed to the object.

131. In addition to the faculty of perceiving sensations, the higher animals have also the faculty of recalling past impressions, or the power of memory. Many animals retain a recollection of pleasure or pain that they have experienced, and seek or avoid the objects which these sensations may have produced; and in doing so, they give proof of judgment.

132. Finally, we notice in some animals acts which prove that they have the faculty of comparing their sensations and their judgments; in other words, that they carry on a process of reasoning.

133. These different faculties, taken together, constitute intelligence. In man, this superior principle, which is an emanation of the divine nature, manifests itself in all its splendor. God " breathed into him the breath of life, and man became a living soul." It is his prerogative, and his alone, to be enabled to guide his conduct by the deductions of reason; he has not only the faculty of exercising his judgment upon the objects which surround him, and of apprehending the many relations which exist between himself and the external world; he may also apply his reason to immaterial things, observe the operations of his own intellect, and, by the analysis of his faculties, may arrive at the consciousness of his own nature, and even conceive of that Infinite Spirit, "whom none by searching can find out." 
134. Other animals cannot aspire to conceptions of this kind ; they contemplate merely those objects which immediately strike the senses, and without exercising any continuous effort of the reasoning faculty in regard to them. Their conduct, moreover, is regulated by another princiciple of inferior order, still derived from the immaterial principle, called Instinct.

135. Under the guidance of Instinct, animals are enabled to perform certain operations, without instruction, in one undeviating manner. When man chooses wood and stone, as the materials for his dwelling, in preference to straw and leaves, it is because he has learned by experience, or because his associates have informed him, that these materials are more suitable for the purpose. But the bee requires no instructions in building her comb. She selects, without hesitation, the fittest materials ; and the young bee exhibits, in this respect, as much discernment as those who have had the benefit of long experience. She performs her task without previous study, and, according to all appearances, without the consciousness of its utility, being in some sense impelled to it by a blind impulse.

136. If, however, we judge of the instinctive acts of animals compared with the acts of intelligence, by the relative perfection of their products, we may be led into gross errors, as a single example will show. No one will deny that the honey-comb is constructed with more art and care than the huts of many tribes of men. And yet, who would presume to conclude from this, that the bee is superior in intelligence to the inhabitant of the desert or of the primitive forest? It is evident, on the contrary, that in this particular case, we are not to judge of the artisan by his work. As a work of man, a structure as perfect in all respects as the honeycomb would indicate very complicated mental operations, and probably numerous preliminary experiments. 
137. The instinctive actions of animals relate either to the procuring of food, or to the rearing of their young; in other words, they have for their end the preservation of the individual and of the species. It is by instinct that the leopard conceals himself, and awaits the approach of his prey. It is equally by instinct that the spider spreads his web to entangle the flies which approach it.

138. Some animals go beyond these immediate precautions; their instinct leads them to make provision for the future. Thus the squirrel lays in his store of nuts and acorns during autumn, and deposits them in cavities of trees, which he readily finds again in winter. The hamster digs, by the side of his burrow, compartments for magazines, which he arranges with much art. Finally, the bee, more than any other animal, labors in view of the future; and for this reason, she has become the emblem of order and domestic economy.

139. Instinct exhibits itself, in a no less striking manner, in the anxiety which animals manifest for the welfare of their anticipated progeny. All birds build nests for the shelter and nurture of their young, and in some cases, these nests are made exceedingly comfortable. Others show very great ingenuity in concealing their nests from the eyes of their enemies, or in placing them beyond their reach. There is a small bird in the East Indies, the tailor bird, (Sylvia sutoria), which spins wool or cotton into threads, with its feet and beak, and uses it to sow together the leaves of trees for its nest.

140. The nest of the fiery hang-bird, (Icterus Baltimore), dangling from the extremity of some slender, inaccessible twig, is familiar to all. The beautiful nest of the hummingbird, seated on a mossy bough, and itself coated with lichen and lined with the softest down from the cotton-grass or the mullein leaf, is calculated equally for comfort and for escaping observation. An East Indian bird, (Ploceus Philippi- 
nus,) not only exhibits wonderful devices in the construction, security, and comfort of its nest, but displays a still further advance towards intelligence. The nest is built at the tips of long pendulous twigs, usually hanging over the water. It is composed of grass, in such a manner as to form a complete thatch. The entrance is through a long tube running downwards from the edge of the nest; and the lower end of it is so imperfectly woven, that any serpent or squirrel, in attempting to enter the aperture, would detach the fibres, and fall to the ground. But the male, who has no occasion for a nest, builds his thatched dome, similar to that of the female,

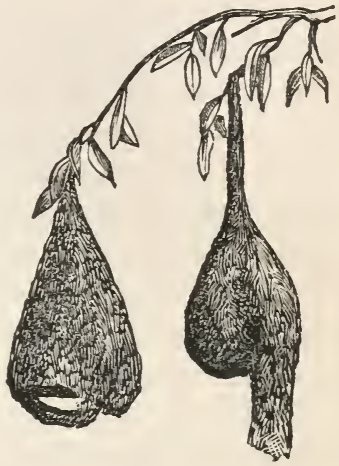

Fig. 24 . and by its side; but makes simply a perch across the bottom of the dome, without the nest-pouch or tube.

141. But it is among insects, that this instinctive solicitude for the welfare of the progeny is everywhere exhibited in the most striking manner. The bees and wasps not only prepare cells for each of their eggs, but take care, before closing the cells, to deposite in each of them something appropriate for the nourishment of the future young.

142. It is by the dictate of instinct also, that vast numbers of animals of the same species associate, at certain periods of the year, for migration from one region to another; as the swallows and passenger pigeons, which are sometimes met with in countless flocks.

143. Other animals live naturally in large societies, and labor in common. This is the case with the ants and bees. Among the latter, even the kind of labor for each member of the community is determined beforehand, by instinct. 
Some of them collect only honey and wax; while others are charged with the care and education of the young; and still others, are the natural chiefs of the colony.

144. Finally, there are certain animals so guided by their instinct as to live like pirates, on the avails of others' labor. The Lestris or Jager will not take the trouble to catch fish for itself, but pursues the gulls, until, worn out by the pursuit, they eject their prey from their crop. Some ants make war upon others less powerful, take their young away to their nests, and oblige them to labor in slavery.

145. There is a striking relation between the volume of the brain, and the degree of intelligence which an animal may attain. The brain of man is the most voluminous of all, and among other animals there is every gradation in this respect. In general, an animal is the more intelligent, in proportion as its brain bears a greater resemblance to that of man.

146. The connection between instinct and the nervous system does not present so intimate a correspondence as exists between the intellect and the brain. Animals which have a most striking development of instinct, as the ants and bees, belong to a division of the Animal Kingdom where the nervous system is much less developed than that of the vertebrates, since they have only ganglions, without a proper brain. There is even a certain antagonism between instinct and intelligence, so that instinct loses its force and peculiar character, whenever intelligence becomes developed.

147. In man, instinct plays but a secondary part, but he is not entirely devoid of it. Some of his actions are entirely prompted by instinct, as for instance, the attempts of the infant to nurse. This fact again, that instinctive actions preponderate in infancy, when intelligence is but slightly developed, goes to confirm the two last propositions. 


\title{
CHAPTER FIFTH.
}

\author{
OF MOTION.
}

\section{SECTION I.}

\section{APPARATUS OF MOTION.}

148. The power of voluntary motion is the second grand characteristic of animals (57). Though they may not all have the means of transporting themselves from place to place, there is no one which has not the power of executing some motions. The oyster, although fixed to the ground, opens and closes its shell at pleasure; and the little coral animal protrudes itself from its retreat, and retires again at its will.

149. The movements of animals are effected by means of muscles, which are organs designed expressly for this purpose, and which make up a large portion of the body, that part which is commonly called flesh. They are composed of a series of fleshy bundles, which are readily seen in boiled meat. These bundles are again composed of parcels of still more delicate fibres, called muscular fibres (45), and in which alone the property of elongation and contraction resides.

150. The motions of animals and plants depend, therefore, upon causes essentially different. The expansion and 
closing of the leaves and blossoms of plants, which are their most obvious motions, are due to the influence of light, heat, moisture, cold, and similar external agents ; but all the motions peculiar to animals are produced by a cause residing within themselves, namely, the contractility of muscular fibres.

151. The cause which determines contractility resides in the nerves, although its action is not precisely known.

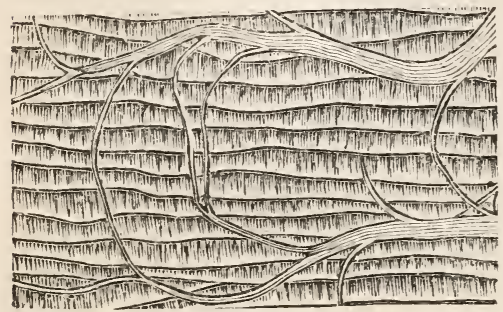

Fig. 25. We only know that each muscular bundle receives one or more nerves, whose filaments pass across all the fibres, as seen in the figure. It has also been shown, by experiment, that when a nerve going from the brain to a muscle is severed, the muscle instantly loses its power of contracting, or, in other words, is paralyzed.

152. The muscles may be classified, according as they are more or less under the control of the will. The contractions of some of them are entirely dependent on the will, as the muscles of the limbs which are used for locomotion. Others are quite independent of it, like the contractions of the heart and stomach. The muscles of respiration act independently of the will, but are partially subject to it; thus, when we attempt to hold the breath, we arrest, for the moment, the action of the diaphragm.

153. In the great majority of animals, motion is greatly aided by the presence of solid parts, of a bony or horny structure, which either serve as firm attachments to the muscles, or, being arranged so as to act as levers, they 
increase the force and precision of the movements. The solid parts are usually so arranged as to form for the body a substantial frame work, which has been variously designated in the several classes of animals, as the test, shell, carapace, skeleton, $\& \cdot c$. The study of these solid parts constitutes the most important branch of comparative anatomy. Their characters are the most constant and enduring of all others. Indeed, these solid parts are all that remains to us of the numerous extinct races of animals of past geological eras; and from these alone, we are to determine the structure and character of the ancient fauna.

154. Most of the Radiata have a calcareous test or crusty shell. In the Polypi, this structure, when it exists, is usually very solid, sometimes in the form of a simple internal stem, or extensively branched, as in the sea-fans; and sometimes in solid masses, furnished at the sides with numerous cavities, in which the animals are lodged, with the power, however, of protruding and retracting themselves at pleasure, by means of their muscles, as in the corals. In the Echinoderms, the test is brittle, and intimately united with the soft parts. It is composed of numerous little plates, sometimes consolidated and immovable, as in the sea-urchins, (Fig. 26) and sometimes so combined, as to allow of various motions, as in the

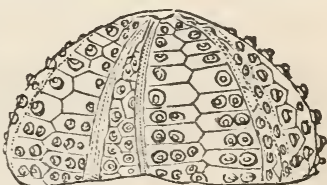
star-fishes, (Fig. 17), which use their arms both for crawling and swimming.

155. In the Mollusks, the solid parts are secreted by the skin, most frequently in the form of a calcareous shell of one, two, or many pieces, serving for the protection of the soft parts which they cover. These shells are generally so constructed as to allow the animal to retire and conceal itself completely within their cavities. In a few, the shell 
is too small for this purpose, and in some it exists only at a very early period, and is lost as the animal is developed, so that at last there is no other covering than a slimy skin. In others, the skin becomes so thick and firm as to have the consistence of elastic leather; or it is gelatinous or transparent, and what is very curious, the tissues are the same as those of woody fibre, as for example, in the Ascidia. As a general thing, these solid parts do not aid in locomotion, so that the mollusks are mostly sluggish animals. It is only in a few rare cases that the shell becomes a true lever, as in the Scollops, (Pecten) which use their shells as oars, in swimming.

156. The muscles of mollusks either form a flat disc, or are distributed in the skin so as to dilate and contract it, or are arranged about the mouth and tentacles, which they put in motion. However varied the disposition of the muscles may be, they always form very considerable masses, in proportion to the size of the animal, and have a soft and mucous appearance, such as is not seen in the contractile fibres of the other departments of the Animal Kingdom. This peculiar aspect no doubt arises from the numerous small cavities found in the muscles, and the mucous glands which are distributed through them.

15\%. In the Articulated animals, the solid parts are rings, generally of a horny structure, but sometimes calcareous, and successively fitting into each other. The tail of a lobster gives a good idea of this structure, which differs, in the several classes of this department, merely as to volume, form, solidity, number of pieces, and the degree of motion which one ring has upon another. In some groups the rings are consolidated, so as to form a shield or carapace, such as we see in the crabs. In others, the rings are so soft that the body is capable of changing into every possible form, as in the leeches and worms generally. 
158. A variety of appendages are attached to these rings, such as jointed legs, or in place of them, stiff bristles, oars fringed with silken threads, wings either firm or membranous, tentacles or antennæ, movable arms which perform the office of jaws, \&c. But, however diversified this solid apparatus may be, it is universally the case that the rings, to which every part may be referred as to a type, constitute but a single simple cavity, in which all the organs are enclosed, the nervous system as well as the organs of vegetative life (63).

159. The muscles which move all these parts have this peculiarity, that they are all situated within the solid parts, and not on their external face, as in the vertebrates; and also that the muscular bundles, which are very considerable in number, have the form of ribbons, or fleshy strips, with parallel fibres of remarkable whiteness. Figure 27 represents the disposi-

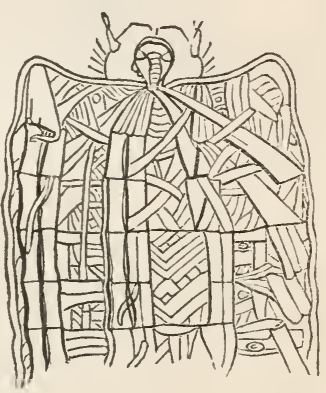

Fig. 27. tion of the muscles of the caterpillar which destroys the willow, (Cossus ligniperda). The right side represents the superficial layer of muscles, and the left side the deepseated layer.

160. The Vertebrata, like the articulated animals, have solid parts at the surface, as the hairs and spines of mammals, the feathers and claws of birds, the bucklers and scales of reptiles and fishes, \&c. But they have besides this, throughout the interior of the whole body, a solid framework not found in the other departments, well known as the SKeleton.

161. The skeleton is composed of a series of separate 
bones, called vertebræ, united to each other by ligaments. Each vertebra has a solid centre with four branches, two of

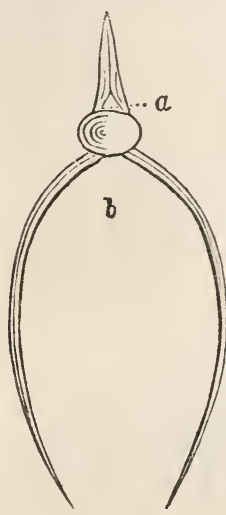

Fig. 28.

which ascend and form an arch above, and two descend, forming an arch below the body of the vertebra. The upper arches form a cavity $(a)$ which, along the region of the trunk, encloses the spinal marrow, and in the head receives the brain (61). The lower arches (b) form a cavity, similar to the superior one, for containing the organs of nutrition, and reproduction; they sometimes meet below, but generally they remain separated, so that the inferior cavity of the body is enclosed, in part, by fleshy walls. Every part of the skeleton may be reduced to this fundamental type, the vertebra, as will be shown, when treating especially of the vertebrate animals; so that between the pieces of the head, the trunk, or the tail, we have only differences in the degree of development of the body of the vertebra, or of its branches, and not different plans of organization.

162. The muscles which move this solid frame-work of the vertebrata are disposed around the vertebræ, as is

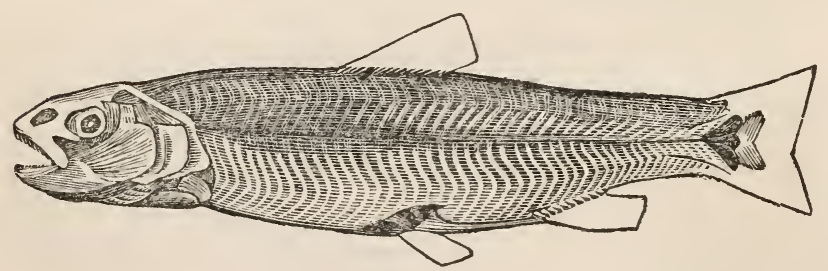

Fig. 29.

well exemplified among the fishes, where there is a band of muscles for each vertebra. In proportion as limbs 
are developed, this intimate relation between the muscles and the vertebræ goes on diminishing. The muscles are more concentrated about the limbs, where the greatestamount of muscular force is required. For this reason, the largest masses of flesh, in the highest vertebrates are found about the shoulders and hips; while in the fishes, they are concentrated about the tail,

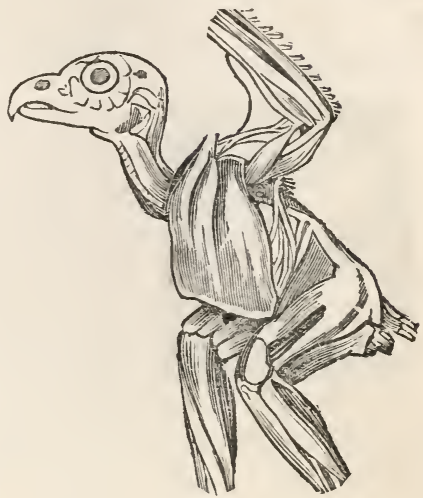

Fig. 30 .

which is the part on which they principally depend for motion.

\section{SECTION II.}

\section{OF LOCOMOTION.}

163. One of the most curious and important applications of this apparatus of bones and muscles, is that for Loconorion. By this is understood the movement by which an animal passes from place to place, in the pursuit of pleasure, sustenance or safety, in distinction from those motions which are performed equally well while stationary, such as the acts of respiration, mastication, \&c.

164. The means which nature has brought into action to effect locomotion under all the various circumstances in which animals are placed, are very diversified; and the study of their adaptation to the necessities of animals is one of the highest interest in a mechanical, as well as in a zoölogical point of view. Two general plans may be noticed, 
under which these varieties may be arranged. Either the whole body is concerned in effecting locomotion, or only some of its parts are employed for the purpose.

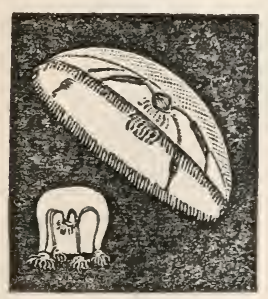

Fig. 31 .

165. The jelly-fishes (Medusæ) swim by contracting their umbrellashaped bodies upon the water contained within, and its resistance urges them forwards. Many others are provided with a sac or siphon, which they fill with water. By forcing out the water suddenly, a jet is produced, which is resisted by the surrounding water, and the animal is thus propelled. The Bîche-le-mar, (Holothuria), the cuttle-fishes, the Salpæ, \&c., employ this method.

166. Others contract small portions of the body in succession, which being thereby rendered firmer, serve as points of resistance, against which the animal may strive, in urging the body onwards. The earth-worm, whose body is composed of a series of rings united by muscles, and shutting more or less into each other, has only to close up the rings at one or more points, to form a sort of fulcrum, against which the rest of the body exerts itself in extending forwards.

167. Some have, at the extremities of the body, a cup or some other organ for maintaining a firm hold, each one acting in turn as a fixed point. Thus the Leech has a cup or sucker at its tail, by which it fixes itself; the body is then elongated by the contraction of the muscular fibres which encircle the animal; the other end is fixed by a similar sucker, then by the contraction

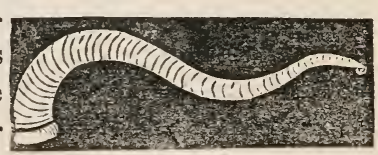

Fig. 32. of muscles running lengthwise, the body is shortened, and the tail is brought forwards to perform the same process 
again. Most of the bivalve mollusks, such as the clams, move from place to place, in a similar way. A fleshy organ, called the foot, is thrust forward, and its extremity fixed in the mud or to some firm object, when it contracts, and thus draws along the body, and the shell enclosing it. The snails and many similar animals have the under surface of the body composed of an infinitude of very short muscles which, by successive contractions, so minute indeed as scarcely to be detected, enable them to glide along smoothly and silently, without any apparent muscular effort.

168. In the majority of animals, however, locomotion is effected by means of organs specially designed for the purpose. The most simple organs are the minute hair-like cilia, which cover the body of most of the microscopic infusory animalcules, and which, by their incessant vibrations, cause rapid movements. The sea-urchins and star-fishes have little thread-like tubes issuing from every side of the body, furnished with a sucker at the end. By attaching these to some fixed object, they are enabled to draw or roll themselves along; but their progress is always slow. Insects are distinguished for the great perfection of their organs of motion. They have at least three pairs of legs, and usually wings also. The Crustacea generally have at least five pairs of legs, which are used for both swimming and walking. The Worms are much less active; some of them have only short bristles at their sides for locomotion; and even those that have numerous feet, like the centipedes, are not distinguished for agility. Some

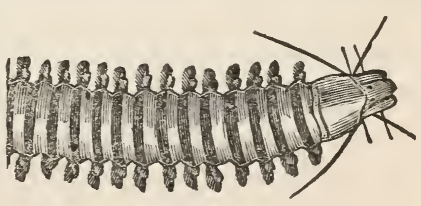

Fig. 33. of the marine species use their gills for paddles. (Fig. 33).

169. Among the Vertebrata, we find the greatest variety of the organs and modes of locomotion, as well as the great- 
est perfection, whatever may be the element in which they are exercised. The sailing of the eagle, the bounding of the antilope, the swimming of the shark, are not equalled by any movements of insects. This supcriority is due to the internal skeleton, which, while it admits a great display of force, gives to the motions, at the same time, a great degree of precision.

\section{Plan of the Organs of Locomotion.}

170. The organs of progression in vertebrated animals never exceed four in number, and to them the term limbs is more particularly applied. The study of these organs, as characteristic of the different groups of vertebrate animals, is most interesting, especially when prosecuted with a view to trace them all back to one fundamental plan, and to observe the modifications, oftentimes very slight, by which a very simple organ is adapted to every variety of movement. No part of the animal structure more fully illustrates the unity of design or the skill of the Intellect which has so adapted a single organ to such multiplied ends. On this account, we propose to illustrate this subject somewhat in detail.

171. It is easy to see that the wing which is to sustain the bird in the air, must be different from the leg of the stag which is made for running, or the fins of the fish that swims. But, notwithstanding this diversity, the wing of the bird, the leg of the stag, and the anterior fin of the fish, may still be traced to the same plan of structure; and if we examine their skeletons, we find the same fundamental parts. In order to show this, it is necessary to give a short description of the composition of the arm or anterior extremity.

172. The anterior member, in the vertebrates, is invariably composed of the following bones; 1 . The shoulder- 
blade or scapula $(a)$, a broad and flat bone, applied upon the bones of the trunk; 2. The arm $(b)$, formed of a single long cylindrical bone, the humerus; 3 . The fore arm, composed of two long bones, the radius $(c)$, and ulna $(d)$, which are often fused into one; 4 . The hand, which is composed of a series of bones, more or less numerous in different classes, and which is divided into three parts, namely, the carpus or wrist $(e)$, the metacarpus or palm $(f)$, and the fingers $(g)$. The clavicle or collarbone $(o)$, when it exists, belongs also to the anterior member. It is a bone of a cylindrical form, fixed as a brace between the breast-bone and shoulder-blade. Its use is to keep the shoulders separated; to this end, we find it fully developed in all animals which raise the limbs from the sides, as the birds and the bats. On the other hand, it is rudimentary, or entirely wanting in animals which move them backwards and forwards only, as with most quadrupeds.

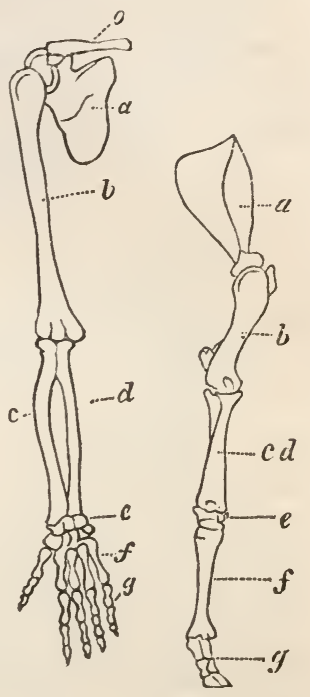

Fig. 34. Fig. 35 .

173. The following outlines will give an idea of the modifications which these bones present, in different classes. In the arm of man, (Fig. 34), the shoulder blade is flat and triangular ; the bone of the arm is cylindrical, and enlarged at its extremities; the bones of the fore arm are about the same length as the humerus, but more slender; the hand is composed of the following pieces, namely, eight small bones of the carpus, arranged in two ranks, five metacarpal bones, which are elongated, and 
succeed those of the wrist; five fingers of unequal length, one of which, the thumb, is opposed to the four others.

174. In the stag, (Fig. 35), the bones of the fore-arm greatly prevail in length over that of the arm, and the radius no longer turns upon the ulna, but is blended with it; but it is especially the metacarpal or cannon-bone, which is greatly developed; and being quite as long as the fore-arm, it is apt to be mistaken for it. The fingers are reduced to two, each of which is surrounded by a hoof, at its extremity.

175. In the arm of the lion, (Fig. 36), the arm bone is

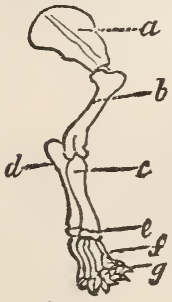

Fig. 36 .

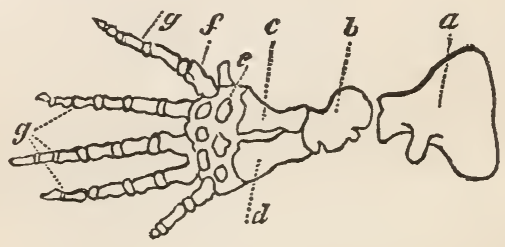

Fig. 37 .

stouter, the carpal bones are less numerous, and the fingers are short, and armed with strong, retractile claws. In the whale, (Fig. 37), the bones of the arm and fore arm are much shortened and very massive; the hand is broad, the fingers strong, and distant from each other.

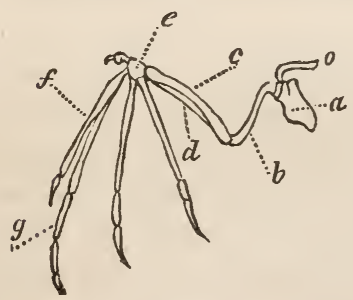

Fig. 38.

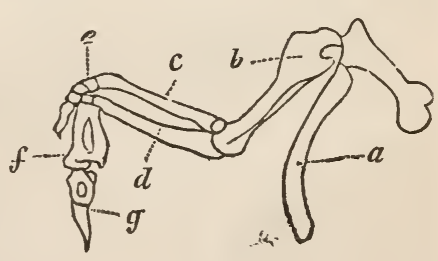

Fig. 39.

In the bat, (Fig. 38), the fingers, with the exception of the thumb, which is represented by a small hook, are elongated in a disproportionate manner, and across them the skin is 
stretched, so as to serve the purpose of a wing. In birds, the pigeon, for example, (Fig. 39), there are but two fingers, which are consolidated and destitute of nails ; and the thumb is rudimentary.

176. The arm of the turtle (Fig. 40) is peculiar in hav-

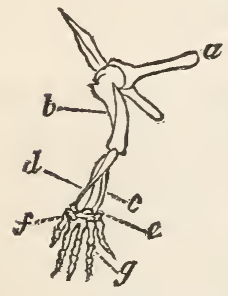

Fig. 40.

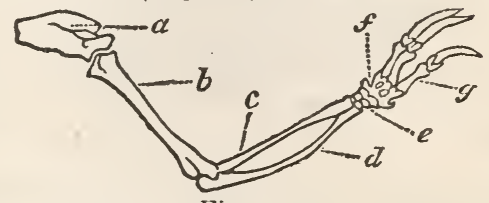

Fig. 41 .

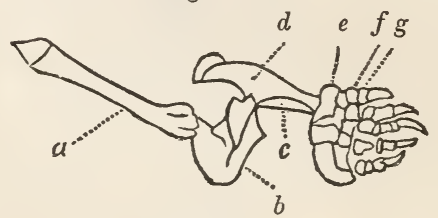

Fig. 42.

ing, besides the shoulder-blade, two clavicles; the arm-bone is twisted outwards, as well as the bones of the fore-arm, so that the elbow, instead of being behind, is turned forwards; the fingers are long and widely separated. In the Sloth (Fig. 41), the bones of the arm and fore-arm are very greatly elongated, and at the same time very slender; the hand is likewise very long, and the fingers are terminated by enormous non-retractile nails. The arm of the mole, (Fig. 42), is still more extraordinary. The shoulder-blade, which is usually a broad and flat bone, becomes very narrow; the arm-bone, on the contrary, is contracted so much as to seem nearly square; and the hand is excessively large and stout.

177. In fishes, the form and arrangement of the bones is so peculiar that it is often difficult to trace their analogy to all the parts found in other animals; nevertheless, the bones of the fore-arm are readily recognized. In the 
Cod, (Fig. 43), there are two flat and broad bones, one of which, the ulna $(d)$, presents a long point, anteriorly.

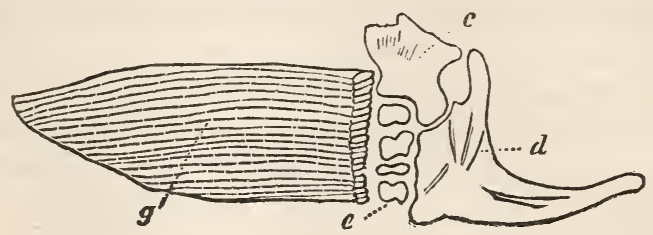

Fig. 43.

The bones of the carpus are represented by four nearly square little bones. But in these again, there are considerable variations in different fishes, and in some genera they are much more irregular in form. The fingers are but imperfectly represented by the rays of the fin $(g)$, which are composed of an infinitude of minute bones, articulated with each other. As to the humerus and shoulder, their analogies are variously interpreted by different anatomists.

178. The form of the members is so admirably adapted to the special offices which they are designed to perform, that by a simple inspection of the bones of the arm, as represented in the preceding sketches, one might infer the uses to which they were to be put. The arm of man, with its radius turning upon its ulna, the delicate and pliable fingers, and the thumb opposed to them, bespeak an organ for the purpose of handling. The slender and long arm of the sloth, with his monstrous claws, would be extremely inconvenient for walking on the ground, but appropriate for seizing upon the branches of the trees, on which these animals live. The short fingers, armed with retractile nails, indicate the lion, at first glance, to be a carnivorous animal. The arm of the stag, with his very long cannon-bone, and that of the horse also, with its single solitary finger enveloped in a hoof, are organs especially adapted for running. 'The very slender, and greatly elongated fingers of the bat are admirably contrived for the spread of a wing, without in- 
creasing the weight of the body. The more firm and solid arm of the bird indicates a more sustained flight. 'The short arm of the whale, with his spreading fingers, resembles a strong oar. The enormous hand of the mole, with its long elbow, is made for the difficult and long-continued efforts requisite in burrowing. The twisted arm of the tortoise can be applied to no other purpose than creeping. And finally, the arm of the fish, completely enveloped in the mass of the flesh, presents, externally, a mere delicate balancer, the pectoral fin.

179. The posterior members are closely analogous in structure to the anterior. The bones of which they are composed, are, 1. The petvis, (Fig. 46), which corresponds to the shoulder blade; 2 . The thigh bone or femur, which is a simple bone like the humerus ; 3 . The bones of the leg, the tibia and fibula, which, like the radius and ulna, sometimes coalesce into one bone; and lastly, the bones of the foot, which are divided, like those of the hand, into three parts, the tarsus, metatarsus, and toes. The modifications are generally less marked than in the arm, inasmuch as there is less diversity of function ; for in all animals, without exception, the posterior extremities are used exclusively for walking or swimming.

180. The anterior extremity of the vertebrates, however

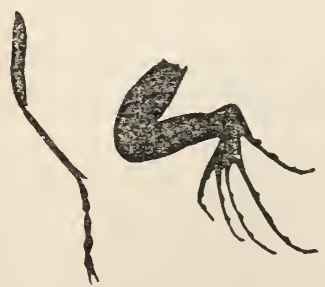
varied in form, whether it be an arm, a wing, or a fin, is thus shown to be composed of essentially the same parts, and constructed upon the same general plan. This affinity does not extend to the invertebrates, although in

Fig. 44 . Fig. 45. many instances their limbs bear certain resemblance to those of the vertebrates, and are even used for similar purposes, yet they have no real 
affinity. Thus the leg of an insect (Fig. 44), and that of a lizard (Fig. 45) ; the wing of a butterfly and the wing of a bat are quite similar in form, position and use; but in the bat and the lizard, the organ has an internal bony support, which is a part of the skeleton; while the leg of the insect has merely a horny covering, proceeding from one of the rings of the body, and the wing of the butterfly is merely a fold of the skin; showing that the limbs of the Articulata are constructed upon a different plan (157). It is by ascertaining and regarding these real affinities, that the true natural grouping of animals is to be attained.

\section{Of Standing, and the Modes of Progression.}

181. Standing, or the natural attitude of an animal, depends on the form and functions of the limbs. Most of the terrestrial mammals and the reptiles, both of which employ all four limbs in walking, have the back-bone horizontal, and resting at the same time upon both the anterior and posterior extremities. Birds, whose anterior limbs are intended for a purpose very different from the posterior, stand upon the latter, when at rest, although the back-bone is still very nearly horizontal. Man alone, is designed to stand upright, with his head supported on the summit of the vertebral column. Some monkeys can rise upon the hind-legs into the erect posture; but it is evidently a constrained posture, and not their habitual attitude.

182. That an animal may stand, it is requisite that the limbs should be so disposed that the centre of gravity, in other words, the point about which the body balances itself, should fall within the space included by the feet. If the centre of gravity is outside of these limits, the animal falls to the side to which the centre of gravity inclines. On 
this account, the albatross, and some other aquatic birds which have the feet placed very far back, cannot use them for walking.

183. The more numerous and the more widely separated are the points of support, the firmer an animal stands. On this account, quadrupeds are less liable to lose their balance than birds. If an animal has four legs it is not necessary that they should have a broad base. Thus we see that most quadrupeds have slender legs touching the earth by only a small surface. Broad feet would only increase the weight of the limbs, without adding to their stability. Birds are furnished with long toes, which, as they spread out, subserve the purpose of tripods. Moreover, the muscles of the toes are so disposed that the weight of the bird causes them to contract firmly, so that it can sleep standing upon the roost without effort, in perfect security.

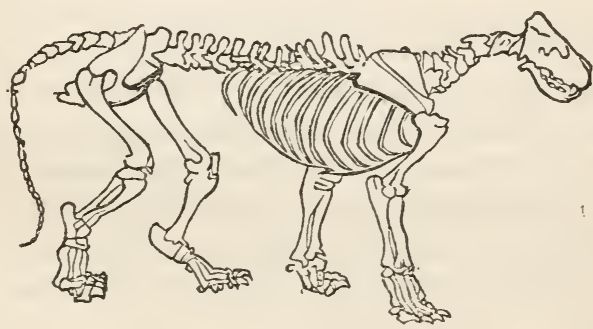

Fig. 46.

184. In quadrupeds, the joints at the junction of the limbs with the body bend readily in one direction only, that is, towards the centre of gravity; so that if one limb yields, the tendency to fall is counteracted by the resistance of the limbs at the other extreme of the body. The same antagonism is observed in the joints of the separate limbs, which are flexed alternately in opposite directions. Thus the thigh bends forwards, and the leg backwards; while the arm bends backwards, and the fore-arm forwards. Different 
terms have been employed to express the various modes of progression, according to the rapidity or the succession in which the limbs are advanced.

185. Progression is a forward movement of the body, effected by successively bending and extending the limbs. WALKING is the ordinary and natural gait, and other paces are only occasionally employed. When walking is accomplished by two limbs only, as in man, the body is inclined forwards, and carries the centre of gravity in that direction, and while one leg sustains the body, the other is thrown forwards to prevent it from falling, and to sustain it in turn. For this reason, walking has been defined to be a continual falling forwards, continually interrupted by the projection of the legs.

186. The throwing forwards of the leg, which would require a very considerable effort were the muscles obliged to sustain the weight of the limbs also, is facilitated by a very peculiar arrangement; that is, the joints are perfectly closed, so that the pressure of the atmosphere outside is sufficient of itself to maintain them in place, without the assistance of the muscles. This may be proved by experiment. If we cut away all the muscles around the hip-joint, the thigh-bone still adheres firmly to the pelvis, but separates the moment a hole is pierced, so as to admit air into the socket.

187. In ordinary walking, the advancing leg touches the ground just before the other is raised; so that there is a moment when the body rests on both limbs. It is only when the speed is very much accelerated, that the two actions become simultaneous. The walking of quadrupeds is a similar process, but with this difference, that the body always rests on two legs at least. The limbs are raised in a determinate order, usually in such a manner that the hind-leg of one side succeeds the fore-leg of the opposite side. Some 
animals, as the giraffe, the lama, and the bear, raise both legs of one side at the same moment. This is called ambling or pacing.

188. Running consists in the rapid repetition of the motions of walking. The running of lizards and birds is merely an accelerated walk; but in the horse and dog, and most of the mammals, a distinction is made between the walk, the trot, and the gallop, all of which have different positions or measures. The trot has but two measures. The animal raises a leg on each side, in a cross direction, that is to say, the right fore leg with the left hind leg, and so on. The gallop has three measures. After advancing the two fore-legs, one after the other, the animal raises and brings forward the two hind legs, simultaneously. Sometimes also, when the gallop is greatly urged, there are but two measures; the fore limbs are raised together, as well as the hind legs.

189. Leaping consists in a bending of all the limbs, followed by a sudden extension of them, which throws the body forwards with so much force as to raise it from the ground, for an instant, to strike it again at a certain distance in advance. For this purpose, the animal always crouches before leaping. Most animals make only an occasional use of this mode of progression, when some obstacle is to be surmounted; but in a few instances, this is the habitual mode. As the hind legs are especially used in leaping, we observe that all leaping animals have the posterior members very much more robust than the anterior, as frogs, the kangaroos, jerboas, and even the hares. Leaping is also common among certain birds, especially among the sparrows, the thrushes, \&c. Finally, there is also a large number of leaping insects, such as the flea, the large tribe of grasshoppers and crickets, in which we find that pair of legs with which leaping is accomplished, much more developed than the others. 
190. Chrmbing is merely walking upon the surface of an inclined or even upright object. It is more frequently accomplished by means of sharp nails; and hence many carnivorous animals climb with great facility, such as the cat tribe, the lizards; and many birds, the woodpecker, for instance. Others employ their arms for this purpose, like the bears, when they climb a tree; or their hands, and even their tails, like the monkeys; or their beaks, like the parrots. Lastly, there are some whose natural mode of progression is climbing. Such are the sloths, with their arms so long, that when placed upon the ground, they move very awkwardly; and yet their structure is by no means defective, for in their accustomed movements upon trees, they can use their limbs with very great adroitness.

191. Most quadrupeds can both walk, trot, gallop, and leap; birds walk and leap; lizards neither leap nor gallop, but only walk and run, and some of them with great rapidity. No insect either trots or gallops, but many of them leap. Yet their leaping is not always the effect of the muscular force of their legs, as with the flea and grasshopper; but some of them leap by means of a spring, in the form of a hook, attached to the tail, which they bend beneath the body, and which, when let loose, causes them to bound to a great distance, as in the Podurellæ. Still others leap by means of a spring, attached beneath the breast, which strikes against the abdomen when the body is bent; as the spring-beetles (Elaters).

192. FligHT is accomplished by the simultaneous action of the two anterior limbs, the wings, as leaping is by that of the two hinder limbs. The wings being expanded, strike and compress the air, which thus becomes a support, for the moment, upon which the body of the bird may rest itself. But as this support very soon yields, owing to the slight density of the air, it follows that the bird must make the greater and more rapid efforts to compensate for this dis- 
advantage. Hence it requires a much greater expenditure of strength to fly than to walk; and therefore, we find the great mass of muscles in birds concentrated about the breast (Fig. 30). To facilitate its flight, the bird, after each flap of the wings, brings them against the body, so as to present as little surface to the air as possible; for a still further diminution of resistance, all birds have the anterior part of the body very slender. Their flight would be much more difficult if they had large heads and short necks.

193. Some quadrupeds have a fold of the skin at the sides, which may be extended by the legs, and which enables them to leap from branch to branch, with more facility, such as the flying-squirrel and Galeopithecus. But this is not flight, properly speaking, since none of the peculiar operations of flight are performed. There are also some fishes, whose pectoral fins are so extended as to enable them to dart from the water, and sustain themselves for a considerable time in the air; and hence they are called flying-fish. But this is not truly flight.

194. Swmming is the mode of locomotion employed by the greater part of aquatic animals. Most animals which live in the water swim with more or less facility. Swimming has this in common with flight, that the medium in which it is performed, the water, becomes also the support, and readily yields also to the impulse of the fins. Only, as water is much more dense than air, and as the body of most aquatic animals is of very nearly the same weight as water, it follows that in swimming, very little effort is requisite to keep the body from sinking. The whole effort of its muscles is consequently employed in progression, and hence swimming requires vastly less muscular force than flying.

195. Swimming is accomplished by means of various or- 
gans designated under the general term, fins, although in an anatomical point of view, these may represent very different parts. In the Whales, it is the anterior extremities and the tail which are transformed into fins. In Fishes, the pectoral fins, which represent the arms, and the ventral fins, which represent the legs, are employed for swimming, but they are not the principal organs; for it is by the tail or caudal fin, that progression is principally effected. Hence the progression of the fish is precisely that of a boat under the sole guidance of the sculling-oar. In the same manner as a succession of strokes alternately right and left, propels the boat straight forwards, so the fish advances by striking alternately right and left. If he wishes to advance obliquely, he has only to strike a little more strongly in the direction opposite to that which he wishes to take. The Whales, on the contrary, swim by striking the water up and down; and it is the same with a few fishes also, such as the rays and the soles. The airbladder facilitates the rising and sinking of the fish by enabling it to vary the specific weight of the body.

196. Most land animals swim with more or less ease, by simply employing the ordinary motions of walking. Those which frequent the water, like the beaver, or which feed on marine animals, as the otter and duck, have webbed feet, that is to say, the fingers are united by a membrane, which, by being expanded, acts as a paddle.

197. There is also a large number of invertebrate animals in which swimming is the principal or the only mode of progression. Lobsters swim by means of their tail, and like the Whales, strike the water up and down. Other crustacea have a pair of legs fashioned like oars; as the posterior legs in Lupa, for example. Many insects, likewise, swim with their legs, which are abundantly fringed with hairs to give them surface; as the little water boat- 
men, (Gyrinus, Dytiscus), whose mazy dances on the summer streams every one must have observed. The cuttlefish uses its long tentacles as oars (Fig. 47); and some star-fishes (Comatula, Euryale), use their arms with great adroitness. Finally, there are some insects, which have their limbs constructed for running on the surface of water, as the water-spiders. (Ranatra, Hydrometra).

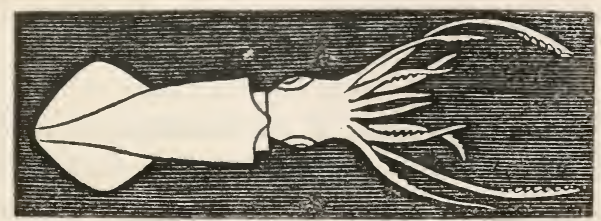

Fig. 47 .

198. A large number of animals have the faculty of moving both in the air and on land, as is the case with most birds, and a large proportion of insects. Others move with equal facility, and by the same members, on land and in water, as some of the aquatic birds and most of the reptiles. The latter have even received the name Amphibia, on this account. Finally, there are some which both walk, fly and swim, as the ducks and water hens; but, on the other hand, they do not excel in either mode of progression.

199. However different may appear to us the movements and offices performed by the limbs, according to the element in which they act, we see that they are none the less the effect of the same mechanism. The contraction of the same set of muscles, causes the leg of the stag to bend for leaping, the wing of the bird to flap in the air, the arm of the mole to excavate the earth, and the fin of the whale to strike the water. 


\section{CHAPTER SIXTH.}

NUTRITION.

200. THE second class of the functions of animal life are those which relate to the maintenance of life and the perpetuation of the species; the functions of vegetative life (59).

201. The increase of the volume of the body must require additional materials. There is also an incessant waste of particles which, having become unfit for further use, are therefore carried out of the system. Every contraction of a muscle expends the energy of some particles, whose place must be supplied. These supplies are derived from every natural source, the animal, vegetable, and even the mineral kingdoms; and are received under every variety of solid, liquid, and gaseous form. Thus, there is a perpetual interchange of substance between the animal body and the world around. The conversion of these supplies into a suitable material, and the appropriation of it to the growth and sustenance of the body, is called Nutrition.

202. In early life, during the period of growth, the amount of substances received is greater than that which is lost. At a later period, when growth is completed, an equilibrium between the matters received and those rejected, is established. At a still later period, the equilibrium is again disturbed, more is rejected than is retained, decrepitude begins, and at last the organism becomes exhausted, the functions cease, and death ensues. 
203. The solids and fluids taken into the body as food are subjected to a process called Digestion, by which the solid portions are also reduced to a fluid state, the nutritive separated from the excrementitious, and the whole is prepared to become blood, bone, muscle, \&c. The residue is afterwards expelled, together with those particles of the body which require to be renewed, and those which have been derived from the blood by several processes, termed Secretions. Matters in a gaseous form are also received and expelled with the air we breathe, by a process called Respiration. The nutritive fluids are conveyed to every part of the body by currents, usually confined in vessels, and which, as they return, bring back the particles which are to be either renovated or expelled. This circuit is what is termed the Circulation. The function of Nutrition, therefore, combines several distinct processes.

\section{SECTION I.}

\section{OF DIGESTION.}

204. Digestion, or the process by which the nutritive parts of food are elaborated and prepared to become blood, is effected in certain cavities, the stomach and intestines, or alimentary canal. This canal is more or less complicated in the various classes of animals ; but there is no animal, however low its organization, which has not a stomach, (54).

205. In the polypi, the digestive apparatus is limited to a single cav-

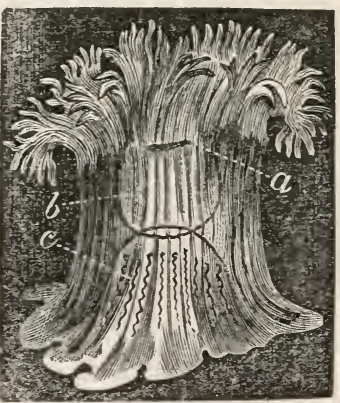

Fig. 48. ity. In the Sea Anemone (Actinia), for example, it is a pouch (Fig. 48, b), suspended in the interior of the body. 
When the food has been sufficiently digested there, it passes into the general cavity of the body $(c)$, which is filled with water, and mingling with it, flows thence into all parts

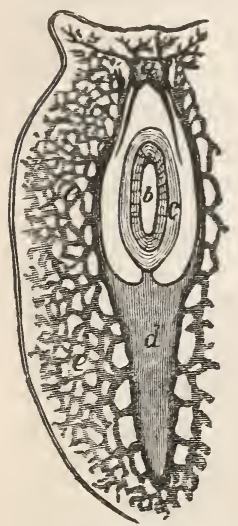

Fig. 49. of the animal. The jelly-fishes (Medusæ), and some Worms have a distinct stomach, with appendages branching off in every direction (Fig. 31), in which a more complete elaboration takes place. The little worms known by the name of Planaria present a striking example of these ramifications of the intestine (Fig. 49,e). But here likewise, the product of digestion, namely, the chyle, mingles with the fluids of the cavity of the body which surround the intestine $(d)$ and its branches, and circulation is not yet distinct from digestion.

206. As we rise in the scale of animals, the functions concerned in nutrition become more and more distinct from each other. Digestion and circulation, no longer confounded, are accomplished separately, in distinct cavities. The most important organs concerned in digestion are the stomach, and the small and large intestine. The first indications of such a distinction are perceived in the higher Radiata, such as the sea-urchins (Fig. 50), in which the stomach $(s)$, is broader than either extremity of the intestine. The dimensions and form of the intestinal cavities vary

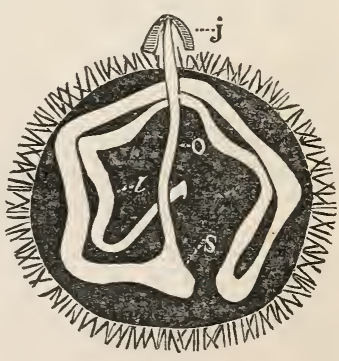

Fig. 50. considerably according to the mode of life of the animal; but the special functions assigned to them are invariable; and the three principal cavities succeed each other, in every animal where they are found, in an invariable order; first, 
the stomach $(s)$, then the intestine, which is small at first,

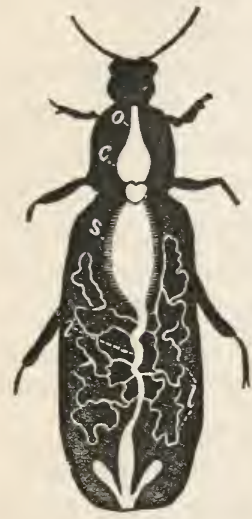

Fig. 51 .

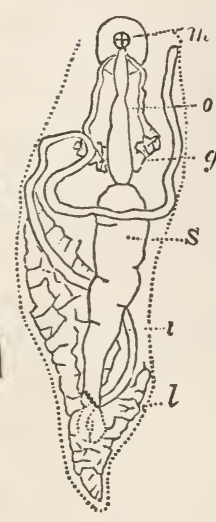

Fig. 52. but often enlarged towards its termination. This arrangement may be seen by the following diagrams from a beetle, and a land-mollusk, where the same letters indicate corresponding parts (Figs. $51,52)$.

207. From the mouth, the food passes into the stomach through a narrow tube in the neck, called the csophagus or gullet (o). This is not always a direct passage of uniform size; but there is sometimes a pouch, the crop $(c)$, into which the food is first introduced, and which sometimes acquires considerable dimensions, especially in birds, and in some insects and mollusks (Fig. 51). In the stomach, the true digestive process is begun. The food no sooner arrives there than changes commence, under the influence of a peculiar fluid called the gastric juice, which is secreted by the glands lining the interior of the stomach. The digestive action is sometimes aided by the movements of the stomach itself, which, by its strong contractions, triturates the food. This is especially the case in the gizzard of some birds, which, in the hens and ducks, for instance, is a powerful muscular organ. In some of the Crustacea and Mollusks, as the Lobster and Aplysia, there are even solid organs for breaking down the food within the stomach itself.

208. The result of this process is the reduction of the food to a pulpy fluid called chyme, which varies in its nature with the food. Hence the function of the stomach has been named chymification. The chyme thus formed 
is transferred to the intestine, by a peculiar movement like that of a worm in creeping, which has accordingly received the name of vermicular or peristaltic motion.

209. The form of the small intestine is less variable than that of the stomach. It is a narrow tube with thin walls, coiled in various directions in the vertebrate animals, but more simple in the invertebrates, especially the insects. Its length varies according to the nature of the food, being in general longer in herbivorous than in carnivorous animals. In this portion of the canal, the aliment undergoes its complete elaboration, through the agency of certain juices which here mingle with the chyme, such as the bile secreted by the liver, and the pancreatic juice secreted by the pancreas. The result of this elaboration is to produce a complete separation of the truly nutritious parts, in the form of a milky liquid called chyle. The process is called chylification.

210. The chyle is composed of minute, colorless globules,

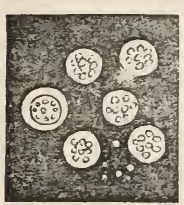

Fig. 53.

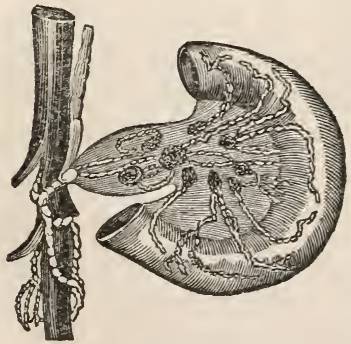

Fig. 54. of a somewhat flattened form (Fig. 53). It is taken up and carried into the blood by means of very minute vessels, called tymphatic vessels or lacteals, which are distributed everywhere in the walls of the intestine, and communicate with the veins, forming also in their course several glandular masses, as seen on the portion of intestine connected with a vein (Fig. 54). The residue passes on to the large intestine, from whence it is expelled in the form of excrement.

211. These organs constitute the essential apparatus for digestion; but there are, in the higher animals, several additional ones for aiding in the reduction of 
the food to chyle which render their digestive apparatus quite complicated. In the first place, hard parts, of a horny or bony texture, are usually placed about the mouth of those animals that feed on solid substances, which serve for cutting or bruising the food into small fragments before it is swallowed; and, in many of the lower animals, these organs are the only hard portions of the body. This process of subdividing or chewing the food, is termed mastication.

212. Beginning with the Radiata, we find the apparatus for mastication partaking of the star-like arrangement which

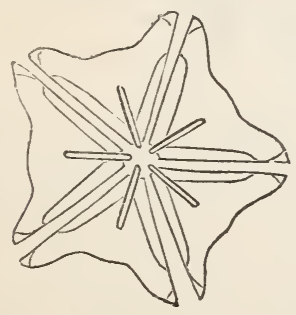

Fig. 55.

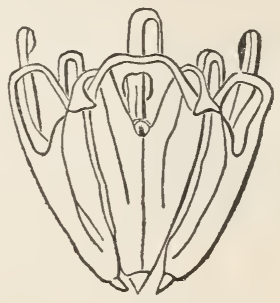

Fig. 56 .

characterizes those animals. Thus, in Scutella (Fig. 55), we have a pentagon composed of five triangular jaws, converging at their summits towards a central aperture which corresponds to the mouth, each one bearing a plate or tooth, like a knife-blade, fitted by one edge into a cleft. The five jaws move towards the centre, and pierce or cut the objects which come between them. In some of the sea-urchins, (Echinus), this apparatus, which has been called Aristotle's lantern (Fig. 56), consists of numerous pieces, and is much more complicated. Still, the five fundamental pieces or jaws, each of them bearing a tooth at its point, may be recognized as in Scutella ; only instead of being placed horizontally, they form an inverted pyramid. 
213. Among the Mollusks, a ferw, like the cuttle-fishes, have solid jaws or beaks closely resem-

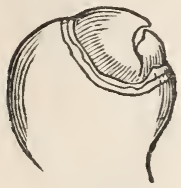

Fig. 57.

bling the beak of a parrot (Fig. 57); and they move up and down as in birds. But a much larger number rasp their food by means of a tongue coiled like a watch-

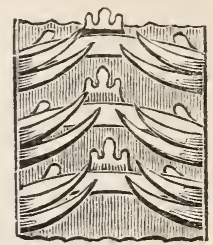

Fig. 58. spring, the surface of which is covered with innumerable minute tooth-like points of a horny consistence, as in the highly magnified portion of the tongue of Natica (Fig. 58).

214. The Articulata are remarkable, as a class, for the diversity and complication of their apparatus for taking and

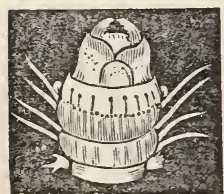

Fig. 59.

dividing their food. In some marine worms, Nereis, for example, the jaws consist of a pair of curved, horny instruments, lodged in a sheath (Fig. 59). In spiders, these jaws are external, and sometimes mounted on long, jointed stems. Insects which masticate their food have, for the most part, at least two pairs of horny jaws (Fig. 60,61, $\mathrm{m}$ ), besides several additional pieces which serve for seizing and holding their food. Those which live on the fluids which they extract either from plants or from the blood of other animals, have the masticatory organs transformed into a trunk or tube for this purpose. This trunk is sometimes rolled up in a spiral manner, as in the butterfly (Fig. 64); or it is stiff, and

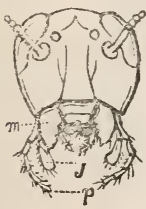

Fig. 60.

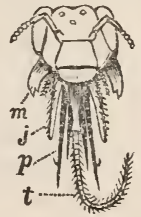

Fig. 61 .

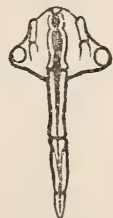

Fig. 62. Fig. 63.

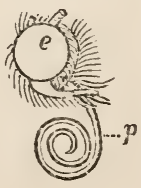

Fig. 64 folded beneath the chest, as in the squash-bugs (Fig. 62), 
and contains several piercers of extreme delicacy, (Fig. 63), adapted to penetrate the skin of animals or other objects whose juices they extract; or they are prolonged so as to shield the tongue when thrust out in search of nutritive juices, as in the bees (Fig. 61.) The crabs have their anterior feet transformed into a kind of jaws. Indeed, even down to the microscopic Rotifers, we find very complicated jaws, as seen in the interior of Brachionus

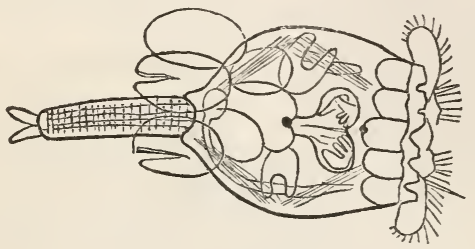

Fig. 65.

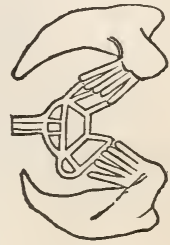

Fig. 66.

(Fig. 65), and represented largely magnified in Fig. 66. But amidst this diversity of apparatus, there is one thing which characterizes all the Articulata, namely, the jaws all move sideways; while those of the Vertebrates move up and down, and those of the Radiata move concentrically.

215. In the Vertebrates, the jaws form a part of the bony

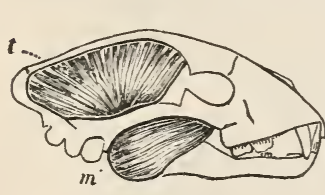

Fig. 67. skeleton. In most of them the lower jaw only is movable, and is brought up against the upper jaw by means of very strong muscles, the temporal and masseter muscles (Fig. 67, $t, m$ ), which perform all the motions requisite for seizing and masticating food.

216. The jaws are usually armed with solid cutting instruments, the Teeth, or else enveloped in a horny covering, the beak, as in the birds and tortoises (Fig. 68). In some of the whales, we have instead, a range of

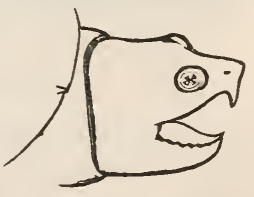

Fig. 68 . 
long, flexible, horny plates or fans, fringed at the margin, which serve as strainers to separate the minute marine ani-

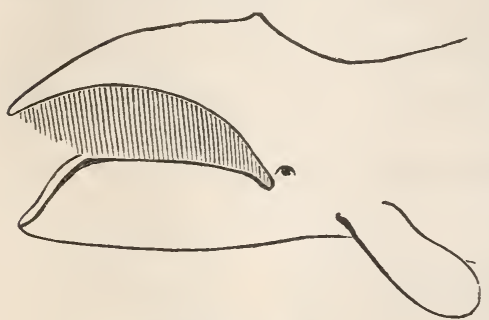

Fig. 69. mals on which they feed, from the water drawn in with them (Fig. 69). A few are entirely destitute of teeth, as the ant-eater (Fig. 70).

21\%. Though all the vertebrates possess jaws, it must not be inferred that they all chew their food. Many of them swallow their prey whole; as most birds, tortoises, and whales. Even those which are furnished with teeth do not all of them masticate their food; some use them merely for seizing and securing their prey, as we find in the lizards, frogs, crocodiles and the great majority of fishes. In such animals, it has been remarked that the teeth are nearly all alike in form and structure, as

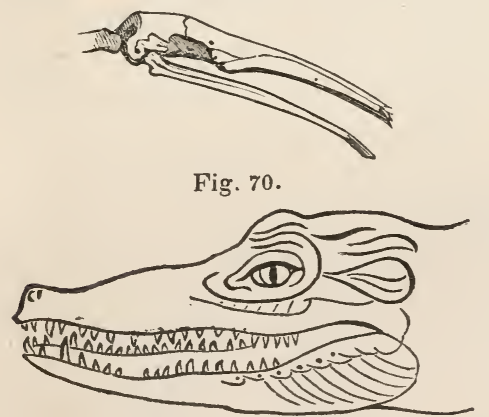

Fig. 71 .

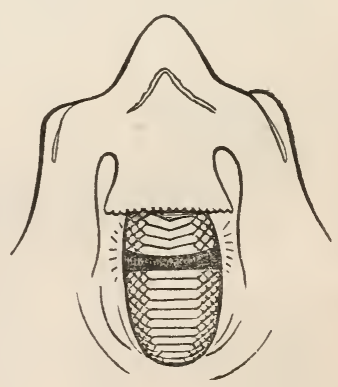

Fig. 72.

for instance in the alligator (Fig. 71); and in most fishes. A few of the latter, some of the Rays, for example, have a sort of bony pavement (Fig. 72), composed of a peculiar 
kind of teeth, with which they crush the shells of the mollusks on which they feed.

218. The Mammals, however, are almost the only vertebrates which can be properly said to masticate their food. Their teeth are well developed, and present great diversity in form, arrangement and mode of insertion. Three kinds of teeth are usually distinguished in most of these animals, whatever may be their mode of life; namely, the cutting teeth, incisors; the tusks or carnivorous teeth, canines; and the grinders, molars (Fig. 73). The incisors (a) occupy the front of the mouth;

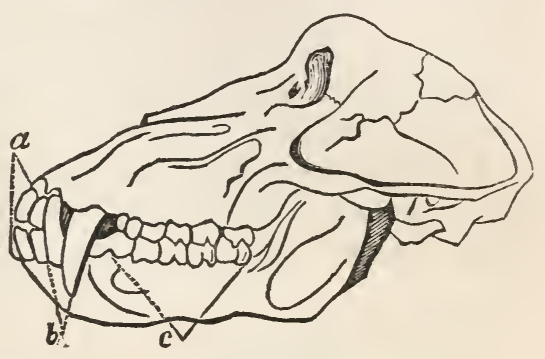

Fig. 73. they are the most simple and the least varied; they have a thin cutting summit, and are employed almost exclusively for seizing food; except in the elephant, in which they assume the form of large tusks. The canines $(b)$ are conical, more prominent than the others, more or less curved, and only two in each jaw. They have but a single root, like the incisors, and in the carnivora become very formidable weapons. In the herbivora, they are entirely wanting, or when existing they are so enlarged and modified as also to become powerful organs of offence and defence, although useless for mastication; as in the babyroussa, \&c. The molars $(c)$ are the most important for indicating the habits and internal structure of the animal; and at the same time they are most varied in shape. Among them we find every transition, from those of a sharp and pointed form, as in the cat tribe, to those with broad and level summits, as in the ruminants and rodents. 
Still, they have one constant character, namely, their roots are never simple, but double or triple, which not only fixes them more firmly, but prevents them from being driven into the jaw in the efforts of mastication.

219. The harmony of organs already spoken of (22-24) is illustrated, in a most striking manner, by the study of the teeth of the mammals, and especially of their molar teeth. So constantly do they correspond with the structure of the other parts of the body, that a single molar is sufficient not only to indicate the mode of life of the animal from which it was obtained, and to show whether it fed on flesh or vegetables, but also to determine the particular group to which it belongs. Thus, those beasts of prey which feed on insects, and which on that account have been

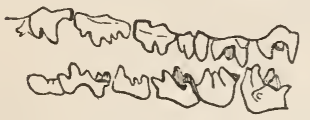

Fig. 74.

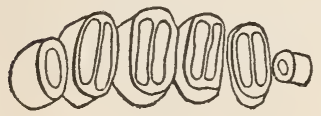

Fig. 76.

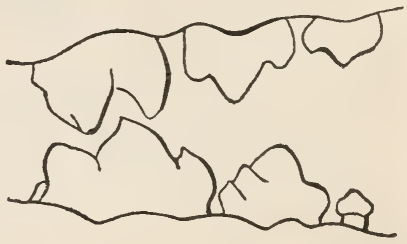

Fig. 75 .

called Insectivora, such as the moles and bats, have the molars terminated by several sharp, conical points (Fig. 74), so arranged that the elevations of one tooth fit exactly into the depressions of the tooth opposite to it. In the true Carnivora (Fig. 75), on the contrary, the molars are compressed laterally, so as to produce a sharp cutting edge; and they shut by the side of each other, like the blades of scissors, thereby dividing the food with great facility.

220. The same adaptation is observed in the teeth of herbivorous animals. Those which chew the cud (ruminants), many of the thick skinned animals (pachydermata), 
like the elephant, and some of the gnawers (rodentia), like the hare (Fig. 76), have the summits of the molars flat, like millstones, for grinding the grass and leaves on which they subsist. Finally, the omnivora, those which feed on both flesh and fruit, like man and the monkeys, have the molars terminating in several rounded tubercles, being thus adapted to the mixed nature of their food.

221. Again, the mode in which the molars are combined with the canines and incisors furnishes excellent means of characterizing families and genera. Even the minute structure of a tooth is so peculiar in each group of animals, and yet is subject to such invariable rules, that it is possible to decide positively the structure of an animal, merely by the inspection of the fragment of a tooth under the microscope.

222. Another process, subsidiary to digestion, is called insalivation. Animals which masticate their food have glands, in the neighborhood of the mouth, which secrete a fluid called saliva. This fluid mingles with the food as it is chewed, and prepares it also to be more readily swallowed. The salivary glands are wanting in all animals which swallow their food without mastication. When the food is masticated and mingled with saliva, it is carried back by the tongue, and passes down a tube, the œsophagus, into the stomach. This act is called deglutition or swallowing.

223. The wisdom and skill of the Creator is strikingly illustrated in the means he has afforded to every creature for securing the means of its subsistence. Some animals have no ability to move from place to place, but are fixed to the soil ; as the oyster, the polypi, \&c. These are dependent for subsistence upon such food as may stray or float near, and they have the means of securing it when it comes within their reach. The oyster closesits shell, and thus secures its prey; 
the polyp has flexible arms (Fig. 77), capable of great extension, which instantly embrace any minute animal that comes in contact with them. The cuttle-fish also, has similar arms about the mouth, furnished with ranges of suckers, by which it secures its prey (Fig. 47).

224. Some are provided with instruments for extracting food from places which would be otherwise inaccessible. Some of the

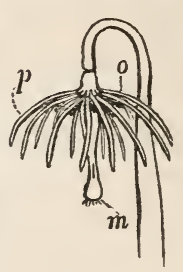

Fig. 77. mollusks, with their rasp-like tongue (Fig. 58), perforate the shells of other animals, and thus reach and extract the inhabitant. Insects have various piercers, suckers, or a protractile tongue for the same purpose (Figs. 61-64). Many of the Annelides, the leeches for example, have a sucker, which enables them to produce a vacuum, and thereby draw out blood from the perforations they make. Many microscopic animals are provided with hairs or cilia around the mouth (Fig. 65), which by their incessant motion produce currents that bring within reach the still more minute creatures or particles on which they feed.

225. Among the Vertebrata, the herbivora generally employ their lips or their tongue, or both together, for seizing the grass or leaves they feed upon. The carnivora use their jaws, teeth, and especially their claws, which are long, sharp and movable, and admirably adapted for the purpose. The woodpeckers have long, bony tongues, barbed at the tip, with which they draw out insects from deep holes and crevices. Some reptiles also use their tongue to take their prey. Thus, the chameleon obtains flies at a distance of three or four inches, by darting out his tongue, the enlarged end of which is covered with a glutinous substance to which they adhere. The elephant, whose tusks and short neck prevent him from bringing his 
mouth to the ground, has the nose prolonged into a trunk, which he uses with great dexterity, for bringing food and drink to his mouth. Doubtless the mastodon, once so abundant in this country, was furnished with a similar organ. Man and the monkeys employ the hand exclusively, for prehension.

226. Some animals drink by suction, like the ox, others by lapping, like the dog. Birds simply fill the beak with water, then raising the head, allow it to run down into the crop; some of them, however, suck up liquids, like the herbivora. 


\section{CHAPTER SEVENTH.}

\section{OF THE BLOOD AND CIRCULATION.}

227. The nutritive portions of the food are poured into the blood or the general mass of fluid which pervades every part of the body, and out of which every tissue is originally constructed, and from time to time renewed.

228. The Blood, when examined by the microscope, is found to consist of a transparent fluid, the serum, in which float many rounded, somewhat compressed bodies, called globules. These globules vary in number with the natural heat of the animal from which the blood is taken. Thus, they are more numerous in birds than in the mammals, and

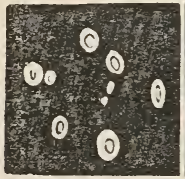

Fig. 78 .

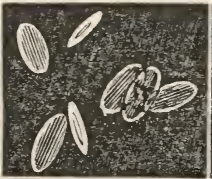

Fig. 79 .

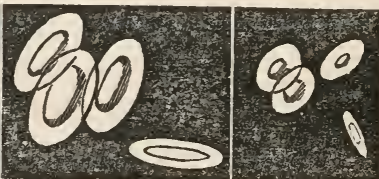

Fig. 81 .

more abundant in the latter than in fishes. In man and other mammals they are very small and nearly circular (Fig. 78); they are somewhat larger and of an oval form in birds and fishes (Figs. 79, 81); and still larger in reptiles (Fig. 80 ).

229. The color of the blood in the vertebrates is bright red; but in some invertebrates, as in the crabs and mollusks, it is nearly or quite colorless; while in the worms 
and some echinoderms, it is variously colored yellow, orange, red, violet, lilac, and even green.

230. The presence of this fluid in every part of the body is one of the essential conditions of animal life. A perpetual current flows from the digestive organs towards the remotest parts of the surface; and such portions as are not required for nutriment return, mingled with those which have become useless and need to be renewed or expelled. The blood is kept in an incessant circulation for this purpose.

231. In the lowest animals, such as the polypi, the nutritive fluid is merely the products of digestion mingled with water in the common cavity of the viscera, with which it comes in immediate contact, as well as with the whole interior of the body. In the jelly-fishes, which occupy a somewhat higher rank, a similar liquid is distributed by prolongations of the principal cavity to different parts of the body (Fig. 31). Currents are produced in these, partly by the general movements of the animal, and partly by means of the incessant vibrations of microscopic hairs which overspread the interior, and are hence called vibratile cilia. In most of the mollusks and insects, the blood is also in immediate contact with the viscera; or the vessels, if any, are not continuous, but terminate in various cavities.

232. In animals of still higher organization, as the vertebrates, the mollusks, and a part of the articulata and echinoderms, we find the vital fluid enclosed in an appropriate set of vessels, by which it is successively conveyed throughout the system to supply its wants, and to the respiratory organs, where it absorbs oxygen, or in other words, becomes oxygenated.

233. The vessels in which the blood circulates are of two kinds: 1. The arteries, of a firm, elastic structure, which may be distended or contracted, according to the 
volume of their contents, and which convey the blood from the centre towards the surface, distributing it to every point of the body; 2. The veins, of a thin, membranous structure, furnished within with valves, (Fig. 82,v), which aid in sustaining the column of blood, and allow it to flow towards the centre only. The arteries constantly subdivide into smaller and smaller branches; while the veins commence in minute twigs, and are gathered into branches and larger trunks to unite finally at the centre.

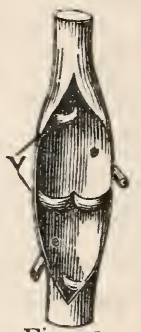

Fig. 82.

234. The extremities of the arteries and veins are con-

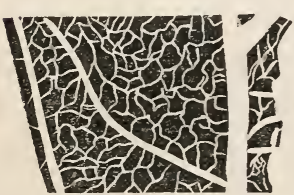

Fig. 83. nected by a net-work of extremely minute and delicate vessels, called capillary vessels (Fig. 83). They pervade every portion of the body, so that almost no point can be pricked from which blood will not issue. Notwithstanding their minuteness, the most important processes of nutrition are performed by these vessels, such as the removal of effete particles and the substitution of new ones, and all those changes by which the bright blood of the arteries becomes the dark blood of the veins; and again, in the capillaries of the respiratory organs, the dark venous blood is oxygenated and restored to the bright scarlet hue of the arterial blood.

235. Where there are blood-vessels in the lowest animals the blood is kept in motion by the occasional contraction of some of the principal vessels, as in the worms. Insects have a large vessel running along the back, furnished with valves so arranged that, when the vessel

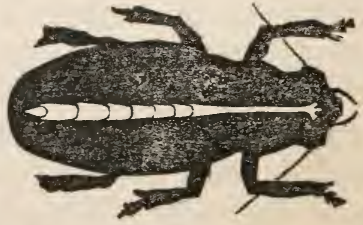

Fig. 84. contracts, the blood can flow only towards the head, and 
being thence distributed to the body, is returned again into the dorsal vessel (Fig. 83), by fissures at its sides.

236. In all the higher animals there is a central organ, the heart, which forces the blood through the arteries towards the surface, and receives it again on its return. The HEART is a hollow muscular organ of a conical form, which dilates and contracts at regular intervals, independently of the will. It is either a single cavity, or is divided by walls into two, three, or four compartments, as seen in the following diagrams. These modifications are important in their connection with the respiratory organs, and indicate the higher or lower rank of an animal, as determined by the quality of the blood distributed in those organs.

237. In the mammals and birds the heart is divided by a vertical partition into two cavities, each of which is again divided into two compartments, one above the other (Fig. 85). The two upper cavities are called auricles, and the lower ones are called ventricles. Reptiles have two

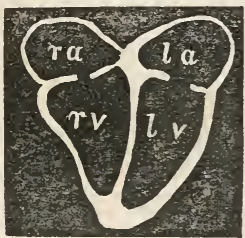

Fig. 85 .

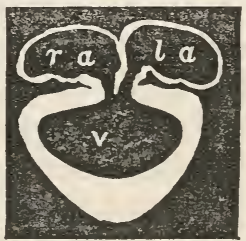

Fig. 86.

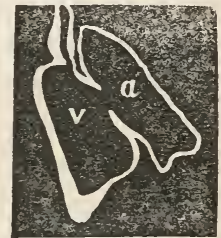

Fig. 87.

auricles and one ventricle (Fig. 86). Fishes have one auricle and one ventricle only (Fig. 87).

238. The auricles do not communicate with each other, nor do the ventricles. The former receive the blood from the body and from the respiratory organs, and each auricle sends it into the ventricle beneath, through an opening guarded by a valve, to prevent its reflux; while the ventricles, by their contractions, force the blood through the arteries into the lungs and through the body generally. 
239. The two auricles dilate at the same instant, and also contract simultaneously; so also do the ventricles. These successive contractions and dilatations constitute the pulsations of the heart. The contraction is called systole, and the dilatation is called diastole. Each pulsation consists of two movements, the diastole or dilatation of the ventricles, during which the auricles contract, and the systole or contraction of the ventricles, while the auricles dilate. The frequency of the pulse varies in different animals, and even in the same animal, according to age, sex, and the degree of health. In adult man, they are commonly about seventy beats per minute.

240. The course of the blood in those animals which have four cavities to the heart is as follows, beginning with the left ventricle (Fig. 85, lv). By the contraction of this ventricle, the blood is driven through the main arterial trunk, called the aorta (Fig. 90,a), and is distributed by its branches throughout the body; it is then collected by the veins, carried back to the heart, and poured into the right auricle (Fig. 85, $r a$ ), which sends it into the right ventricle $(r v)$. The right ventricle propels it through another set of arteries, the pulmionary arteries (Fig. 90,p), to the lungs $(l)$; it is there collected by the pulmonary veins, and conveyed to the left auricle (Fig. 85, $l a$ ), by which it is returned to the left ventricle, thus completing the circuit.

241. Hence the blood in performing its whole circuit passes twice through the heart. The first part of this circuit, the passage of the blood through the body, is called the great circulation; and the second part, the passage of the blood through the lungs, is the lesser or pulmonary circulation: this double circuit is said to be a complete circulation. In this case the heart may be justly regarded as two hearts conjoined, and in fact the whole of the lesser circulation intervenes in the passage of the blood 
from one side of the heart to the other; except during the embryonic period, when there is an opening between the two auricles, which closes as soon as respiration commences.

242. In reptiles (Fig. 86), the venous blood from the body is received into one auricle, and the oxygenated blood from the lungs into the other. These throw their contents into the single ventricle below, which propels the mixture in part to the body, and in part to the lungs ; but as only the smaller portion of the whole quantity is sent to the lungs in a single circuit, the circulation is said to be incomplete. In the Crocodiles, the ventricle has a partition which keeps separate the two kinds of blood received from the auricles; but the mixture soon takes place by means of a special artery which passes from the pulmonary artery to the aorta.

243. In fishes (Fig. 87) the blood is carried directly from the ventricle to the gills, which are the respiratory organs; whence it passes into the arteries for distribution to the system in general, and returns by the veins to the auricle. Here the blood, in its circuit, passes but once through the heart; but the heart of a fish corresponds nevertheless to the heart of a mammal, and not to one half of it, as has often been maintained.

244. Crabs and other crustacea have but a single ventricle without an auricle. In the mollusks there is likewise but a single ventricle, as in Natica (Fig. 88, $h$ ). Some have in addition one or two auricles. These auricles are sometimes so dis-

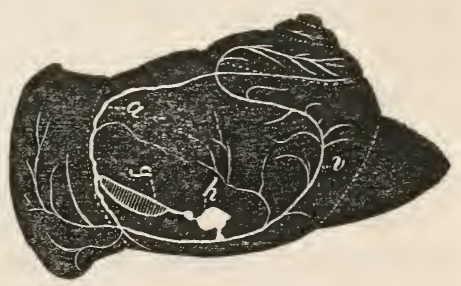

Fig. 88. joined as to form so many isolated hearts, as in the cuttlefish. Among Radiata, the sea-urchins are provided with a tubular heart. 


\section{CHAPTER EIGHTH.}

OF RESPIRATION.

245. For the maintenance of its vital properties, the blood must be submitted to the influence of the air. This is true of all animals, whether they live in the atmosphere or in the water. No animal can survive for any considerable period of time without air; and the higher animals almost instantly die when deprived of it. It is the office of RESPIRATION to bring the blood into communication with the air.

246. Among animals which breathe in the open air, some have a series of tubes branching through the interior of the body, called trachere (Fig. 89, t), and opening externally upon the sides of the body, by small apertures, called stigmata $(s)$; as in the insects and in some spiders. But the most common mode of respiration is by means of the LuNGS, a pair of peculiar spongy or cellular organs, in the form of large pouches, which are the more complicated in proportion to the quantity of air to be consumed.

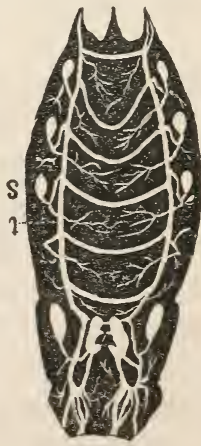

Fig. 89.

247. In the lower vertebrata provided with lungs there is a single organ; but in the higher classes they are in pairs, placed in the cavity formed by the ribs, one on each side of 
the vertebral column, and enclosing the heart $(h)$ between them (Fig. 90,ll). The lungs communicate with the atmosphere by means of a tube composed of cartilaginous rings which arises from the back part of the mouth, and divides below, first into a branch for each organ, and then into innumerable branches penetrating their whole mass, and finally terminating in minute sacs. This tube is the trachea or windpipe ( $w)$, and its branches are the bronchi. In the higher airbreathing animals the lungs and heart occupy an apartment by themselves, the chest, which is separated from the other contents of the lower arch (161), by a fleshy partition, called the diaphragm, passing across the cavity of the

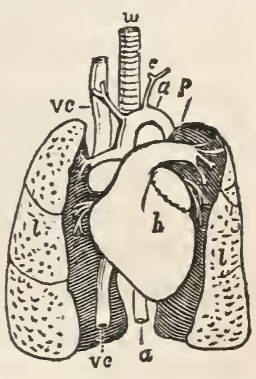

Fig. 90. body, and arching into the chest. The only access to this apartment is by the glottis (Fig. 22,o) through the trachea.

248. The mechanism of respiration by lungs may be compared to the action of a bellows. The cavity of the chest is enlarged by raising the ribs, the arches of which naturally slope somewhat downward, but more especially by the contraction of the diaphragm, whereby its intrusion into the chest is diminished. This enlargement causes the air to rush in through the trachea, distending the lung so as to fill the additional space. When the diaphragm is again relaxed, and the ribs are allowed to subside, the cavity is again diminished, and the air expelled. These movements are termed inspiration or inhalation, and expiration. The spongy pulmonary substance being thus distended by air, the blood sent from the heart is brought into such contact with it as to allow the requisite interchange to take place (235).

249. The respiration of animals breathing in water is ac- 
complished by a different mechanism. The air is to be

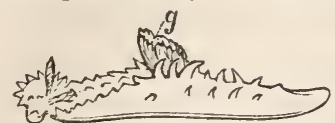

Fig. 91. derived from the water, in which more or less is always diffused. 'The organs for this purpose are called branchice or gills, and are either delicate tufts or plumes floating outside of the body, as in some of the marine worms (Fig. 33), and many mollusks (Fig. $91, g)$; or they consist of delicate folds, as in fishes (Fig. 92), crabs and most mollusks (Fig. $88, g$ ). These gills are always so situated that the water has free access to

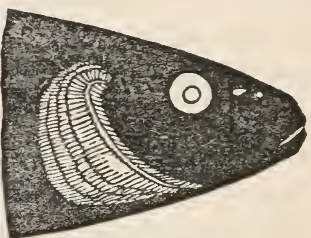

Fig. 92. them. In the lower aquatic animals, such as the polypi, jelly-fishes and some mollusks, respiration is facilitated by the incessant motions of vibratory cilia, which line the respiratory organs as well as other portions of the surface of the body; the currents they produce bringing constantly fresh supplies of water containing air in contact with the respiratory organs.

250. Many animals living in water, however, rise to the surface and breathe the atmosphere there, or are furnished with the means of carrying away a temporary supply of air. This is the case with the whale tribe, many insects and mollusks.

251. The vivifying power of the air upon the blood is due to its oxygen. If an animal be confined for a time in a closed vessel, and the contained air be afterwards examined, a considerable portion of its oxygen will have disappeared, and another gas of a very different character, namely, carbonic acid gas, will have taken its place. The essential office of respiration is to supply oxygen to the blood, whereby also carbon is removed from it.

252. An immediately obvious effect of respiration in the 
red-blooded animals is a change of color. The blood in passing through the respiratory organs, being changed from a very dark purple to a bright scarlet. In the great circulation (241) the scarlet blood occupies the arteries, and is usually called red blood, in contradistinction from the venous blood, which is called black blood. In the lesser circulation, on the contrary, the arteries carry the dark, and the veins the red blood.

253. The quantity of oxygen consumed by various animals in a given time has been accurately ascertained by experiment. It has been found, for instance, that a commonsized man consumes, on an average, about 150 cubic feet in twenty-four hours; and as the oxygen constitutes but 21 per cent. of the atmosphere, it follows that he inhales, during a day, about 700 cubic feet of atmospheric air. In birds, the respiration is still more active, while in reptiles and fishes it is much more sluggish.

254. The energy and activity of an animal correspond with the activity of its respiration. Thus the toad, whose movements are very sluggish, respires much more slowly than the mammals, birds, and even insects ; and it has been ascertained that a butterfly, notwithstanding its comparatively diminutive size, consumes more oxygen than a toad.

255. The circulation and respiration have a reciprocal influence upon each other. If the heart be powerful, or if violent exercise demand a more rapid supply of blood to repair the consequent waste (201), respiration must be proportionally accelerated to supply air to the greater amount of blood sent to the lungs. Hence the panting occasioned by running or other unusual efforts of the muscles. On the other hand, if respiration be hurried, the blood being rendered more stimulant by greater oxygenation, causes an acceleration of the circulation. The quantity of air consumed varies therefore with the proportion of the blood which is sent to the lungs. 
256. The proper temperature of an animal, or what is termed ANIMAL HEAT, depends on the combined activity of the respiratory and circulating systems, and is in direct proportion to it. In many animals the heat is maintained at a uniform temperature, whatever may be the variations of the surrounding medium. Thus, birds maintain a temperature of about $108^{\circ}$ Fahrenheit; and in a large proportion of mammals it is generally from $95^{\circ}$ to $105^{\circ}$. These bear the general designation of warm-blooded animals.

257. Reptiles, fishes, and most of the still lower animals, have not this power of maintaining a uniform temperature. The heat of their body is always as low as from $35^{\circ}$ to $50^{\circ}$, but varies perceptibly with the surrounding medium, being however, often a little above it when the external temperature is very low, though some may be frozen without the loss of life. For this reason they are denominated coldblooded animals; and all of them have such a structure of the heart, that only a part of the blood which enters it is sent to the respiratory organs (243).

258. The production of animal heat is obviously connected with the respiratory process. The oxygen of the respired air is diminished, and carbonic acid takes its place. The carbonic acid is formed in the body by the combination of the oxygen of the air with the carbon of the blood. The chemical combination attending this function is therefore essentially the same as that of combustion. It is thus easy to understand how the natural heat of an animal is greater, in proportion as respiration is more active. How far nutrition in general, and more particularly assimilation, by which the liquid parts are fixed and solidified, is connected with the maintenance of the proper temperature of animals, and its uniform distribution through the body, has not yet been satisfactorily ascertained.

259. Some of the higher warm-blooded animals do not 
maintain their elevated temperature during the whole year ; but pass the winter in a sort of lethargy called HIBERNATION, or the hibernating sleep. The marmot, the bear, the bat, the crocodile and most reptiles, furnish examples. During this state the animal takes no food; and as it respires only after very prolonged intervals, its heat is diminished, and its vital functions generally are much reduced. The structural cause of hibernation is not ascertained; but the phenomena attending it fully illustrate the laws already stated (254-8).

260. There is another point of view in which respiration should be considered, namely, with reference to the specific gravity of animals, or their power of rising in the atmosphere, and of living at different depths in the water, under a diminished or increased pressure. The organs of respiration of birds and insects are remarkably adapted for the purpose of admitting at will a greater quantity of air into their body, the birds being provided with large pouches extending into the abdominal cavity and into the bones of the wing; whilst in insects the whole body is penetrated by air tubes enlarged at intervals into wider cells. Aquatic animals are all provided with minute, almost microscopic water-tubes, penetrating from the surface into their substance, or the cavity, by which the body is adapted to pressures which otherwise would crush the animal. In fishes, these water-tubes penetrate through the bones of the skull, and through skin and scales; in mollusks they are more numerous in the fleshy parts, as for example, in the foot; in echinoderms they pass through the skin, and even through the hard shell, whilst in polyps they perforate the walls of the general cavity of the body. 


\section{CHAPTER NINTH.}

\section{OF THE SECRETIONS.}

261. While the body is assimilating foreign substances for its nutrition and growth, it is also freeing itself from other substances which have become useless (201). The different processes for effecting this latter object are called Secretions.

262. In this operation the skin is largely concerned. Being the outermost envelop of the body, and designed to protect it from external influences, it is the seat of continual loss and reparation. New membranes and new tissues are constantly forming, while the old ones are removed. This removal is sometimes gradual and continual, in the form of slime, as in the fishes and most of the mollusks, their mucus being in fact a collection of cells detached from the surface of the skin; and sometimes periodical, when it constitutes moulting. Thus, the mammals cast their hair, the birds their feathers, the serpents their outer skin, the crabs their test, the caterpillars their outer envelop with the hairs arising from it.

263. We shall hereafter see that the skin presents such varieties of composition in the different groups of the Animal Kingdom as to furnish excellent distinctions for species, genera, and even families. In the vertebrates it is composed of three very distinct layers of unequal thickness, as 
may be seen by Fig. 94, which represents a magnified section of the human skin traversed by the sudoriferous canals. The lower layer or the leather $(a)$ is the thickest ; it covers the muscles, from which it is separated by a bed of fat in which the glands of transpiration are situated. Above the leather is a thinner layer, the vascular layer (b), so called from the abundance of blood vessels it contains; it is also traversed by numerous nerves, which render it very sensitive. The third or superficial layer is called epidernis $(c)$. It contains neither nerves nor blood vessels, and consequently is insensible. The scales of reptiles, the nails of mammals, and the solid envelops of the crustacea are merely indurated products of the epidermis. On the other hand, the feathers of birds and the scales of fishes belong to the vascular layer.

264. Besides these general functions of the skin, nature has provided several other means for carrying out of the system the superfluous parts, the most important of which are exhalation and secretion. We have already seen (37) that there is a general property of all animal tissues, called endosmosis and exosmosis, by which they may be traversed by liquids and gases. The blood vessels, especially the capillary vessels, share this property of permeability to liquids. Hence, while the circulation goes on, portions of the circulating fluid, especially its watery parts, escape through the walls of the vessels, and pass off at the surface. This superficial loss, termed exhalation, is most active where vessels most abound, and accordingly most copious from the surface of the lungs. It has been estimated that, under certain circumstances, the human body loses, by exhalation, five eighths of the whole weight of substances taken into it.

265. Secretion is a more complicated process than exhalation. It is not a mere mechanical operation, but is ac- 
complished by means of peculiar organs, called glands; which elaborate peculiar juices, such as the sweat, the tears, the milk, the saliva, the bile, the urine, \&c.

266. At first glance there would seem to be nothing in common between the organs which secrete the tears and that which produces the bile, or between the kidneys and the salivary glands. Still they all have the same elementary structure. Every gland is composed of minute vesicles, or extremely thin membranous sacs, generally too small to be discerned by the naked eye, but easily distinguished by the microscope. Sometimes these vesicles are

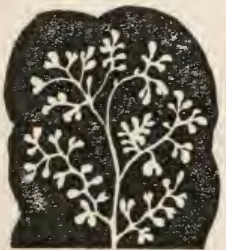

Fig. 93. single and open separately at the surface; they are then called crypts or follicles, but more frequently they unite to form clusters opening into a common canal, which itself unites with the canals of similar clusters to form trunks of various sizes, such as are found in the salivary glands (Fig. 92), in the mammæ, or in the liver, which is merely a very large gland receiving a large quantity of blood from the veins of the alimentary canal.

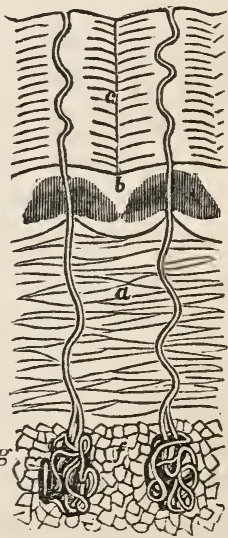

Fig. 94.

267. Sometimes the canals of the little clusters do not unite, but open separately upon the surface of the body or into its cavities, as in the intestinal glands or those from which the perspiration issues (Fig. 94, g). Occasionally, the canals themselves combine into bundles composed of a multitude of parallel tubes, as we find in the kidneys.

268. The operation of the glands is one of the most extraordinary and mysterious of the whole organization. By virtue of the peculiar properties with which they are en- 
dowed, they select from the blood, which penetrates to their remotest ramifications, the elements of the special humors they are designed to elaborate. Thus the liver extracts the elements of the bile; the salivary glands the elements of saliva; the pancreas those of the pancreatic juice; and the sudoriferous glands those of the sweat, \&c.

269. Among the humors thus formed by the different glands, some are immediately expelled, and the body freed from them, as the sweat, the urine, \&c.; these are denominated excretions. Others, on the contrary, which are properly denominated secretions, are destined either to be used as food for the young, as the milk; or to take part in the different functions of the body, as the saliva, the tears, the gastric and pancreatic juices, and the bile. The last is the most important of all the secretions, and hence a liver, or some analogous organ by which bile is secreted, is found in animals of every department, whilst most of the other glands are only found in certain classes of animals.

270 . In the vertebrates the liver is the largest of the viscera. It is of a reddish brown color, and varies but little in the different classes. In the mollusks it is noless preponderant. In the gasteropods, like the snails, it envelops the intestine in its folds (Fig. 52) ; and in the acephala, like the clam and oyster, it generally surrounds the stomach. In the articulated animals it is not so compact, nor so voluminous as in the mollusks. In insects it is represented by long tubes variously contorted and interlaced (Fig. 51). In the Radiata this organ is largely developed, especially among the echinoderms. In the star-fishes it is very large, extending into all the recesses of the arms; and in color and structure resembles that of the mollusks. Even in polyps we find peculiar brown cells lining the stomach, which probably perform functions similar to those of the liver of higher animals. 
CHAPTER TENTH.

\author{
EMBR YOLOG Y.
}

\title{
SECTION I.
}

OF THE EGG.

271. THE functions of vegetative life, of which we have treated in the preceding chapters, namely, digestion, circulation, respiration and secretion, have for their end the preservation of the individual. We have now to treat of the functions that serve for the perpetuation of the species, namely those of reproduction (200).

272. It is a law of nature that animals as well as plants are preceded only by individuals of the same species ; and vice versa, that none of them can produce a species different from themselves. Reproduction in animals is almost universally accomplished by the association of individuals of two kinds, males and females, living commonly in pairs or flocks, and each of them characterized by peculiarities of structure and external appearance.

273. As this distinction prevails throughout the animal kingdom, it is always necessary for obtaining a correct and complete idea of a species, to bear in mind the peculiarities of both sexes. Every one is familiar with the differences between the cock and the hen, the lion and the lioness. 
Among Articulata, the differences are no less striking, the male being often of a different shape or color, as in crabs; or having even more complete organs, as in many tribes of insects, where the males have wings, while the females are deprived of them.

274. Even higher than specific distinctions are based upon peculiarities of the sexes; for example, the whole class of Mammalia is characterized by the fact that the female is furnished with organs for nourishing her young with a peculiar liquid, the milk, secreted by herself. Again, the order Marsupialia, to which the opossum belongs, is distinguished by the circumstance of the female having a pouch in which the young are received after birth.

275. That all animals are produced from eggs, (Omne vivum ex ovo), is an old adage in Zoölogy, which modern researches have fully confirmed. In tracing back the phases of animal life, we invariably arrive at an epoch when the incipient animal is enclosed within an egg. It is then called an embryo, and the period passed in this condition is called the embryonic period.

276. Before the various classes of the animal kingdom had been attentively compared during the embryonic period, all animals were divided into two great divisions: the oviparous, comprising those which lay eggs, such as birds, reptiles, insects, mollusks, \&c., and the viviparous, which bring forth their young alive, namely, the mammalia. This distinction lost much of its importance when it was shown that viviparous animals are produced from eggs, as well as the oviparous ; only that their eggs, instead of being laid before the development of the embryo begins, undergo their early changes in the body of the mother. Production from eggs should therefore be considered as a universal characteristic of the Animal Kingdom.

27\%. Form of the Egg. - The general form of the egg 
is more or less spherical. The eggs of birds have the form of an elongated spheroid; and this form is so constant, that the term oval has been universally adopted to designate it. But this is by no means the usual form of the eggs in other

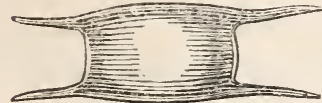

Fig. 95. animals. In most instances, on the contrary, they are spherical, especially among the lower animals. Some have singular appendages, as those of the skates and sharks (Fig. 95), which are shaped like a hand-barrow, with four hooked horns at the corners. The eggs of the hydra, or fresh water polyps, are thickly covered with prickles (Fig. 96). Those of certain insects, for example the Podurella, are furnished with fila-

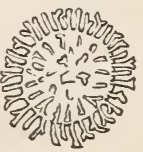

Fig. 96.

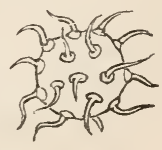

Fig. 97. ments which give them a hairy aspect (Fig. 97); others are cylindrical or prismatic, and frequently the surface is sculptured.

278. Formation of the Egg. - The egg originates within peculiar organs, namely, the ovaries, which are glands, ordinarily situated in the abdominal cavity. So long as they remain in the ovary, they are very minute in size. In this condition they are called ovarian, or primitive eggs. They are nearly the same in all animals, and are in fact merely little cells containing yolksubstance $(y)$, including other similar cells, namely, the germinative vesicle $(g)$, and the germinative dot $(d)$. The yolk-substance itself is deposited in the ovary, and afterwards

Fig. 98. enclosed in cells. The number of these eggs is large in proportion as the animal stands lower in the class to which it belongs. The ovary of a herring contains more than 25,000 eggs; whilst that of birds contains a much smaller number, perhaps one or two hundred. 
279. Ovulation. - Having attained a certain degree of maturity, which varies in different classes, the eggs leave the ovary. This is called ovulation. It must not be confounded with the laying of the eggs, which is the subsequent expulsion of them from the abdominal cavity, either immediately, or through a particular canal, the oviduct. Ovulation takes place at certain seasons of the year, and never before the animal has reached a particular age, which commonly coincides with its full growth. In a majority of species, ovulation is repeated for a number of years consecutively, generally in the spring, and frequently several times a year. In others, on the contrary, it occurs but once during life, at the period of maturity, and the animal soon afterwards dies. Thus the butterfly dies shortly after having laid her eggs.

280. The period of ovulation is one of no less interest to the zoölogist than to the physiologist, since the peculiar characteristics of each species are then most clearly marked. Ovulation is to animals what flowering is to plants ; and indeed, few phenomena are more interesting to the student of nature than those exhibited by animals at the pairing season. Then their physiognomy is the most animated, their song the most melodious, and their attire the most brilliant. Some birds appear so different at this time, that zoölogists are always careful to indicate whether or not a bird is represented at the breeding season. Similar differences occur also among fishes and other animals, whose colors are then much brighter.

281. Laying. - After leaving the ovary, the eggs are either discharged from the animal, that is, laid; or they continue their development within the parent animal, as is the case in some fishes and reptiles, which for that reason have been named ovo-viviparous animals. The eggs of the mammalia are not only developed within the mother, but 
become intimately united to her; this peculiar mode of development has received the name of gestation.

282. Eggs are sometimes laid one by one, as in birds; sometimes collectively and in great numbers, as in the frogs, the fishes, and most of the invertebrates. In some instances they are united in clusters by a gelatinous envelop; or are enclosed in cases or between membranous discs, forming long strings, as in the eggs of the Pyrula (Fig. 99). The conditions Fig. 99. under which the eggs of different animals are placed, on being laid, are very different. The eggs of birds, and of some insects, are deposited in nests constructed for that purpose by the parent. Other animals carry their eggs attached to their bodies; sometimes under the tail, as in the lobsters and crabs, sometimes hanging in large bundles on both sides of the tail, as in the Monoculus (Fig. 100,a).

283. Some toads carry them on the back,

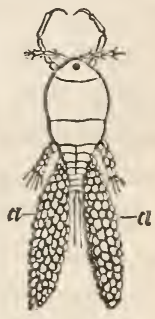

Fig. 100. and, what is most extraordinary, it is the male which undertakes this office. Many mollusks, the Unio for example, have them attached to the gills during incubation. In the polyps they hang in clusters (Fig. 7\%,o), either inside or outside, at the bottom of the cavity of the body. Some insects, such as the gad-flies, deposit their eggs on other animals. Finally, many abandon their eggs to the elements, taking no further care of them after they have been laid; such is the case with most fishes, some insects, and many mollusks. As a general rule, it may be said that animals take the more care of their eggs and brood, as they occupy a higher rank in their proper class.

284. The development of the embryo does not always take place immediately after the egg is laid. A considerable time even may elapse before it commences. Thus, the first 
eggs laid by the hen do not begin to develop until the whole number which is to constitute the brood is deposited. The eggs of the butterfly and of most insects are laid in autumn, and remain in the same condition until the following spring. During this time the principle of life in the egg is not extinct, but is simply inactive, or in a latent state. This tenacity of life is displayed in a still more striking manner in plants. The seeds, which are equivalent to eggs, preserve for years, and even for ages, their power to germinate. Thus, wheat taken from the catacombs of Egypt has been made to sprout and grow in some well-authenti. cated cases.

285. A certain degree of warmth is requisite for the hatching of eggs. Those of birds, especially, demand a uniform temperature, corresponding to the natural heat of the future bird, to be constantly applied for a certain length of time; this is naturally supplied by the body of the parent. In other words, incubation is necessary for their growtl. Incubation is not a purely vital phenomenon, but may be readily imitated by artificial means. Some birds of warm climates dispense with this task; for example, the ostrich often contents herself with depositing her eggs in the sand of the desert, where they are hatched of themselves. In like manner, the eggs of most birds may be hatched at will, by maintaining them at the proper temperature. Before entering into the details of embryonic transformations, a few words are necessary respecting the composition of the egg. 286. Composition of the Egg. - The egg is composed of several substances, varying in structure, as well as in appearance. Thus, in a a new laid hen's egg (Fig. 101), we have first a calcareous shell; then an albuminous substance, the white; within this the yolk; and before it was laid, there was in the midst of the latter a minute vesicle, the germinative vesicle (Fig. 99, g), containing a still smaller 
one, the germinative dot $(d)$. These different parts are not equally important in a physio-

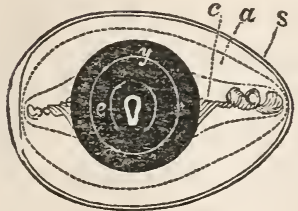

Fig. 101. logical point of view. The most conspicuous of them, namely, the shell and the white, are not essential parts, and therefore are often wanting; while the yolk, the germinative vesicle, and the germinative dot are found in the eggs of all animals, and out of these, and these only, the germ is formed, in the position shown by Fig. 101, e.

28\%. The vitellus or yolk (Fig. 101,y) is the most essential part of the egg. It is a liquid of variable consistence, sometimes opaque, as in the egg of birds, sometimes transparent and colorless, as in the eggs of some fishes and mollusks. On examination under the microscope, it appears to be composed of an accumulation of granules. The yolk is surrounded by a very thin skin, the vitelline membrane (Fig. $98, v)$. In some insects, when the albumen is wanting, this membrane forms the exterior covering of the egg; in such cases it is generally of a firm consistence, and sometimes even horny.

288. 'The germinative vesicle (Fig. 98, $g$ ) is a cell of extreme delicacy, situated, in the fresh egg, near the middle of the yolk, and easily recognized by the greater transparency of its contents when the yolk is opaque, as in the hen's egg, or by its outline, when the yolk itself is transparent, as in the fish. It contains one or more little spots, somewhat opaque, appearing as small dots, the germinal dots $(d)$. On closer examination these dots are themselves found to contain smaller nucleoli.

289. The albumen, or white of the egg, (Fig. 101,a), is a viscous substance, generally colorless, but becoming white on coagulation. Voluminous as it is in bird's eggs, it neverthe- 
less plays but a secondary part in the history of their development. It is not formed in the ovary, like the yolk, but is secreted by the oviduct, and deposited around the yolk during the passage of the egg through that canal. It consists of several layers, one of which, the chalaza $(c)$, is twisted. On this account, the eggs of those animals in which the oviduct is wanting are generally without the albumen. Like the yolk, the albumen is surrounded by a single or double membrane, the shell membrane, which, in birds and some reptiles and mollusks, is again protected by a calcareous covering, forming a true shell $(s)$. In most cases, however, this envelop continues membranous, particularly in the eggs of the mollusks, most crustaceans and fishes, salamanders, frogs, \&c. Sometimes it is horny, as in the sharks and skates.

\section{SECTION II.}

\section{DEVELOPAENT OF THE YOUNG WITHIN THE EGG.}

290. The formation and development of the young animal within the egg is a most mysterious phenomenon. From a hen's egg, for example, surrounded by a shell and composed, as we have seen (Fig. 101), of the albumen and the yolk, with a little vesicle in the middle, there is produced, at the end of a certain time, a living animal, composed in part of totally different elements; endowed with organs perfectly adapted to the exercise of all the functions of animal and vegetative life, having a pulsating heart, intestines fitted for digestion, organs of sense for the reception of outward impressions, and having, moreover, the faculty of performing voluntary motions, and of experiencing pain and pleasure. 
To learn how this takes place is certainly sufficient to excite the curiosity of every intelligent person.

291. By opening eggs which have been subjected to incubation for different periods of time, we may easily satisfy ourselves that these changes are effected gradually. We thus find that those which have undergone but a short incubation exhibit only faint indications of the future animal; while those which have been sat upon for a longer period include an embryo chicken proportionally more developed. Modern researches have taught us that these gradual changes, although complicated, and at first sight so mysterious, follow laws which are uniformly the same in each department of the Animal Kingdom.

292. The study of these changes constitutes that peculiar branch of Physiology called Enbryology ; and as there are distinctions of the four great departments of the Animal Kingdom perceptible at an early stage of embryonic life, quite as positive as those found at maturity; as also, the phases of embryonic development indicate still other grounds for natural classification, we propose to give the outlines of Embryology, so far as it is concerned in zoölogical arrangement.

293. In order to understand the successive steps of embryonic development, we must bear in mind that the whole animal body is composed of tissues, whose elements are cells (39). These cells are much diversified in the full grown animal; but, at the commencement of embryonic life, the whole embryo is composed of minute cells of nearly the same form and consistence. These cells originate within the yolk, and constantly undergo new changes under the influence of life. New cells are formed, while others disappear, or are modified so as to become blood, bones, muscles, nerves, \&c.

294. We may form some idea of this singular process, by noticing how, in the healing of a wound, new substance 
and a new skin is supplied by the transformations of the blood. Similar changes take place in the embryo, during its early life ; only, instead of being limited to a part of the body, they pervade the whole animal.

295. The series of changes commences, in most animals, soon after the eggs are laid; in others, the birds for example, they are delayed till the commencement of incubation. The yolk, which before was a mass of uniform appearance, now begins to present a diversified aspect. Some portions become more opaque, and others more transparent; and the germinal vesicle, which was in the midst of the yolk, is seen at the upper part of it, where the germ is to be formed. These early changes are accompanied, in some animals, by a rotation of the yolk inside of the egg, as may be distinctly seen in the eggs of some of the mollusks, especially of the snails.

296. At the same time the yolk divides itself into two spheres, which are again regularly subdivided into two more, and so on, till the whole yolk assumes the form of a mulberry, each of the spheres composing the mulberry having in its interior a transparent vesicle. In many animals, however, these divisions or fissures are only temporary, and seem to be merely a peculiar mode of transformation common to all invertebrate animals, and also to fishes, naked reptiles, and mammals, but not yet observed in birds and the higher reptiles.*

297. In the next place, there appears upon the yolk of the Vertebrates a disc-shaped protuberance, composed of little cells, which has been variously designated under the names of germinative disc, proligerous disc, blastoderma, germinal membrane, or simply the germ. This disc gradually extends itself, until it embraces the whole, or nearly the whole, of the yolk.

* In the Birds and higher reptiles we find, instead, a peculiar organ called cicatricula, which may, nevertheless, have been formed by a similar pro. cess before the egg was laid. 
298. At this early epoch, namely, a few days, and, in

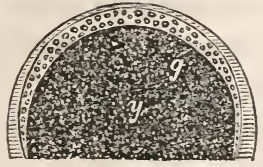

Fig. 102.

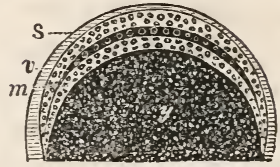

Fig. 103. some animals, a few hours after development has begun, the germ consists of a single layer composed of very minute cells, all of them having the same appearance and the same form (Fig. 102, g). But soon after, as the germ increases in thickness, several layers may be discerned (Fig. 103), which become more and more distinct.

299. The upper layer $(s)$, in which are subsequently formed the organs of animal life, namely, the nervous system, the muscles, the skeleton, \&c. (59), has received the name of serous or nervous layer. The lower layer $(m)$, which gives origin to the organs of vegetative life, and especially to the intestines, is called the mucous or vegetative layer, and is generally composed of larger cells than those of the upper or serous layer. Finally, in the embryos of vertebrated animals, there is a third layer $(v)$, interposed between the two others, and giving rise to the organs of circulation and to the blood; whence it has been called blood layer, or vascular layer.

300 . Even before this epoch, we can generally distinguish, from the manner in which the germ is modified, to what department of the animal kingdom the individual is to belong. Thus in the Articulata, the germ is divided into

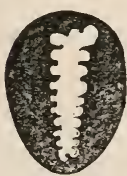

Fig. 104.

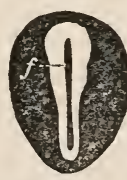

Fig. 105. segments, indicating the rings of the body, as for example, in the embryo of the crabs (Fig. 104). The germ of the vertebrated animals, on the other hand, displays a longitudinal the future back-bone is to occupy (Fig. 105). 
301. The development of this furrow is highly important in indicating the plan of structure of vertebrated animals in general, as will be shown by the following figures, which represent vertical sections of the embryo at different epochs.* At first the furrow (Fig. 106, $b$ ), is very shal-

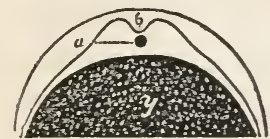

Fig. 106.

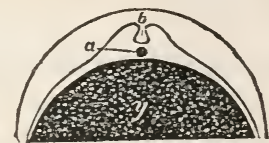

Fig. 107.

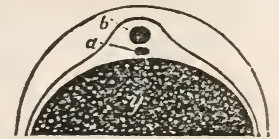

Fig. 108.

low, and a little transparent narrow band appears under it, called the primitive stripe $(a)$. The walls of the furrow consist of two raised edges formed by a swelling of the germ along both sides of the primitive stripe. Gradually, these walls grow higher, and we perceive that their summits have a tendency to approach each other, as seen in Fig. 107; at last they meet and unite completely, so that the furrow is now changed into a closed canal (Fig. $108, b)$. This canal is soon filled with a peculiar liquid from which the spinal marrow and brain are to be formed.

302. The primitive stripe is gradually obliterated by a peculiar organ of a cartilaginous nature, the dorsal cord, formed in the lower wall of the dorsal canal. This is found in the embryos of all vertebrates, and is the representative of the back-bone. In the mean time, the margin of the germ gradually extends farther and farther over the yolk, so as finally to enclose it entirely, and form another cavity in which the organs of vegetative life are to be developed. Thus the embryo of vertebrates has two cavities, namely, a superior, very small one, for the nervous system, and an inferior, much larger one, for the intestines.

* Only the cut edge of the embryo is supposed to be seen, whereas, if viewed from above, it would be seen to extend over the yolk in every direction; so that the furrow at $b$, of Fig. 106, would be seen as in Fig. 105. 
303. In all classes of the Animal Kingdom, the embryo.

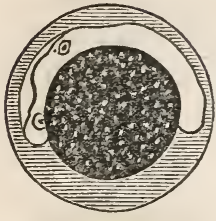

Fig. 109. rests upon the yolk, and covers it like a cap. But the direction by which its edges approach each other, and unite to form the cavity of the body, is very unlike in different animals; and these several modes are of high importance in classification. Among the Vertebrates, the embryo lies with its face or ventral surface towards the yolk (Fig. 109), and thus the suture, or line at which the edges of the germ unite to enclose the yolk, and which in the mammals forms the navel, is found at the belly. Another suture is found along the back, arising from the actual folding upwards of the upper surface of the germ, to form the dorsal cavity.

304. The embryo in the Articulata, on the contrary, lies with its back upon the yolk, as seen in the following figure, which represents an embryo of Podurella; consequently the yolk enters the body from the opposite direction; and the suture, which in the vertebrates is found on the belly, is here found on the back. In the Mollusks there is this peculiarity, that the whole yolk is changed into the substance

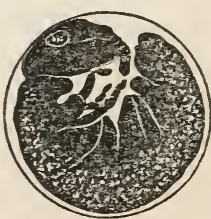

Fig. 110 . of the embryo; whilst in Vertebrates, a part of it is reserved, till a later period, to be used as food by the embryo. Among Radiata the germ is formed around the yolk, and seems to surround the whole of it, from the first.

305. Among the vertebrated animals, the development of the embryo may be best observed in the eggs of fishes. Being transparent, they do not require to be cut open, and, by sufficient caution, we may observe the whole series of changes upon the same individual, and thus make sure of the succession in which the organs appear; whereas, if we employ the eggs of birds, which are opaque, we are obliged to sacrifice an egg for each observation. 
306. To illustrate these general views as to the development of the embryo, we will briefly describe the principal phases, as they have been observed in the White-fish of Europe, which belongs to the salmon family. The following magnified figures will illustrate this development, and show the successive appearance of the different organs.

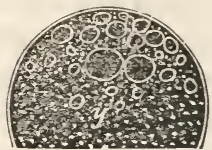

Fig. 111 .

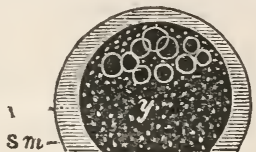

Fig. 112.

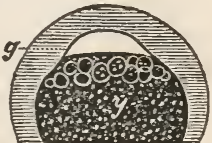

Fig. 113.

30\%. The egg when laid (Fig. 111) is spherical, about the size of a small pea, and nearly transparent. It has no albumen, and the shell-membrane is so closely attached to the membrane of the yolk, that they cannot be distinguished. Oil-like globules are scattered through the mass of the yolk, or grouped into a sort of disc, under which lies the germinative vesicle. The first change in such an egg occurs a few hours after it has been laid, when the shell-membrane separates from the yolk-membrane, in consequence of the absorption of a quantity of water (Fig. 112). Between the shell-membrane $(\mathrm{sm})$, and the yolk $(y)$, there is now a considerable transparent space, which corresponds, in some respects, to the albumen found in the eggs of birds.

308. Soon afterwards we see, in the midst of the oil-like

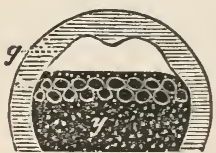

Fig. 114 .

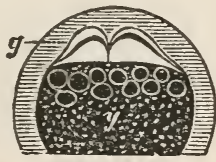

Fig. 115.

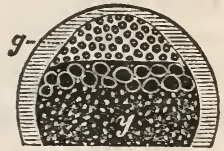

F'ig. 116.

globules, a swelling in the shape of a transparent vesicle (Fig. 113, g), composed of very delicate cells. This is the first indication of the germ. This swelling rapidly enlarges until it envelops a large part of the yolk, when a 
depression is formed in it (Fig. 114). This depression becomes by degrees a deep furrow, and soon after a second furrow appears at right angles with the former, so that the germ now presents four elevations (Fig. 115). The subdivision goes on in this way, during the second and third days, until the germ is divided into numerous little spheres, giving it the appearance of a mulberry (Fig. 116). This appearance, however, does not long continue; at the end of the third day, the fissures again disappear and leave no visible traces. After this, the germ continues to extend as an envelop around the yolk, which it at last entirely encloses.

309. On the tenth day, the first outlines of the embryo begin to appear, and we soon distinguish in it a depression between two little ridges, whose edges are constantly approaching each other until they unite and form a canal (Fig. $117, b)$, as has been before shown. At the same time

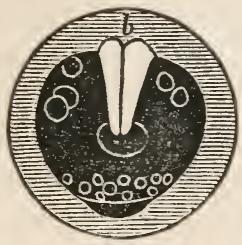

Fig. 117 .

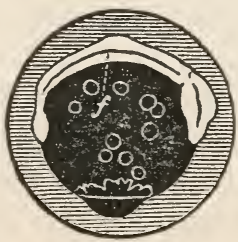

Fig. 118.

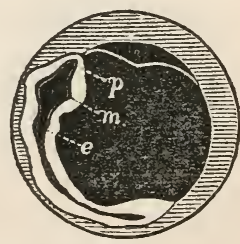

Fig. 119.

an enlargement of one of the extremities is observed. This is the rudiment of the head (Fig. 118), in which may soon be distinguished traces of the three divisions of the brain (Fig. 119), corresponding to the senses of sight $(m)$, hearing $(e)$, and smell $(p)$.

310. Towards the thirteenth day we see, in the place afterwards occupied by the back-bone, a transparent, cartilaginous cord, composed of large cells, on which transverse divisions are successively forming (Figs. 120, 121,c). This is the dorsal cord, an organ which, as we have before seen, 
is common to all embryos of vertebrated animals. It always precedes the formation of the back-bone; and in some fishes, as the sturgeon, this cartilaginous or embryonic state is permanent through life, and no true back-bone is ever formed. Soon after, the first rudiments of the eye appear, being a fold in the external membrane of the germ, in which the crystalline lens (Fig. 121,x) is afterwards formed. At the same time we see at the posterior part of the head an elliptical vesicle, which is the rudiment of the ear.

311. After the seventeenth day, the mucous layer divides into two sheets, the inferior of which becomes the intestine. The heart shows itself about the same time, under the form of a simple cavity (Fig. 121, $h$ ), in the midst of a mass of cells belonging to the middle or vascular layer. As soon as the cavity of the heart is closed in, regular motions of contraction and expansion are perceived, and the globules of blood are seen to rise and fall in conformity with these motions.

312. There is as yet, however, no circulation. It is not until the thirtieth day that its first traces are manifest in the existence of two currents, one running towards the head, the other towards the trunk (Fig. 122), with sim-

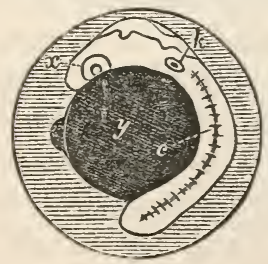

Fig. 120.

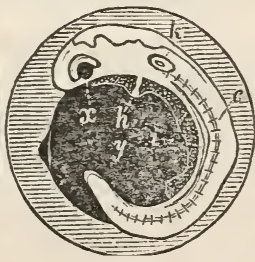

Fig. 121.

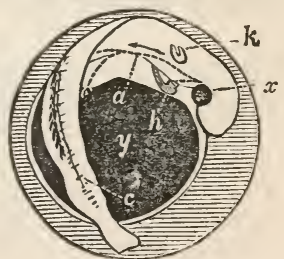

Fig. 122.

ilar returning currents. At this time the liver begins to form. Meanwhile the embryo gradually disengages itself, at both extremities, from its adherence to the yolk; the tail 
becomes free, and the young animal moves it in violent jerks.

313. The embryo, although still enclosed in the egg, now unites all the essential conditions for the exercise of the functions of animal life. It has a brain, an intestine, a pulsating heart and circulating blood, and it moves its tail spontaneously. But the forms of the organs are not yet complete; nor have they yet acquired the precise shape that characterizes the class, the family, the genus and the species. The young White-fish is as yet only a vertebrate animal in general, and except for the fin that surrounds its body, might be taken for the embryo of a frog.

314. Towards the close of the embryonic period, after the fortieth day, the embryo acquires a more proper shape. The head is more completely separated from the yolk, the jaws protrude, and the nostrils approach nearer and nearer to the end of the snout; divisions are formed in the fin which surrounds the body; the anterior extremities, which were indicated only by a small protuberance, assume the shape of fins; and finally, the openings of the gills appear, one after the other, so that we cannot now fail to recognize the type of fishes.

315. In this state, the young white-fish escapes from the

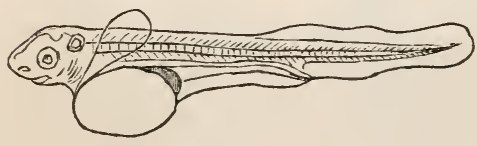

Fig. 123. egg, about the sixtieth day after it is laid (Fig. 123). But its development is still incom. plete. The outlines are yet too indistinct for us to recognize the genus and the species to which the fish belongs; at most we distinguish its order only. The opercula or gill-covers are not formed; the teeth are wanting; the fins have as yet no rays; the mouth is underneath, and it is some time before it as. 
sumes its final position at the most projecting point of the head. The yolk is suspended from the belly, in the form of a large bladder, but it daily diminishes in size, until it is at length completely taken into the animal. The duration of these metamorphoses varies extremely in different fishes ; some accomplish it in the course of a few days, while in others months are required.

$315 a$. In frogs and all the naked reptiles, the development is very similar to that of fishes. It is somewhat different in the scaly reptiles (snakes, lizards and turtles), which have peculiar membranes surrounding and protecting the embryo during its growth. From one of these envelops, the allantois (Fig. 125,a,) is derived their common name of Allantoidian Vertebrates, in opposition to the naked reptiles and fishes, which are called Anallantoïdian.

315 b. The Allantoidian Vertebrates differ among themselves in several essential peculiarities. Among Birds, as well as in the scaly reptiles, we find at a certain epoch, when the embryo is already disengaging itself from the yolk, a fold rising around the body from the upper layer of the germ, so as to present, in a longitudinal section, two prominent walls (Fig. 124,

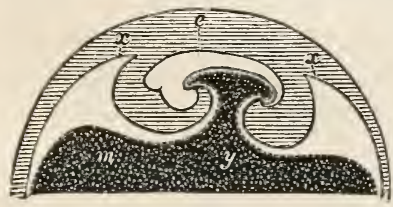

Fig. 124.

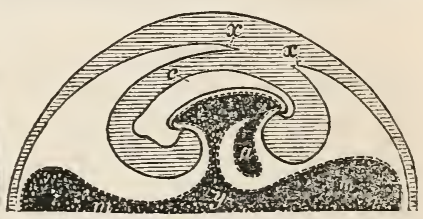

Fig. 125.

$x x$ ). These walls, converging from all sides upwards, rise gradually till they unite above the middle of the back (Fig. 125). When the junction is effected, which in the hen's egg takes place in the course of the fourth day, a cavity is formed between the back of the embryo (Fig. 126,e) and the new membrane, whose walls are called the amnios. This cavity becomes filled with a peculiar liquid, the amniotic water.

315 c. Soon after the embryo becomes enclosed in the amnios, a shallow pouch forms from the nucous layer below the posterior extremity of the embryo, between the tail and the vitelline mass. This pouch, at first a simple little sinus (Fig. 125,a), grows larger and larger, till it forms an extensive sac, bending backwards and upwards, so as to 
316. As a general fact, it should be further stated, that the envelops which protect the egg, and also the embryo, are the more numerous and complicated as animals belong to a higher class, and produce a smaller number of eggs. This is particularly evident when contrasting the innumerable eggs of fishes, discharged almost without protection into the water, with the well-protected eggs of birds, and still more with the growth of young mammals within the body of the mother.

separate completely the two plates of the amnios (Fig. 126, a), and finally

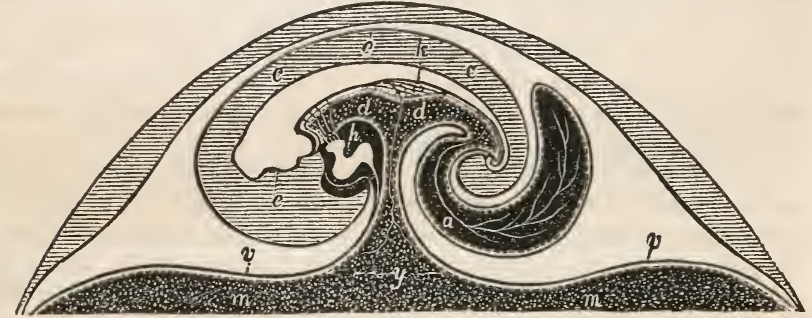

Fig. 126.

to enclose the embryo, with the amnios, in another large sac. The tubular part of this sac, which is nearest the embryo, is at last transformed into the urinary bladder. The heart $(h)$ is already very large, with minute arterial threads passing off from it.

$315 \mathrm{~d}$. The development of mammals exhihits the following peculiarities. The egg is exceedingly minute, almost microscopical, although composed of the same essential elements as those of the lower animals 'The vitelline membrane, called chorion, in this class of animals, is coinparatively thicker (Fig. 127, v, ) always soft, surrounded by peculiar

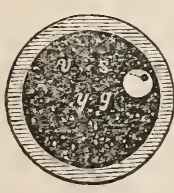

Fig. 127 .

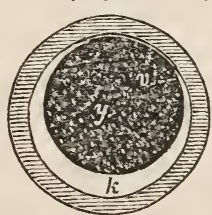

Fig. 128. cells, being a kind of albumen. The chorion soon grows proportionally larger than the vitelline sphere itself (Fig. 12s, y), so as no longer to invest it directly, being separated from it by an empty space $(k)$. The germ is formed in the same position as in the other classes of Vertebrates, namely, at the top of the vitellus (Fig. 129); and here also two layers may be distinguished, the upper or serous layer $(s)$, and the lower or 
31\%. But neither in fishes, nor in reptiles, nor in birds, does the vitelline membrane, or any other envelop of the egg, take any part in the growth of the embryo; while on the contrary, in the mammals, the chorion, which corresponds to the vitelline membrane, is vivified, and finally becomes attached to the maternal body, thus establishing a direct connection between the young and the mother; a connection which is again renewed in another mode, after birth, by the process of nursing her milk.

mucous layer $(m)$. As it gradually enlarges, the surface of the chorion becomes covered with little fringes, which, at a later epoch, will be attached to the mother by means of similar fringes arising from the walls of the matrix, or organ which contains the embryo.

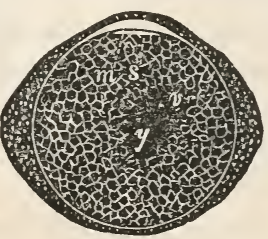

Fig. 129.

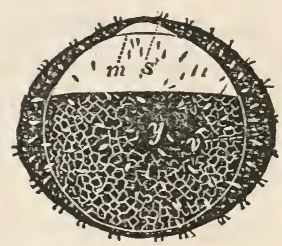

Fig. 130.

$315 e$. The embryo itself undergoes, within the chorion, changes similar to those described in the hirds; its body and its organs are formed in the same way; an amnios encloses it, and an allantois grows out of the lower extremity of the little animal. As soon as the allantois has surrounded the embryo, its blood vessels become more and more numerous, so as to

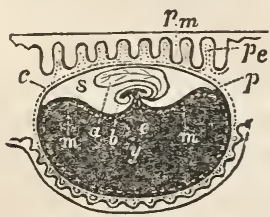

Fig. 131 . extend into the fringes of the chorion (Fig. 131, $p e)$, while, on the other hand, similar vessels from the mother extend into the corresponding fringes of the matrix $(p m)$, but without directly communicating with those of the chorion. These two sorts of fringes soon become interwoven so as to form an intricate organ filled with blood, called the placenta, to which the embryo remains suspended until birth.

$315 f$. From the fact above stated, it is clear that there are three modifications of embryonic development among vertebrated animals, namely, that of fishes and naked reptiles, that of scaly reptiles and hirds, and that of the mammals, which display a gradation of more and more complicated adaptation. In fishes and the naked reptiles, the germ simply encloses the yolk, and the embryo rises and grows from its upper part. In the scaly reptiles and birds there is besides, an amnios arising from the peripheric part of the embryo, and an allantois growing out of the lower cavity, both enclosing and protecting the germ. 


\section{SECTION III.}

ZOÖLOGICAL IMPORTANCE OF EMBRYOLOGY.

318. As a general result of the observations which have been made, up to this time, on the embryology of the various classes of the Animal Kingdom, especially of the vertebrates, it may be said, that the organs of the body are successively formed in the order of their organic importance, the most essential being always the earliest to appear. In consequence of this law, the organs of vegetative life, the intestines and their appurtenances, make their appearance subsequently to those of animal life, such as the nervous system, the skeleton, \&c.; and these, in turn, are preceded by the more general phenomena belonging to the animal as such.

319. Thus we have seen that, in the fish, the firstchanges relate to the formation and furrowing of the germ, which is a character common to all classes of animals. It is not until a subsequent period that we trace the dorsal groove, which indicates that the forming animal will have a double cavity, and consequently belong to the division of the vertebrates; an indication afterwards fully confirmed by the successive appearance of the brain and the organs of sense. Later still, the intestine is formed, the limbs become evident, and the organs of respiration acquire their definite form, thus enabling us to distinguish with certainty the class to which the animal belongs. Finally, after the egg is hatched, the peculiarities of the teeth, and the shape of the extremities mark the genus and species.

320. Hence, the embryos of different animals resem- 
ble each other more strongly in proportion as we examine them at an earlier period. We have already stated that, during almost the whole period of embryonic life, the young fish and the young frog scarcely differ at all : so it is also with the young snake compared with the embryo bird. The embryo of the crab, again, is scarcely to be distinguished from that of the insect; and if we go still farther back in the history of development, we come to a period when no appreciable difference whatever is to be discovered between the embryos of the various departments. The embryo of the snail, when the germ begins to show itself, is nearly the same as that of a fish or a crab. All that can be predicted at this period is, that the germ which is unfolding itself will become an animal; the class and the group are not yet indicated.

321. After this account of the history of the development of the egg, the importance of Embryology to the study of Zoölogy cannot be questioned. For evidently, if the formation of the organs in the embryo takes place in an order corresponding to their importance, this succession must of itself furnish a criterion of their relative value in classification. Thus, those peculiarities that first appear should be considered of higher value than those that appear later. In this respect, the division of the Animal Kingdom into four types, the Vertebrates, the Articulates, the Mollusks, and the Radiates, corresponds perfectly with the gradations displayed by Embryology.

322. This classification, as has been already shown (61), is founded essentially on the organs of animal life, the nervous system and the parts belonging thereto, as found in the perfect animal. Now, it results from the above account, that in most animals the organs of animal life are precisely those that are earliest formed in the embryo; whereas those of vegetative life, on which is founded the division into 
classes, orders, and families, such as the heart, the respiratory apparatus, and the jaws, are not distinctly formed until afterwards. Therefore a classification, to be true and natural, must accord with the succession of organs in the embryonic development. This coincidence, while it corroborates the anatomical principles of Cuvier's classification of the Animal Kingdom, furnishes us with a new proof that there is a general plan displayed in every kind of development.

323. Combining these two points of view, that of Embryology and that of Anatomy, the four divisions of the Animal Kingdom may be represented by the four figures which are to be found, at the centre of the diagram, at the beginning of the volume.

324. The type of Vertebrates, having two cavities, one above the other, the former destined to receive the nervous system, and the latter, which is of a larger size, for the intestines, is represented by a double crescent united at the centre, and closing above, as well as below.

325. The type of Articulata, having but one cavity, and growing from below upwards, (the nervous system forming a series of ganglions, placed below the intestine,) is represented by a single crescent, with the horns directed upwards.

326. The type of Mollusks having also but one cavity, the nervous system being a simple ring around the œsophagus, with threads going off from it, is represented by a single crescent with the horns turned down.

327. Finally, the type of Radiata, the radiating form of which is seen even in the youngest individuals, is represented by a star. 


\section{CHAPTER E L E V E N TH.}

PECULIAR MIODES OF REPRODUCTION.

\section{SECTION I.}

\section{GEMMIPAROUS AND FISSIPAROUS REPRODUCTION.}

328. WE have shown in the preceding chapter, that ovulation, or the development of the embryo from the egg, is common to all classes of animals, and must be considered as the great law for the reproduction of species. Two other modes of reproduction, applying to only a limited number of animals, remain to be mentioned, namely, gemmiparous reproduction, or multiplication by means of buds, and fissiparous reproduction, or propagation by division; and also some still more extraordinary modifications yet involved in much obscurity.

329. Reproduction by buds occurs among the polyps and some of the infusoria. On the stalk, or even on the body of the Hydra, and of many Infusoria (Fig. 132), there are formed buds, like those of plants. On close examination they are found to contain young animals, at first very imperfectly formed, and communicating at the base with the parent body, from which they derive their nourishment. By degrees the

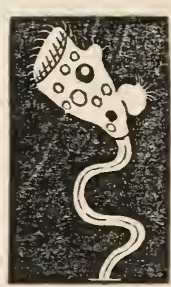

Fig. 132 . animal is developed; in most cases, the tube by which it is 
attached to the parent withers away, the animal is detached and becomes independent. Others remain through life attached to the parent stalk, and in this respect, present a more striking analogy to the buds of plants. But in the polyps, as in trees, budding is only an accessary mode of reproduction, which presupposes a trunk already existing, originally the product of ovulation.

330. Reproduction by division, or fissiparous reproduction, is still more extraordinary; it takes place only in polyps and some infusoria. A cleft or fission at some part of the body takes place, very slight at first, but constantly increasing in

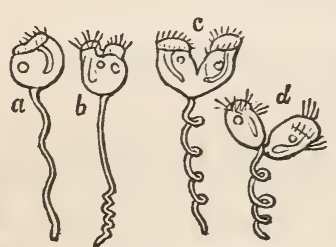

Fig. 133. depth, so as to become a deep furrow, in the same way as takes place in the yolk, at the beginning of embryonic development; at the same time the organs are divided and become double, and thus two individuals are formed of one, so similar to each other that it is impossible to say which is the parent and which the offspring. The division takes place sometimes vertically, as for example, in the Vorticella (Fig. 133) and in some
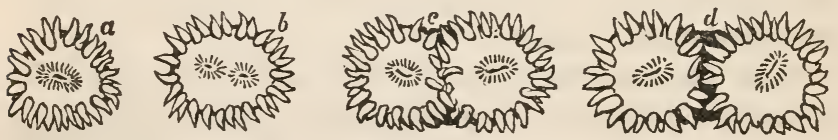

Fig. 134.

Polyps (Fig. 134), and sometimes transversely. In some Infusoria, the Paramecia, for instance, this division occurs as often as three or four times in a day.

331. In consequence of the same faculty, many animals are able to reproduce various parts of their bodies when accidentally lost. It is well known that crabs and spiders, on losing a limb, acquire a new one. The same 
happens with the arms of the star-fishes. 'The tail of a lizard is also readily reproduced. Salamanders even pos. sess the faculty of reproducing parts of the head, including the eye with all its complicated structure. Something similar takes place in our own bodies, when a new skin is formed over a wound, or when a broken bone is reunited.

332. In some of the lower animals, this power of reparation is carried much farther, and applies to the whole body, so as closely to imitate fissiparous reproduction. If an earth-worm be divided into several pieces, the injury is soon repaired; and if we cut in fragments a fresh-water polyp, each one speedily becomes a perfect animal. Something like this reparative faculty is seen in the vegetable kingdom, as well as the animal. A willow branch, planted in a moist soil, throws out roots below and branches above; and thus, after a time, assumes the shape of a perfect tree.

333. These various modes of reproduction do not exclude each other. All animals which propagate by gemmiparous or fissiparous reproduction also lay eggs. Thus the fresh-water polyps (Hydra) propagate both by eggs and by buds. In Vorticella, according to Ehrenberg, all three modes are found; it is propagated by eggs, by buds, and by division. Ovulation, however, is the mode of reproduction that most generally prevails; the others, and also alternate reproduction, are additional means employed by nature to secure the perpetuation of the species.

\section{SECTION II.}

ALTERNATE AND EQUIVOCAL REPRODUCTION.

334. It is a matter of common observation, that individuals of the same species have the same general appear- 
ance, by which their peculiar organization is indicated. The transmission of these characteristics, from one generation to the next, is justly considered as one of the great laws of the Animal and Vegetable Kingdoms. It is indeed one of the points on which the definition of species is founded.

335. But it does not follow that animals must resemble their parents in every condition, and at every epoch of their existence. On the contrary, as we have seen, this resemblance is very faint in most species, at birth, and some of them, such as the butterfly and the frog, undergo complete metamorphoses, before attaining their final shape. Nevertheless, we do not hesitate to refer the tadpole and the frog to the same species; and so with the caterpillar and the butterfly, because we know that it is the same individual observed in different stages of development.

336. There is also another series of cases in which the offspring not only do not resemble the parent at birth, but moreover remain different during their whole life, so that their relationship is not apparent until a succeeding generation. The son resembles not the father, but the grandfather; and in some cases the resemblance reappears only at the fourth or fifth generation, and even later. This singular mode of propagation has received the name of alternate reproduction. The phenomena attending it have been of late the object of numerous scientific researches, which are the more deserving of our attention, as they furnish a solution to several problems alike interesting in a zoölogical and in a philosophical point of view.

337. Alternate reproduction was first observed among the Salpæ. These are marine mollusks, without shells, belonging to the family Tunicata. They are distinguished by the curious peculiarity of being united together in considerable numbers, the mouth $(m)$ being free, so as to 
form long chains which float in the sea (Fig. 135). The

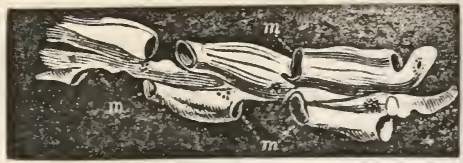

ilg. 135.

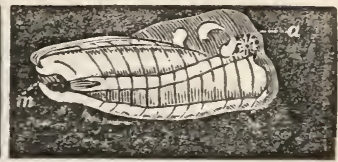

H'ig. 136.

individuals thus joined in floating colonies produce eggs; but in each individual there is generally but one egg formed, which is developed in the body of the parent, and from which is hatched a little mollusk (Fig. 136), which remains solitary, and differs in many respects from the parent. This little animal, on the other hand, does not produce eggs, but propagates by a kind of budding which gives rise to chains seen within the body of the parent $(a)$, and these again bring forth solitary individuals, \&.c.

338. In some parasitic worms, the alternate reproduction is accompanied by still more extraordinary phenomena, as is shown by the late discoveries of the Danish naturalist, Steenstrup. It is well known that the stagnant pools in which fresh-water shells (particularly the Lymnea and the Paludina) are found, contain an innumerable variety of minute animals of various kinds. Among these is a small

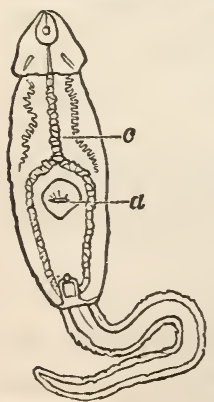

Fig. 137 . worm, known to naturalists under the name of Cercaria (Fig. 137). When examined with a lens, it looks much like a tadpole, with a long tail, a triangular head, and a large sucker $(a)$ in the middle of the body. Various viscera appear within, and among others a very distinct forked cord (c), which embraces the sucker, and which is thought to be the liver.

339. If we watch these worms, which always abound in the neighborhood of the shells mentioned, 
we find them after a while attaching themselves, by means of their sucker, to the body of the mollusks. When fixed they soon undergo considerable alteration. The tail, which is now useless, falls off, and the animal surrounds itself with a mucous substance, in which it remains nearly motionless, like the caterpillar on its transformation into the Pupa. If we remove the little animal from its retreat we find it to be no longer a Cercaria, but an intestinal worm called Distoma, having the shape of Fig. 138, with two suckers. The Distoma, therefore, is only a particular state of

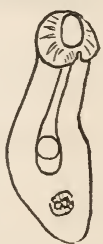
the Cercaria, or rather the Cercaria is only the Fig. 138. larva of the Distoma.

340. What now is the origin of the Cercaria? The following are the results of the latest researches on this point. At certain periods of the year, we find in the viscera of the Lymnea (one of the most common fresh-water mollusks) a quantity of little worms of an elongated form, with a well

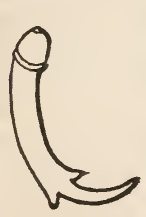
marked head, and two posterior projections like limbs (Fig. 139). On examining these worms attentively under the microscope we discover that the cavity of their body is filled by a mass of other little worms, which a practised eye easily recognizes as young Cercaria,

Fig. 139. the tail and the other characteristic bifurcated organ (a) within it being distinctly visible (Fig. 140). These little embryos increase in size, distending the worm which contains them, and

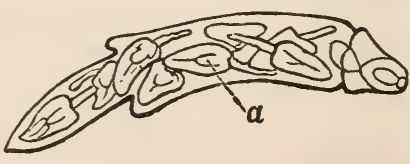

Fig. 140 . which seemingly has no other office than to protect and forward the development of the young Cercaria. It is, as it were, their living envelop. On this account, it has been called the nurse. 
341. When they have reached a certain size, the young Cercariæ leave the body of the nurse, and move freely in the abdominal cavity of the mollusks, or escape from it into the water to fix themselves, in their turn, to the body of another mollusk, and begin their transformations anew.

342. But this is not the end of the series. The nurses of

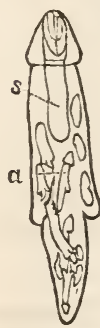
the Cercaria are themselves the offspring of little worms of yet another kind. At certain seasons, we find in the viscera of the Lymnea, worms somewhat like the nurses of the Cercaria in shape (Fig. 141), but rather longer, more slender, and having a much more elongated stomach $(s)$. These worms contain, in the hinder part of the body, little embryos $(a)$, which are the Fig. 141. young nurses of Figures 139, 140. This generation has received the name of grand-nurses.

343. Supposing these grand-nurses to be the immediate offspring of the Distoma (Fig. 138), as is probable, we have thus a quadruple series of generation. Four generations and one metamorphosis are required to evolve the perfect animal; in other words, the parent finds no resemblance to himself in any of his progeny, until he arrives at the great-grandson.

344. Among the Aphides, or plant-lice, the number of generations is still greater. The first generation, which is produced from eggs, soon undergoes metamorphoses, and then gives birth to a second generation, which is followed by a third and so on; so that it is sometimes the eighth or ninth generation before the perfect animal appears as male and female, the sexes being then for the first time distinct, and the male provided with wings. The female lays eggs which are hatched the following year, to repeat the same succession. Each generation is an additional step towards the perfect state; and as each member of the suc- 
cession is an incomplete animal, we cannot better explain their office, than by considering them analogous to the larvæ of the Cercaria, that is, as nurses.*

345. The development of the Medusæ is not less instructive. According to the observations of M. Sars, a Norwegian naturalist, the Medusa brings forth living young, which, after having burst the covering of the egg, swim about freely for some time in the body of the mother. When born, these animals have no resemblance whatever to the perfect Medusa. They are little cylindrical bodies (Fig. $142, a)$, much resembling infusoria, and like them covered with fine cilia, by means of which they swim with much activity.

346. After swimming about freely in the water for some days, the little animal fixes itself by one extremity (Fig. $142, e)$. At the opposite extremity a depression is gradu-

* There is a certain analogy between the larvæ of the plant-louse (Aphis) and the neuters of the working ants and bees. This analogy has given rise to various speculations, and, among others, to the following theory, which is not without interest. The end and aim of all alternate generation, it is said, is to favor the development of the species in its progress towards the perfect state. Among the plant-lice, as among all the nurses, this end is accomplished unconsciously, by means of the body of the nurse. Now a similar end is accomplished by the working ants and bees, only, instead of being performed as an organic function, it is turned into an outward activity, which makes them instinctively watch over the new generation, and nurse and take care of it. It is no longer the body of the nurse, but its instincts, which hecome the instrument of the development. This seems to receive confirmation from the fact that the working bees, like the nurses of the plant-lice, are barren females. 'The attributes of their sex, in both, seem to consist only in their solicitude for the welfare of the new generation, of which they are the natural guardians, but not the parents. The task of bringing forth young is confided to other individuals, to the queen among the bees, and to the female of the last generation among the plant-lice. Thus the barrenness of the working bees, which seems an anomaly as long as we consider them complete animals, receives a very natural explanation so soon as we look upon them merely as nurses. 
ally formed, the four corners $(b, f)$ become elongated, and by degrees are transformed into tentacles $(c)$. These

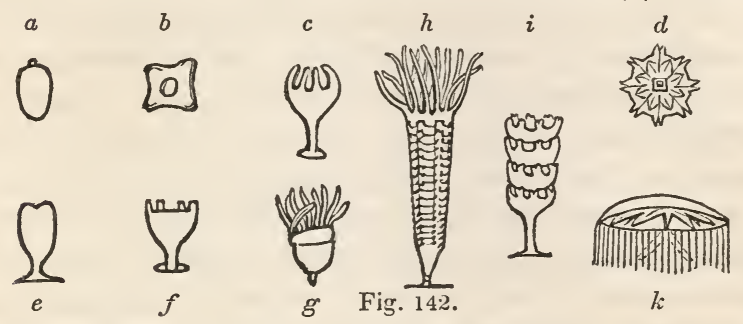

tentacles rapidly multiply, until the whole of the upper margin is covered with them $(g)$. Then transverse wrinkles are seen on the body at regular distances, appearing first above and extending downwards. These wrinkles, which are at first very slight, grow deeper and deeper, and at the same time, the edge of each segment begins to be serrated, so that the animal presents the appearance of a pine cone, surmounted by a tuft of tentacles $(h)$; whence the name of Strobila, which was originally given to it, before it was known to be only a transient state of the jelly-fish. The separation constantly goes on, until at last the divisions are united by only a very slender axis, and resemble a pile of cups placed within each other $(i)$. The divisions are now ready for separation; the upper ring first disengages itself, and then the others in succession.* Each segment $(d)$ then continues its development by itself, until it becomes a complete Medusa $(k)$; while, according to recent researches, the basis or stalk remains and produces a new colony.

347. It is thus, by a series of metamorphoses, that the little animal which, on leaving the egg, has the form of the

* These free segments have been described as peculiar animals, under the name of Ephyra. 
Infusoria, passes in succession through all the phases we have described. But the remarkable point in these metamorphoses is, that what was at first a single individual is thus transformed, by tranverse division, into a number of entirely different animals, which is not the case in ordinary metamorphoses. Moreover, the upper segment does not accompany the others in their development. Its office seems to be accomplished so soon as the other segments begin to be independent of it ; being intended merely to favor their development, by securing and preparing the substances necessary to their growth. In this respect it resembles the nurse of the Cercaria.

348. The Polyps present phenomena no less numerous and strange. The Campanularia has a branching, plantlike form, with little cup-shaped cells on the ends and in the axils of the branches, each of which contains a little animal.

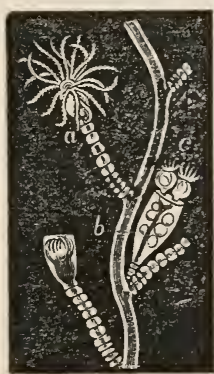

rig. 143. These cups have not all the same organization. Those at the extremity of the branches $(a)$, and which appear first, are furnished with long tentacles, wherewith they seize their food (Fig. 143). Those in the axils of the branches, and which appear late, are females $(b)$, and have no such tentacles. Inside of the latter, little spherical bodies are found, each having several spots in the middle; these are the eggs. Finally, there is a third form, different from the two preceding, produced by budding from the female polyp, to which it in some sort belongs $(c)$. It is within this third sort that the eggs arrive, after having remained some time within the female. Their office seems to be to complete the incubation, for it is always within them that the eggs are hatched.

349. The little animal, on becoming free, has not the 
slightest resemblance to the adult polyp. As in the young Medusa, the body is cylindrical, covered with delicate cilia. After having remained free for some time, the young polyp fixes itself in a flattened form. By degrees a little swelling rises at the centre which elongates, and at last forms a stalk. This stalk ramifies, and we soon recog- Fig. 144. nize in it the polyp of figure 143, with the three kinds of buds, which we may consider as three distinct forms of the same animal.

350. The development of the Campanularia presents, in some respects, an analogy with what takes place in the reproduction of plants, and especially of trees. They should be considered as groups of individuals, and not as single individuals. The seed, which corresponds to the embryo of the Polyp, puts forth a little stalk. This stalk soon ramifies by gemmiparous reproduction, that is, by throwing out buds which become branches. But ovulation, or reproduction by means of seeds, does not take place until an advanced period, and requires that the tree should have attained a considerable growth. It then produces flowers with pistils and stamens, that is, males and females, which are commonly united in one flower, but which in some instances are separated, as in the hickories and elders.*

* Several plants are endowed with organs similar to the third form of the Polyps, as we see it in the Campanularia; for example, the liverwort (Marchantia polymorpha), which has at the base of the cup a little receptacle, from the bottom of which little disc-like bodies are constantly forming, which, when detached, send out roots, and gradually become complete individuals. Besides that, we find in the Polyps, as in plants, the important peculiarity, that all the individuals are united in a common trunk which is attached to the soil; and that all are intimately dependent on each other, so that they perish if severed from the trunk. And if we compare, in this point of view, the various species in which alternate reproduction has been observed, we find that the progress displayed in each type 


\section{SECTION III.}

\section{CONSEQUENCES OF ALTERNATE REPRODUCTION.}

351. These various examples of alternate reproduction render it evident, that this phenomenon can be no longer considered as an anomaly in Nature; but as the plan for advancing those animals in which it occurs to the highest point of perfection of which they are susceptible. Moreover, it has been noticed among all classes of invertebrated animals; while among the Vertebrates it is as yet unknown. It would seem that the individual life of the lower animals has not force enough to pass continuously, and, as it were, with one stride, through all the phases of its development; but, in order to accomplish this, it must either be born in a new form, as in the case of alternate reproduction, or undergo metamorphoses, which are a sort of second birth.

352. Many analogies may be discovered between alternate reproduction and metamorphosis. They are parallel lines that lead to the same end, namely, the development of the species. Nor is it rare to see them coexisting in the same animal. Thus, in the Cercaria, we have seen an animal produced from a nurse afterwards transformed into a Distoma, by undergoing a regular metamorphosis.

consists precisely in the increasing freedom of the individual in its various forms. At first, we have all the generations united in a common trunk, as in the lower Polyps and in plants ; then in the Medusa and in some of the higher Polyps (the Coryne), the third generation begins to disengage itself. Among some of the intestinal worms (the Distoma), the third generation is enclosed within its nurse, and this in its turu is contained in the body of the grand-nurse, while the complete Distoma lives as a parasitic worm in the body of other animals, or even swims freely about in the larva state, as Cercaria. Finally, in the Plant-lice, all the generations, the nurses as well as the perfect animals, are separate indiriduals. 
353. In each new generation, as in each new metamorphosis, a real progress is made, and the form which results is more perfect than its predecessor. The nurse that produces the Cercaria is manifestly an inferior state, just as the chrysalis is inferior to the butterfly.

354. But there is this essential difference between the metamorphoses of the caterpillar and alternate reproduction, that in the former case, the same individual passes through all the phases of development; whereas, in the latter, the individual disappears, and makes way for another, which carries out what its predecessors had begun. It would give a correct idea of this difference to suppose that the tadpole, instead of being itself transformed into a frog, should die, having first brought forth young frogs; or that the chrysalis should, in the same way, produce young butterflies. In either case, the young would still belong to the same species, but the cycle of development, instead of being accomplished in a single individual, would involve two or more generations.

355. It follows, therefore, that the general practice of deriving the character of a species from the sexual forms alone, namely, the male and the female, is not always satisfactory; since there is a large number of animals whose various phases are represented by distinct individuals, endowed with peculiarities of their own. Thus, while in the stag the species is represented by two individuals only, stag and hind, the Medusa, on the other hand, is represented under the form of three different types of animals; the first is free, like the Infusoria, the second is fixed on a stalk, like a polyp, and the third again is free, consisting in its turn of male and female. In the Distoma also, there are four separate individuals, the grand-nurse, the nurse, the larva or Cercaria, and the Distoma, in which the sexes are not sepa- 
rate. Among the Aphides the number is much greater still.

356. The study of alternate generation, besides making us better acquainted with the organization of animals, greatly simplifies our nomenclature. Thus, in future, instead of enumerating the Distoma and the Cercaria, or the Strobila, the Ephyra and the Medusa, as belonging to different classes and families, only the name originally given to the perfect animal will be retained, and the rest be struck from the pages of Zoölogy, as representing only the transitory phases of the same species.

357. Alternate generation always presupposes several modes of reproduction, of which the primary is invariably by ovulation. Thus, we have seen that the Polyps, the Medusa, the Salpa, \&c., produce eggs, which are generally hatched within the mother. The subsequent generation, on the contrary, is produced in a different manner, as we have shown in the preceding paragraphs; as among the Medusæ, by transverse division; among the Polyps and Salpæ, by buds, \&c.

358. The subsequent generations are, moreover, not to be regarded in the same light as those which first spring directly from eggs. In fact, they are rather phases of development, than generations properly so called; they are either without sex, or females whose sex is imperfectly developed. The nurses of the Distoma, the Medusa, and the Campanularia, are barren, and have none of the attributes of maternity, except that of watching over the development of species, being themselves incapable of producing young.

359. Another result of the above observations is this, that the differences between animals which are produced by alternate generation are less, the earlier the epoch at which we examine them. No two animals can be more unlike, than an adult Medusa (Fig. 31) and an adult Campanularia 
(Fig. 143); they even belong to different classes of the Animal Kingdom, the former being an Acaleph, the latter a Polyp. On the other hand, if we compare them when first hatched from the egg, they appear so much alike that it is with the greatest difficulty they can be distinguished. They are then little Infusoria, without any very distinct shape, and moving with the greatest freedom. The larvæ of certain intestinal worms, though they belong to a different department, have nearly the same form, at one period of their life. Farther still, this resemblance extends to plants. The spores of certain sea-weeds have nearly the same appearance as the young Polyp, or the young Medusa; and what is yet more remarkable, they are also furnished with cilia, and move about in a similar manner. But this is only a transient state. Like the young Campanularia and the young Medusa, the spore of the sea-weed is free for only a short time; soon it becomes fixed, and from that moment the resemblance ceases.

360. Are we to conclude then, from this resemblance of the different types of animals at the outset of life, that there is no real difference between them ; or that the two Kingdoms, the Animal and the Vegetable, actually blend because their germs are similar? On the contrary, we think nothing is better calculated to strengthen the idea of the original separation of the various groups, as distinct and independent types, than the study of their different phases. In fact, a difference so wide as that between the adult Medusa and the adult Campanularia must have existed even in the young; only it does not show itself in a manner to be appreciable by our senses; the character by which they subsequently differ so much, being not yet developed. To deny the reality of natural groups, because of these early resemblances, would be to take the appearance for the reality. It would be the same as saying that the frog and 
the fish are one, because at one stage of embryonic life it is impossible, with the means at our command, to distinguish them.

361. The account we have above given of the development, the metamorphoses and the alternate reproduction of the lower animals, is sufficient to undermine the old theory of Spontaneous Generation, which was proposed to account for the presence of worms in the bodies of animals, for the sudden appearance of myriads of animalcules in stagnant water, and under other circumstances rendering their presence mysterious. We need only to recollect how the

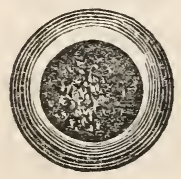

Fig. 145.

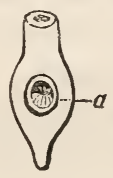

Fig. 146. occur even in the eye of many animals, especially of fishes; they are numerous in the eye of the common fresh-water perch of Europe. To the naked eye they seem like little white spots (Fig. 145); but when magnified they have the form of Fig. 146.

362. As to the larger intestinal worms found in other animals, the mystery of their origin has been entirely solved by recent researches. A single instance will illustrate their history. At certain periods of the year, the Sculpins of the Baltic are infested by a particular species of Tænia or tape-worm, from which they are free at other seasons. Mr. Eschricht, found, that at certain seasons, the worms lose a great portion of the long chain of rings of which they are composed. On a careful examination, he found that each ring contained several hundred eggs, which, on being freed from their envelop, floated in the water. As these eggs are innumerable, it is not astonishing that the Sculpins should occasionally swallow some of them with 
their prey. 'The eggs, being thus introduced into the stomach of the fish, find conditions favorable to their development; and thus the species is propagated, and at the same time transmitted from one generation of the fish to another. The eggs which are not swallowed are probably lost.

363. All animals swallow, in the same manner, with their food, and in the water they drink, numerous eggs of such parasites, any one of which, finding in the intestine of the animal favorable conditions, is hatched. It is probable that each animal affords the proper conditions for some particular species of worm ; and thus we may explain how it is that most animals have parasites peculiar to themselves.

364. As respects the Infusoria, we also know that most of them lay eggs. These eggs which are extremely minute, (some of them are only $\frac{1}{120} \overline{0}$ of an inch in diameter), are scattered everywhere in great profusion, in water, in the air, in mist, and even in snow. Assiduous observers have not only seen the eggs laid, but moreover, have followed their development, and have seen the young animal forming in the egg, then escaping from it, increasing in size, and, in its turn, laying eggs. They have been able, in some instances, to follow them even to the fifth and sixth generation.

365. This being the case, it is much more natural to suppose that all the Infusoria are products of like germs, than to assign to them a spontaneous origin altogether incompatible with what we know of organic development. Their rapid appearance is not at all astonishing, when we reflect that some mushrooms attain a considerable size in a few hours, but yet pass through all the phases of regular growth; and, indeed, since the knowledge of the different modes of generation among the lower animals, no substantial difficulties to the axiom "omne vivum ex ovo" (275), any longer exist. 


\section{CHAPTER TWELFTH.}

\section{METAMORPHOSES OF ANIMALS.}

366. UNDER the name of metamorphoses are included those changes which the body of an animal undergoes after its birth, and which modify, in various degrees, its organization, form, and even its mode of life. Such modifications are not peculiar to certain classes, as has been so long supposed, but are common to all animals, without exception.

367. Vegetables also undergo metamorphoses, but with this essential difference, that in vegetables the process consists in an addition of new parts to the old ones. A succession of leaves, differing from those which preceded them, comes on each season; branches and roots are added to the old stem, and woody layers to the trunk. In animals, the whole body is transformed, in such a manner that all the existing parts go to make up a new body. The chrysalis becomes a butterfly; the frog, after having been herbivorous during its tadpole state, becomes carnivorous, and its stomach is accommodated to a new mode of life; at the same time, instead of breathing by gills, it becomes an air-breathing animal ; its tail and the gills disappearing, and legs being formed.

368. The nature, the duration, and the importance of metamorphoses, and also the epoch at which they take place, are subjected to infinite variations. The most striking changes which naturally present themselves to the mind 
when we speak of metamorphoses, are those of insects. Not merely is there a change of physiognomy and form, or the possession of an organ more or less, but their whole organization is modified. The animal enters into new relations with the external world; and at the same time, new instincts are imparted to it. It has lived in water, and respired by gills; it is now furnished with a windpipe, and breathes air. It passes by, with indifference, objects which before were attractive, and its new instincts prompt it to seek conditions which would have been most pernicious during its former period of life. All these changes are brought about without destroying the individuality of the animal. The mosquito, which to-day haunts us with its shrill trumpet, and pierces us for our blood, is the same animal that a few days ago lived obscure and unregarded in stagnant water, under the guise of a little worm.

369. Every one is familiar with the metamorphoses of the silk-worm. On escaping from the egg, the little worm or caterpillar grows with great rapidity for twenty days, when it ceases to feed, spins its silken cocoon, casts its skin, and remains enclosed in its chrysalis state.* During this period of its existence most extraordinary changes take place. The jaws with which it masticated mulberry leaves are exchanged for a coiled tongue; the spinning organs disappear; the gullet is lengthened and more slender; the stomach, which was nearly as long as the body, is now contracted into a circular bag; the intestine, on the contrary, becomes elongated and tortuous, having also one portion much smaller than the other. The dorsal vessel is also shortened. The ganglions near the head approach each other, and unite into a single

* In the raising of silk-worms this period is not waited for, but the animal is billed as soon as it bas spun its cocoon. 
mass in the chest. Antennæ and palpi are developed on the head, and simple eyes are exchanged for compound nnes. The muscles, which before were uniformly distributed (159), are now gathered into masses. The limbs are elongated, and wings spring out from the thorax. More active motions then reappear in the digestive organs, and the animal, bursting the envelop of its chrysalis, issues in the form of a winged moth.

370. The different external forms which an insect may assume is well illustrated by one which is unfortunately too well known in this country, namely, the canker-worm. Its eggs are laid near the tips of the small branches of the apple-tree, elm, and some other trees. They are hatched about the time the tender leaves of these trees begin to unfold.
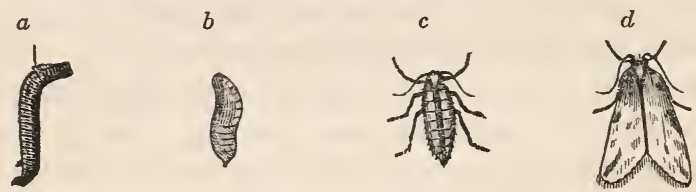

Fig. 147.

The caterpillar $(a)$ feeds on the leaves, and attains its full growth at the end of about four weeks, being then not quite an inch in length. It then descends to the ground, and enters the earth to the depth of four or five inches, and having excavated a sort of cell, is soon changed into a chrysalis or nymph $(b)$. At the usual time in the spring, it bursts the skin, and appears in its perfect state, under the form of a winged moth $(d)$. In this species, however, only the male has wings. The perfect insects soon pair, the female (c) crawls up a tree and deposits her eggs, and then dies.

371. Transformations no less remarkable are observed among the Crustacea. The metamorphoses in the family Cirrhipedes are especially striking. It is now known that the barnacles (Balanus), which have been arranged among the 
mollusks are truly crustaceans; and this result of modern researches is confirmed in the clearest manner by the study of their transformations. The following figures represent the different phases of the duck-barnacle (Anatifa).

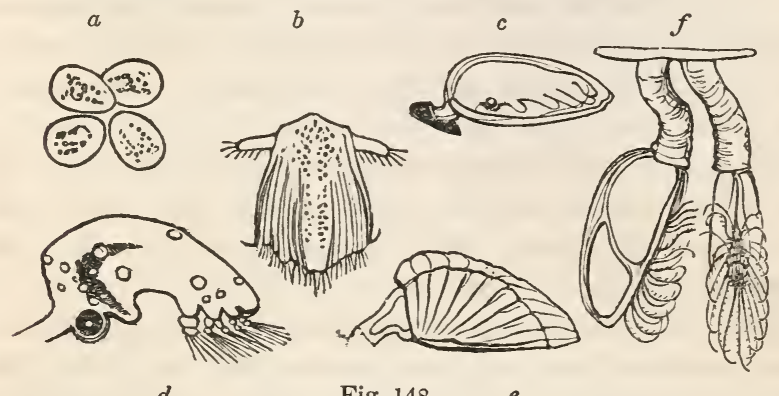

372. The Anatifa, like all crustacea, is reproduced by eggs, specimens of which, magnified ninety diameters, are represented in figure 148, $a$. From these eggs little animals issue which have not the slightest resemblance to the parent. They have an elongated form $(b)$, a pair of tentacles, and four legs, with which they swim freely in the water.

373. Their freedom, however, is of but short duration. The little animal soon attaches itself by means of its tentacles, having previously become covered with a transparent shell, through which the outlines of the body, and also a very distinct eye, are easily distinguished (Fig. 148, c). Figure $148, d$, shows the animal taken out of its shell. It is plainly seen that the anterior portion has become considerably enlarged. Subsequently, the shell becomes completed, and the animal casts its skin, losing with it both its eyes and its tentacles. On the other hand, a thick membrane lines the interior of the shell, which pushes out and forms a stem (e), by means of which the animal fixes itself to 
marine bodies, after the loss of its tentacles. This stem gradually enlarges, and the animal soon acquires a definite shape, such as it is represented in figure $148, f$, attached to a piece of floating wood.

374. There is, consequently, not only a change of organization in the course of the metamorphoses, but also a change of faculties and mode of life. The animal, at first free, becomes fixed; and its adhesion is effected by totally different organs at different periods of life, first by means of tentacles, which were temporary organs, and afterwards by means of a fleshy stem designed especially for that purpose.

375. The Radiata also furnish us with examples of various metamorphoses, especially among the star-fishes. A small species living on the coast of New England (Echinaster sanguinolentus) undergoes the following phases (Fig. 149).
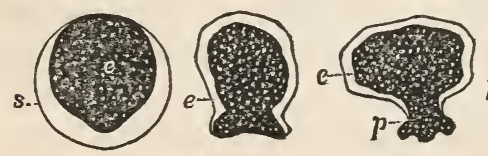

Fig. 149.
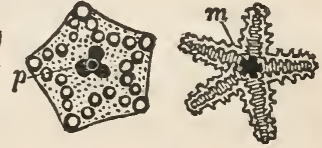

376. If the eggs are examined by the microscope, each one is found to contain a small, pear-shaped body, which is the embryo $(e)$, surrounded by a transparent envelop. On escaping from the egg, the little animal has an oblong form with a constriction at the base. This constriction becoming deeper and deeper forms a pedicle, $(p)$, which soon divides into three lobes. The disc also assumes a pentagonal form, and five double series of vesicles, which are the first rudiments of the rays, are seen to form in the interior of the pentagon. At the same time, the peduncle contracts still more, and at last is entirely absorbed into the cavity of the body, and the animal soon acquires its final form $(m)$. 
377. Analogous transformations take place in the Comat-

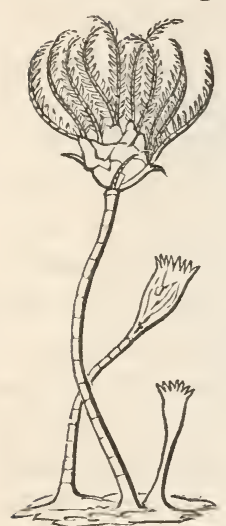

Fig. 150. ula. In early life (Fig. 150) it is fixed to the ground by a stem, but becomes detached at a certain epoch, and then floats freely in the sea (Fig. 151). On the other hand,

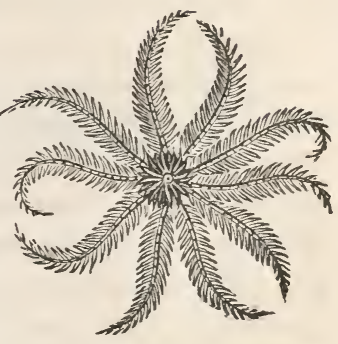

Fig. 151. the Polypi seem to follow a reverse course, many of them becoming fixed to the earth after having been previously free.

378. The metamorphoses of mollusks, though less striking, are not less worthy of notice. Thus, the oyster, with which we are familiar in its adhering shell, is free when young, like the clam (Mya) and most other shell-fishes. Others, which are at first attached or suspended to the gills of the mother, afterwards become free, as the Unio. Some naked Gasteropods, the Acteon or the Eolis, for example, are born with a shell, which they part with, shortly after leaving the egg.

379. The study of metamurphosis is therefore of the utmost importance for understanding the real affinities of animals very different in appearance, as is readily shown by the following instances. The butterfly and the earth-worm seem, at the first glance, to have no relation whatever. They differ in their organization no less than in their outward appearance. But if we compare the caterpillar and the worm, these two animals closely resemble each other. The analogy however, is only transient; it lasts only during the larva state of the caterpillar, and is effaced as it passes to the chrysalis and butterfly states. The latter be- 
comes a more and more perfect animal, whilst the worm remains in its inferior state.

380. Similar instances are furnished by animals belonging to all the types of the Animal Kingdom. Who would think, at the first glance, that a Barnacle or an Anatifa were more nearly allied to the crabs than to the oyster? And, nevertheless, we have seen (372), in tracing back the Anatifa to its early stages, that it then bears a near resemblance to a little Crustacean (Fig. 148, d). It is only when full grown that it assumes its peculiar mollusk-like covering.

381. Among the Cuttle-fishes there are several, the Loligo (Fig. 47) for example, which are characterized by the form of their tentacles, the two interior being much longer than the others, and of a different form; whilst in others, as the Octopus, they are all equal. But if we compare the young, we find that in both animals the tentacles are all equal, though they differ in number. The inequality in the tentacles is the result of a further development.

382. Among the Radiata, the Pentacrinus and the Comatula exemplify the same point. The two are very different when full grown, the latter being a free-swimming star-fish (Fig. 151), while the former is attached to the soil, like a Polyp. But we have seen (377) that the same is the case with Comatula in its early period; and that in consequence of a further metamorphosis, it becomes disengaged from its stem, and floats freely in the water.

383. In the type of Vertebrates, the considerations drawn from metamorphoses acquire still greater importance in reference to classification. The Sturgeon and the White-fish before mentioned (306) are two very different fishes; yet, taking into consideration their external form and bearing merely, it might be questioned which of the two should take the highest rank; whereas, the doubt is very easily resolved by an examination of their anatomical structure. 
The White-fish has a skeleton, and moreover, a vertebral column composed of firm bone. The Sturgeon (Fig. 152),

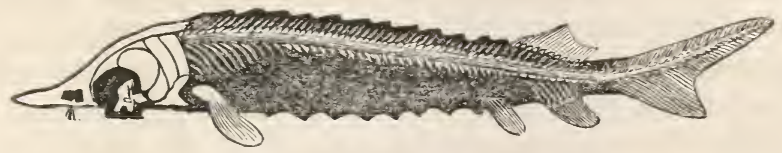

Fig. 152.

on the contrary, has no bone in the vertebral column, except the spines or apophyses of the vertebræ. The middle part, or body of the vertebra, is cartilaginous; the mouth is transverse, and underneath the head; and the caudal fin is unequally forked, while in the White-fish it is equally forked.

384. If, however, we observe the young White-fish just after it has issued from the egg (Fig. 123), the contrast will be less striking. At this period the vertebræ are cartilaginous, like those of the Sturgeon; its mouth also is transverse, and its tail undivided; at that period the White-fish and the Sturgeon are therefore much more alike. But this similarity is only transient; as the White-fish grows, its vertebræ become ossified, and its resemblance to the Sturgeon is comparatively slight. As the Sturgeon has no such transformation of the vertebræ, and is in some sense arrested in its development, while the White-fish undergoes subsequent transformation, we conclude that, compared with the White-fish, it is really inferior in rank.

385. This relative inferiority and superiority strikes us still more, when we compare with our most perfect fishes (the Salmon, the Cod) some of those worm-like animals, so different from ordinary fishes that they were formerly placed

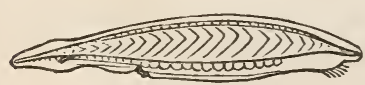

Fig. 153. among the worms. The Amphioxus, represented of its natural size (Fig. 153), not only has no bony skeleton, but not even a head, properly 
speaking. Yet the fact that it possesses a dorsal cord, extending from one extremity of the body to the other, proves that it belongs to the type of Vertebrates. But as this peculiar structure is found only at a very early period of embryonic development, in other fishes, we conclude that the Amphioxus holds the very lowest rank in this class.

386. Nevertheless, metamorphoses will not indicate the true measure of the perfection of animals, if limited to those changes which take place after birth; because there are many animals which undergo no changes of great importance after their escape from the egg, and occupy, nevertheless, a high rank in the Zoölogical series, as for example, Birds and many Mammals. The question now is, whether such animals are developed according to different plans, or whether their dissimilarity in that respect is merely apparent, arising from an incorrect interpretation. To answer this question, let us go back to the period anterior to birth, and see if some connection may not be made out between embryonic changes, and metamorphoses which take place subsequently.

387. We have already shown that embryonic development consists in a series of transformations; the young animal enclosed in the egg differing, at each period of its development, from what it was in the preceding period. But because these transformations precede birth, and are therefore not easily observed, does not make them the less important. To be satisfied that these transformations are real metamorphoses, in every respect similar to those which follow birth, we have only to compare, on the other hand, those changes which immediately precede birth with those which immediately follow it, and we shall readily perceive that the latter are simply a continuation of the former, till all are completed.

388. Let us recur to the development of fishes for illus- 
tration. The young White-fish, as we have seen (315), is far from having acquired its complete development, when born. The vertical fins are not yet separate; the mouth has not yet its proper position; the yolk has not yet retreated within the cavity of the body, but hangs below the chest in the form of a large vesicle. Much therefore remains to be done, in order to complete its development. But the fact of its being born does not prevent its future evolution, which goes on without interruption.

389. Similar inferences may be drawn from the development of the chicken. The only difference is that the young chicken is born in a more complete state, the most important transformations having taken place during the embryonic period, while those to be undergone after birth are less considerable, though they complete the process begun in the embryo. Thus we see it, shortly after birth, completely changing its covering, and clothed with feathers instead of down; still later its crest appears, and its spurs begin to be developed.

390. In certain Mammals, known under the name of Marsupials (the Opossum and Kangaroo), the link between the metamorphoses which take place before birth, and those that occur at a later period, is especially remarkable. These animals are brought into the world so weak and undeveloped that they have to undergo a second gestation, in a pouch with which the mother is furnished, and in which the young remain, each one fixed to a teat, until they are entirely developed. Even those animals which are born nearest to the complete state have, nevertheless, transformations to undergo. Ruminants acquire their horns; and the lion his mane. Most mammals, at birth, are destitute of teeth, and incapable of using their limbs; and all are dependent on the mother and the milk secreted by her, until the stomach is capable of digesting other aliment. 
391. If it be thus shown that the transformations which take place in the embryo are of the same nature and of the same importance as those which occur afterwards, the circumstance that some precede and others succeed birth, cannot make any radical distinction between them. Both are processes of the life of the individual. Now, as life does not commence at birth, but goes still farther back, it is quite clear that the modifications which supervene during the former period are essentially the same as the later ones; and, hence, that metamorphoses, far from being an exception in the Animal Kingdom, are one of its general features.

392. We are therefore perfectly entitled to say that all animals, without exception, undergo metamorphoses. Were it not so, we should be at a loss to conceive why animals of the same division present such wide differences; and that there should be, as in the class of Reptiles, some families that undergo important metamorphoses, (the frogs, for example), and others in which nothing of the kind is known, (the Lizards and Tortoises).

393. It is only by connecting the two kinds of transformation, namely, those which take place before, and those after birth, that we are furnished with the means of ascertaining the relative perfection of an animal; in other words, these transformations become, under such circumstances, a natural key to the gradation of types. At the same time, they will force upon us the conviction that there is an immutable principle presiding over all these changes, and regulating them in a peculiar manner in each animal.

394. These considerations are important, not only from their bearing on classification, but not less so from the application which may be made of them to the study of fossils. If we examine attentively the fishes that have been found in the different strata of the earth, we remark that those of the most ancient deposits have in general preserved only the 
apophyses of their vertebræ, whilst the vertebræ themselves are wanting. It would be the same, were the Sturgeons of one of the American rivers to become petrified. As the apophyses are the only bony portions of the vertebral column, they alone would be preserved. Indeed, fossil Sturgeons are known, which are in precisely this condition. 395. From the fact above stated, we may conclude that the oldest fishes have not passed through all the metamorphoses which our osseous fishes undergo, and consequently that they are inferior to analogous species of the present epoch, which have bony vertebræ. Similar considerations apply to the fossil crustacea and to the fossil Echinoderms, when compared with the living ones, and will probably be true of all classes of the Animal Kingdom, when fully studied as to their geological succession. 


\section{CHAPTER THIRTEENTH.}

GEOGRAPHICAI، DISTRIBUTION OF ANIMALS.

\section{SECTION I.}

\section{GENERAL LAWS OP DISTRIBUTION.}

396. No animal, excepting man, inhabits every part of the surface of the earth. Each great geographical or climatal region is occupied by some species not found elsewhere ; and each animal dwells within certain limits, beyond which it does not range while left to its natural freedom, and within which it always inclines to return, when removed by accident or design. Man alone is a cosmopolite. His domain is the whole earth. For him, and with a view to him, it was created. His right to it is based upon his organization and his relation to Nature, and is maintained by his intelligence and the perfectibility of his social condition.

397. A group of animals which inhabits any particular region, embracing all the species, both aquatic and terrestrial, is called its $\mathrm{F}_{\mathrm{AUNA}}$; in the same manner as the plants of a country are called its Flora. To be entitled to this name, it is not necessary that every animal in the group should be different from those inhabiting any other region; it is sufficient that there should be peculiarities in the distribution of the families, genera, and species, and in the preponderance 
of certain types over others, sufficiently prominent to impress upon the group well-marked features. Thus, for example, in the islands of the Pacific are found terrestrial animals, altogether peculiar, and not found on the nearest continents. There are numerous animals in New Holland differing from any found on the continent of Asia, or, indeed, on any other part of the earth. If, however, some species inhabiting both shores of a sea which separates two terrestrial regions, are found to be alike, we are not to conclude that those regions have the same Fauna, any more than that the Flora of Lapland and England are alike, because some of the sea-weeds found on both shores are the same.

398. There is an evident relation between the fauna of any locality and its climate; and, on that account, the faunas of the two hemispheres have been distributed into three principal divisions, namely, the arctic, the temperate, and the tropical faunas; in the same manner as we have arctic, temperate, and tropical floras. Hence also, animals dwelling at high elevations upon mountains, where the temperature is much reduced, resemble the animals of colder latitudes, rather than those of the surrounding plains.

399. In some respects, the peculiarities of the fauna of a region depends upon its flora, at least so far as land animals are concerned; for herbivorous animals will exist only where there is an adequate supply of vegetable food. But taking the terrestrial and aquatic animals together, the distribution of a fauna is less intimately dependent on climate than that of a flora. Plants, in truth, are for the most part terrestrial (marine plants being relatively very few), while animals are chiefly aquatic. The ocean is the true home of the Animal Kingdom; and while plants, with the exception of the lichens and mosses, become dwarfed or perish under the influence of severe cold, the sea teems with animals of all classes, far beyond the extreme limit of flowering plants. 
400. The influence of climate, in the polar regions, acts merely to induce a greater uniformity in the species of animals. Thus the same animals inhabit the polar regions of the three continents. The polar bear is the same in Europe, Asia, and America, and so are also a great many birds. In the temperate regions, on the contrary, the species differ on each of the continents, but they still preserve the same general features. The types are the same, but they are represented by different species. In consequence of these general resemblances, the first colonists of New England erroneously applied the names of European species to American animals. Similar differences are observed as to regions of the same continent, within the same parallels of latitude. The animals of Oregon and of California are not the same as those of New England. The difference, in certain respects, is even greater than between the animals of New England and Europe, as the researches of the naturalists of the United States Exploring Expedition have proved. In like manner, the animals of temperate Asia differ more from those of Europe than they do from those of America.

401. Under the torrid zone, the Animal Kingdom, as well as the Vegetable, attains its highest development. The animals of the tropics are not only different from those of the temperate zone, but, moreover, they present the greatest variety among themselves. The most gracefully proportioned forms are found by the side of others the most odd, decked with every combination of the most brilliant coloring. At the same time, the contrast between the animals of different continents is more marked; and in many respects, the animals of the different tropical faunas differ not less among themselves than they do from those of the temperate or frozen zones. Thus, the fauna of Brazil is quite as different from that of Central Africa as it is from that of the United States. 
402. This diversity upon different continents cannot depend simply on any influence of the climate of the tropics; if it were so, uniformity ought to be restored in proportion as we recede from the tropics towards the antarctic temperate regions. But, instead of this, the differences continue to increase; - so much so, that no faunas are more in contrast than those of Cape Horn, the Cape of Good Hope, and New Holland. Hence other influences must be in operation besides those of climate;-influences of a higher order, which are involved in a general plan, and intimately associated with the development of life on the surface of the earth.

403. Faunas are more or less distinctly limited, according to the natural features of the earth's surface. Sometimes two faunas are separated by an extensive chain of mountains, like the Rocky Mountains. Again, a desert may intervene, like the desert of Sahara, which separates the fauna of Central Africa from that of the Atlas and the Moorish coast, the latter of which is merely an appendage to the fauna of Europe. But the sea effects the most complete separation. The depths of the ocean are quite as impassable for marine species as high mountains are for terrestrial animals. It would be quite as difficult for a fish or a mollusk to cross from the coast of Europe to the coast of America, as it would be for a reindeer to pass from the arctic to the antarctic regions, across the torrid zone. Experiments of dredging in very deep water have also taught us that the abyss of the ocean is nearly a desert. Not only are no materials found there for sustenance, but it is doubtful if animals could sustain the pressure of so great a column of water, although many of them are provided with a system of pores (260), which enables them to sustain a much greater pressure than terrestrial animals.

404. When there is no great natural limit, the transition 
from one fauna to another is made insensibly. Thus, in passing from the arctic to the temperate regions of North America, one species takes the place of another, a third succeeds the second, and so on, until finally the fauna is found to be an entirely new one, without its being always possible to mark the precise limit between the two.

405. The range of species does not at all depend upon their powers of locomotion; if it were so, animals which move slowly and with difficulty would have a narrow range, whilst those which are very active would be widely diffused. Precisely the reverse of this is actually the case. The common oyster extends at least from Cape Cod to the Carolinas ; its range is consequently very great; much more so than that of some of the fleet animals, as, for instance, the Moose. It is even probable that the very inability of the oyster to travel, really contributes to its diffusion, inasmuch as being once removed, it is difficult for it to return; and moreover, being fixed, and consequently unable to choose positions for its eggs, they must be left to the mercy of currents ; while Fishes, by depositing their eggs in the bays and inlets of the shore, undisturbed by currents and winds, secure them from too wide a dispersion.

406. The nature of their food has an important bearing upon the grouping of animals, and upon the extent of their distribution. Carnivorous animals are generally less confined in their range than herbivorous ones; because their food is almost everywhere to be found. The herbivora, on the other hand, are restricted to the more limited regions corresponding to the different zones of vegetation. The same remark may be made with respect to Birds. Birds of prey, like the eagle and vulture, have a much wider range than the granivorous and gallinaceous birds. Still, notwithstanding the facilities they have for change of place, even the birds that wander widest recognize limits which 
they do not overpass. The Condor of the Cordilleras does not descend into the temperate regions of the United States; and yet it is not that he fears the cold, since he is frequently known to ascend even above the highest summits of the Andes, and disappears from view where the cold is most intense. Nor can it be from lack of prey.

407. Again, the peculiar configuration of a country sometimes determines a peculiar grouping of animals, into what may be called local faunas. Such, for example, are the prairies of the West, the Pampas of South America, the Steppes of Asia, the Deserts of Africa ; - and for marine animals, the basin of the Caspian. In all these localities, animals are met with which exist only there, and are not found except under those particular conditions.

408. Finally, to obtain a true picture of the zoölogical distribution of animals, not the terrestrial types alone, but the marine species must also be included. Notwithstanding the uniform nature of the watery element, the animals which dwell in it are not dispersed at random; and though the limits of the marine may be less easily defined than those of the terrestrial fauna, still, marked differences of the animals in the great basins are not less observable. Properly to apprehend how marine animals may be distributed into local faunas, it must be remembered that their residence is not in the high sea, but along the coasts of continents and on soundings. It is on the Banks of Newfoundland, and not in the deep sea, that the great cod-fishery is carried on; and it is well known that when fishes migrate, they take care to run along the shores. The range of marine species being therefore confined to the vicinity of the shores, their distribution must be subjected to laws similar to those which regulate the terrestrial faunas. As to the fresh-water fishes, not only do the species vary in the different zones, but even the different rivers of the same region have species peculiar to them, and not found in neighboring streams. 
409. A very influential cause in the distribution of aquatic animals is the depth of the water. The Mollusks, and even the Fishes found near the surface between high and low water differ, in general, from those living at the depth of twenty or thirty feet, and these again are found to be different from those which are met with at a greater depth. Their coloring, in particular, varies, according to the quantity of light they receive, as has also been shown to be the case with the marine plants.

410. It is sometimes the case that one or more animals are found upon a certain chain of mountains, and not elsewhere; as, for instance, the Mountain Sheep (Ovis montana), upon the Rocky Mountains, or the Chamois and the Ibex upon the Alps. The same is also the case on some of the wide plains or prairies. This, however, does not entitle such regions to be considered as having an independent fauna, any more than a lake is to be regarded as having a peculiar fauna, exclusive of the animals of the surrounding country, merely because some of the species found in the lake may not ascend the rivers emptying into it. It is only when the whole group of animals inhabiting such a region has such peculiarities as to give it a distinct character, when contrasted with animals found in surrounding regions, that it is to be regarded as a separate fauna. Such, for example, is the fauna of the great steppe or plain of Gobi, in Asia ; and such indeed that of the chain of the Rocky Mountains may prove to be, when the animals inhabiting them are better known.

411. The migration of animals might at first seem to present a serious difficulty in determining the character or the limits of a fauna; but this difficulty ceases, if we regard the country of an animal to be the place where it makes its habitual abode. As to Birds, which of all animals wander the farthest, it may be laid down as a rule, that they 
belong to the zone in which they breed. Thus, the gulls, many of the ducks, mergansers, and divers, belong to the boreal regions, though they pass a portion of the year with us. On the other hand, the swallows and martins, and many of the gallinaceous birds belong to the temperate faunas, notwithstanding they migrate during winter to the confines of the torrid zone. This rule does not apply to the fishes, who annually leave their proper home, and migrate to a distant region merely for the purpose of spawning. The Salmon, for example, comes down from the North to spawn on the coasts of Maine and Nova Scotia.

412. Few of the Mammals, and these mostly of the tribe of Rodents, make extensive migrations. Among the most remarkable of these are the Kamtschatka rats. In Spring they direct their course westward, in immense troops; and after a very long journey, return again in Autumn to their quarters, where their approach is anxiously awaited by the hunters, on account of the fine furs to be obtained from the numerous carnivora which always follow in their train. The migrations of the Lemmings are marked by the devastations they commit along their course, as they come down from the borders of the Frozen Ocean to the valleys of Lapland and Norway; but their migrations are not periodical.

\section{- SECTION II.}

\section{DISTRIBUTION OF THE FAUNAS.}

413. We have stated that all the faunas of the globe may be divided into three departments, corresponding to as many great climatal divisions, namely, the glacial or arctic, the temperate and the tropical faunas. These three divisions 
appertain to both hemispheres, as we recede from the equator towards the north or south poles. It will hereafter be shown that the tropical and temperate faunas may be again divided into several zoölogical provinces, depending on longitude or on the peculiar configuration of the continents.

414. No continent is better calculated to give a correct idea of distribution into faunas, as determined by climate, than the continent of America; extending as it does across both hemispheres, and embracing all latitudes, so that all climates are represented upon it, as shown by the chart on the following page.

415. Let a traveller embark at Iceland, which is situated on the borders of the polar circle, with a view to observe, in a zoölogical aspect, the principal points along the eastern shore of America. The result of his observation will be very much as follows. Along the coast of Greenland and Iceland, and also along Baffin's Bay, he will meet with an unvaried fauna composed of the same animals, which are also for the most part identical with those of the arctic shores of Europe. It will be nearly the same along the Labrador coast.

416. As he approaches Newfoundland, he will see the landscape, and with it the fauna, assuming a somewhat more varied aspect. To the wide and naked or turfy plains of the boreal regions succeed forests, in which he will find various animals which dwell only in forests. Here the temperate fauna commences. Still the number of species is not yet very considerable; but as he advances southwardly, along the coasts of Nova Scotia and New England, he finds these species gradually increasing, while those of the cold regions diminish, and at length entirely disappear, some few accidental or periodical visiters excepted, who wander during winter, as far south as the Carolinas.

417. But it is after having passed the boundaries of the United States, among the Antilles, and more especially on 


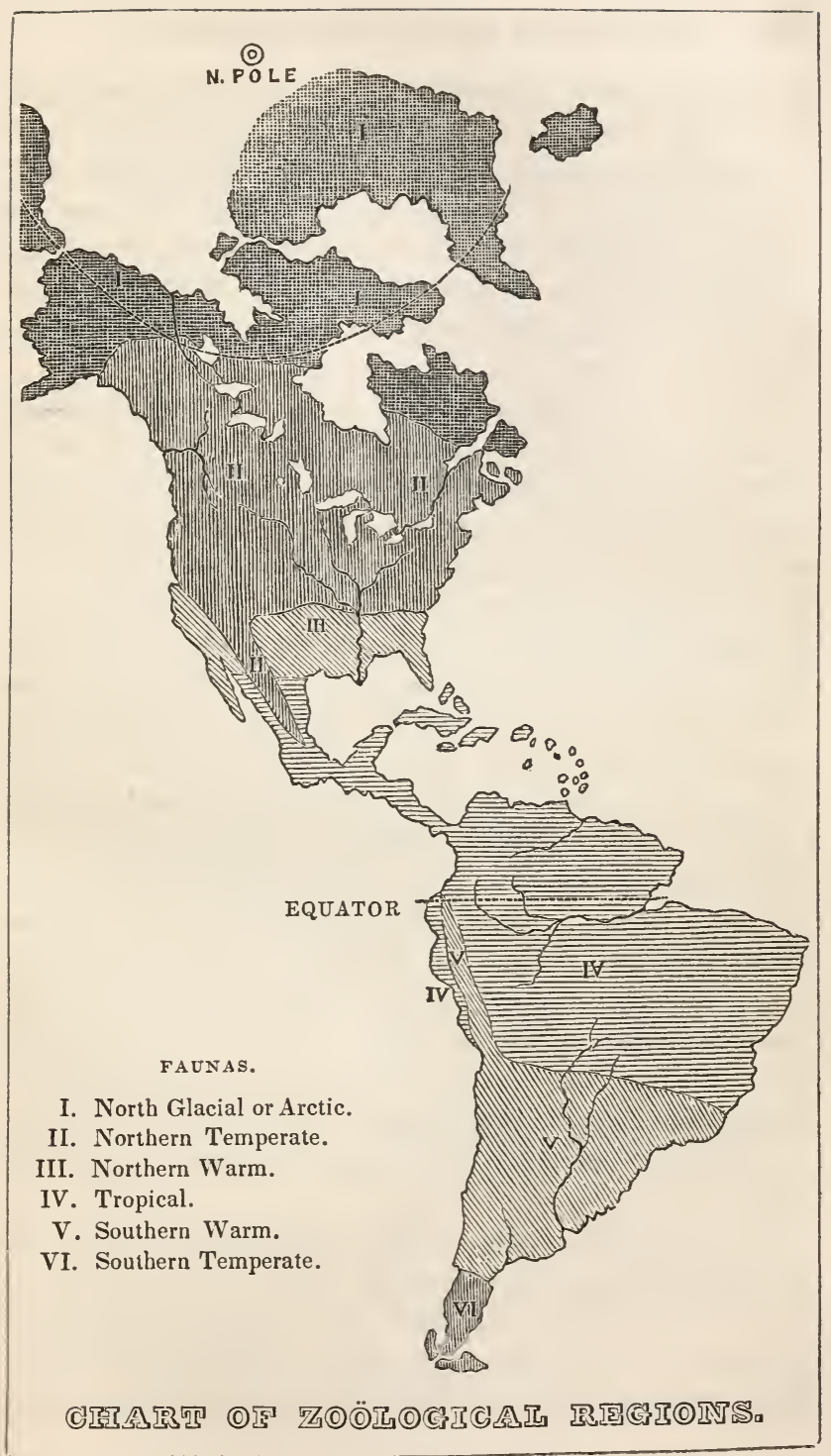


the southern continent, along the shores of the Orinoco and the Amazon, that our traveller will be forcibly struck with the astonishing variety of the animals which people the forests, the prairies, the rivers, and the sea-shores, most of which he will also find to be different from those of the northern continent. By this extraordinary richness of new forms, he will become sensible that he is now in the domain of the tropical fauna.

418. Let him still travel on beyond the equator towards the tropic of Capricorn, and he will again find the scene change as he enters the regions where the sun casts his rays more obliquely, and where the contrast of the seasons is more marked. The vegetation will be less luxuriant; the palms will have disappeared to make place for other trees; the animals will be less varied, and the whole picture will recall to him, in some measure, what he witnessed in the United States. He will again find himself in the temperate regions, and this he will trace on, till he arrives at the extremity of the continent, the fauna and the flora becoming more and more impoverished as he approaches Cape ITorn.

419. Finally, we know that there is a continent around the South Pole. Although we have as yet but very imperfect notions respecting the animals of this inhospitable clime, still the few which have already been observed there, all present a close analogy to those of the arctic region. It is another glacial fauna, namely, the antarctic. Having thus sketched the general distribution of the fauna, it remains to point out the principal features of each of them.

420. I. Arctic Fauna. - The predominant feature of the Arctic Fauna is its uniformity. The species are few in number; but, on the other hand, the number of individuals is immense. We need only refer to the clouds of birds which hover upon the islands and shores of the North; the 
shoals of fishes, the salmon among others, which throng the coasts of Greenland, Iceland, and Hudson's Bay. 'The same uniformity appears in the form and color of the animals. There is not a single bird of brilliant plumage, and not a fish with varied hues. Their forms are regular, and their tints as dusky as the northern heavens. The most conspicuous animals are the white-bear, the moose, the reindeer, the musk-ox, the white-fox, the polar-hare, the lemming, and various Seals; but the most important are the Whales, which, it is to be remarked, rank lowest of all the Mammals. Among the Birds, may be enumerated some seaeagles and a few Waders, with an immense number of other aquatic species, such as gulls, cormorants, divers, petrels, ducks, geese, \&c., all belonging to the lowest order of Birds. Reptiles are altogether wanting. The Articulata are represented by numerous marine worms, and by minute crustaceans of the orders Isopoda and Amphipoda. Insects are rare, and of inferior types. Of the type of Mollusks, there are Acephala, particularly Tunicata, fewer Gasteropods, and very few Cephalopods. Among the Radiata are a great number of jelly-fishes, particularly the Beröe ; and to conclude with the Echinoderms, there are several star-fishes and Echini, but few Holothuriæ. The class of Polypi is very scantily represented, and those producing stony corals are entirely wanting.

421. This assemblage of animals is evidently inferior to that of other faunas, especially to those of the tropics. Not that there is a deficiency of animal life; for if the species are less numerous, there is a compensation in the multitude of individuals, and also in this other very significant fact, that the largest of all animals, the whales, belong to this fauna.

422. It has already been said (400) that the arctic fauna of the three continents is the same; its southern limit, how- 
ever, is not a regular line. It does not correspond precisely with the polar circle, but rather to the isothermal zero, that is, the line where the average temperature of the year is at $32^{\circ}$ of Fahrenheit. The course of this line prescants numerous undulations. In general, it may be said to coincide with the appearance of trees, so that it passes where forest vegetation succeeds the vast arid plains, the barrens of North America, or the tundras of the Samoyedes. The uniformity of these plains involves a corresponding uniformity of plants and animals. On the North American continent it extends much farther southward on the eastern shore, than on the western. From the peninsula of Alashka it bends northwards towards the Mackenzie, then descends again towards the Bear Lake, and comes down to near the northern shore of Newfoundland.

423. II. Temperate Faunas. - The faunas of the temperate regions of the northern hemisphere are much more varied than that of the arctic zone. Instead of consisting mainly of aquatic tribes, we have a considerable number of terrestrial animals of graceful form, animated appearance, and varied colors, though less brilliant than those found in tropical regions. Those parts of the country covered with forests especially swarm with insects, worms, terrestrial and fluviatile mollusks, which become the food of still other animals.

424. Still, the climate is not sufficiently warm over the whole extent of this zone to allow the trees to retain their foliage throughout the year. At its northern margin the leaves, excepting those of the pines and spruces, fall, on the approach of the cold season, and vegetation is arrested for a longer or shorter period. Insects retire, and the animals which live upon them no longer find nourishment, and are obliged to migrate to warmer regions, on the borders of the tropics, where, on the eververdant vegetation, they find the means of subsistence. 
425. Some of the herbivorous Mammals, the Bats, and the reptiles which feed on insects, pass the winter in a state of torpor, from which they awake in spring. Others retire into dens, and live on the provisions they have stored up during the warm season. The Carnivora, the Ruminants, and the most active portion of the Rodents, are the only animals that do not change either their abode or their habits. The fauna of the temperate zone thus presents an ever-changing picture, which may be considered as one of its most important features, since these changes recur with equal constancy in the Old and the New World.

426. Taking the contrast of the vegetation, as a basis, and the consequent changes of habit imposed upon the denizens of the forests, the temperate fauna has been divided into two regions; a northern one, where the trees, except the pines, drop their leaves in winter, and a southern one, where they are evergreen. Now, as the limit of the former, that of the deciduous trees, coincides, in general, with the limit of the pines, it may be said that the cold region of the temperate fauna extends as far as the pines. In the United States this coincidence is not so marked as in other regions, inasmuch as the pines extend into Florida, while they do not prevail in the Western States; but we may reckon as belonging to the southern portion of the temperate region, that part of the country south of the latitude where the Palmetto or Cabbage-tree (Chamarops) commences, namely, all the States to the south of North Carolina; while the States to the north of this limit belong to the northern portion of the temperate region.

427. This division into two zones is supported by observations made on the maritime faunas of the Atlantic coast. The line of separation between them, however, being influenced by the Gulf Stream, is considerably farther to the north; - namely, at Cape Cod. It has been ascertained that of one hundred and ninety-seven Mollusks inhabiting the 
coast of New England, fifty do not pass to the north of Cape Cod, and eighty-three do not pass to the south of it; only sixty-four being common to both sides of the Cape. A similar limitation of the range of Fishes has been noticed by Dr. Storer; and Dr. Holbrook has found the Fishes of South Carolina to be different from those of Florida and the West Indies. In Europe, the northern part of the temperate region extends to the Pyrennees and the Alps; and its southern portion consists of the basin of the Mediterranean, together with the northern part of Africa, as far as the desert of Sahara.

428. A peculiar characteristic of the faunas of the temperate regions in the northern hemisphere, when contrasted with those of the southern, is the great similarity of the prevailing types on both continents. Notwithstanding the immense extent of country embraced, the same stamp is everywhere exhibited. Generally, the same families, frequently the same genera, represented by different species, are found. There are even a few species of terrestrial animals regarded as identical on the continents of Europe and America ; but their supposed number is constantly diminished, as more accurate observations are made. The predominant types among the mammals are the bison, deer, ox, horse, hog, numerous rodents, especially squirrels, and hares, nearly all the insectivora, weasels, martens, wolves, foxes, wild cats, \&c. On the other hand, there are no Edentata and no Quadrumana, with the exception of some monkeys on the two slopes of the Atlas. Among Birds, there is a multitude of climbers, passerine, gallinaceous, and many rapacious birds. Of Reptiles, there are lizards and tortoises of small or medium size, serpents, and many batrachians, but no crocodiles. Of Fishes, there is the trout family, the cyprinoids, the sturgeons, the pikes, the cod, and especially the great family of Herrings and Scomberoids, to which latter belong the mackerel and 
the tunny. All classes of the Mollusks are represented; though the cephalopods are less numerous than in the torrid zone. There is an infinite number of Articulata of every type, as well as numerous Polyps, though the corals proper do not yet appear abundantly.

429. On each of the two continents of Europe and America, there is a certain number of species which extend from one extreme of the temperate zone to the other. Such, for example, are the deer, the bison, the cougar, the flying-squirrel, numerous birds of prey, several tortoises, and the rattlesnake, in America. In Europe, the brown bear, wolf, swallow, and many birds of prey. Some species have a still wider range, like the ermine, which is found from Bhering's Straits to the Himalaya Mountains, that is to say, from the coldest regions of the arctic zone, to the southern confines of the temperate zone. It is the same with the muskrat, which is found from the mouth of Mackenzie's River to Florida. The field-mouse has an equal range in Europe. Other species, on the contrary, are limited to one region. The Canadian elk is confined to the northern portion; and, on the other hand, the prairie wolf, the foxsquirrel, the Bassaris and numerous birds, never leave the southern portion.*

430. In America, as in the Old World, the temperate

* The types which are peculiar to temperate America, and are not found in Europe, are the Opossum, several genera of Insectivora, among them the shrew-mole (Scalops aquaticus), and the star-nose mole (Condylura cristata), which replaces the Mygale of the Old World; several genera of rodents, especially the muskrat. Among the types characteristic of America must also be reckoned the snapping-turtle among the tortoises; the Menobranchus and Menopoma, among the Salamanders; the Garpike and Amia among the fishes; and finally among the Crustacea, the Limulus. Among the types which are wanting in temperate America, and which are found in Europe, may be cited the horse, the wild boar, and the true mouse. All the species of domestic mice which live in America, have been brought from the Old World. 
fauna is further subdivided into several districts, which may be regarded as so many zoölogical provinces, in each of which there is a certain number of animals differing from those in the others, though very closely allied. Temperate America presents us with a striking example in this respect. We have, on the one hand:

1st. The fauna of the United States properly so called, on this side of the Rocky Mountains.

2d. The fauna of Oregon and California, beyond those mountains.

Though there are some animals which traverse the chain of the Rocky Mountains, and are found in the prairies of the Missouri as well as on the banks of the Columbia, as, for example, the Rocky Mountain deer, (Antilope furci$f e r)$, yet if we regard the whole assemblage of animals, they are found to differ entirely. Thus, the rodents, part of the ruminants, the insects, and all the mollusks, belong to distinct species.

431. The faunas or zoölogical provinces of the Old World which correspond to these are :

1st. The fauna of Europe, which is very closely related to that of the United States proper.

2d. The fauna of Siberia, separated from the fauna of Europe by the Ural Mountains.

3d. The fauna of the great Asiatic table-land, which, from what is as yet known of it, appears to be quite distinct.

4th. The fauna of China and Japan, which is analogous to that of Europe in the Birds, and to that of the United States in the Reptiles - as it is also in the flora.

Lastly, it is in the temperate zone of the northern hemisphere, that we meet with the most striking examples of those local faunas which have been mentioned above. Such, for example, is the fauna of the Caspian Sea, of the steppes of Tartary, and of the Western prairies. 
432. The faunas of the southern temperate regions differ from those of the tropics as much as the northern temperate faunas do; and, like them also, may be distinguished into two provinces, the colder of which embraces Patagonia. But besides differing from the tropical faunas, they are also quite dissimilar to each other on the different continents. Instead of that general resemblance, that family likeness which we have noticed between all the faunas of the temperate zone of the northern hemisphere, we find here the most complete contrasts. Each of the three continental peninsulas which jut out southerly into the ocean represents, in some sense, a separate world. The animals of South America, beyond the tropic of Capricorn, are in all respects different from those at the southern extremity of Africa. The hyenas, wild-boars, and rhinoceroses of the Cape of Good Hope, have no analogues on the American continent; and the difference is equally great between the birds, reptiles and fishes, insects and mollusks. Among the most characteristic animals of the southern extremity of America are peculiar species of seals, and especially, among aquatic birds, the penguins.

433. New Holland, with its marsupial mammals, with which are associated insects and mollusks no less singular, furnishes a fauna still more peculiar, and which does not approach those of any of the adjacent countries. In the seas of that continent, where every thing is so strange, we find the curious shark, with paved teeth and spines on the back (Cestracion Philippii), the only living representative of a family so numerous in former zoölogical ages. But a most remarkable feature of this fauna is, that the same types prevail over the whole continent, in its temperate as well as its tropical portions, the species only being different at different localities. 
434. Tropical Faunas. - The tropical faunas are distinguished, on all the continents, by the immense variety of animals which they comprise, not less than by the brilliancy of their coverings. All the principal types of animals are represented, and all contain numerous genera and species. We need only refer to the tribe of humming-birds, which numbers not less than 300 species. But what is very important is, that here are concentrated the most perfect, and also the oddest types of all the classes of the Animal Kingdom. The tropical region is the only one occupied by the Quadrumana, the herbivorous bats, the great pachydermata, such as the elephant, the hippopotamus, and the tapir, and the whole family of Edentata. Here also are found the largest of the cat tribe, the lion and tiger. Among the Birds we may mention the parrots and toucans, as essentially tropical; among the Reptiles, the largest crocodiles, and gigantic tortoises; and finally, among the articulated animals, an immense variety of the most beautiful insects. The marine animals, as a whole, are equally superior to those of other regions; the seas teem with crustaceans and numerous cephalopods, together with an infinite variety of gasteropods and acephala. The Echinoderms there attain a magnitude and variety elsewhere unknown; and lastly, the Polyps there display an activity of which the other zones present no example. Whole groups of islands are covered with coral reefs formed by those little animals.

435. The variety of the tropical fauna is further enriched by the circumstance that each continent furnishes new and peculiar forms. Sometimes whole types are limited to one continent, as the sloth, the toucans, and the humming-birds to America, the giraffe and hippopotamus to Africa ; and again, animals of the same group have different characteristics, ac- 
cording as they are found on different continents. Thus, the monkeys of America, have flat and widely separated nostrils, thirty-six teeth, and generally a long, prehensile tail. The monkeys of the old world, on the contrary, have nostrils close together, only thirty-two teeth, and not one of them has a prehensile tail.

436. But these differences, however important they may appear at first glance, are subordinate to more important characters, which establish a certain general affinity between all the faunas of the tropics. Such, for example, is the fact that the quadrumana are limited, on all the continents, to the warmest regions; and never, or but rarely, penetrate into the temperate zone. This distribution is a natural consequence of the distribution of the palms ; for as these trees, which constitute the ruling feature of the flora of the tropics, furnish, to a great extent, the food of the monkeys on the two continents, we have only to trace the limits of the extent of the palms, to have a pretty accurate indication of the tropical faunas on all three continents.

437. Several well-marked faunas may be distinguished in the tropical part of the American continent, namely :

1. The fauna of Brazil, characterized by its gigantic reptiles, its monkeys, its Edentata, its tapir, its hummingbirds, and its astonishing variety of insects.

2. The fauna of the western slope of the Andes, comprising Chili and Peru; and distinguished by its Llamas, vicuñas, and birds, which differ from those of the basin of the Amazon, as also do the insects and mollusks.

3. The fauna of the Antilles and the Gulf of Mexico. This is especially characterized by its marine animals, among which the Manatée is particularly remarkable; an infinite variety of singular fishes, embracing a large number of Plectognaths; also Mollusks, and Radiata of 
peculiar species. It is in this zone that the Pentacrinus caput-meduse is found, the only representative, in the existing creation, of a family so numerous in ancient epochs, the Crinoidea with a jointed stem.

The limits of the fauna of Central America cannot yet be well defined from want of sufficient knowledge of the animals which inhabit those regions.

438. The tropical zone of Africa is distinguished by a striking uniformity in the distribution of the animals, which corresponds to the uniformity of the structure and contour of that continent. Its most characteristic species are spread over the whole extent of the tropics : thus, the giraffe is met with from Upper Egypt to the Cape of Good Hope. The hippopotamus is found at the same time in the Nile, the Niger, and Orange River. This wide range is the more significant as it also relates to herbivorous animals, and thus supposes conditions of vegetation very similar, over wide countries. Some forms are nevertheless circumscribed within narrow districts; and there are marked differences between the animals of the eastern and western shores. Among the remarkable species of the African torrid region are the baboons, the African elephant, the crocodile of the Nile, a vast number of Antelopes, and especially two species of Ourang-outang, the Chimpanzée and the Engeena, a large and remarkable animal, recently described by Drs. Savage and Wyman. The fishes of the Nile have a tropical character, as well as the animals of Arabia, which are more allied to those of Africa than to those of Asia.

439. The tropical fauna of Asia, comprising the two peninsulas of India and the isles of Sunda, is not less marked. It is the country of the gibbons, the red ourang, the royal tiger, the gavial, and a multitude of peculiar birds. Among the fishes, the family of Chetodons is most numerously represented. Here also are found those curious spiny 
fishes, whose intricate gills suggested the name Labyrinthici, by which they are known. Fishes with tufted gills are more numerous here than in other seas. The insects and mollusks are no less strongly characterized. Among others is the nautilus, the only living representative of the great family of large, chambered-shells which prevailed so extensively over other types, in former geological ages.

440. The large island of Madagascar has its peculiar fauna, characterized by its makis and its curious rodents. It is also the habitat of the Aya-aya. Polynesia, exclusive of New Holland, furnishes a number of very curious animals, which are not found on the Asiatic continent. Such are the herbivorous bats, and the Galeopithecus or flying Maki.

\section{SECTION III.}

\section{CONCLUSIONS.}

441. From the survey we have thus made of the distribufion of the Animal Kingdom, it follows :

1st. Each grand division of the globe has animals which are either wholly or for the most part peculiar to it. These groups of animals constitute the faunas of different regions.

2 d. The diversity of faunas is not in proportion to the distance which separates them. Very similar faunas are found at great distances apart; as, for example, the fauna of Europe and that of the United States, which yet are separated by a wide ocean. Others, on the contrary, differ considerably, though at comparatively short distances; as the fauna of the East Indies and the Sunda Islands, and that of New Holland; or the fauna of Labrador and that of New England.

$3 \mathrm{~d}$. There is a direct relation between the richness of a 
fauna and the climate. The tropical faunas contain a much larger number of more perfect animals than those of the temperate and polar regions.

4th. There is a no less striking relation between the fauna and flora, the limit of the former being oftentimes determined, so far as terrestrial animals are concerned, by the extent of the latter.

442. Animals are endowed with instincts and faculties corresponding to the physical character of the countries they inhabit, and which would be of no service to them under other circumstances. The monkey, which is a frugivorous animal, is organized for living on the trees from which he obtains his food. The reindeer, on the contrary, whose food consists of lichens, lives in cold regions. The latter would be quite out of place in the torrid zone, and the monkey would perish with hunger in the polar regions. Animals which store up provisions are all peculiar to temperate or cold climates. Their instincts would be uncalled for in tropical regions, where the vegetation presents the herbivora with an abundant supply of food at all times.

443. However intimately allied the climate of a country may be to the peculiar character of its fauna, we are not to conclude that the one is the consequence of the other. The differences which are observed between the animals of different faunas are no more to be ascribed to the influences of climate, than their organization is to the influence of the physical forces of nature. If it were so, we should necessarily find all animals precisely similar, when placed under the same circumstances. We shall find, by the study of the different groups in detail, that certain species, though very nearly alike, are nevertheless distinct in two different faunas. Between the animals of the temperate zone of Europe, and those of the United States, there is similarity, but not iden- 
tity; and the particulars in which they differ, though apparently trifling, are yet perfectly constant.

444. Fully to appreciate the value of these differences, it is often requisite to know all the species of a genus or of a family. It is not uncommon to find, upon such an examination, that there is often the closest resemblance between species that dwell far apart from each other, while species of the same genus, that live side by side, are widely different. This may be illustrated by a single example. The Menopoma, Siren, Amphiuma, Axolotl, and the Menobranchus, are Batrachians which inhabit the rivers and lakes of the United States and Mexico. They are very similar in external form, yet differ in some of them having external gills at the sides of the head, while others have them not; and also in having either two or four legs. Hence we might be tempted to refer them to different types, did we not know intermediate animals, completing the series, namely, the Proteus and Megalobatrachus. Now the former exists only in the lakes of Austria, and the latter in Japan. The connection in this case is consequently established by means of species which inhabit distant continents.

445. Neither the distribution of animals therefore, any more than their organization, can be the effect of external influences. We must, on the contrary, see in it the realization of a plan wisely designed, the work of a Supreme Intelligence who created, at the beginning, each species of animal at the place, and for the place, which it inhabits. To each species has been assigned a limit which it has no disposition to overpass so long as it remains in a wild state. Only those animals which have been subjected to the yoke of man, or whose subsistence is dependent on man's social habits, are exceptions to this rule.

446. As the human race has extended over the surface of the earth, man has more or less modified the animal popu- 
lation of different regions, either by exterminating certain species, or by introducing others with which he desires to be more intimately associated, - the domestic animals. Thus, the dog is found wherever we know of the presence of man. The horse, originally from Asia, was introduced into America by the Spaniards; where it has thrived so well, that it is found wild, in innumerable herds, over the Pampas of South America, and the prairies of the West. In like manner the domestic ox became wild in South America. Many less welcome animals have followed man in his perigrinations; as, for example, the rat and the mouse, as well as a multitude of insects, such as the house-fly, the cockroach, and others which are attached to certain species of plants, as the white-butterfly, the Hessian-fly, \&c. The honey-bee also has been imported from Europe.

447. Among the species which have disappeared, under the influence of man, we may mention the Dodo, a peculiar species of bird which once inhabited the Mauritius, some remains of which are preserved in the British and Ashmolean Museums; a large cetacean of the north (Rytina Stelleri), which formerly inhabited the coasts of Behring's Straits, and which has not been seen since 1768. According to all appearances, we must also reckon among these the great stag, the skeleton and horns of which have been found buried in the peat-bogs of Ireland. There are also many species of animals whose numbers are daily diminishing, and whose extinction may be foreseen; as the Canada deer (Wapiti), the Ibex of the Alps, the Lämmergeyer, the bison, the beaver, the wild-turkey, \&c.

448. Other causes may also contribute towards dispersing animals beyond their natural limits. 'Thus the sea-weeds are carried about by marine currents, and are frequently met with far from shore, thronged with little crustaceans, which are in this manner transported to great distances from 
the place of their birth. The drift-wood which the Gulf stream floats from the Gulf of Mexico even to the western shores of Europe, is frequently perforated by the larvæ of insects, and may probably serve as depositories for the eggs of fishes, crustacea and mollusks. It is possible also that aquatic birds may contribute in some measure to the diffusion of some species of fishes and mollusks, either by the eggs becoming attached to their feet, or by means of those which they evacuate undigested, after having transported them to considerable distances. Still, all these circumstances exercise but a very feeble influence upon the distribution of species in general, and each country, none the less, preserves its peculiar physiognomy, so far as its animals are concerned.

449. There is only one way to account for the distribution of animals as we find them, namely, to suppose that they are autochthonoi, that is to say, that they originated like plants, on the soil where they are found. In order to explain the particular distribution of many animals, we are even led to admit that they must have been created at several points of the same zone, as we must infer from the distribution of aquatic animals, especially that of Fishes. If we examine the fishes of the different rivers of the United States, peculiar species will be found in each basin, associated with others which are common to several basins. Thus, the Delaware River contains species not found in the Hudson. But, on the other hand, the pickerel is found in both. Now if all animals originated at one point, and from a single stock, the pickerel must have passed from the Delaware to the Hudson, or vice versa, which it could only have been done by passing along the sea-shore, or by leaping over large spaces of terra firma; that is to say, in both cases it would be necessary to do violence to its organization. Now such 
a supposition is in direct opposition to the immutability of the laws of Nature.

450. We shall hereafter see that the same laws of distribution are not limited to the actual creation only, but that they have also ruled the creations of former geological epochs, and that the fossil species have lived and died, most of them, in the spot where their remains are found.

451. Even Man, although a cosmopolite, is subject, in a certain sense, to this law of limitation. While he is everywhere the one identical species, yet several races, marked by certain peculiarities of features, are recognized; such as the Caucasian, Mongolian, and African races, of which we are hereafter to speak. And it is not a little remarkable, that the abiding places of these several races correspond very nearly, with some of the great zoölogical regions. Thus we have a northern race, comprising the Samoyedes in Asia, the Laplanders in Europe, and the Esquimaux in America, corresponding to the arctic fauna (400), and like it, identical on the three continents, having for its southern limit the region of trees (422). In Africa, we have the Hottentot and Negro races, in the south and central portions respectively, while the people of northern Africa are allied to their neighbors in Europe; just as we have seen to be the case with the zoölogical fauna in general (403). The inhabitants of New Holland, like its animals, are the most grotesque and uncouth of all races (433).

452. The same arrangement holds good elsewhere, though not always in so remarkable a degree. In America, especially, while the aboriginal race is as well distinguished from other races as is its flora, the minor divisions are not so decided. Indeed, the facilities, or sometimes we might rather say necessities, arising from the varied supplies of 
animal and vegetable food in the several regions, might be expected to involve, with his corresponding customs and modes of life, a difference in the physical constitution of man, which would contribute to augment any primeval differences. It could not indeed be expected, that a people constantly subjected to cold, like the people of the North, and living almost exclusively on fish, which they cannot obtain without great toil and peril, should present the same characteristics, either bodily or mental, as those who idly regale on the spontaneous bounties of tropical vegetation. 


\section{CHAPTER FOURTEENTH.}

\section{GEOLOGICAL SUCCESSION OF ANIMALS; OR, THEIR DISTRIBUTION IN TIME.}

\section{SECTION I.}

\section{STRUCTURE OF THE EARTH'S CRUST.}

453. The records of the Bible, together with human tradition, teach us that man and the animals associated with him were created by the word of God; " the Lord made heaven and earth, the sea, and all that in them is;" and this truth is confirmed by the revelations of science, which unequivocally indicate the direct interventions of creative power.

454. But man and the animals which now surround him are not the only kinds which have had a being. The surface of our planet, anterior to their appearance, was not a desert. There are, scattered through the crust of the earth, numerous animal and vegetable remains, which show that the earth had been repeatedly supplied with, and long inhabited by animals and plants altogether different from those now living.

455. In general, their hard parts are the only relics of them which have been preserved, such as the skeleton and teeth of Vertebrates; the shells of the Mollusks and Radiata; 
the shields of the Crustaceans, and sometimes the wing-cases of Insects. Most frequently they have lost their original chemical composition, and are changed into stone; and hence the name of petrifactions or fossils, under which latter term are comprehended all the organized bodies of former epochs, obtained from the earth's crust.

456. The study of these remains and of their position in the rocks constitutes PaLeontology; one of the most essential branches of Zoölogy. Their geological distribution, or the order of their successive appearance, namely, the distribution of animals in time, is of no less importance than the geographical distribution of living animals, of which we have treated in the preceding chapter. To obtain an idea of the successive creations, and of the stupendous length of time they have required, it is necessary to sketch the principal outlines of Geology.

457. The rocks* which compose the crust of our globe are of two kinds :

1. The Massive Rocks, called also Plutonic or Igneous Rocks, which lie beneath all the others, or have sometimes been forced up through them, from beneath. They were once in a melted state, like the lava of the present epoch, and on cooling at the surface formed the original crust of the globe of granite, porphyry, basalt, \&c.

2. The Sedimentary or Stratified Rocks, called also Neptunian Rocks, which have been deposited in water, in the same manner as modern seas and lakes deposit sand and mud on their shores, or at the bottom.

458. These sediments have been derived partly from the disintegration of the older rocks, and partly from the decay of plants and animals. The materials being disposed in

* Rocks, in a geological sense, include all the materials of the earth, the loose soil and gravel, as well as the firm rock. 
layers or strata have become, as they hardened, limestones, slates, marls, or grits, according to their chemical and mechanical composition, and contain the remains of the animals and plants which were scattered through the waters.*

459. The different strata, when undisturbed, are arranged one above the other in a horizontal manner, like the leaves of a book, the lowest being the oldest. In consequence of the commotions which the crust of the globe has undergone, many points of its surface have been elevated to great heights, in the form of mountains; and hence it is that fossils are sometimes found at the summit of the highest mountains, though the rocks containing them were originally formed at the bottom of the sea. But even when folded, or partly broken, their relative age may still be determined by an examination of the ends of the upturned strata, where they appear or crop out in succession, at the surface, or on the slopes of mountains, as seen in the diagram (Fig. 154).

460. The sedimentary rocks are the only ones which have been found to contain animal and vegetable remains. They are found imbedded in the sediment, just as we should find them in the mud now deposited at the bottom of the sea, if laid dry. The strata containing fossils are numerous. The comparison and detailed study of them belongs

* Underneath the deepest strata containing fossils, between these and the Plutonic rocks, are generally found very extensive layers of slates without fossils (gneiss, mica-slate, talcose-slate), though stratified, and known to the geologist under the name of Metamorphic Rocks (Fig. 154, M), being probably sedimentary rocks which have undergone considerable changes. 'The Plutonic rocks, as well as the metamorphic rocks, are not always confined to the lower levels, but they are often seen rising to considerable heights, and forming many of the loftiest peaks of the globe. The former also penetrate, in many cases, like veins, through the whole mass of the stratified and metamorphic layers, and expand at the surface; as is the case with the trap dykes, and as lava streams actually do now (Fig. 154, $T, L$ ). 
to Geology, of which it forms an essential part. A group of strata extending over a certain geographical extent, all of which contain some fossils in common, no matter what may be the chemical character of the rock, whether it be limestone, sand or clay, is termed a geological Formation. Thus, the coal beds, with the intervening slates and grits, and the masses of limestone in which they are often imbedded, constitute but one formation, the carboniferous formation.

461. Among the stratified rocks we distinguish ten principal Formations, each of which indicates an entirely new era in the earth's history; while each of the layers which compose a formation indicates but some partial revolution. Proceeding from below upwards, they are as follows, as indicated in the cut, and also in the lower diagram on the frontispiece.

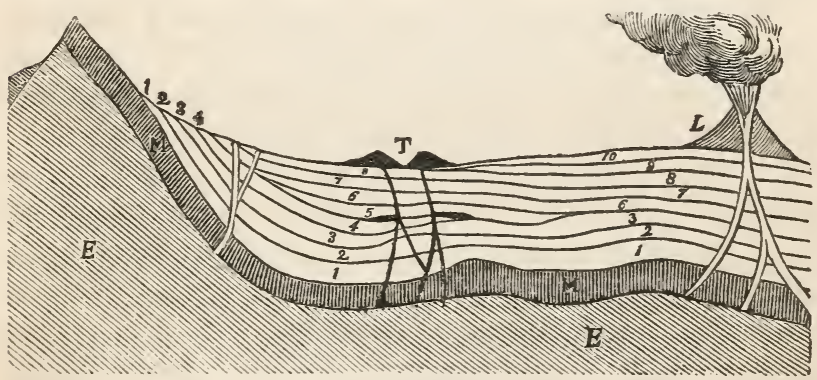

Fig. 154.

1st. The Lower Silurian. This is a most extensive formation, no less than eight stages of which have been made out by Geologists in North America, composed of various limestones and sandstones.*

* 1. Potsdam Sandstone ; 2. Calciferous Sandstone; 3. Chazy Limestone; 4. Bird's-eye Limestone; 5. Black River Limestone ; 6. Trenton Limestone; 7. Utica Slate; 8. Hudson River Group; being all found in the western parts of the United States. 
2d. The Upper Silurian. It is also a very extensive formation, since about ten stages of it are found in the State of New York.*

3d. The Devonian, including in North America no less than eleven stages. $t$ It occurs also in Russia and Scotland, where it was first made out as a peculiar formation.

4th. The Carboniferous Formation, consisting of three grand divisions. $\ddagger$

5th. The Trias, or Saliferous Formation which, containing the richest deposits of Salt on the continent of Europe, comprises three stages, $\oint$ to one of which the Sandstone of the Connecticut valley belongs.

6th. The Oölitic Formation, only faint traces of which exist on the continent of America. It comprises at least four distinct stages.\|

7th. The Cretaceous or Chalk Formation, of which three principal stages have been recognized, two of which are feebly represented in this country, in the Southern and Middle States.

8th. The Lower Tertiary or Eocene, very abundant in the Southern States of the Union, and to which belong the coarse limestone of Paris, and the London clay in England.

* 1. Oneida Conglomerate ; 2. Medina Sandstone ; 3. Clinton Group; 4. Niagara Group; 5. Onondaga Salt Group; 6. Water Limestone; 7. Pentamerus Limestone; 8. Delthyris Shaly Limestone; 9. Encriual Limestone; 10 . Upper Pentamerus Limestone.

$\dagger$ 1. Oriskany Sandstone ; 2. Cauda-Galli Grit ; 3. Onondaga Limestone; 4. Corniferous Limestone; 5. Marcellus Shale; 6. Hamilton Group; 7. Tully Limestone; 8. Genesee Slate; 9. Portage Group; 10. Chemung Group; 11. Old Red Sandstone.

$\ddagger$ 1. The Permian, extensively developed in Russia, especially in the government of Perm; 2. The coal measures, containing the rich deposits of coal in the Old and New World; 3. The Magnesian Limestone of England.

§1. New Red Sandstone; 2. Muschelkalk ; 3. Keuper.

II 1. The Lias; 2. The Lower Oölite; 3. The Middle Oölite; 4. The Upper Oölite. 
9th. The Upper Tertiary or Miocene, and Pleiocene, found also in the United States, as far north as Martha's Vineyard, and very extensive in Southern Europe, as well as in South America.

10th. The Drift, forming the most superficial deposits, and extending over a large portion of the northern countries in both hemispheres.

We have thus more than forty distinct layers already made out, each of which marks a distinct epoch in the earth's history, indicating a more or less extensive and important change in the condition of its surface.

462. All the formations are not always found, or are not developed to the same extent, in all places. It is the same with the several strata of which they are composed. In other words, the layers of the earth's crust are not continuous throughout, like the coats of an onion. There is no place on the globe where, if it were possible to bore down to its centre, all the strata would be found. It is easy to understand how this must be so. Since irregularities in the distribution of water upon the hard crust have, necessarily, always existed to a certain extent, portions of the earth's surface must have been left dry at every epoch of its history, gradually forming large continents and islands, as the changes were multiplied. And since the rocks were formed by the subsidence of sediment in water, no rocks would be formed except in regions then covered by water; they would be thickest at the parts where most sediment was deposited, and gradually thin out towards their circumference. We may therefore infer, that all those portions of the earth's surface which are destitute of a certain formation were dry land, during that epoch of the earth's history to which such formation relates, excepting, indeed, where the rocks have been subsequently removed by the denuding action of water or other causes. 
463. Each formation represents an immense period of time, during which the earth was inhabited by successive races of animals and plants, whose remains are often found, in their natural position, in the places where they lived and died, not scattered at random, though sometimes mixed together by currents of water, or other influences, subsequent to the time of their interment. From the manner in which the remains of various species are found associated in the rock, it is easy to determine whether the animals to which these remains belonged lived in the water, or on land, on the beach or in the depths of the ocean, in a warm or in a cold climate. They will be found associated in just the same way as animals that live under similar influences at the present day.

464. In most geological formations, the number of species of animals and plants found in any locality of given extent, is not below that of the species now living in an area of equal extent; for though, in some deposits, the variety of the animals contained may be less, in others it is greater than that on the present surface. Thus, the coarse limestone in the neighborhood of Paris, which is only one stage of the lower tertiary, contains not less than 1200 species of shells; whereas the species now living in the Mediterranean do not amount to half that number. Similar relations may be pointed out in America. Mr. Hall, one of the geologists of the New York Survey, has described, from the Trenton limestone (one of the ten stages of the lower Silurian), 170 species of shells, a number almost equal to that of all the species found actually living on the coast of Massachusetts.

465. Nor was the number of individuals less than at present. Whole rocks are entirely formed of animal remains, particularly by corals and shells. So, also, coal is composed of the remains of plants. If we consider the slowness with which corals and shells are formed, it will give us 
some faint notion of the vast series of ages that must have elapsed in order to allow the formation of those rocks, and their regular deposition, under the water, to so great a thickness. If, as all things combine to prove, this deposition took place in a slow and gradual manner in each formation, we must conclude, that the successive species of animals found in them followed each other at long intervals, and are not the work of a single epoch.

466. It was once believed that animals were successively created in the order of their relative perfection; so that the most ancient formations contained only animals of the lowest grade, such as the Polyps, the Echinoderms, to which succeeded the Mollusks, then the Articulated Animals, and last of all, the Vertebrates. This theory, however, is now untenable; since fossils belonging to each of the four departments have been found in the fossiliferous cieposits of every age. Indeed, we shall see that even in the lower Silurian formation there exist not only Polyps and other Radiata, but also numerous Mollusks, Trilobites (belonging to the Articulata), and even Fishes.

\section{SECTION II.}

AGES OF NATURE.

467. Each formation, as has been before stated (460), contains remains peculiar to itself, which do not extend into the neighboring deposits above or below it. Still there is a connection between the different formations, more strong in proportion to their proximity to each other. Thus, the animal remains of the chalk, while they differ from those of all other formations, are nevertheless much more nearly related to those of the oölitic formation, which immediately 
precedes, than to those of the carboniferous formation, which is much more ancient; and in the same manner, the fossils of the carboniferous group approach more nearly to those of the Silurian formation, than to those of the Tertiary.

468. These relations could not escape the observation of naturalists, and indeed they are of great importance for the true understanding of the development of life at the surface of our earth. And, as in the history of man, several grand periods have been established, under the name of Ages, marked by peculiarities in his social and intellectual condition, and illustrated by cotemporaneous monuments, so, in the history of the earth also, are distinguished several great periods, which may be designated as the various Ages of Nature, illustrated in like manner by their monuments, the fossil rem xins, which, by certain general traits stamped upon them, clearly indicate the eras to which they belong.

469. We distinguish four Ages of Nature, corresponding to the great geological divisions, namely:

1st. The Primary or Paleozoic Age, comprising the lower Silurian, the upper Silurian, and the Devonian. During this age there were no air-breathing animals. The fishes were the masters of creation. We may therefore call it the Reign of Fishes.

2d. The Secondary Age, comprising the carboniferous formation, the Trias, the oölitic, and the cretaceous formations. This is the epoch in which air-breathing animals first appear. The reptiles predominate over the other classes, and we may therefore call it the Reign of Reptiles.

3d. The Tertiary Age, comprising the tertiary formations. During this age, terrestrial mammals, of great size, abound. This is the Reign of Mammals.

4th. The Modern Age, characterized by the appearance of the most perfect of all created beings. This is the Reign of Man. 
Let us review each of these four Ages of Nature, with reference to the diagram at the beginning of the volume.

470. The Paleozoic Age. Reign of Fishes. - The paleozoic fauna, being the most remote from the present epoch, presents the least resemblance to the animals now existing, as will easily be perceived by a glance at the fol-

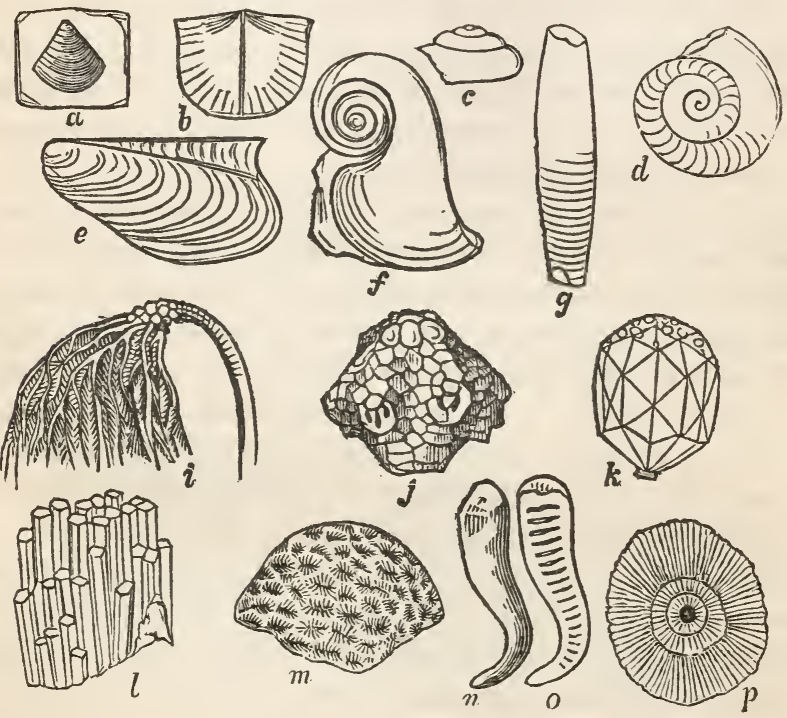

Fig. 155.

lowing sketches (Fig. 155). In no other case do we meet with animals of such extraordinary shapes, as in the strata of the Paleozoic age.

4;1. We have already stated (466) that there are found, in each formation of the primary age, animal remains of all the four great departments, namely, vertebrates, articulata, mollusks, and radiata. We have now to examine to what peculiar classes and families of each department these remains belong, with a view to ascertain if any relation 
between the structure of an animal, and the epoch of its first appearance on the earth's surface may be traced.

472. As a general result of the inquiries hitherto made, it may be stated that the paleozoic animals belong, for the most part, to the lower divisions of the different classes. Thus, of the class of Echinoderms, we find scarcely any but Crinoids, which are the least perfect of the class. We have represented, in the above sketches, several of the most curious forms, * as well as of the Polyps, of which there are some quite peculiar types from the Trenton limestone and from the Black River limestone.

473. Of the Mollusks, the bivalves or Acephala are numerous, but for the most part belong to the Brachiopoda, that is to say, to the lowest division of the class, including mollusks with unequal valves having peculiar appendages in the interior. The Leptena alternata $(b)$ which is found very abundantly in the Trenton limestone is one of these shells. The only fossils yet found in the Potsdam sandstone, the oldest of all fossiliferous deposits, belong also to this family (Lingula prima, a). Besides this, there are also found some bivalves of a less uncommon shape (Avicula decussata, $e$ ).

474. The Gasteropods are less abundant; some of them are of a peculiar shape and structure (Bucania expansa, $f$; Euomphalus hemispharicus, c). Those more similar to our common marine snails have all an entire aperture; those with a canal being of a more recent epoch.

475. Of the Cephalopods we find some genera not less curious, part of which disappear in the succeeding epochs;

* (i) Cyathocrinus ornatissimus, Hall ; (j) Melocrinus Amphora, Goldf.

(k) Cariocrinus ornatus, Say; $(l)$ Columnaria alveolatn; $(m)$ Cyathophyllum quadrigeminum, Goldf.; $(n, o)$ Caninia flexuosa; $(p)$ Chøetes lycoperdon. 
such, in particular, as those of the straight, chambered shells called Orthoceratites, some of which are twelve feet in length (Orthoceras fusiforme, $g$ ). There are also found some of a coiled shape, like the Ammonites of the secondary age, but having less complicated partitions (Trocholites ammonius, $d)$. The true cuttle-fishes, which are the highest of the class, are not yet found. On the contrary, the Bryozoa, which have long been considered as polyps, but which, according to all appearances, are mollusks of a very low order, are very numerous in this epoch.

476. The Articulata of the Paleozoic age are mostly Trilobites, animals which evidently belong to the lower order of the Crustaceans (Fig. 156). There is an incompleteness and want of development, in the form of their body, that strongly reminds us of the embryo among the crabs. A great many genera have already been discovered.

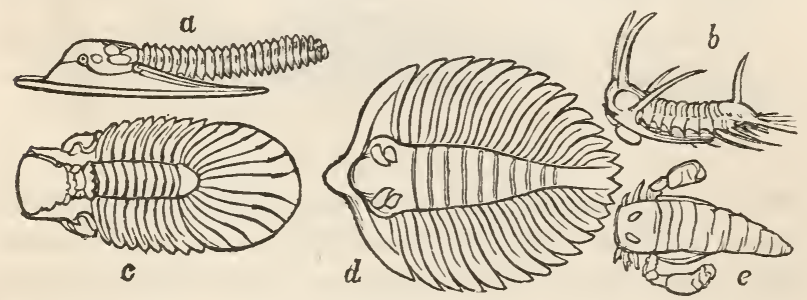

Fig. 156.

We may consider as belonging to the more extraordinary, the forms here represented, (Harpes, $a$; Arges, $b$; Brontes, $c$; and Platynotus, $d)$; the latter, as well as the Isotelus, the largest of all, being peculiar to the Paleozoic deposit of this country. Some others seem more allied to the crustaceans of the following ages, but are nevertheless of a very extraordinary form, as Eurypterus remipes $(e)$. There are also found, in the Devonian, some very large Entomostraca. The class of Worms is represented only by a 
few Serpulæ, which are marine worms, surrounded by a solid sheath. The class of Insects is entirely wanting.

477. 'The inferiority of the earliest inhabitants of our earth appears most striking among the Vertebrates. 'There are as yet neither reptiles, birds, nor mammals. The fishes, as we have said, are the sole representatives of this division of animals.

478. But the fishes of that early period were not like ours. Some of them had the most extraordinary forms, so that they have been often mistaken for quite different animals; for example, the Pterichthys (a), with its two wing-

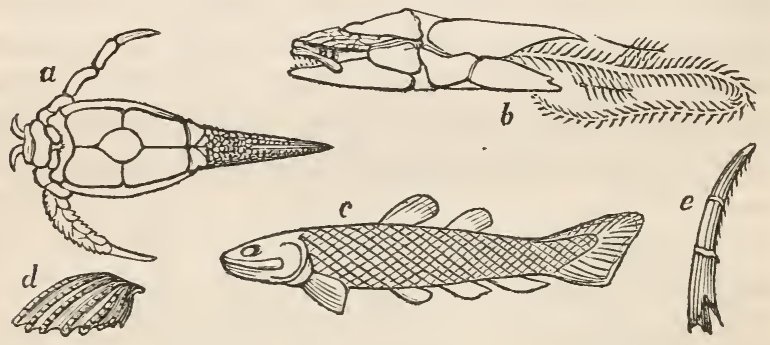

Fig. 157 .

like appendages, and also the Coccosteus ( $b$ ) of the same deposit, with its large plates covering the head and the anterior part of the body. There are also found remains of shark's spines $(e)$, as well as palatal bones $(d)$, the latter of a very peculiar kind. Even those fishes which have a more regular shape, as the Dipterus $(c)$, have not horny scales like our common fishes, but are protected by a coat of bony plates, covered with enamel, like the gar-pikes of the American rivers. Moreover, they all exhibit certain characteristic features, which are very interesting in a physiological point of view. They all have a broad head, and a tail terminating in two unequal lobes. What is still more curious, the best preserved specimens show no indications 
of the bodies of vertebræ, but merely the spinous processes; from which it must be infered that the body of the vertebra was cartilaginous, as it is in our Sturgeons.

479. Recuring to what has been stated on that point, in Chapter Twelfth, we thence conclude, that these ancient fishes were not so fully developed as most of our fishes, being, like the Sturgeon, arrested, as it were, in their development; since we have shown that the Sturgeon, in its organization, agrees, in many respects, with the Cod or Salmon in their early age.

480. Finally, there was, during the Paleozoic age, less variety among the animals of the different regions of the globe; and this may be readily explained by the peculiar configuration of the earth at that epoch. Great mountains did not then exist; there were neither lofty elevations nor deep depressions. The sea covered the greater part, if not the whole, of the surface of the globe; and the animals which then existed, and whose remains have been preserved, were all, without exception, aquatic animals, breathing by gills. This uniform distribution of the waters impressed a very uniform character upon the whole Animal Kingdom. Between the different zones and continents, no such strange contrasts of the different types existed as at the present epoch. The same genera, and often the same species were found in the seas of America, Europe, Asia, Africa, and New Holland; from whence we must conclude that the climate was much more uniform than at the present day. Among the aquatic population, no sound was heard. All creation was then silent.

481. The Secondary Age. Reign of Reptiles. - The Secondary age displays a greater variety of animals as well as plants. The fantastic forms of the Paleozoic age disappear, and in their place we see a greater symmetry of shape. The advance is particularly marked in the series of 
vertebrates. The fishes are no longer the sole representatives of that department. Reptiles, Birds, and Mammals successively make their appearance, but the Reptiles are preponderant, particularly in the oölitic formation; on which account we have called this the Reign of Reptiles.

482. The carboniferous formation is the most ancient of the Secondary age. Its fauna shows, in various respects, a great analogy with that of the Paleozoic epoch, especially in its Tribolites and Mollusks.* Besides these, we meet here with the first air-breathing animals, which are Insects and Scorpions. At the same time, land-plants first make their appearance, namely, ferns of great size, club-mosses, and other fossil plants. This corroborates what has been already said concerning the intimate connection that exists, and from all times has existed, between animals and the land-plants (399). The class of Crustaceans has also improved during the epoch of the coal. It is no longer composed exclusively of Trilobites, but the horse-shoe crabs also appear, with other gigantic forms. Some of the Mollusks seem also to approach those of the Oölitic period, particularly the Bivalves.

483. In the Trias period, which immediately succeeds the Carboniferous, the fauna of the Secondary age acquires its definitive character; here the Reptiles first appear. They are huge Crocodilian animals, belonging to a peculiar order, the Rhizodonts (Protosaurus, Notosaurus, and Labyrinthodon). The well-known discoveries of Professor

* This circumstance, in connection with the absence of Reptiles, has caused the coal-measures to be generally referred to the Paleozoic epoch. But there are other reasons which induce us to unite the carboniferous period with the secondary age, especially when considering that here the land animals first appear, whereas, in the Paleozoic age, there are only marine animals, breathing by gills; and also, that a luxuriant terrestrial vegetation was developed at that epoch. 
Hitchcock, in the red sandstone of the Connecticut, have made us acquainted with a great number of birds' tracks

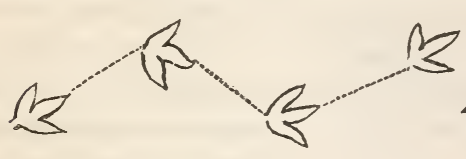

$a$

Fig. 158.

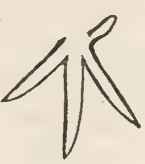

$b$

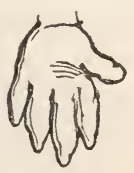

c

(Fig. 15\%, $a, b$ ), belonging to this epoch, for the most part indicating birds of gigantic size. These impressions, which he has designated under the name of Ornithichnites, are some of them eighteen inches in length, and five feet apart, far exceeding in size the tracks of the largest ostrich. Other tracks, of a very peculiar shape, have been found in the red sandstone of Germany and in Pennsylvania. They were probably made by Reptiles, which have been called Cheirotherium, from the resemblance of the track to a hand $(c)$. The Mollusks, Articulates, and Radiates of this period, approach to the fauna of the succeeding period.

484. The fauna of the Oölitic formation is remarkable for the great number of gigantic Reptiles which it contains. In

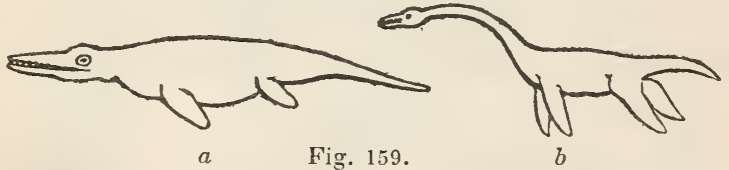

this formation we find those enormous Amphibia, known under the name Ichthyosaurus, Plesiosaurus, Megalosaurus, and Iguanodon. The first, in particular, the Icthyosaurus (Fig. 159, a), greatly abounded on the coast of the continents of that period, and their skeletons are so well preserved, that we are enabled to study even the minutest details of their structure, which differs essentially from that of the Reptiles of the present day. In some respects they form an intermediate link between the Fishes and Mammals, 
and may be considered as the prototypes of the Whales, having, like them, limbs in the form of oars. The Plesiosaur'us (b), agrees, in many respects, with the Ichthyosaurus, in its

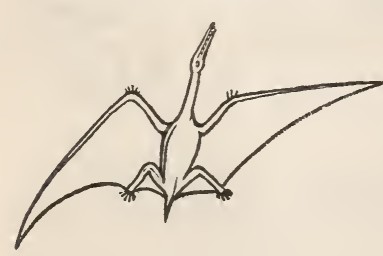

Fig. 160 . structure, but is easily distinguished by its long neck, which resembles somewhat the neck of some of our birds. A still more extraordinary Reptile is the Pterodactylus (Fig. 160), with its long fingers, like those of a bat, and which is thought to have been capable of flying.

485. It is also in the upper stages of this formation that we first meet with Tortoises. Here also we find impressions of several families of insects, (Libellula, Coleoptera, Ichneumons, \&c.) Finally, in these same stages, the slates of Stonesfield, the first traces of Mammals are found, namely, the jaws and teeth of animals having some resemblance to the Opossum.

486. The department of Mollusks is largely represented in all its classes. The peculiar forms of the primary age have almost all disappeared, and are replaced by a much larger quantity of new forms. Of the Brachiopods only one
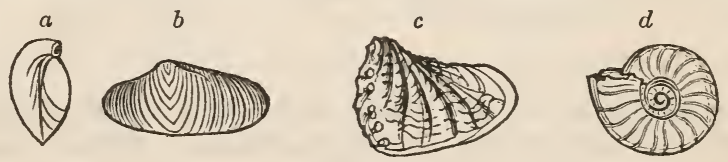

Fig. 161 .

type is very abundant, namely, that of the Terebratula (Fig. 161, a). Among the other Bivalves there are many peculiar forms, as the Goniomya $(b)$, and the Trigonia $(c)$. The Gasteropods display a great variety of species, and also the Cephalopods, among which the Ammonites are the 
most prominent $(d)$. There are also found, for the first time, numerous representatives of the Cuttle-fishes, under the form of Belemnites (Fig. 162), an extinct type of animals, sur-

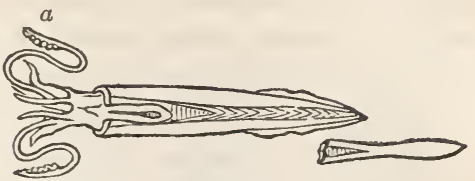

Fig. 162 . $b$

rounded by a sheath, and containing in their interior a peculiar bone, somewhat similar to the bone of the Sepia, and which commonly is the only preserved part $(b)$.

487. The variety is not less remarkable among the Radiates. There are to be found representatives of all the classes; even traces of Jelly-fishes have been made out in the slate of Solenhofen, in Bavaria. The Polyps were very abundant at that epoch, especially in the upper stages, one of which has received the name of Coral-rag. Indeed, there are to be found whole reefs of corals in their natural position, similar to those which are to be seen in the islands

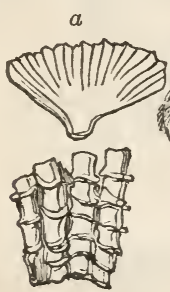

$b$

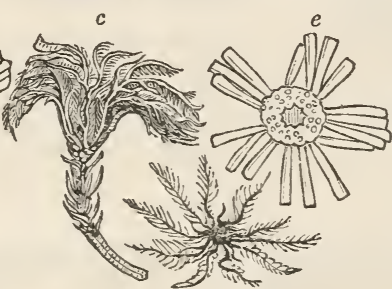

Fig. 163. $d$

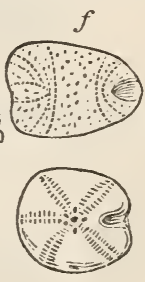

g

of the Pacific. Among the most remarkable types of stony Polyps, may be named the fan-like Lobophyllia (L. flabellum, a), and various forms of tree-corals (Lithodendron pseudostylina, $b$ ). But the greatest variety exists among the Echinoderms. The Crinoids are not quite so numerous as in former ages. Among the most abundant are the Pentacrinus $(c)$. There are also already found Comatula-like animals, that is to say, free Crinoids, (Pterocoma pinnata, $d)$. 
Many Star-fishes are likewise to be found in the various stages of this formation. Finally, there is an extraordinary variety of Echini, among them Cidaris $(e)$, with large spines, and several other types not found before, as, for example, the Dysaster $(f)$ and the Nucleolites $(g)$.

488. The fauna of the Cretaceous period bears the same general characters as the Oölitic, but with a more marked tendency towards the actual forms. Thus the Ichthyosauri and Plesiosauri, that characterize the preceding epoch, are succeeded by gigantic Lizards, more nearly approaching the Reptiles of the present day. Among the Mollusks, a great number of new forms appear, especially among the Cephalopods, * some of which resemble
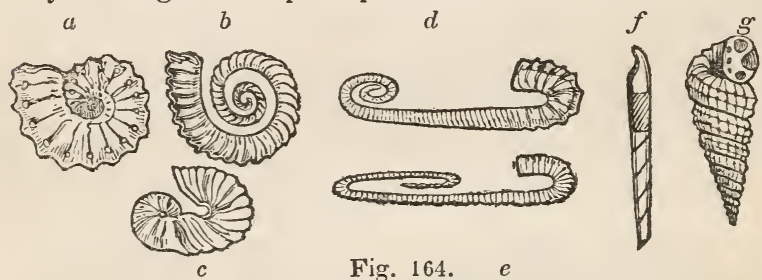

Fig. 164. $e$

the Gasteropods in their shape, but are nevertheless chambered. The Ammonites themselves are quite as

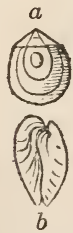

$c$

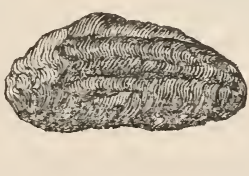

$d$

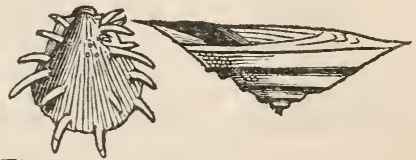

Fig. 165 .

numerous as in the Oölitic period, and are in general much ornamented $(a)$. The Acephala furnish us also with peculiar types, not found elsewhere, Magas (a),

* (a) Ammonites; (b) Crioceras; (c) Scaphites; (d) Ancyloceras; (e) Hamites; ( $f$ ) Baculites; ( $g$ ) Turrilites. 
the Inoceramus (b), the Hippurites (c), and peculiar Spon$d y l i$, with long spines $(d)$. There is also a great variety of Gasteropods, among which are some peculiar forms of Pleu-
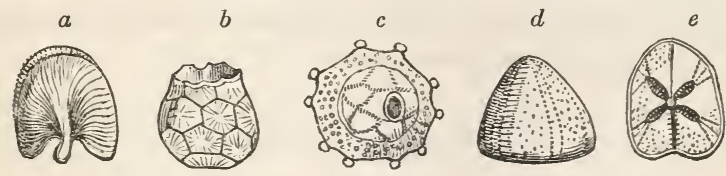

Fig. 166 .

rotomaria $(e)$. The Radiates are not inferior to the others in variety.*

489. Tertiary Age. Reign of Mammals. - The most significant characteristic of the Tertiary faunas is their great resemblance to those of the present epoch. The animals belong in general to the same families, and mostly to the same genera, differing only as to the species. And the specific differences are sometimes so slightly marked, that a considerable familiarity with the subject is required, in order readily to detect them. Many of the most abundant types of former epochs have now disappeared. The changes are especially striking among the Mollusks, the two great families of Ammonites and Belemnites, which present such an astonishing variety in the Oölitic and Cretaceous epochs, being now completely wanting. Changes of no less importance take place among the Fishes, which are for the most part covered with horny scales, like those of the actual epoch, while in earlier ages they were generally covered with enamel. Among the Radiata, we see the family of Crinoids reduced to a very few species, while, on the other hand, a great number of new Star-fishes and Seaurchins make their appearance. There are besides, innumerable remains of a very peculiar type of animals, almost

* (a) Diploclenium cordalum; (b) Marsupites; (c) Salenia ; (d) Galerites: (e) Micraster cor-anguinum. 
unknown to the former ages, as well as to the actual period.

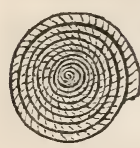

Fig. 167.

They are little-chambered shells, known to geologists under the name of Nummulites, from their coin-like appearance, and form very extensive layers of rocks (Fig. 167).

490. But what is more important, in a philosophical point of view, is, that the aquatic animals are no longer predominant in the Creation. The great marine or amphibian reptiles give place to numerous mammals of great size. For which reason we have called this age the Reign of Mammals. Here are also found the first distinct remains of fresh-water animals.

491. The lower stage of this formation is particularly characterized by great Pachyderms, among which we may mention the Paleotherium and Anoplotherium, which have acquired such celebrity from the researches of Cuvier. These animals, among others, abound in the Tertiary formations of the neighborhood of Paris. The Paleotheriums, of

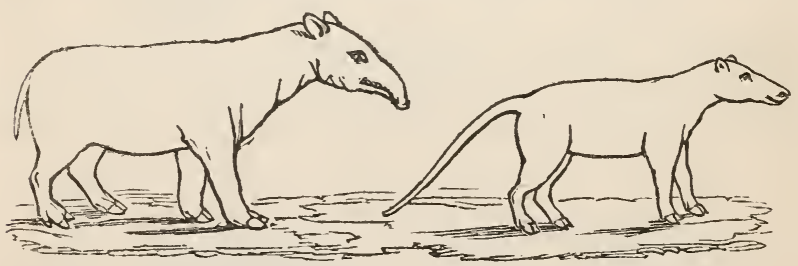

Fig. 168.

Fig. 169.

which several species are known, are the most common; they resemble (Fig. 168), in some respects, the Tapirs, while the Anoplotheriums are more slender animals (Fig. 169). On this continent are found the remains of a most extraordinary animal of gigantic size, the Basilosaurus, a true cetacean. Finally, in these stages, the earliest remains of Monkeys have been detected.

492. The fauna of the upper stage of the Tertiary forma- 
tion approaches yet more nearly to that of the present epoch. Besides the Pachyderms, that were also predominant in the lower stage, we find numbers of carnivorous animals, some of them much surpassing in size the lions and tigers of our day. We meet also gigantic Edentata, and Rodents of great size.

493. The distribution of the Tertiary fossils also reveals to us the important fact, that in this epoch, animals of the same species were circumscribed in much narrower limits than before. The earth's surface, highly diversified by mountains and valleys, was divided into numerous basins, which, like the Gulf of Mexico, or the Mediterranean of this day, contained species not found elsewhere. Such was the basin of Paris, that of London, and on this continent, that of South Carolina.

494. In this limitation of some types within certain bounds, we distinctly observe another approach to the actual condition of things, in the fact that certain groups of animals which occur only in particular regions are found to have already existed in the same regions during the Tertiary epoch. Thus the Edentata are the predominant animals in the fossil fauna of Brazil as well as in its actual fauna ; and Marsupials were formerly as numerous in New Holland as they now are, though in general of much larger size.

495. The Modern Epoch. Reign of Man.-The Present epoch succeeds to, but is not a continuation of, the Tertiary age. These two epochs are separated by a great geological event, traces of which we see everywhere around us. The climate of the northern hemisphere, which had been, during the Tertiary epoch, considerably warmer than now, so as to allow of the growth of palm-trees in the temperate zone of our time, became much colder at the end of this period, causing the polar glaciers to advance south, much beyond their previous limits. It was this ice, either floating 
like icebergs, or, as there is still more reason to believe, moving along the ground, like the glaciers of the present day, that, in its movement towards the South, rounded and polished the hardest rocks, and deposited the numerous detached fragments brought from distant localities, which we find everywhere scattered about upon the soil, and which are known under the name of erratics, boulders, or greyheads. This phase of the earth's history has been called, by geologists, the Glacial or Drift period.

496. After the ice that carried the erratics had melted away, the surface of North America and the North of Europe was covered by the sea, in consequence of the general subsidence of the continents. It is not until this period that we find, in the deposits known as the diluvial or pleistocene formation, incontestable traces of the species of animals now living.

497. It seems, from the latest researches of Geologists, that the animals belonging to this period are exclusively marine; for, as the northern part of both continents was covered to a great depth with water, and only the summits of the mountains were elevated above it, as islands, there was no place in our latitudes where land or fresh-water animals could exist. They appeared therefore at a later period, after the water had again retreated; and, as from the nature of their organization, it is impossible that they should have migrated from other countries, we must conclude that they were created at a more recent period than our marine animals.

498. Among these land animals which then made their appearance, there were representatives of all the genera and species now living around us, and besides these, many types now extinct, some of them of a gigantic size, such as the Mastodon, the remains of which are found in the uppermost strata of the earth's surface, and probably the very 
last large animal which became extinct before the creation of man.*

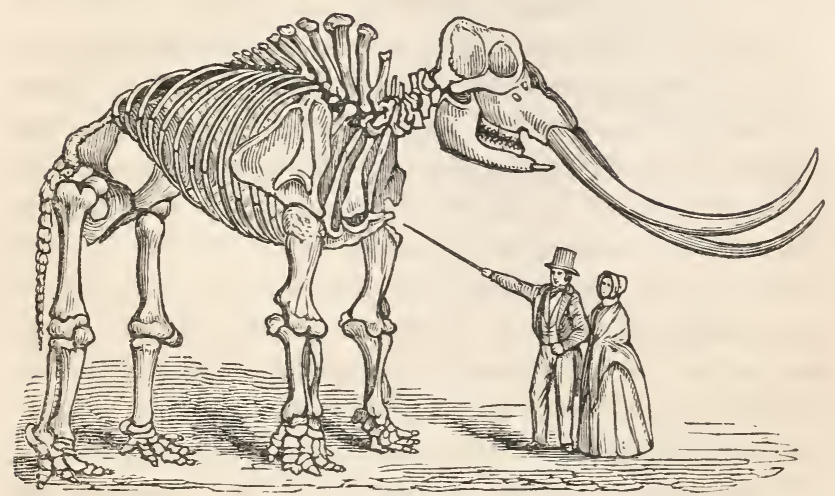

Fig. 170.

499. It is necessary therefore, to distinguish two periods in the history of the animals now living; one in which the marine animals were created, and a second, during which the land and fresh-water animals made their appearance, and at their head MAN.†

\section{CONCLUSIONS.}

500. From the above sketch it is evident that there is a manifest progress in the succession of beings on the surface

* The above diagram is a likeness of the splendid specimen disintered at Newburg, N. Y., now in the possession of Dr. J. C. Warren, in Boston; the most complete skeleton which has ever been discovered. It stands nearly twelve feet in height, the tusks are fourteen feet in length, and nearly every bone is present, in a state of preservation truly wonderful.

+ The former of these phases is indicated in the frontispiece, by a narrow circle, inserted between the upper stage of the Tertiary formation and the Reign of Man properly so called. 
of the earth. This progress consists in an increasing similarity to the living fauna, and among the Vertebrates, especially, in their increasing resemblance to Man.

501. But this connection is not the consequence of a direct lineage between the faunas of different ages. There is nothing like parental descent connecting them. The Fishes of the Paleozoic age are in no respect the ancestors of the Reptiles of the Secondary age, nor does Man descend from the Mammals which preceded him in the Tertiary age. The link by which they are connected is of a higher and immaterial nature ; and their connection is to be sought in the view of the Creator himself, whose aim, in forming the earth, in allowing it to undergo the successive changes which Geology has pointed out, and in creating successively all the different types of animals which have passed away, was to introduce Man upon the surface of our globe. Man is the end towards which all the animal creation has tended, from the first appearance of the first Paleozoic Fishes.

502. In the beginning His plan was formed, and from it He has never swerved in any particular. The same Being who, in view of man's moral wants, provided and declared, thousands of years in advance, that " the seed of the woman shall bruise the serpent's head," laid up also for him in the bowels of the earth, those vast stores of granite, marble, coal, salt, and the various metals, the products of its several revolutions; and thus was an inexhaustible provision made for his necessities, and for the development of his genius, ages in anticipation of his appearance.

503. To study, in this view, the succession of animals in time, and their distribution in space, is therefore to become acquainted with the ideas of God himself. Now, if the succession of created beings on the surface of the globe is the realization of an infinitely wise plan, it follows that there 
must be a necessary relation between the races of animals, and the epoch at which they appear. It is necessary, therefore, in order to comprehend Creation, that we combine the study of extinct species with that of those now living, since one is the natural complement of the other. A system of Zoölogy will consequently be true, in proportion as it corresponds with the order of succession among animals. 



\section{INDEX AND GLOSSARY.}

Abdomen, the lower cavity of the body, 17.

Abranchiates, without gills, xvii.

Acalèpha, a class of Radiates many species of which produce tingling when handled.

Acéphala, mollusks having no distinct head, like clams, xix.

Acoustic, pertaining to the sense of hearing, 32 .

Actínia, digestive apparatus of, 73 .

Affinity, relationship, 6,63 .

Ages of Nature, 189.

Albumen, the white of egg, 108.

Alimentary canal, 73 .

Alimentation, the process of nutrition, 18.

Allántois, Allantoidian, 119.

Alligator, teeth of, 80 .

Alternate reproduction, 127; consequences of, 136 ; difference between, and metamorphosis, 137.

Amblyópsis spelæus, 31 .

Ammonites, xvii. 198, 200, 201.

Amnios, 120.

Amplibia, 71.

Amphipods, a family of crustaceans.

Amphioxus, its place, 148.

Amphiùma, 177.

Analogy, 6 .

Anátifa, metamorphoses of, 145 .

Ancylóceras, 200.

Animaleule, a minute animal, xix.

Animal heat, 96.

Animal life, 20 ; organs of, 20.

Animals, number of; 3 .

Animals and plants, differences between, 17.
Animate, possessed of consciousness, 19.

Anoplothèrium, 202.

Antenna, the jointed feelers of lobsters, insects, \&c., 53.

Aorta, the great blood-vessel arising from the heart, 90 .

Aphides, reproduction of, 131 .

Apóphysis, a projection from the body of a bone, 149 .

Apparatus of motion, 48.

Aptera, wingless insects, xvii.

Aquatic, living in water.

Aqueous, like water.

Aqueous humor, 126.

Arctic fauna, 164.

Areolar tissue, 14.

Arges, 193.

Aristotle's lantern, 77.

Arm, different forms of, 59 .

Artery, 90.

Articulates, composed of joints, like the lobster or caterpillar; number of, 3 .

Ascidia, bottle-shaped mollusks without a shell.

Assimilation, the cliange of blood into bone, muscle, \&c. 96.

Astacus pellucidus, 31 .

Asteridæ, the family of star-fishes, $\mathrm{x}$ viii.

Auditory, pertaining to the sense of hearing, 32 .

Auricle, a cavity of the heart, like a little ear, 89.

Avícula decussata, 192.

Axolotl, 177. 
Baculites, 200.

Bálanus, the barnacle, 144.

Basilosaurus, 202.

Batrachians, the frog tribe, xvi.

Beak, 79.

Belemnites, 199, 201.

Bird-tracks, in red sandstone, 197.

Birds, number of, 3.

Bivalve, having two shells, like the clam, 3.

Blastoderm, the embryonic germ, 111.

Blind-fishes, 31.

Blood, 86.

Boulders, 204.

Brachiopods, a class of mollusks, $\mathrm{x}$ viii.

Brain, 21.

Branchiæ, gills, 94 .

Branchifers, univalve mollusks breatling by gills, xviii.

Bronchi, tubes branching from the windpipe in the lungs, 93.

Brontes, 193.

Bryozoa, xviii. 193.

Bucania expansa, 192.

Calcareous, composed of lime, 51, 107.

Campanularia, reproduction of, 134 , 139.

Canine teeth, 81.

Caninia flexuosa, 192.

Canker-worm, metamorphoses of, 144.

Cannon-bone, 60.

Capillary vessels, 88 .

Carapace, the upper covering of the crab or tortoise, 51.

Carbon, the basis of charcoal and most combustibles, 17.

Carboniferous rocks, 186, 196.

Cariocrinus ornatus, 192.

Carnívora, animals feeding on flesh, xvi. ; teeth of, S2.

Carpus, the wrist, 59.

Cartilage, gristle, 15.

Cartilaginous tissue, 14 .

Cell, 13; nucleated, 14 .

Cephalopods, mollusks with arms surrounding the head, like the cuttle-fish, xvii.

Cercaria, reproduction of, 129,135 .

Cerebral, pertaining to the brain, 21 .

Cestracion Philippi, 171.

Cetaceans, marine animals which nurse their young, like the whale, porpoise, \&c. xvi.
Chætetes lycoperdon, 102.

Chalaza, the albuminous thread by which the yolk of the egg is suspeinded, 109.

Chambers of the eye, 26.

Cheirotherium, 197.

Chelonians, reptiles of the tortoise tribe, xvi.

Chorion, 120.

Choroid, coat of the eye, 25 .

Chrysalis, the insect in its passage from the worm to the fly state, 143.

Chyle, 74.

Chyme, 75.

Cilia, microscopic hairs, like eyelashes, 57, 84, 87, 94.

Circulation, 86 ; great, 90 ; pulmonary or lesser, 90 ; complete, 90 ; incomplete, 91 .

Cirrhípedes, crustacea having curled feelers, like the barnacles, fig. 145.

Clavicle, the collar-bone, 59 .

Climbing, 68.

Coccósteus, 194.

Cold-blooded animals, 96 .

Coleopterous, insects with hard wing cases, like the dor-bug, 3 .

Collar-bone, 59.

Columnaria alveolata, 102.

Comátula, metamorphosis of, 147 , 148.

Constancy of species, 43.

Cornea, the transparent portion of the eye, 25.

Corpuscles, minute bodies, 15 .

Cossus ligniperda, muscles of, 53 .

Cretaceous, or chalk formation, 186.

Cricoid, ring-like, 41 .

Crinoid, lily-like star-fishes, xviii.

Crióceras, 200.

Crustacea, articulated animals having a crust-like covering, like the crab and horse-shoe; heart of, 91 .

Crypts, little recesses or sacs, 100.

Crystalline lens, 25.

Ctenoids, fishes which have the edge of the scales toothed, xvi.

Ctenóphori, soft, radiated animals, moving by cilia, xix.

Cuttle-fish, jaws of, 78 ; heart of, 91 ; metamorphosis of, 148; mode of swimming, 71.

Cyathocrinus ormatissimus, 192.

Cyathophyllum quadrigeminum, 192.

Cycloids, fishes with smooth scales, xvi. 
Deciduous, not permanent during a lifetime, 426.

Deglutition, the act of swallowing, 83.

Dentition, form and arrangement of thc teeth.

Department, a primary division of the animal kingdom, xiv.

Development of the white-fish, 115.

Devonian rocks, 156.

Diaphragm, the partition between the chest and abdomen, 50, 93 .

Diastole, the dilatation of the heart, 90.

Digestion, 73.

Diploctenium cordatum, 201.

Dipterus, 194.

Disc, a more or less circular, flattened body, iii.

Discóphori, disc-shaped animals, like the jelly-fish, xviii.

Distoma, reproduction of, 130 ; in eye of the perch, 140.

Distribution of animals in time, 182.

Dodo, its disappearance, $17 \mathrm{~S}$.

Dorsal cord, 113.

Dorsibranchiates, mollusks having gills upon the back, xviii.

Drift, 157, 204.

Duck-barnacle. See Anatifa.

Dysaster, 200.

Ear, 32.

Echìnoderms, radiate animals armed with spines externally, like the sea-urchin, xviii.

Echinus, the sea-urchin xviii; jaws of, 77; heart of, 91 ; mode of progression, 57.

Echinus sanguinolentus, metamorphosis of, 146.

Egg, 102 ; form of, 103 ; formation of, 104; ovarian, 104; laying of, 105; composition of, 107; development of, 109 ; of Infusoria, 141.

Elementary structure of organized bodies, 12.

Embryo, the young animal bcfore birth, 9, 102; development of, 109.

Embryology, 102, 110; importance of, 122.

Endosmose, 99 . See Exosmose.

Engeena, a large ourang, 174.

Entomóstraca, xrii.

Eocene formation, 186.

Ephyra, 133, 138.

Epidermis, the scarf-skin, 99.

Equivocal reproduction, 127.
Erratics, rolling stones, 204.

Euomphalus hemisphericus, 192.

Eurypterus remipes, 193.

Excretions, 101.

Exhalation, 99.

Exosmose and Endosinose, the process by which two fluids pass each way, through a membrane which separates them, so as to become mingled, 99.

Eye, simple, 27; aggregate, 29; compound, 30 ; destitution of, 31 ; compared to a camera ubscura, 27.

Façette, a very small surface, 30 .

Family, a group including several genera, xiv.

Fauna, 154; distribution of, 161.

Femur, the thigh-bone, 63.

Fibula, the smallest of the two bones of the leg, 63 .

Fins, 70 .

Fishes, number of, 3 ; heart of, 91 ; reign of, $190,191$.

Fissiparous reproduction, propagagation by fissure or division, 125.

Flight, 68.

Fluviatile, pertaining to rivers, 3 .

Follicles, minute pouches, 100.

Formation, geological, 155.

Fossil, dug from the earth, applied to the remains of animals and plants.

Function, the office which an organ is designed to perform, 5 .

Galeopithècus, its facilities for leaping, 69, 175.

Galerìtes, 201.

Gallinaceots, birds allied to the domestic fowl, 161.

Gallop, 67.

Ganglions, scattered nervous masses, from which nervous threads arise, $2 \%$.

Ganoids, fishes having large, bony, cnamelled scales, mostly fossil, xvi.

Gàsteropods, mollusks which cravvl by a tlattened disc, or foot, on the under part of the body, like the snail, xvii.

Gastric juice, 75.

Gavial, a crocodile, with a long, slender head.

Gemmiparous reproduction, propagation by budding, 125 .

General properties of organized bodies, 11. 
Genus, xiv.

Geographical distribution of animals, 154 .

Geological succession of animals, 182.

Germ, the earliest manifestation of the embryo, 18, 111.

Germinative disc, 111 ; vesicle, 104 ; dot, 104, 108.

Gestation, the period of carrying young, 106.

Gills, 7, 94 .

Glacial period, 204.

Glands, 100 ; salivary, 100 .

Globules of chyle, 76 ; of blood, 86 .

Glottis, 41.

Grallatores, birds with long legs for wading, xvi.

Grand-nurses of Cercaria, 131.

Granivorous, birds feeding on grain.

Grit, coarse sandstone, 184.

Hamites, 200.

Harmony of organs, 82 .

Harpes, 193.

Hearing, 31.

Heart, 89.

Herbívora, animals feeding on grass and leaves, xvi.

Hibernation, torpid state of animals during winter, 97.

Hippurites, 201.

Holothurians, soft sea-slugs, bichele-mar, xviii.

Homology, 6.

Humerus, the shoulder-bone, 69.

Hyaline matter, pure, like glass, 15.

Hydra, egg of, 104; propagation of, $125,127$.

Hydrogen, a gas which is the principal constituent of water, 17 .

Hydroids, a family of polyps, xix.

Ichthyosaurus, 197, 200.

Icterus Baltimòre, nest of, 46 .

Igneous, that have been acted upon by fire, 183 .

Iguánodon, 197.

Inanimate, destitute of consciousness, 19.

Incessores, perching birds, like birds of prey, $\mathrm{xV}$.

Incisor teeth, 81 .

Incubation, hatching of eggs by the mother, 107.

Infusoria, microscopic animals inhabiting the water, not yet fully arranged in their proper classes, xix. ; motions of, 16 ; generation of, 141.

Inocéramus, 201.

Inorganic, not made up of tissues, 11 .

Insalivation, 83 .

Instinct, 45.

Intelligence, 44.

Intercellular passages, 13.

Invertebrates, animals destitute of a back-bone.

Iris, the colored portion of the eye, 25.

Isótelus, 193.

Jelly-fish. See Medusa.

Judgment, 44.

Labyrinthodon, 196.

Lacertans, animals of the lizard tribe, xvi.

Lacteals, vessels which take up the nutriment, 76 .

Lamellibránchiates, mollusks having gills arranged in sheets, like the clam and oyster, xviii.

Larva, the caterpillar or worm state of an insect.

Larynx, 41.

Layers of the embryo, 112.

Leaping, 67.

Leptæena alternata, 192.

Life, 11, 20.

Limbs, 38.

Limuea, parasites of, $129-31$.

Lingula prima, 192.

Lithodendron pseudostylina, 199.

Liver, 101.

Lobopbyllia flabellum, 199.

Lobsters, mode of swimming, 70 ; nervous system, 22.

Locomotion, 55; organs of, 58; modes of, 64 .

Lungs, 92.

Lymphatic vessels, 76 .

Magas, 200.

Mammals, animals which nurse their young, xvi.; number of, 3 ; reign of, 190, 201, 202.

Man, reign of, 190,203 ; races of, 180 ; his twofold nature, 1.

Manducata, insects furnished with jaws, xvii.

Marchantia polymorpha, reproduction of, 135.

Marl, earth principally composed of decayed shells and corals, 184 .

Marsupials, animals with a pouch 
for earrying their young, as the opossum ; gestation of, 151 .

Marsupites, 201.

Mustication, 77.

Mástodon, 204.

Matrix, the organ in which the embryo is developed, 121.

Medulla oblongata, continuation of the brain into the back-bone.

Medusa, jelly-like animals living in the sea, xviii.; development of, 132; digestive organs, 70.

Megalobátrachus, 177.

Megalosáurus, 197.

Melocrìnus amphòra, 192.

Memory, 44.

Menobránchus, 169, 177.

Menopòma, 169, 177.

Merganser, an aquatic bird allied to the goose, 42, 161 .

Metacarpus, the wrist, 59.

Metamorphic rocks, 184.

Metamorphosis, 119,142 ; of the silkworm, 143; canker-worm, 144; duck-barnacle, 145; star-fish, 146; comatula, 147.

Micraster cor-anguinum, 201.

Miocene formation, 187.

Modern age, 190, 203.

Molar teeth, 81.

Molecules, very minute particles, 11.

Mollusks, soft animals of the snail and oyster kind; heart of, 90 ; liver of, 101 ; number of, 3 ; metamorphosis of, 147.

Monkey, teeth of, 81 .

Monóculus, mode of carrying eggs, 106.

Moulting, the shedding of feathers, hair, \&c. 98.

Muscles, 48; disposition of, in insects, 53 ; in fishes, 54 ; in birds, 55.

Muscular tissue, 15.

Myxine glutinosa, its eye, 31 .

Natatores, birds with webbed feet for swimming, xvi.

Natica, tongue of, 78 ; heart of, 91 .

Nautili, xvii.

Neptunian rocks, 183.

Nereis, jaws of, 78; gills of, 57 ; eye, 29.

Nervous system, 20 ; in mammals, 21 ; in articulates, 22 ; in crustaceans, 22 ; in radiates, 23.

Nervous tissue, 15.
Nest of Baltimore oriole, 46 ; of tailor bird, 46; of Ploceus, 47.

Nomenclature, the naming of objects and their classes, family, \&c.

Notosáurus, 196.

Nucleolites, 200.

Nuclèolus, a little nucleus, 14.

Nucleus, a kernel, or condensed central portion, 14 .

Nudibránchiates, mollusks having the gills floating externally, fig. 91 .

Númmulites, 202.

Nurses, of Cercaria, 130 ; ants and becs, 132.

Nutrition, 72.

Ocelli, minute eyes, 28.

Esophagus, the gullet, 22, 75.

Olfactory, pertaining to the sense of smell, 21, 36.

Omnívora, feeding upon all kinds of food, 83 .

Ö̈lític formation, 186.

Operculum, a cover for the aperture of a shell.

Ophidians, animals of the serpent kind, xvi.

Optic nerves, 24.

Orbits, 24.

Orders, xiv.

Organism, 7, 13.

Organized bodies, general properties of, 11 ; elementary structure, 12.

Ornithíchnites, 197.

Orthóceras fusifórme, 193.

Osseous tissue, 15.

Otolites, little bones in the ears of mollusks and crustacea, 35.

Ovary, the organ in which eggs originate, 104.

Oviduct, the passage through which the egg is excluded, 105.

Oviparous, producing eggs, 103.

Ovis montàna, 160 .

Ovo-viviparous, animals which hatch their eggs within their body, 105.

Ovulation, the production of eggs, 105.

Oxygen, its consumption in respiration, 17,95 .

Pachydérmata, thick-skinned animals, like the elephant, hog, \&c. \$2, 202.

Paleontólogy, 183.

Paleozoic age, 190, 191.

Paleothèrium, 202. 
Palpation, the exercise of the touch, 40.

Palpi,jointed organs for touch, about the mouth of insects, 40 .

Páncreas, 101.

Papilla, a little pimple, 38 .

Paramecia, reproduction of, 126.

Parasitic, living on other objects.

Passerine, birds of the sparrow kind, 168.

Peduncle or Pedicle, a slender stem.

Pelvis, the cavity formed by the hipbones, 60 .

Pentácrinus, 199 ; metamorphosis of, 148 .

Perception, 43.

Perchers, a class of birds, xvi.

Peristaltic motion, 76.

Petrifactions, $1 \$ 3$.

Pigment, a coloring substance, 27.

Pituitary membrane, 37.

Placenta, the organ by which the cmbryo of mammals is attached to the mother, 121.

Placoids, fishes with a rough skin, like the shark or sliate, xvi.

Planaria, its digestive apparatus, 74 ; an eye of, 29.

Plant-lice. See Aphides.

Plants compared with animals, 16.

Platynotus, 193.

Pleiocene formation, 187.

Plesiosáurus, 197, 200.

Pleurotomària, 201.

Ploceus Philippinus, nest of, 47.

Plutonic rocks, 182.

Podurella, mode of leaping, 68 ; embryo of, 114; egg of, 104 ; reproduction of, 125.

Polyps, a small animal fixed at one end, with numcrous flexible feelers at the other, 3, 29.

Prehcnsion, act of grasping, 85 .

Primary age, 195.

Primitive stripe, 113.

Progression, 66.

Proligerous, the part of the egg where the embryo is placed, 111 .

Pròteus, 177.

Protosáurus, 196.

Protractile, capable of being extended.

Pteríchthys, 194.

Ptcrócoma pinnàta, 199.

Pterodáctylus, 198.

Pteropods, molluslis with wing-like expansions for swimming, xviii.

Pulmonary, relating to the lungs, 90 .
Pulmonates, mollusks which breathe air, xviii.

Pupil, 25.

Pyrula, egg-cases of, 106.

Quadrumanous, four-handed, 168.

Quadruped, animals with four lcgs, 16.

Radiata, animals whose organs radiate from a centre, 3 .

Radius, one of the bones of the arm, 59.

Relation, functions of, 21 .

Reproduction, peculiar modes, 125.

Reptiles, number of, 3 ; reign of, 190, 195.

Respiration, 92.

Retractile, that may be drawn back, 60.

Rhizodonts, xvi; of the trias, 196.

Rhizopods, xix.

Rocks, classification of, 183.

Rodents, quadrupeds with teeth for gnawing, 83.

Rotifers, jaws of, 79 .

Ruminants, quadrupeds which chew the cud.

Running, 67.

Rytìna Stélleri, 178.

Salènia, 201.

Salíferous formation, 186.

Saliva, 83.

Sálivary glands, 100 .

Salpa, reproduction of, 128 .

Scansores, birds adapted for climbing, xvi.

Scaphites, 200.

Scapula, 59.

Sclerotic, the principal coat of the eye, 25.

Scutella, jaws of, 77.

Sea-anemone. See Actinia.

Sea-urchin, eye of, 29; digestive organs, 74.

Secondary age, 190, 195 .

Secretions, 98.

Sedimentary rocks, 183.

Segment, portion of a circle or sphere.

Scnsation, general, 19, 23.

Senses, special, 23.

Serous, watery, 112.

Shark, egg of, 104.

Shoulder-blade, 58.

Sight, 24.

Silex, flinty rock. 
Siliceous, made of flint.

Silk-worm, metamorphosis of, 143.

Silurian rocks, lower, 185 ; upper, 156.

Sinuous, bending in and out, xvii.

Siphonóphori, xviii.

Siren, 177.

Skeleton, 51, 53.

Skin, structure of, 99.

Smell, 36.

Species, the common name of a thing; constancy of, 43 ; definition of,

Spinal marrow, 21.

Spondyli, 201.

Sponges not animal, 17.

Spontaneous generation, 140 .

Standing, 64 .

Stapes, 33.

Star-fish, metamorphoses of, 146 ; eye of, 26 ; mode of progression, 57 ; reproduction of parts, 126.

Stigmata, openings in insects for the admission of air, 92 .

Stomach, 73.

Stratified rocks, 1 S3.

Stratum, a layer.

Strobila, 133, 138.

Structure of the eartll's crust, $1 \mathrm{~S} 2$.

Sturgeon, compared with white-fish, 148.

Suctoria, insects taking their food by suction, xvii.

Swimming, 69 .

Sylvia sutoria, nest of, 46 .

Systole, the contraction of the heart to force out the blood, 90 .

Tape-worm, reproduction of, 140 .

Tarsus, the ancle.

Taste, 38.

Teeth, 79

Temperate faunas, 166 .

Temporal, relating to the temples, 79.

Tentacle, the horn-like organs on the head of mollusks, usually bearing the eycs, 28.

Terebratula, 198.

Tertiary age, 190, 201.

Tertiary formation, lower, 186 ; upper, 187.

Test, the bristle crust covering the crustaceans, \&c. 51.

Teuthideans, the family of cuttlefishes, xvii.

Tibia, one of the bones of the leg, 63 .
Tissues, 13; areolar, 14 ; cartilaginous, 14 ; osscous, 15 ; nervous, 15.

Tongue, 38 .

Touch, 39.

Trachea, the windpipe, 93 .

Trachex, the air-tubes of insects, 92.

Trias formation, 186, 196.

Trigònia, 198.

Trilobites, 9, 193, xvii.

Trocholites ammònius, 193.

Trophi, organs for feeding, of insects, crabs, \&c.

Tropical faunas, 172 .

Trot, 67.

Tubulibranchiates, xvii.

Tunicata, mollusks with a lcathery covering, 128 .

Turrilites, 200.

Tympanum, a drum; the membrane separating the internal and external ear, 33.

Type, an ideal image. See $p$.

Ulna one of the bones of the arm, 59.

Ultimate, final.

Univalve, having a single shell, like the snail, 3 .

Vascular, composed of vessels, 99.

Vegetative life, 20 ; layer, 112.

Veins, 88 .

Ventricle, a cavity of the heart, 89 .

Vermicular, 76.

Vertebra, a joint of the back-bone, 54.

Vertebrate, having a back-bone, 3 .

Vertical, in a perpendicular direction, 24.

Vesicle, a small membranous bag, 13.

Vestibule, a porch; the entrance to one of the cavities of the ear, 34 .

Vibratile, moving to and fro, 87.

Viscera, 128.

Vitelline membrane, 108.

Vitellus, 108.

Vitreous humor, 26.

Vivíparous, producing living young, 103.

Vocal cords, 41.

Voice, 40.

Voluntary, under control of the will, 19.

Vorticella, reproduction of, 126. 
Walking, 66.

Warm-blooded animals, 96 .

Water-tubes of aquatic animals, 97 .

Whale, fans of, 80 .

Whales, mode of swimming, 70.

White-fish, development of, 115 .
Worms, eye of, 29.

Zoölogy, its sphere, 1 .

Zoöphytes, animals of a very low type, mostly fixed to the ground of a plant-like form. 


\title{
VALUABLE SCHOOL, BOOKS,
}

\author{
PUBLISHED BY \\ GOULD, KENDALL AND LINCOLN,
}

NO. 59, WASHINGTON BTRET,

B O S T O N.

THE attention of Teachers, and all intercsted in education, is invited to the valuable works here presented. They arc confdently commended as the best text-books in their several departments of learning, and have received the highcst commendations.

School and Classical Books of all kinds supplicd wholesale and retail, on the most favorable terms.

\section{JUST PUBLISHED.}

PRINCIPLES OF ZOÖLOGY; Touching the Structure, Development, Distribution, and Natural Arrangement of the Races of Axrmals, living and extinct, with numerous illustrations. For the use of Schools and Colleges. Part I., Comparative Physiology. By Lovis Agassiz and Augustus A. Gould.

\section{Extracts from the Preface.}

"The design of this work is to furnish an epitome of the leading principles of the science of Zoölogy, as deduced from the present statc of knowledge, so illustrated as to be intelligible to the beginning student. No similar treatise now exists in this country, and indecd, some of the topics have not been touched upon in the language, unless in a strictly technical form, and in scattered articles."

"Being designed for American students, the illustrations have been drawn, as far as possible, froin American objects. * * * Popular names have been employed as far as possible, and to the scientific names an Énglish termination has generally been given. The first part is devoted to Comparative Physiology, as the basis of Classification; thc second, to Systematic Zoölogy, in which the principles of Classification will be applied, and the principal groups of animals briefly characterized."

MODERN FRENCH LITERATURE; By L. RAYMOND DE VÉRICovR, formerly lecturer in the Royal Athenæum of Paris, member of the Institute of France, \&c. American edition, brought bown to the present day, and revised with notes by WrLliam S. Chase. With a fine portrait of LAMARTINE.

** This Trcatise has received the highest praise as a comprehensive and thorough survey of the various departments of Modern French Literature. It contains biographical and critical notes of all the prominent names in Philosophy, Criticism, Bistory, Romance, Poetry, and the Drama; and presents a full and impartial consideration of the Political Tendencics of France, as they may be traced in the writings of authors equally conspicuous as Scholars and as Statesmen. Mr. Chase, who has been the Parisian correspondent of several leading periodicals of this country, is well qualified, from a prolonged residence in France, his familiarity with its Literature, and by a personal acquaintance with mauy of these authors, to introduce the work of De Véricour to the American public.

"This is the only complete treatise of the kind on this subject, either in French or English, and has received the highest commendation. Mr. Chase is well qualified to introduce the work to the public. The book cannot fail to be both useful and popular." - Vew York. Evening Post.

"Literature and Politics are more closely allicd than many are atrare of. It is particularly so in France; and the work announced by this learned French writer will, doubtless, be eagerly sought after." - The Symbol, Boston.

"Mr. Chase is entirely competent for the task he has undertaken in the present instance. His introduction and notes have doubtless added much to the value of the work, especially to the American reader."-Evening Gazette, Boston. 


\section{Waluable Sithool Boolis.}

THE ELEMENTS OF MORAL SCIENCE. By Francis WaYLAND, D.D. President of Brown University, and Professor of Moral Philosophy. Thirty-sixth Thousand. 12mo. cloth. Price \$1.25.

*** This work has been extensively and favorably reviewed and adopted as a class-book in most of the collegiate, theological, and academical institutions of the country.

From Rev. Wilbur Fisk, Presilent of the Wesleyan University.

"I have examined it with great satisfaction and interest. The work was greatly needed, and is well executed. Dr. Wayland deserves the grateful acknowledgments and liberal patronage of the public. I need say nothing further to express my high estimate of the work, thian that we shall immediately adopt it as a text-book in our university."

From Hon. James Kent, late Chancellor of New York.

"The work has beeu read by nie attentively and thoroughly, and I think very highly of it. The author himself is one of the most estimable of men, and I do not know of any ethical treatise, in which our duties to God and to our fellow-men arc laid down with more precision, simplicity, clearness, euergy, and truth."

"The work of Dr. Wayland has arisen gradually from the necessity of correcting the false principles and fallacious reasonings of Puley. It is a radical mistake, in the education of youth, to permit any book to be used by students as a text-book, which contains erroneous doctrines, especially when these are findameutal, and tend to vitiate the whole system of morals. We have been greatly pleased with the method which President Wayland has adopted; he goes back to the simplest and inost fundamental principles; and, in the statement of his views, he unites perspicuity with conciscness and precision. In all the author's leading fundamental principles we entirely concur." - Biblical Repository.

"This is a new work on morals, for academic use, and we welcome it with much satisfaction. It is the result of several years' reflection and experience in teaching, on the part of its justly distinguished author; and if it is not perfectly what we could wish, yet, in the most important respects, it supplies a want which has been extensively felt. It is, we think, substantially sound in its fundamental principles; and being comprchensive and elementary in its plan, and adapted to the purposes of instruction, it will be gladly adopted by those who have for a long time been dissatisfied with the existing works of Paley."

The Literary and Theological Review.

MORAL SCIENCE, ABRIDGED, by the Author, and adapted to the use of Schools and Academies. Twenty-fifth Thousand. $18 \mathrm{mo}$. half morocco. Price 50 cents.

** The attention of Teachers and School Committees, and all interested in the moral training of youth is invited to this valuable work. It has received the unqualified approbatiou of all who have examined it; and it is believed to be admirably adapted to exert a wholesome influence on the minds of the young, and lead to the formation of correct moral principles.

"Dr. Wayland has published an abridgment of his work, for the use of schools. Of this step we can hardly speak too highly. It is more than time that the study of moral philosophy should be introduced into all our institutions of education. We are happy to see the way so auspiciously opened for such an introduction. It has been not merely abridged, but also re-written. We cannot but regard the labor as well bestowed." - North Americun Review.

"We speak that we do know, when we express our high estimate of Dr. Wayland's ability in teaching Moral Philosophy, whether orally or by the book. Having listened to his instructions, in this interesting department, we can attest how lofty are the principlcs, how exact and severe the argumentation, how appropriate and strong the illustrations which characterize his system and enforce it on the mind." - The Christian Witness.

"The work of which this volume is an abridgment, is well known as one of the best and most complete works on Moral Philosophy extant. The author is well known as one of the most profound scholars of the age. That the study of Moral Science, a science which teaches goorlness, should be a branch of education, not only in our colleges, but in our schools and academies, we believe will not be denied. The abridgment of this work seems to us admirably calculated for the purpose, and we hope it will be extensively applied to the purposes for which it is intended." - The Mercantile Journal.

"We hail the abridgment as admirably adapted to supply the deficiency which has long been felt in common school education, - the study of moral obligation. Let the child early be taught the relations it sustains to man and to its Maker, the first acquainting it with the duties owed to society, the second with the duties owed to God, and who ean foretell how many a sad and disastrous overthrow of character will be prevented, and how elevated and pure will be the sense of integrity and virtue?" - Evening Gazette. 


\section{Ualuable sachool 3oolis.}

ELEMENTS OF POLITICAL ECONOMY. BV FRAXCIS Waylaxn, D.D., President of Brown University. Fifteenth Thousand. 12mo. cloth. Price $\$ 1.25$

"His object has bcen to write a book, which any one who chooses may understand. He has, therefore, labored to express the general principles iu the plainest manner possible, and to illustrate them by eases with which every person is familiar. It has been to the author a source of regret, that the coursc of discussion in the following pages, has, unavoidably, led him over ground which has frequently been the arena of political controversy. In all such cases, he has endeavored to state what seemed to him to be truth, without fear, favor, or affection. He is conscious to himself of no bias towards any party whatever, and he thinks that he who will read the whole work, will be convinced that he has been influcnced by none." - Extract from the Prejace.

POIITICAI ECONOMY, ABRIDGED, by the Author, and adapted to the use of Schools and Academies. Seventh Thousand. 18 mo. half morocco. Price 50 cents.

** The success which has attended the abridgment of "The Elements of Moral Science" has induced the author to prepare an abridgment of this work. In this case, as in the otlier, the work has been wholly re-written, and an attempt has been made to adapt it to the attainments of youth.

"The original work of the author, on Political Economy, has already been noticed on our pages; aud the present abridgment stands in no nced of a recommendation from us. We may be permitted, however, to say, that both the rising and risen generations are decply indebted to Dr. Wayland, for the skill and power he has put forth to bring a highly important subject distinetly before them, within such narrow limits. Though 'abridged for the use of academies, it deserves to be introduced into every private family, and to be stidied by every man who has an interest in the wealth and prosperity of his country. It is a subject little understood, even practically, by thousands, and still less understood theoretically. It is to be hoped, this will form a class-book, and be faithfully studied in our academies; and that it will find its way into every family library; not there to be shut up unread, but to afford rich material for thought and discussion in the family circle. It is fitted to enlarge the mind, to purify the judgment, to correct erroneous popular impressions, and assist every man in forming opinions of public measures, which will abide the test of time and experience." - Boston Recorder.

"An abridgment of this clear, common sense work, designed for the use of academies is just published. We rejoice to see such treatises spreading among the people; and we urge all who would be intelligent freemen, to read them." - New York Transcript.

"We can say, with safety, that the topics are well selected and arranged; that the author's name is a guarantee for more than usual excelleuce. We wish it an extensive circulation." - New York Observer.

"It is well adapted to high schools, and embraces the soundest system of republican political economy of any treatise extant." - Daily Advocate.

THOUGHTS on the present Collegiate System in the United States. By Fraxcis Wayland, D.D. Price 50 cents.

"These Thoughts come from a source entitled to a very respectful attention; and as the author goes over the whole ground of collegiate education, criticising freely all the arrancements in every department and in all their bearings, the book is very full of matter. We hope it will prove the beginning of a thorough discussion."

PALEY'S NATURAL THEOLOGY. Illustrated by forty plates, and Selections from the notes of Dr. Paxton, with additional Notes, original and selected, for this edition; with a vocabulary of Scientific Terms. Edited by JoHn Ware, MI.D. 12mo. sheep. Price \$1.25.

"The work before us is one which deserves rather to be studied than merely read. Indeed, without diligent attention and study, neither the excellences of it can be fully discovered, nor its advantages realized. It is, therefore, gratifying to find it introduced, as a text-bonk, into the colleges and literary institutions of our country. The edition before us is superior to any we have seen, and, we believe, superior to any that has yet been published." - Spirit of the Pilgrims.

"Perhaps no one of our author's works gives greater satisfaction to all classes of readers, the young and the old, the ignorant and the enlightened. Indeed, we recollect no book in which the arguments for the existence and attributes of the Supreme Being, to be drawn from his works are exhibited in a manner more attractive and more convincing." 


\section{Waluable Sislool Books.}

CIASSICAI STUDIES. Essays on Ancient Literature and Art. With the Biograplyy and Correspondence of eminent Philologists. By Barnas Sears, President Newton 'Theol. Institution, B. B. Edwards, Prof. Andover Theol. Seminary, and C. C. Felton, Professor Harvard University. 12mo. cloth. Price $\$ 1.25$.

"This book will do good in our colleges. Every student will want a copy, and many will be stimulated by its perusal to a more vigorous and enthusiastic pursuit of that higher and more solid learning which alone deserves to be called 'classical.' The recent tendencies have been to the neglect of this, and we rejoice in this timely effort of minds so well qualified for such a work." - Reflector.

"The object of the accomplished gentlemen who have engaged in its preparation has been, to foster and extend among educated men, in this country, the already growing interest iu classical studies. The design is a uoble and generous one, and has been executcd with a taste and good sense, to do honor both to the writers and the publishers. The book is one which deserves a place in the library of every educated man. To those now engaged in classical study it cannot fail to be highly useful, while to the more advanced scholar it would open new sources of interest and delight in the unforgotten pursuits of his earlier days." - Providencc Journal.

THE CICERONIAN: Or the Prussian Method of Teaching the Latin Language. Adapted to the use of American Schools, by B. SEARs. $18 \mathrm{mo}$. half morocco. Price 50 cents.

\section{From the Professors of Harvard University.}

"We beg leave to observc, that we consider this book a very valuable addition to our stock of elementary works. Its great merit is, that it renders the elementary instruction in Latin less mechanical, by constantly calling the reasoning power of the pupil into action, and gives, from the beginning, a deeper insight into the very nature, principles, and laws not only of the Latin language, but of language in general. If the book required any other recommendation besides that of being the work of so thorough and experienced a scholar as Dr. Sears, it would be this, that the system illustrated in it is not a mere theory, but has been practically tested by many able instructors in Germany. We wish that the same trial may be made here.

Very respectfully yours,

Charles Beck,

Cambridge, Oct, 2, 1844.

C. C. FELTON.

From S. H. Taylor, Principal of Phillips' Academy, Andover.

'I have cxamined, with much pleasure and profit, the 'Ciceronian,' prepared by Dr. Sears. It is adnirably adapted to make thorough teachers and thorough pupils. It requires of the teacher a precise and intimate acquaintance with the minutia of the Latin tongue, and necessarily induces in the pupil habits of close thought and nice discrimination. The plan of the work is excellent, as it constantly calls the attention of the pupil to the peculiar construction and idioms of the language; and, by a system of constant reviews, keeps the attention upon them till they are permanently fixed. The pupil who shall go through this book in the manner pointed out in the plan of instruction, will know more of the Latin than most do who have read volumes.

"Andover, Oct. $3,1844$.

S. H. TAYLOR."

MEMORIA TECHNICA: Or, the Art of Abbreviating those Studies which give the greatest Labor to the Memory; including Numbers, Historical Dates, Geography, Astronomy, Gravities, \&c. ; also Rules for Memorizing Technicalities, Nomenclatures, Proper Names, Prose, Poetry, and Topics in general. Embracing all the available Rules found in Mnemonics or Mnemotechny of Ancient and Modern Times. To which is added a perpetual Almanac for Two Thousand Years of Past Time and Time to Come. By L. D. Johnsox. Third Edition, revised and improved. Octavo, cloth back. Price 50 cents.

"This system of Mnemotechny, differing considerably from the one introduced by Prof. Gourand, is designed to furnish all the rules for aiding the memory without lesscning mental culture, which can be made available during a course of elementary study. The illustrations may be easily comprchended by any person of ordinary mental capacity; and the application of the principles upon which the system is based, must necessarily furnish an agreeable and useful exercise to the mind." - New York Teachers' Advocate.

"We fecl no hesitation in recommending this work to the deliberate attention of teachers, and the guardians of youth. We learn that it is received into several schools in Boston, and used as an auxiliary help to the studies now pursued by the pupils."

Boston Courier.

"The 'Memoria Technica' is now studied in some of our best schools; and the system taught in it appears to be much approved by those who have made trial of it."

Evening Traveller. 


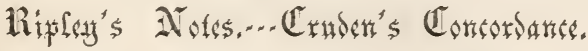

THE FOUR GOSPELS, WITH NOTES. Chiefly Explanatory; intended principally for Sabbath School Teachers and Bible Classes, and as an aid to Family Instruction. By Hexry J. Riplex, Newton Theol. Institution. Seventh Edition. Price $\$ 1.25$.

** This work should be in the hands of every student of the Bible, especially every Sabbath School and Bible Class teacher. It is prepared with special reference to this class of persons, and contains a mass of just the kind of information wanted.

"The undersigned, having examined Professor Ripley's Notes on the Gospcls, can recommend them with confidence to all who need such helps in the study of the sacred Scriptures. Those passages which all can understand are left 'without note or comment,' and the principal labor is devoted to the explanation of such parts as need to be explained and rescued from the perversions of errorists, both the ignorant and the learned. The practical suggestions at the close of each chapter, are not the least raluable portion of the work. Most cordially, for the sake of truth and righteousness, do we wish for these Notes a wide circulation.

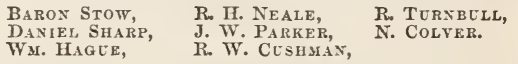

THE ACTS OF THE APOSTLES, WITH NOTES. Chiefly Explanatory. Designed for Teachers in Sabbath Schools and Bible Classes, and as an Aid to Family Instruction. By Prof. Hexry J. Ripley. Price 75 cents.

"The external appearance of this book, - the binding and the printed page, - 'it is a pleasant thing for the eyes to behold.' On examining the contents, we are favorably impressed, first, by the wonderful perspicuity, simplicity, and comprehensiveness of the author's style; secondly, by the completeness and systematic arrangement of the work, in all its parts, the ' remarks' on each paragraph being carefully separated from the exposition; thirdly, by the correct theology, solid instruction, and consistent explanations of difficult passages. The work cannot fail to be received with favor. These Notes are much more full than the Notes on the Gospels, by the same author. A beautiful map accompanies them." - Christian Reflector, Boston.

CRUDEN'S CONDENSED CONCORDANCE. A Complete Concordance to the Holy Scriptures; by Alexavder Crudex, M.A. A New and Condensed Edition, with an Introduction; by Rev. DAvid KIxG, LL.D. Fifth Thousand. Price in Boards, $\$ 1.25$; Sheep, $\$ 1.50$.

$*_{*}^{*}$ " This edition is printed from English plates, and is a full and fair copy of all that is valuable in Cruden as a Concordance. The principal variation from the larger book consists in the exclusion of the Bible Dictionary, which has long been an incumbrance, and the accuracy and value of which have been depreciated by works of later date, containing recent discoveries, facts, and opinions, unknown to Cruden. The condensation of the quotations of Scripture, arranged under their most obvious heads, while it diminishes the bulk of the work, greatly facilitates the finding of any required passage.

"Those who have been acquainted with the various works of this kind now in use, well know that Cruden's Concordance far excels all others. Yet we have in this edition of Cruden, the best made better. That is, the present is better adapted to the purposes of a Concordance, by the erasure of superfluous refercnces, the omission of unnecessary explanations, and the contraction of quotations, \&c.; it is better as a manual, and is better adapted by its price to the means of many who need and ought to possess such a work, than the former larger and expensive edition." - Boston Recorder.

"The new, condensed, and cheap work prepared from the voluminous and costly one of Cruden, opportunely fills a chasm in our Biblical literature. The work has been examined critically by several ministers, and others, and pronounced complete and accurate."

"This is the very work of which we have long felt the need. We obtained a copy of the English edition some months since, and wished some one would publish it; and we are much pleased that its enterprising publishers can now furnish the student of the Bible with a work which he so much needs at so cheap a rate." - Advent Herald, Boston.

"We cannot see but it is, in all points, as valuable a book of reference, for ministers and Bible students, as the larger edition." - Christian Reflector, Boston.

"The present edition, in being relieved of some things which contributed to render all former ones unnecessarily cumbrous, without adding to the substantial value of the work, becomes an exceedingly cheap book." - Albany Argus. 


\section{$\mathfrak{C}_{\text {fanmbets's }} W_{\text {of }}$ is.}

\section{CHAMBERS'S CYCLOPFDIA OF ENGLISH LITERATURE;} A Selection of the Choicest Productions of English Authors, from the earliest to the present time; Connected by a Critical and Biographical History. Edited by RoBErT CHAMBERs, assisted by RoEERT Cariouthers, and other eminent Gentlemen. Complete in two imperial octavo rolumes, of more than fourteen hundred pages of double column letter press; and upwards of 300 elegant illustrations. Price, in cloth, $\$ 5,00$.

*** The Publishers of the AMIERICAN Edition of this valuable work desire to state, that, besides the numerous pictorial illustrations in the English Edition, they have greatly enriched the work by the addition of fine steel and mezzotint eugravings of the heads of Shakspeare, Addison, Byron ; a full length portrait of Dr. Johnson, and a beautiful seeuic representation of Oliver Goldsuith and Dr. Johnson. These important and elegant additions together with superior paper and binding, must give this a decided preference over all other editions.

"We hail with peculiar pleasure the appearance of this work, and more especially its republication in this country at a price which places it within the reach of a great number of readers. We have been inundated by a stream of cheap reprints, teuding to corrupt the morals and vitiate the taste of our eommunity, and we are pleased that the publishers have still sufficient fuith in the purity of botl, to induce them to incur the large outlay which the production of the work before us must have occasioned, and for which they can expcet to be remunerated only by a very extcusive salc."

"The selections giveu by Mr. Chambers from the works of the early English writers are copious, aud judiciously made. ***** We shall conclude as we commenced, with expressing a hope that the publication which has ealled forth our remarks will exert an influence in directing the attention of the public to the literature of our forefathers."

North Americun Review.

CHAMBERS'S MISCELLANY of Useful and Entertaining Knowledge, with elegant illustrative engravings. Edited by Willias Chàrers. Price 25 cents per number, to be completed in ten Elegant volumes.

** The design of the Mrscellavy is to supply the increasing demand for useful, instructive, and entertaining reading, and to bring all the aids of literature to bear on the cultivation of the feclings and understanding of the veople - to impress correct views on important moral and social questions - suppress every specics of strife and savagery - cheer the lagging and desponding by the relation of tales drawil from the imagination of popular writers - rouse the faucy by descriptious of interesting forcign scenes-give a zest to every-day occupations by ballad and lyrical poetry - in short, to furnish an unobtrusive friend and guide, a lively fircside companion, as far as that object ean be attained through the instrumentality of books.

CHAMBERS'S LIRRARY FOR YOUNG PEOPLE. A series of small books, elegantly illuminated. Edited by WiLlian Chanbers. Each volume forms a complete work, embellished with a fine steel engraving, and is sold separately. Price $37 \frac{1}{2}$ cents.

ORLANDINO: A Story of Self-Denial. By Maria Edgeworth.

THE LITTLE ROBINSON: And other Tales.

UNCLE SAM'S MONEY BOX. BY MrS. S. C. HALL.

TRUTH AND TRUST. Jervis Ryland - Victor and Lisette.

JACOPO: Tales by Niss EDGEwORTH and others.

POEMS, By various Authors, for the young.

The aim of this serics is to makc the young rearer better and happicr; to this end, the selection of subjects will be designed to influence the heart and feelings. 


\section{Waluable siljool doolis.}

BLAKE'S FIRST BOOK IN ASTRONOMY. 1)esigned for the Use of Cummon Schools. By J. I. BLAKE, D.D. Illustrated by Steel Plate Engravings. 8vo. cloth back. Price 50 cents.

\section{From E. Hinckley, Professor of Hathematics in Maryland Unirersity.}

"I am mueh indebted to you for a eopr of the First Book in Astronomy. It is a work of ntility aud merit, fur superior to auy otler which I have scen. The author has seleeted his topies with great judgment, - arramged them in admirable order, - exhibited them in a style and manner at once tasteful and philosophieal. Nothing seeuns wanting, - nothing redundant. It is truly a very beautiful and attractive book, caleulated to aftord both pleasure and pronit to all who niay enjoy the advautage of perusing it."

From B. Field, Principal of the Hancock School, Boston.

"I know of no other work on Astronomy so well ealeulated to interest and instruet young learners in this sublime seience."

From James F. Gould, A.M., Principal of the High School for Young Ladies, Baltimore, $\mathrm{ll}$.

"I shall introduee your First Book in Astronomy into my Academy in September. consider it deeidedly superior to any elementary work of the kind I have ever seen."

\section{From Isaac Foster, Instructor of Youth, Portland.}

"I have examined Blake's First Book in Astronomy, and am much pleased with it. A very happy selection of topies is presented in a manner which eannot fail to interest the learner, while the questions will assist him materially in fixing in the memory what onght to be retained. It leaves the most intrieate parts of the subjeet for those who are able to master them, and brings before the young pupil only what ean be made intelligible and interesting to him."

"The illustrations, both pietorial and verbal, are admirably intelligible; and the definitions are sueh as to te easily eomprehended by juvenile seholars. The author has interwoven with his seientific instruetions mueh interesting historieal information, and eontrived to dress his philosophy in a garb truly attraetive. - N. Y. Daily Ezemng Journal.

"We are free to sar, that it is, in our opinion, deeidedly the best work we have any knowledge of, on the sublime and interesting subject of Astronomy. The engravings are exeeuted in a superior style, and the neehanieal appearanee of the book is extremely prepossessing. The knowledge imparted is in language at once ehaste, elegant, and simple - adapted to the eomprehension of those for whom it was designed. The subject matter is selected with great judgment, and evinces uneommon industry and researeh. We earnestly hope that parents and tealehers will exanine and judge for themselves, as we feel eonfident they will eoineide with us in opinion. We only hope the eireulation of the work will be eommensurate with its merits." - Boston Evening Gazette.

"The book now before us eontains forty-two short lessons, with a few additional ones, which are appended in the form of problems, with a design to exereise the young learner in finding out the latitude and longitude on the terrestrial globe. We do not hesitate to recommend it to the notice of the superintending eommittees, teachers, and pupils of our public sehools. The definitions in the first part of the volume are given in brief and elear language, adapted to the understanding of beginners."-State Herald, Portsmouth, N. H.

BLAKE'S NATURAL PHILOSOPHY. Being Conversations on Philosophy, with the addition of Explanatory Notes, Questions for Examination, and a Dictionary of Philosophical Terms. With twenty-eight steel Engravings. By J. L. BlAKE, D.D. 12mo. sheep. Price 67 cents.

*** Perhaps no work has contributed so mueh as this to exeite a fondness for the study of Natural Philosophy in youthful minds. The familiar eomparisons, with which it abounds, awaken interest, and rivet the attention of the pupil.

From Rev. J. Adans, President of Charleston College, S. C.

"I have been highly gratified with the perusal of your edition of Conversations on Natural Philosophy. The Questions, Notes, and Explanations of Terms, are valuable additions to the work, and make this edition superior to any other with whieh I am aequainterl. I shall reeonmend it wherever I have an opportunity."

"We arail ourselves of the opportunity furnished us by the publieation of a new edition of this deservedly popular work, to reeoinmend it, not only to those instruetors who may not already have adopted it, but also generally to all readers who are desirous of obtaining information on the subjects on which it treats. By Questions arranged at the bottom of the pages, in which the collateral facts are arranged, he directs the attention of the learner to the prineipal topies. Mr. Blake has also added many Notes, which illustrate the passages to which they are appended, and the Dietionary of Philosophical Terms is a useful addition." - U. S. Literary Garette. 


\section{baluable $\mathfrak{s}$ sljool 3ooks.}

THE YOUNG LADIES' CLASS BOOK. A Selection of Lessons for Reading in Prose and Verse. By E. BAIley, A.M., late Principal of the Young Ladies' High School, Boston. Stereotyped Edition. 12mo. sheep. Price $83 \frac{1}{3}$ cents.

\section{From the Principals of the Public Schools for Females, Boston.}

"Gexthemen:- We have examined the Young Ladies' Class Book with interest and pleasure; with interest, because we have felt the want of a Reading Book expressly designed for the use of females; and with pleasure, because we have found it well adapted to supply the deticiency. In the selections for a Reader designed for boys, the eloquence of the bar, the pulpit, and the forum may be laid under heavy contribution; but such selections, we conceive, are out of place in a book designed for females. We have been pleased, therefore, to observe, that in the Young Ladies' Class Book such pieces are rare. The high-toned morality, the freedom from sectarianism, the taste, richness, and adaptation of the selections, added to the neatness of its external appearance, must commend it to all; while the practical teacher will not fail to observe that diversity of style, together with those peculiar points, the want of which, few, who have not felt, know how to supply.
Respectfully yours,
BARNUM FIELD,
ABRAHAM ANDREWS, R. G. PARKER,
Charles Fox,

From the Principal of the Mount Vernon School, Boston.

"I hare examined with much interest the Young Ladies' Class Book, by Mr. Bailey and have been very highly plcased with its contents. It is my intention to introduce it into my own school ; as I regard it as not only remarkably well fitted to answer its particular object as a book of exercises in the art of elocution, but as calculated to have an influence upon the character and conduct, which will be in every respect favorable.

JACOB ABBotT."

"We were neverso struck with the importance of having reading books for female schools, adapted particulurly to that express purpose, as while looking over the pages of this selcction. The eminent success of the compiler in teaching this branch, to which we can personally bear testimony, is sufficient evidence of the character of the work, considered as a selection of lessons in elocution; they are, in general, admirably adapted to eultivate the amiable and gentle traits of the female character, as well as to elevate and improve the inind." - Annils of Education.

"The reading books prepared for academic use, are often unsuitable for femalcs. We are glad, therefore, to perceive that an attempt has been made to supply the deficiency; and we belicve that the task has been faithfully and successfully accomplished. The selections are judicious and chaste; and 80 far as they have any moral bearing, appear to be unexceptionable." - Education Reporter.

\section{ROMAN ANTIQUITIES AND ANCIENT MYTHOLOGY.} By C. K. Dillaway, A.M., late Principal in the Boston Latin School. With Engravings. Eighth Ed., improved. 12mo. half mor. Price $67 \mathrm{cts}$.

From E. Bailey, Principal of the Young Ladies' High School, Boston.

" Having used Dillaway's Roman Antiquities and Ancient Mythology in my school for sevcral years, I commend it to teachers with great confidence, as a valuable text-book on those interesting branches of education.

E. BAILEY.'

"The want of a chcap volume, embracing a succinct account of ancient customs, together with a view of classical mythology, has long been felt To the student of a language, some knowledge of the manners, habits, and religious feelings of the people whose language is studied is indispensably requisite. This knowledge is seldom to be obtained without tedious research or laworious investigation. Mr. Dillaway's book seems to have been prepared with special reference to the wants of those who are just entering upon a classical career; and wc deem it but a simple act of justice to say, that it supplies the want, which, as we have before said, has long been felt. In a small duodecimo, of about one hundred and fifty pages, he concentrates the most valuable and interesting particulars relating to Roman antiquity; together with as full an account of heathen mythology as is generally needed in our highest seminaries. A pcculiar merit of this compilation, and one which will gain it admission into our highly respectable female seminaries, is the total absence of all allusion, even the most remote, to the disgusting obscenities of ancient mythology; while, at the same time, nothing is omitted which a pure mind would feel interested to know. We rccommend the book as a valuable addition to the treatises in our schools and academies." - Education Reporter, Boston.

"We well remember, in the days of our plipilage, how unpopular as a study was the volume of Roman Antiquities introduced in the academic course. It wearied on account of its prolixity, filling a thick octavo, and was the prescribed task each afternoon for a long three months. It was reserved for one of our Boston instructors to apply the condensing apparatus to this mass of crudities, and so to modernize the antiouities of the old Romans, as to make a befitting abridgment for schools of the first order. Mr. Dillaway has presented such a compilation as must bc interesting to lads, and become popular as a textbook. Historical facts are stated with great simplicity and clearness; the most important points are seised upon, while trifling peculiarities are passed unnoticed." - Am. Traveller. 


\section{filliscerfatisuts.}

THE CHRISTIAN'S DAILY TREASURY. A Religious Exercise for every day in the Year. By Rev. Lisenezer Temple. Price $\$ 1.00$

** This work is strictly evangelieal, and prescnts with great distinetness the peeuliar points of orthodoxy. The texts are happily ehosen, and all the thoughts suggested by the author are interesting and profitable. The skeletons are generally of the textual eharaeter, very neat, comprehensive, and each of them contains matter enough for a sermon. There is a great variety of beautiful gems seattered through it, both original and selected.

This work might appropriately be called a guide to meditation. It eonsists of a subject for every day in the ycar, drawn from an appropriate portion of Seript ure, with reflections upon it. It does not attempt to exhaust the daily subjeets, but merely to direct the reader's thoughts. The plan strikes us as a very happy one. Mrany do not know how to meditate. A eareful usc of this volume, for a year, will do very nueh to form habits of profitable meditation on Scripture. As habits of meditation are so intimately eonnected $w$ ith Christian progress and enjoyment, we think the influence of sueh a work as is here presented, must be very happy. - Ohristian Chronicle, Philadelphia.

Onc of the best books of the kind we have reeently met with. The daily refleetions, instearl of being general and diffuse, are thrown into the sermonic form, and thus the instruetion is made more impressive and easy of retention.

liew York Commercial Advertiser.

LEARNING TO ACT. An interesting and instructive work for the Young. Witl numerous illustrations. Price $37 \frac{1}{2}$ cents.

LEARNING TO FEEL. An interesting and instructive work for the Young. With numerous illustrations. Price $37 \frac{1}{2}$ cents.

LEARNING TO THINK. An interesting and instructive work for the Young. With numerous Illustrations. Price $37^{1 / 2}$ cents.

THE SAINT'3 EVERLASTING REST, By RICHAID BAXTER. Abridged by B. FAwCETt, A.M. Fine Edition. Price 50 cents.

"I am gratified to pereeive that you have published a handsome edition of Baxter's Saint's Rest. Of the value of the work itself, it is superfluous to speak. It has few equals in anv language. The ordinary copies are palpably beneath the ralue of the work." Rev. Dr. Wayland, President of Brown University.

MEMOIR CF REV. EDWARD PAYSON, D.D. By Rev. ASA Commings. Price $62 \frac{1}{2}$ Cents.

MEMOIR OF HARLAN PAGE: Or the Power of Prayer and Personal Effort for the Souls of Individuals. By Wr. A. HALLOCK. Price $37 \frac{1}{2}$ cents.

THE ANXIOUS INQUIRER AFTER SALVATION. By ReV. JoHN AXgEll JaIIES. Price $37 \frac{1}{2}$ cents.

THE YOUNG MAN FROM HOME. By Rev. JoHN Axgell JAMES. Price $37 \frac{1}{2}$ cents.

ANECDOTES for the Family and Social Circle. Upwards of 300 instructive Anecdotes, illustrating important truths. Price $62 \frac{3}{2}$ cents.

BUCK"S RELIGIOUS EXPERIENCE; A Treatise in which its Nature, Evidence, and Advantages are considered. By Rev. Charles Buck, D.D. Price 50 cents.

THE CALVINISTIO AND SOCINIAN SYSTEMS, Compared as to their Noral tendency. By Axdrew Fuller. Price 50 cents.

VITAL CHRISTIANITY: Essays and Discourses on the Religions of Man and the Religion of God. By A. Vinet, D.D. Translated, with an Introduction. By Rev. Robert T'urasull. Price $\$ 1.13$. 


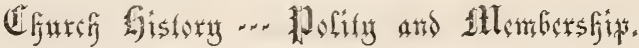

THE APOSTOLICAL AND PRIMITIVE CHURCH; Popular in its government and simple in its worship. By LYMAN Coleman. With an introductory essay, by Dr. Augustus Nesnder, of Berlin. Second Edition. Price $\$ 1.25$.

The Publishers have been favored with many highly commendatory notices of this work, from individuals and public journals. The first edition found a rapid sale; it has been republished in England, and received with much favor; it is universally pronounced to be standard authority on this subject; and is adopted as a Text Book in Theological Seminaries.

\footnotetext{
From the Professors in Andover Theological Seminary.
}

"The undersigned are pleased to hear that you are soon to publish a new edition of the 'Primitive Church,' by LYMAN COLEMAN. 'They regard this volume as the result of exteusive and original research; as embodying very important materials for reference, much sound thought and conclusive argument. In their estimation, it may both interest and instruct the intelligent layman, may be profitably used as a Text Book for Theological Students, and should especially form a part of the libraries of clergymen. The introduction, by NEANDER, is of itself sufficient to recommend the volume to the literary public." LEONARD WOODS, BELA B. EDWARDS,

\section{From Samuel Miller, D.D., Princeton Theological Seminary.}

"Gentlemen, - I am truly gratified to find that the Rev. Mr. Colemax's work on the 'Apostolical and Primitive Churcli,' is so soon to reach a second edition. It is, in my judgment, executed with learning, skill, and fidelity; and it will give me great pleasure to learn that it is in the hands of every minister, and every candidate for the ministry in our land, and indeed of every one who is disposed, and who wishes for enlightened and safe guidance, on the great subject of which it treats."

$$
\text { Yours, respectfully, }
$$

Samuel Miller.

THE CHURCH MEMBER'S MANUAL Of Ecclesiastical Principles, Doctrines, and Discipline ; presenting a Systematic View of the Structure, Polity, Doctrines, and Practices of Christian Churches, as taught in the Scriptures; by War. Crowell. With an Introductory Essay, by Henry J. Ripley, D.D. Price 90 cents.

The Rer. J. Dowling D.D. of New Fork, writes : - "I llave perused, with great satisfaction 'The Church Member's Manual.' I have long felt in common with many of my ministering brethren, the need of just such a work to put into the hands of the members, and especially the pastors and deacons of our churches. . As a whole, I have great pleasure in commending the work to the attention of all Baptists. I think that Bro. Crowell has performed his task in an admirable manner, and deserves the thanks of the whole Baptist community."

We cordially concur in the above recommendation. S. H. Cone, Elisha Tucker, W. W. Evarts, David Bellamy, Henry Davis, A. N. Mason, and A. Haynes.

The pastor of one of the largest and most influential churches in New England, writes as follows.

"The work is admirably adapted to the wants of pastors and private members. If I could lave my wish, not only the ministers, but the deacons and scnior members of our churches wonld own and rcad the book."

Another writes - "I have read this work with great pleasure. For a long time such a guide has been needed, and much detriment to the church would have been avoided, had it made its appearance sooner."

"'This very complete Manual of Church Polity is all that could be desired in this department. Every important point within a wide range, is brought forward, and cvery point touched is settled." - Christian Review.

"While we dissent from the positions laid down in this book, yet we honor the author for carrying out his principles. He undertook to write a Baptist book, and we checrfully bear teatimony that he has done his work and done it well. We bear testimony to the depth of thought and conciseness and purity of style which do credit to the author."

Christian Witness (Episcopal).

THE CHURCH MEMBER'S GUIDE, By Rev. J. A. JAMEs. Edited by Rev. J. O. Choules. New Edition ; with an Introductory Essay, by Rev. Hubbard Winslow. Price 38 cents.

A pastor writes - "I sincerely wish that evcry professor of religion in the land may possess this excellent manual. I am anxions that cvery member of my church should possess it, and shall be happy to promote its circulation still more extensively."

"The spontaneous effusion of our heart, on laying the book down, was, - may every church-member in our land soon possess this book, and be blessed with all the happiness which conformity to its evangelic sentiments and directions is calculated to confer.' 


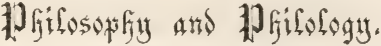

CLASSICAL STUDIES: Essays on Ancient Literature and Art. With the Biography and Correspondence of eminent Philologists. By Barnas Seaps, Pres. Newton Theol. Inst., B. B. EDwarins, Prof. Andover Theol. Seminary, and C. C. Feltox, Prof. Harvard University. Price $\$ 1.25$.

"This volume is no common-place production. It is truly refreshing, when we are obliged, from week to week, to look through the mass of books which increases upon our table, many of which are extremely atten uated in thought and jejunc in style, to find something which carries us back to the pure and invigorating influcnce of the master minds of antiquity. The gentlemen who have produced this volume deserve the cordial thanks of the literary world." - New England Puritan.

"The object of the accomplislied gentlemen who have engaged in its preparation has becn, to foster and exteud among educated men, in this country, the already growiug interest in classical studies. The design is a noble and generous one, and has been executed with a taste and good sense that do honor both to the writers and the publishers. The book is one which deserves a place in the library of every educated man. To those now engaged in classical study it canuot fail to be highly uscful, while to the more advanced seholar, it will open new sources of interest and delight in the unforgotten pursuits of his earlier days." - Providence Journal.

GESENIUS'S HEBREW GRAMMAR. Translated from the Eleventh German Edition. By T. J. CoxAst, Prof. of Hebrew and of Biblical Criticism and Interpretation in the Theol. Institution at Hamilton, N. Y. With a Course of Exercises in Hebrew Grammar, and a Hebrew Chrestomathy, prepared by the Translator. Price $\$ 2.00$.

"*** Special reference has been had in the arrangement, illustrations, the addition of the Course of Exercises, the Chrestomathy, \&c., to adapt it to the wants of those who may wish to pursue the study of Hebrew without the aid of a teacher.

Prof. Stewart, in an article in the Biblical Repository, says : - "With such efforts, - such uuremitted, unwearied, energetic efforts, - what are we to expect from such a man as Gesenius? Has he talent, judgment, tact, as a philologist? Read his work on Isaiah ; compare his Hebrew Grammar with the other grammars of the Hebrew which Germany has yet produced; read and compare any twenty, or even ten articles ou any of the difficnlt and inportant words in the Hebrew with the same in Buxtorff, Cocceius, Stockins, Eichhorn's Simoni, Winer, even (Parkhurst, I cannot once name), and then say whetler Gesenius, as a Hebrew philologer, has talents, tact, and judgment. Nothing but rival feelings, or prejudice, or antipathy to his theological sentimeuts, can prevent a unity of answer."

\section{LIFE OF GODFFEY WILLIAM VON LIEBNITZ. On the basis} of the German Work of Dr. G. E. Guhrauer. By JoHs M. Mackie. Price 75 cents.

"The peculiar relation which Liebnitz sustained during his life to Locke and Newton may partly account for the fact that a biography of this great man has been so long wanting in the English language. . . . We commend this book, not only to scholars and men of science, but to all our readers who love to contemplate the life and labors of a great and good man. It merits the special notice of all who are interested in the business of education, and descrves a place by the side of Brewster's Life of Newton, in all the libraries of our schools, academies, and literary institutions."-Christian Watchman.

"There is perhaps no case on record of a single man who has so gone the rounds of human knowledge as did Liebnitz: he was not a recluse, like Spinoza and Kant, but went from capital to capital, and associated with kings and premiers. All branches of thought were intercsting to him, and he seems in pursuing all to lave been actuated not by ambition, but by a sincere a desire to promote the knowledge and welfare of mankind. - Ohrist. World.

LIFE OF ROGER WILLIAMS, The Founder of the State of Rhode Island. By Wr. Gammel, Professor of Rhetoric in Brown University. With a likeness. Price 75 cents.

"Mr. Gammell's fine belles-letters attainments have enabled him to present his distinguished subject in the most captivating light. So far as the work touches controversies which reach and influence the present times, it is our privilege as well as duty to read it as a private citizen, and not as a public journalist. Its mechanical execution is in the usually neat style of the respectable publishers." - Christian Alliance.

"This life has many virtues - brevity, simplicity, fairness. Though written by a Rhode Island man, and warm in its approval of Roger Williams, it is not unjust to his Puritan opponents, but only draws such deductions as were unavoidable from the premises. It is the life of a good man, and we read with grateful complacency the commendation of his excellences." - Christian World. 


\section{$\mathbb{1 l}_{\text {orfis on }}$ oflissions.}

THE MISSIONARY ENTERPRISE; A Collection of Discourses on Christian Missions, by American Authors. Edited by BAroN STow, D.D. Second Thousand. Price 85 cents.

"If we desired to put into the hands of a foreigner a fuir exhibition of the capacity and spirit of the American church, we would give him this volume. You have here thrown together a few discourses, preached from time to time, by different individuals, of different denominations, as circumstances have demanded them; and you see the stature and feel the pulse of the American Church in these discourses with a certainty not to be mistaken. "You see the high talent of the Amcrican chirch. We venture the assertion, that no nation in the world has such an amount of forceful, available talent in its pulpit. The energy, directness, scope, and intellectual spirit of the American church is wonderful. In this book, the discourses by Dr. Beccher, Pres. Wayland, and the Rev. Dr. Stone of the Episcopal church, are among the very highest cxhibitions of logical correctness, and burning, popular fervor. This volume will have a wide circulation."-T'he New Englander.

"This work contains fifteen sermons on Missions, by Rev. Drs, Wayland, Griffin, Anderson, Williams, Beceher, Miller, Fuller. Beman, Stonc, Mason, and by Rev. Messrs. Kirk, Stow, and Ide. It is a rich treasure, which ought to be in the possession of every Auncrican Christian."-Carolina Baptist.

THE GREAT COMMISSION; Or, the Christian Church constituted and charged to convey the Gospel to the World. A Prize Essay. By John HaRis, D.D. With an Introductory Essay, by W. R. WrLliams, D.D. Fifth Thousand. Price $\$ 1.00$.

"Iris plan is original and comprehensive. In filling it up the author has interwoven facts with rich and glowing illustrations, and with trains of thought that are sometimes almost resistless in their appeals to the conscience. The work is not more distinguished for its arguments and its genius, than for the spirit of deep and fervent piety that pervades it."-T'he Dayspring.

"This work comes forth in circumstances which give and promise extraordinary interest and value. Its general circulation will do much good." - Jew York Evangelist.

"In this volume we have a work of great excellence, rich in thought and illustration of a subject to which the attention of thousands has been called by the word and providence of God." - Philadelphia Observer.

"The merits of the book entitle it to more than a prize of money. It constitutes a most powerful appeal on the subject of Missions." - New York Baptist A lvocate.

"Its style is remarkably chaste and elegant. Its sentiments richly and fervently evangelized, its argumentation conclusive. Preachers especially should read it; they will renew their strength over its noble pages." - Zion's Herald, Boston.

"To recommend this work to the friends of missions of all denominations would be but faint praise; the author deserves and will undoubtedly receive the credit of having applied a new lever to that great moral machine which, by the blessing of God, is destined to evangelize the world." - Christian Secretary, Hartford.

"We hope that the volume will be attentively and prayerfully read by the whole church, which are elothed with the "Great Commission" to evangelize the world, and that they will be moved to an immediate discharge of its high and momentous obligations. N. E. Puritan, Boston.

THE KAREN APOSTLE; Or, Memoir of Ko Thah-Byu, the first Karen convert, with notices concerning his Nation. With maps and plates. By the Rev. Francis Mason, Missionary. American Edition. Edited by Prof. H. J. RIPLEY, of Newton Theol. Institution. Fifth Thousand. Price 25 cents.

** " This is a work of thrilling interest, containing the history of a remarkable man, and giving, also, much information respecting the Karen Mission, heretofore unknown in this country. It must be sought for, and read with avidity by those interested in this most interesting mission. It gives an account, which must be attractive, from its novelty, of a people that have been but little known and visited by missionaries, till within a few years, The baptism of Ko Thah-Byu, in 1828, was the beginning of the mission, and at the end of these twelve years, twelve hundred and seventy Karens are officially reported as members of the churches, in good standing. The mission has been carried on pre-eminently by the Karens themselves, and there is no doubt, from much touching evidence contained in this volume, that they are a people peculiarly susceptible to religious impressions. The account of Mr. Mason must be interesting to every one. 


\section{Allemoirs of Disfinguisfyed fllisstomaties.}

MEMOIR OF ANN H. JUDऽON, late Missionary to Burmah. By Rev. JAMES D. KNowles. 12mo. Edition, price 85 cents. $18 \mathrm{mo}$, price 58 ets.

"We are particularly gratified to perceive a new cdition of the Memoirs of Mrs. Judson. She was an honor to our country - onc of the most noble-spirited of her scx. It cannot, therefore, be surprising, that so many editions, and so many thonsand copies of her life and adventures have been sold. The name - the long career of suffering - the self-sacriticing spirit of the retired country-girl, have spread over the whole world; and the heroism of her apostleship and almost martyrdom, stands ont a living and heavenly beacon-fire, amid the dark midnight of ages, and human history and exploits. She was the first woman who resolved to become a missionary to heathen countries." - Americun Traveller.

"This is one of the most interesting pieces of female biography which has erer come nnder our notice. No quotation, which our limits allow, would do justice to the facts, and we must, therefore, refer our readers to the volume itself. It ought to be immediately added to every family library." - London Miscellany.

MEMOIR OF GEORGE DANA BOARDMAN, Late Missionary to Burmah, containing much intelligence relative to the Burman Mission. By Rev. Aloxzo King. A new Edition. With an Introductory Essay, by a distinguished Clergyman. Embellished with a Likeness; a beautiful Vignette, representing the baptismal scene just before his death; and a drawing of his tomb, taken by Rev. H. MaLcom, D.D. Price 75 cents.

" One of the brightest luminaries of Burmah is extinguished, - dear brother Boardman is gone to his eternal rest. He fell gloriously at the head of his troops - in the arms of victory, - thirty-eight wild Karcns having been brought in to the camp of king Jesus since the beginning of the year, besides the thirty-two that were bronght in during the two preceding years. Disabled by wounds, he was obliged, through the whole of the last expedition, to be carricd on a litter; but his preseuce was a host, and the Holy Spirit accompanied his dying whispers with almighty influence."

REv. Dr. Judsun.

"No one can read the Memoir of Boardman, without feeling that the religion of Christ is suited to purify the affections, exalt the purposes, and give energy to the character. Mr. Boardman was a man of rare excellence, and his biographer, by a just exhibition of that excellence, has rendered an important service, not only to the cause of Christian missions, but to the interests of personal godliness."

Baron Stow.

\section{MEMOIR OF MRS. HENRIETTA SHUCK, The First American} Female Missionary to China. By Rev. J. B. Jeter. Fourth thousand. Price 50 cents.

"We have seldom taken into our hands a more beautiful book than this, and we have no small pleasure in knowing the degree of perfection attained in this country in the arts of printing and book-binding, as seen in its appearance. The style of the author is sedate and perspicuous. such as we might expect from his known piety and learning, his attachment to missions, and the amiable lady whose memory he embalms. The book will be extensively read and eminently useful, and thus the ends sought by the author will be happily secured. We think we are not mistaken in this opinion; for those who taste the effect of early education upon the expansion of regenerated convictions of duty and happiness, who are charmed with youthful, heroic self-consecration upon the altar of God, for the welfare of man, and who are interested in those struggles of mind wlich lead men to shut their cyes and ears to the importunate pleadings of filial affection - those who are interested in China, that large opening field for the glorious conquests of divine truth, who are interested in the government and habits, social and business-like, of the people of this empire all such will be interested in this Memoir. To them and to the friends of missions generally, the book is commended, as worthy of an attentive perusal."-T'he Family Visiter, Boston.

MEMOIR OF REV. WILLIAM G. CROCKER, Late Missionary in West Africa, among the Bassas, Including a History of the Mission. By R. B. Mediery. Price $62 \frac{1}{2}$ cents.

"This interesting work will be found to contain much valuable information in rclation to the present state and prospects of Africa, and the success of Missioms in that interesting country, which has just taken a stand among the nations of the earth, and, it is to be hoped, may successfully wicld its new powers for the ultimate good of the whole continent. The present work is commended to the attention of every lover of the liberties of man.

"Our acquaintance with the excellent brother, who is the subject of this Memoir, will be long and fondly cherished. This volume, prepared by a larly, of true taste and talent, and of a kindred spirit, while it is but a just tribute to his worth, will, we doubt not, furnish lessons of humble and practical piety, and will give such ficts relative to the nission to which he devoted his life, as to render it worthy a distinguished place among the religious and missionary biography which has so much enriched the family of God."-Ch. Watchman. 


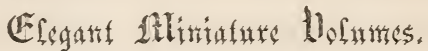

Gilt Edges and Beautifully Ornamented Covers. Price 311/4 Cents Each.

DAILY MANNA for Christian Pilgrims. Containing a text of Scripture for each day in the year, with an analysis of its contents, and a verse of poetry. By Rev. BApon Stow.

"A perfect gem of a book, and full of gems from the mine that yields the purest and brightest that are found in the world." $-N . Y$. Observer.

THE ATTRACTIONS OF HEAVEN. Edited by Rev. H. A. GRAYES.

THE YOUNG COMMUNICANT. An Aid to the Right Understanding and Spiritual Improvement of the Lord's Supper.

THE ACTIVE CHRISTIAN. From the Writings of JoHn Harris, D.D.

THE BIBLE AND THE CLOSET: Or, how we may read the Scriptures with the most spiritual profit. By T. WATson. And Secret Prayer successfully managed. By S. LEe. Edited by Rev. J. O. Choules.

THE MARRIAGE RING, or how to make Home Happy. From the writings of J. A. JAMES.

"It is a precious little work, calculated alikc to improve the morals and promote the happiness of the domestic hearth." - Southern Whig.

LYRIC GEMS. A Collection of Original and Select Sacred Poetry. Edited by Rev. S. F. SMITH.

"It is appropriately named ' Gems,'- not the least brilliant of which are the contributions of the editor himself." - Christian Reflector.

THE CASKET OF JEWELS, for Young Christians. By JAMEs, EDWARDS, and HARRIS.

THE CYPRESS WREATH. A Book of Consolation for those who Mourn. Edited by Rev. R. W. Griswold.

"This is a most beautiful and judicious selection of prose and poetry, from the most popular authors, interspersed with select passages from Scripture."

THE MOURNER'S CHAPLET. An offering of Sympathy for Bereaved Friends. Selected from American Poets. Edited by John Krese.

THE FAMILY CIRCLE. Its Affections and Pleasures. Edited by H. A. GRAVES.

THE FAMILY ALTAR. Or the Duty, Benefits, and Mode of Conducting Family Worship.

Sets of the above, put up in neat boxes, and forming a beautiful "Miniature Library" in 12 Volumes. Price, \$3.75.

THE SILENT COMFORTER. A Companion for the Sick Room, by Mrs. Louisa Payson Hopkins.

[G Other volumes are in preparation and will soon be issued.

Double miniatures. Price 50 Cents Each.

THE WEDDING GIFT; Or the Duties and Pleasures of Domestic Life. Containing the Marriage Ring and the Family Circle, in one Volume.

THE YOUNG CHRISTIAN'S GUIDE to the Doctrines and Duties of a Religious Life. Containing the Casket of Jewels and the Active Christian. In one volume.

THE MOURNER COMFORTED. Containing the Cypress Wreath, and the Nourner's Chaplet, in One Volume. 


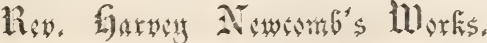

HOW TO BE A LADY; A Book for Girls, containing useful hints on the formation of character. Fifth Thousand. Price 50 cents.

"Having daughters of his own, and having beeu many years employed in writing for the young, he hopes to be able to offer some good adviee, in the following pages, iu an entertaining way, for girls or misses, between the ages of eight and tifteeu. Ilis objeet is, to assist them in forming their eharaeters upon the best model; that they may become wellbred, intelligeut, refined, and good ; aud then they will be real ludies, in the highest sense." Prejace.

"We notice these two books together, not merely beeause they are by the same author, and contemplate the same general end, but beeause they are, to some extent, identieal. They are both full of wholesome and judieious eounsels, which are well fitted to preserve the young from the numberless evils to whiel they are exposed, and to mould them to virtue and usefulness. The style is simple and perspicuous; and there is a direetness and earnestness pervading the whole, which, one would suppose, must seeurc for it a ready access to the youthful mind and heart."-Albany Argus.

HOW TO BE A MAN; A Book for Boys, containing useful hints on the formation of Character. Fifth Thousand. Price 50 cents.

"My design in writing has been to contribute something towards forming the eharaeter of those who are to be our future eleetors, legislators, governors, judges, ministers, lawyers, and physicians, - after the best model; and, from the kind reception of my former attempts to benefit Ameriean youth, I trust they will give a eandid hearing to the hints eontained in the following pages. It is intended for boys - or, if you please, for young gentlemen, in early youth, from eight or ten to fifteen or sixteen years of age." - Preface.

"Two delightful volumes by the Rev. Harvey Neweomb. These are written by an intelligent Christian father. They contain wise and important counsels and eautions, adapted to the young, and made entertaining by the interesting style and illustrations by the author. They are fine mirrors, in which are refleeted the prominent lineaments of the Christian young gentleman and young lady. The exeeution of the works is of the first order, and the books will afford elegant and most profitable presents for the young." - American Pulpit.

ANECDOTES FOR BOYS; Entertaining Anecdotes and Narratives, illustrative of principles and character. Price 42 cents.

"Nothing has a greater interest for a youthful mind than a well-told story, and no medium of eonveying moral instructions so attraetive or so suceessful. The influenee of all such stories is far more powerful when the ehild is assured that they are true. The book before us is condueted upon these ideas. It is made up of a series of aneedotes, every one of which ineuleates some exeellent moral lesson. We eannot too highly approve of the book, or too strongly recommend it to parents." - Western Continent, Baltimore.

ANECDOTES FOR GIRLS ; Entertaining Anecdotes and Narratives, illustrative of principles and character. Price 42 cents.

"There is a eharm about these two beautiful volumes not to be mistaken. They are deeply interesting and instruetive, without being fietitious. The aneedotes are many, short, and spirited, with a moral drawn from each, somewhat after the manner of Todd ; and no youth ean read them without finding something therein adapted to every age, condition, and duty of life. We eommend it to families and sehools." - Albany Spectutor.

"No fietitious narratives have been introduced. The anecdotes are drawn from a great variety of sources, and have many important applieations to the temptations and dangers to which the young are speeially exposed. Like all the publications which have proeeeded from Mr. Neweomb's prolifie pen, these volumes are highly, and in the best sense, utilitarian. He desires to instruet rather than to dazzle; to infuse eorreet prineiples into the minds and the hearts of the young, than eater to a depraved appetite for romantie exeitement. We cordially eommend these volumes to all parents and ehildren." - Christiun dlliance.

CHRISTIANITY DEMONSTRATED in four distinct and independent series of proofs; with an explanation of the Types and Prophecies concerning the Messiah. Price 75 cents.

The object of the writer has been to elassify and condense the evidence, that the whole foree of each particular kind might be seen at one view. He has also aimed to render the work practicul, so as to have it a book to be read as well as studied. The Types and Prophecies furnish an important species of eridence, and are rich in instruetion npon the way of Salvation. 


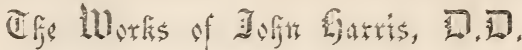

THE PREAADAMIITE EARTH: Contributions to Theological Science. Price bj cents.

This volume is the first of a series, eaeh being complete in itself. By special arrangement with the Author (who will participate in the profits of this edition), the American publishers will be supplied with the early sheets of the future volumes, and issue it simultaneously with the London Edition.

"It seeins to us a rery sueeessful specimen of the synthetical mode of reasoning. It puts the mind on a new traek, and is well titted to awaken its energies and expand its views. We have never seen the natural seienees, partieularly Geology, made to give so decided and unimpeachable a testimony to revealed truth. He appears to allow it all that it ean justly claim, all indeed that its advoeates ean fairly claim for it, while the integrity and truth of the Seriptures are maintained inviolate. And the wonders of God's works, whieh he has here grouped together, eonvey a most magnilicent and even overpowering idea of the Great Creator." - Christiun Ifirror, P'ortland.

THE GREAT COMMISSION; Or, the Christian Church constituted and charged to convey the Gospel to the World. A Prize Essay. With an Introductory Essay, by W. R. Wrllidus, D.D. Price $\$ 1.00$

"Of the several produetions of Dr. Harris, - all of them of great valne, - that now before us is destined, probably, to exert the most powerful influenee in forming the religious and missionary eliaracter of the coming generations. But the vast fund of argument and instruetion eomprised in these pages will exeite the admiration and inspire the gratitude of thousands in our own land as well as in Europe. Every clergyman and pious and reflecting liyman ought to possess the volume, and make it familiar by repeated perusai." Jiston Recoriler.

" His plan is original and eomprehensive. In filling it up, the author has interwoven facts with rieh and glowing illustrations, and with traius of thought that are sometimes almost resistless in their appeals to the conseienee. The work is not more distinguished for its arguments and its genius, than for the spirit of deep and fervent piety that pervades it." The Duy-Spring.

THE GREAT TEACHER: Or, Characteristics of our Lord's Ministry. With an Introductory Essay, by H. Husiphrex, D.D. Tenth thousand. Price 85 cents.

"The book itself inust have cost mueh meditation, mueh eommunion on the bosom of Jesus, and much prayer. Its style is, like the eountry which gave it birth, beautiful, varied, finished, and everywhere delightful. But the style of this work is its smallest excellence. It will be read : it ought to be read. It will find its way to many parlors, and add to the comforts of many a happy fireside. The reader will rise from each ehapter, not able, perhaps, to carry with hin inany striking remarks or apparent paradoxes, but he will have a sweet impression made npon his soul, like that whieh soft and touehing in usic makes when every thing about it is appropriate. The writer pours forth a elear and beautiful light, like that of the evening light-house, when it sheds its rays upon the sleeping waters, and covers them with a surfice of gold. We ean have no sympathy with a heart which yields not to impressions delieate and holy, which the perusal of this work will naturally make."

Hampshire Guzette.

MISCELLANIES; Consisting principally of Sermons and Essays. With an Introductory Essay and Notes, by J. Belcher, D.D. Price 75 cents.

"Some of these essays are among the finest in the language; and the warmth and energy of religious feeling manifested iu several of them, will render them peeuliarly the treasure of the eloset and the Christian fireside."-Dangor Gazctte.

MAMMON: Or, Covetousness, the Sin of the Christian Church. A Prize Essay. Price 45 cents. Twentieth thousand.

** This masterly work has already engaged the attention of churches and individuals, and receives the highest coinmendations.

ZEBULON ; Or the Moral Claims of Seamen stated and enforced. Edited by Rev. W. M. Rogers and D. M. Lord. Price 25 cents.

**A well written and spirit-stirring appeal to Christians in favor of this numerous, useful, and loug negleeted elass.

THE ACTIVE CHPISTIAN" Containing the "Witnessing Church," "Christian Excellence," and "Means of Usefulness:" three popular productions of this talented author. Price 31 cents. 


\section{CHAMBERS'S MISCELLANY \\ OF USEFUL AND ENTERTAINING KNOWLEDGE. \\ Edited by William Chambers.}

With Elegant Illustrative Engravings. Price, 25 cts. per No.

Gould, Kendall \& Lincolis are happy to announce that they have completed arrangements with the Messrs. Chambers, of Edinburgh, for the re-publication, in semi-monthly numbers, of Chambers's Miscellavy. The first number will be issued in July, and continued at regular intervals antil the work is completed.

The design of the IIIscellavy is to supply the increasing demand for useful, instructive, and entertaining reading, and to bring all the aids of literature to bear on the cultivation of the feelings and understandings of the people - to impress correct views on important moral and social questions - suppress every species of strife and savagery - cheer the lagging and desponding, by the relation of tales drawn from the imagination of popular writers - rouse the fancy, by descriptions of interesting foreign scenes - give a zest to every-day occupations, by ballad and lyrical poetry - in short, to furnish an unobtrusive friend and guide, a lively fireside companion, as far as that object can be attained through the instrumentality of books.

The universally acknowledged merits of the CrcLopedia of Exglish Literature, by the Chambers', connected with its rapid sale, and the unbounded commendation bestowed by the press, give the publishers full confidence in the real value and entire success of the present work.

The subjoined table of contents of the first two volumes will give the best idea of the comprehensive character and diversified contents of this work:

$$
\text { voL. } 1 .
$$

No. 1. Life of Louis Philippe.

Tale of Norfolk Island.

Story of Colbert.

The Employer and Employed.

Time Enough. By Mrs. S. C. Hall.

Manual for Infant Management.

Piccioli, or the Prison Flower.

Life in the Bush. By a Jady.

No. 2. William Tell and Switzerland.

The Two Beggar Boys. A Tale.

Poems of the Domestic Affections.

Life of Grace Darling, \&c.

Story of Maurice and Genevieve.

Religious Imposters.

Anecdotes of Dogs.

No. 3. La Rochejaquelein and the $W$ ar in La Vendee.

Journal of a Poor Ticar.

Romance of Geology.

History of the Slave Trade.

Walter Ruysdael, the Watchmaker.

Chevy-Chase, and the Beggar's

Daughter of Bethnal-Green.
No. 4. Life of Nelson.

The Temperance Movement.

Story of Peter Williamson.

Joan of Arc, Maid of Orleans.

Annals of the Poor - Female Industry and Intrepidity.

Slavery in America.

No. 5. A Tisit to Tesuvius, Pompeii, and Herculaneum.

Story of Baptiste Lulli.

Select Poems of Kindness to Animals.

Wallace and Bruce.

Cases of Circumstantial Evidence.

Story of Richard Falconer, \&c.

No. 6. The Goldmaker's Village.

The Last Earl of Derwentwater.

The Heroine of Siberia.

Domestic Flower-Culture.

Insurrections in Lyons.

The Hermit of Warkworth, and Other Ballads.

Each number will form a complete work, and every third number will be furnished with a title page and table of contents, thus forming a beautifully illustrated voluME of over 500 pages, of useful and entertaining reading, adapted to every class of readers. The whole to be completed in THIRTY NUMBERS, forming TEN ELEGANT VOLUMES.

[5. This work can be sent by mail to any part of the country. A direct remittance to the publishers of SIX DOLLARs will pay for the entire work. This liberal discount for advance pay will nearly cover the cost of postage on the work. Those wishing for one or more sample numbers can remit accordingly.

D $\mathrm{F}$ Booksellers and Agents supplied on the most liberal terms. 


\section{CYCLOPADIA OF ENGLISH LITERATURE:}

\section{A SELECTION OF THE CHOICEST PRODUCTIONS}

OF ENGLISH AUTHORS, FRON THE EARLIEST TO THE PRESENT TIDE.

CONNECTED BY A CRITICAL AND BIOGRAPIICAL HISTORY.

EDITED BY ROBERT CHAMBERS,

ASSISTED BY ROBERT CARRTTHERS AND OTHER EMINENT GENTLEMEN.

Complete in two imperial octavo volumes, of more than fourteen hundred pages of double column letter press: and upwards of three hundred

elegant illustrations.

The Cyclopedia of English Literature, now presented to the American public, originated in a desire to supply the great body of the people with a fund of reading derived from the productions of the most talented and the most elegant writers in the English language. It is hoped hereby to supplant, in a measure, the frivolous and corrupting productions with which the community is flooded, and to substitute for them the pith and marrow of substantial English literature; - something that shall prove food for the intellect, shall cultivate the taste, and stimulate the moral sense.

The design has been admirably executed, by the selection and concentration of the most exquiaite productions of English intellect, from the earliest Anglo-Saxon writers down to those of the present day. The series of authors commences with Langland and Chaucer, and is continuous down to our time. We have specimens of their best writings, headed in the several departments by Chaucer, Shakspeare, Milton, - by More, Bacon, Locke, - by Hooker, Taylor, Barrow, - by Addison, Johnson, Goldsmith, by Hume, Robertson, Gibbon, - set in a biographical and critical history of the literature itself. The whole is embellished with splendid wood engravings of the heads of the principal anthors, and of interesting events connected with their history and writings. No one can give a glance at the work without being struck with its beauty and cheapness. The editor, Robert Chambers, is distinguished as the author of many valuable works, and as joint editor of Chambers's Edinburgh Journal.

To those whose educational privileges are few, who reside at a distance from libraries, and whose means are limited, such a book must be of unspeakable value, - A WHOLE ENGLISH LIBRARY FUSED DOWN INTO ONE CHEAP BOok! Any man, whatever his avocation or his location, may thus possess, in a portable and available form, the best intellectual treasures the language affords. To those more fortunate individuals who may have the advantages of a regular course of education, this multum in parvo will be a valuable introduction to the great galaxy of English writers.

As an evidence of the great popularity of the work in England, it may be stated that no less than forty thousand copies have been sold in less than three years; and this almost without advertising or being indebted to any notice in the literary Reviews.

In addition to the great number of pictorial illustrations given in the English edition, the American publishers have greatly enriched the work by the addition of fine steel and mezzotint engravings of the heads of Shakspeare, Addison, Byron, a full length portrait of Dr. Johnson, and a beautiful scenic representation of Oliver Goldsmith and Dr. Johnson.

DF Booksellers and Agents supplied on the most liberal terms. GOULD, KENDALL \& LINCOLN, Publishers, BOSTON. 




(2)

1.

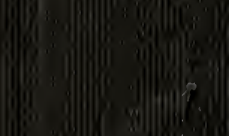

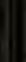
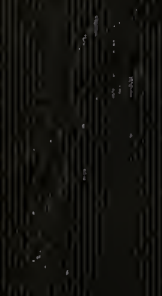